Universidade de São Paulo

Instituto de Física

\title{
Danos físicos em membranas por \\ processos de fotossensibilização
}

Raffaela De Rosa

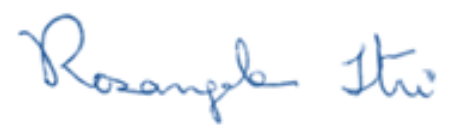

Orientadora: Prof(a). Dr(a). Rosangela Itri

Tese de doutorado apresentada ao Instituto de Física da Universidade de São Paulo, como requisito parcial para a obtenção do título de Doutora em Ciências.

Banca Examinadora:

Profa. Dra. Rosangela Itri - Orientadora (IF-USP)

Prof. Dr. Pietro Ciancaglini (IF-USP)

Profa. Dra. Tayana Mazin Tsubone (IQ-UFU)

Prof. Dr. José Luiz de Souza Lopes (IF-USP)

Prof. Dr. Leandro Ramos Souza Barbosa (IF-USP)

São Paulo 
FICHA CATALOGRÁFICA

Preparada pelo Serviço de Biblioteca e Informação do Instituto de Física da Universidade de São Paulo

De Rosa, Raffaela

Danos físicos em membranas por processos de fotossensibilização. São Paulo, 2020.

Tese (Doutorado) - Universidade de São Paulo. Instituto de Física. Depto. de Física Aplicada

Orientador: Profa. Dra. Rosangela Itri

Área de Concentração: Física da Matéria Condensada.

Unitermos: 1. Lipídio oxidado; 2. SAXS; 3. Foto-oxidação; 4. Dissociação de proteína; 5. Domínio lipídico. 
University of Sao Paulo

Institute of Physics

\title{
Physical damage to membranes by
}

\section{photosensitization processes}

\author{
Raffaela De Rosa
}

Supervisor: Prof. Dr. Rosangela Itri

$\mathrm{PhD}$ thesis submitted to the Institute of Physics of the University of Sao Paulo as a partial requirement to obtain a Doctor of Science degree.

Thesis Examination Committee:

Prof. Dr. Rosangela Itri - Supervisor (IF-USP)

Prof. Dr. Pietro Ciancaglini (IF-USP)

Prof. Dr. Tayana Mazin Tsubone (IQ-UFU)

Prof. Dr. José Luiz de Souza Lopes (IF-USP)

Prof. Dr. Leandro Ramos Souza Barbosa (IF-USP)

Sao Paulo 
"O universo não se revela a mim no espaço, impondo-me uma presença maciça a que só posso me adaptar, mas como um campo, um dominio, que vai tomando forma na medida de minha ação."

Pierre Furter 
"À minha Mãe ..."

"Por ser a pessoa mais importante da minha vida" 



\section{Agradecimentos Especiais}

Gostaria de expressar os meus sinceros agradecimentos:

À Prof(a). Dr(a). Rosangela Itri pela confiança, apoio e orientação durante esses 6 anos de doutorado. Obrigada por compartilhar comigo o seu conhecimento acadêmico e de vida e me guiar na realização do meu sonho;

À minha família, pelo suporte a mim e a minha mãe principalmente no período em que me ausentei de Sorocaba. Gostaria de agradecer especialmente à Tata e meus queridos primo Mauro e tio Carlos;

Ao Sr. Arlindo por estar sempre presente junto à minha mãe ajudando diariamente a preencher o buraco que eu deixei com a minha ausência. Muito obrigada por nunca nos deixar;

Aos meus professores do ensino fundamental e médio Jorge (história), Michel (geografia) e Ulisses (matemática) que me ajudaram a compreeender o que eu gostaria de estudar, onde fazer e os desafios iniciais para alcançar meu (recém definido naquele momento) objetivo. Gostaria de salientar a extrema importância desses professores neste meu momento de vida. Em um mundo onde o nome USP não era sequer conhecido, eles conseguiram me guiar me fornecendo acesso à informações sobre ciências, universidades e mais ainda acreditando que eu seria capaz de realizar esse salto entre dois universos sociais tão distantes entre si;

Ao meu querido amigo Marcos por todo suporte durante diferentes fases da minha vida, principalmente no meu processo de ingresso na Física e durante meu primeiro ano de graduação. Você sempre foi uma referência de dedicação e inteligência; 
À minha amiga e companheira de laboratório Juliana Yoneda por estar ao meu lado em tantos momentos importantes que eu nem tenho palavras para descrever quão importante você é para mim. Brigada Ju. Você é incrível;

À querida Elisa que desde o primeiro momento em que nos conhecemos nos tornamos grandes amigas. A fluidez da nossa interação sempre me impressionou. Obrigada também por todo suporte no doutorado com os seus super didáticos manuais de estudo e por toda paciência para me ajudar a entender. E obrigada por estar presente quando eu mais precisei;

Ao Gustavo pela parceria durante esses 6 anos, tanto em laboratório quanto na vida. Obrigada por deixar as madrugadas de medidas mais divertidas, ouvir músicas aleatórias comigo e por me dar suporte nos momentos difíceis;

Aos companheiros de laboratório Maressa, Tayana e Fernado pelas sábias dicussões sobre física, química e biologia e por me aguentarem quando eu queria só conversar sobre nada;

Ao Gabriel pela amizade independente do momento. Obrigada por tentar me tirar do meu típico estado de isolamento e estar sempre ao meu lado. Você nunca me deixou. Muito obrigada por isso;

Ao Renato Vaconscelos por ser meu amigo e estar presente em muitos momentos além do mundo física;

Aos meus amigos da graduação que sempre me ajudaram a estudar e ainda hoje fazem parte da minha vida;

Aos meus companheiros de CRUSP por me aguentarem por muitos anos: Rogério (Bom), Luiz, Lígia e Arthur;

Aos funcionários do IFUSP pela cordialidade durante esses 11 anos com especial agradecimento à secretária Lia por todo o apoio. Agradeço também às tias da lanchonete pela incrível simpatia e feornecimento de cookies;

Aos meus companheiros da OLX (mesmo os que não estão mais lá) por me incentivarem a finalizar o doutorado principalmente nos momentos em que me faltava energia;

À Dr(a). Helena Junqueira do Instituto de Química da USP pela amizade, apoio, ensinamentos de técnicas e teoria e pela imensa paciência em me explicar tudo em detalhes; 
Ao Prof. Dr. Leandro R. S. Barbosa do Instituto de Física da USP pelas explicações e discussões envolvendo experimentos e teoria de SAXS e DLS;

Ao Prof. Dr. Francesco Spinozzi da Università Politecnica delle Marche, pelo fornecimento do software de ajuste GENFIT, bem como pelas discussões e explicações envolvendo o programa e análises de SAXS. Obrigada também pela paciência;

Ao Prof. Dr. Maurício Baptista do Instituto de Química da USP por me deixar utilizar as instalaçãoes e equipamentos de medidas de Fluorescência e Absorção;

Aos técnicos do departamento de Física aplicada e departamento de Física Geral, pelo suporte; 



\section{Agradecimentos}

Gostaria de agradecer

À Fundação de Amparo à Pesquisa do Estado de São Paulo (FAPESP) pelo apoio financeiro ao meu curso doutorado e consequentemente a este projeto de pesquisa. Processo $n^{o}: 2014 / 02511-5$.

"As opiniões, hipóteses e conclusões ou recomendações expressas neste material são de responsabilidade do autor(es) e não necessariamente refletem a visão da FAPESP"

À CAPES e CNPq pelo apoio financeiro ao grupo de pesquisa da minha orientadora, Prof(a). Dr(a). Rosangela Itri;

Ao Laboratório Nacional de Luz Síncrotron (LNLS) pelo uso de suas instalações;

Ao Instiuto de Física da USP (IFUSP) pelos cursos de Bacharelado em Física e Doutorado em Ciências. 


\section{Resumo}

Nesta tese de doutoramento, utilizamos a técnica de espalhamento de raios-x a baixos ângulos (SAXS) para: (i) caracterizar membranas modelo (vesículas unilamelares grandes, LUVs) compostas por POPC (PC), PC:esfingomielina (PC:SM, razão molar 1:1) e PC:SM:colesterol (PC:SM:CO, 1:1:1), (ii) estudar mudanças estruturais nestas membranas devido à foto-oxidação in situ na presença de quatro fotossensibilizadores (FS): azul de metileno (MB), azures A e B (AA e AB) e tionina (Ti), (iii) avaliar do ponto de vista estrutural a influência dos lipídios oxidados PC-OOH (POPC hidroperoxidado) e 1-palmitoil-2-azelaoilsn-glicero-3-fosfatidilcolina (PAzPC) na composição da membrana lipídica e (iv) investigar os mecanismos de interação e agregação da enzima gliceraldeido-3-fosfato-desidrogenase (GAPDH) na superfície de membranas oxidadas e contendo domínios lipídicos. A caracterização inicial de membranas modelo mostrou que a composição lipídica influencia nos parâmetros estruturais como espessura de bicamada e perfil de densidade eletrônica. Bicamadas lipídicas compostas apenas por PC apresentaram espessura de bicamada lipídica igual a 46(2) A. Em sistemas compostos por PC:SM (1:1) foi evidenciado aumento de $6.6 \AA$ na espessura da bicamada. No caso de membranas compostas por PC:SM:CO (1:1:1) a análise das curvas de SAXS indicou uma coexistência de fases líquido desordenado (Ld)-líquido ordenado (Lo), com diferenças na espessura da bicamada de 9.4Å. No estudo de fotossensibilização de membranas, foram analisadas curvas de SAXS de LUVs de PC, PC:SM (1:1) e PC:SM:CO (1:1:1) foto-irradiadas por $2 h$ na presença dos FS MB, AA, AB e Ti. Vesículas compostas por PC:SM:CO apresentaram menor alteração estrutural sugerindo que a presença domínios lipídicos de SM:CO protegem a bicamada lipidica dos efeitos de foto-oxidação. Ressalta-se aqui que CO também é alvo de foto-oxidação. Para os sistemas PC e PC:SM, o FS Tionina promoveu maior foto-dano na membrana resultando em oxidação lipídica de cerca de $31 \%$ para membranas de PC e de $17 \%$ para PC:SM. Foi observado efeito de indução à formação de multilamelas para todas as composições lipídicas com FSs mesmo antes da exposição à foto-irradiação, sugerindo que o FS por si só promove formação de multilamelas. De um modo geral, os efeitos de fotossensibilização observados neste estudo não foram significativos no que se refere a danos físicos em membranas em termos de ruptura das mesmas. Em termos do impacto de lipídio oxidado em membranas modelo, foi observado que a adição controlada de $\mathrm{PC}-\mathrm{OOH}$ em bicamadas de PC leva à diminuição da espessura da bicamada

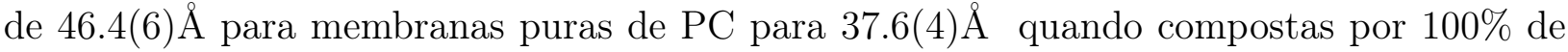
PC-OOH. No caso do sistema PC:PAzPC (67:33) foi obtida espessura de bicamada igual

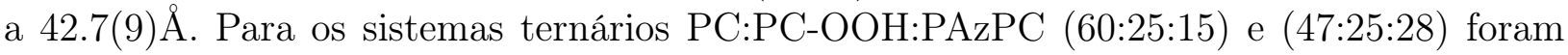
observadas espessuras equivalentes aos valores obtidos para $\mathrm{PC}$ com $33 \%$ de lipídio oxidado (PC-OOH ou PAzPC). A análise dos sistemas PC:PC-OOH e PC:PAzPC via modelo de grupos químicos mostrou que o grupo oxidado $O O H$ do $\mathrm{PC}-\mathrm{OOH}$ se encontra preferencialmente na região polar da membrana, próximo aos grupos carbonila e fosfato. No caso do PAzPC, o grupo $\mathrm{COO}^{-}$apresentou uma distribuição bimodal com localização nas regiões hidrofóbica e hidrofílica da membrana. Por fim, o estudo de interação GAPDH/PC:PC-OOH mostrou que a GAPDH sofre agregação ao longo do tempo de observação independente do nível de oxidação da membrana. A quantificação da estrutura oligomérica da enzima mostrou que na presença de membranas contendo $\mathrm{PC}-\mathrm{OOH}$ a enzima sofre dissociação da forma inicial de tetrâmero para monômeros ou dímeros, não sendo possível a distinção entre os dois. Para medidas realizadas diretamente após a mistura das soluções $(t=0 h)$ foi observada maior dissociação para vesículas com menor grau de oxidação (PC-PC-OOH (67:33)). Em sistemas compostos por PC:SM:CO e PC-OOH:SM:CO a GAPDH manteve a estrutura de tetrâmero mesmo após $2 h$ de interação indicando que a formação de domínios lipídicos inibe a dissociação da enzima em monômeros ou dímeros.

Palavras-chave: Lipídio oxidado; SAXS; Foto-oxidação; Dissociação de proteína; Domínio lipídico 


\section{Abstract}

Small angle x-ray scattering (SAXS) technique was here applied to (i) to characterize model membrane(large unilamellar vesicles LUVs) composed of POPC (PC), PC:sphingomyelin (PC:SM, 1:1) and PC:SM:cholesterol (PC:SM:CO, 1:1:1), (ii) study structural changes in these membranes due to in situ photo-oxidation in the presence of four photosensitizers (FS): methylene blue (MB), azure A and $\mathrm{B}(\mathrm{AA}$ and $\mathrm{AB}$ ) and thionine (Ti), (iii) evaluate the influence of the oxidized lipids PC-OOH (hidroperodidated POPC) and 1-palmitoyl-2-azelaoylsn-glycero-3-phosphocholine (PAzPC) on the composition of the lipid membrane and (iv) investigate the interaction and aggregations mechanisms of the glyceraldehyde-3-phosphate dehydrogenase (GAPDH) enzyme on the surface of oxidized membranes and membranes containing lipid domains. The initial characterization of model membranes showed that the lipid composition affects structural parameters like membrane thickness and electron density dis-

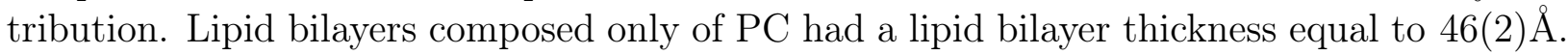
Compared to the PC system, membrane composed of PC:SM (1:1) showed an increase of $6.6 \AA$ in the bilayer thickness. In the case of membranes composed by PC:SM:CO (1:1:1) the analysis of the SAXS curves indicated a coexistence of Ld-Lo phases, with differences in the bilayer thickness of $9.4 \AA$. For membrane photosensitization study, we analyzed SAXS curves of LUVs composed of PC, PC:SM (1:1) and PC:SM:CO (1:1:1) photo-irradiated for $2 h$ in the presence of FS MB, AA, AB and Ti. Vesicles composed by PC:SM:CO presented lower structural alteration due to photosensitivity, suggesting that lipid domains of SM:CO hinder membrane damage. PC and PC:SM systems, the FS Ti promoted the greatest photodamage in the membrane, resulting in lipid oxidation of about $31 \%$ for PC membranes and $17 \%$ for PC:SM. It was observed an induction to formation of multilamellar structures for all lipid compositions with FSs even before exposure to photo-irradiation, suggesting that FS by itself promotes the multilamella formation. In general, the photosensitization effects observed in this study were not significant with regard to physical damage to membranes in terms of rupture. In terms of the impact of oxidized lipid on model membranes, it has been observed that the controlled addition of $\mathrm{PC}-\mathrm{OOH}$ to $\mathrm{PC}$ bilayers leads to a decrease in the layer thickness of 46.4(6) $\AA$ for pure PC membranes to 37.6(4) $\AA$ when composed of $100 \%$ PC-OOH. For PC:PAzPC (67:33) we obtained bilayer thickness of 42.7(9) . For the ternary mixtures of PC:PC-OOH:PAzPC (60:25:15) and (47:25:28), the bilayer thickness was similar to that obtained for PC with $33 \%$ of oxidized lipid (PC-OOH or PAzPC). Analysis of PC:PC-OOH and PC:PAzPC systems taking into account the scattering of the chemical groups showed that the oxidized group $O O H$ of the $\mathrm{PC}-\mathrm{OOH}$ is placed preferably in the polar region of the membrane, close to the carbonyl and phosphate groups. In the case of $\mathrm{PAzPC}$, the $\mathrm{COO}^{-}$group presents a bimodal distribution with location in the hydrophobic and hydrophilic regions of the membrane. Finally, the GAPDH/PC:PC-OOH interaction study showed GAPDH aggregation regardless the membrane oxidation. Quantification of the enzyme's oligomeric structure in the presence of membranes containing PC:PC-OOH showed dissociation from the tetrameric structure to monomers or dimers, without the possibility of distinguishing between the two structures. For measurements performed directly after mixing the solutions $(t=0 h)$, the greatest enzyme dissociation was observed for lower oxidized membranes (PC-PC-OOH (67:33)). In systems composed of PC:SM:CO and PCOOH:SM:CO under $2 h$ of interaction the GAPDH kept the tetrameric structure, suggesting that lipid domains inhibit the enzyme dissociation in monomers or dimers.

Keywords: Oxidized Lipids; SAXS; Photo-oxidation; Protein dissociation; Lipid domain 



\section{Sumário}

\begin{tabular}{lll}
\hline 1 & Introdução & 1
\end{tabular}

$1.1 \quad$ Objetivos $\ldots \ldots \ldots \ldots \ldots \ldots \ldots$

1.2 Estrutura da Tese . . . . . . . . . . . . . . . . . . . . . . . . . . . . . . . . . 10

2 Espalhamento de Raios-X a Baixos Ângulos (SAXS) 13

2.1 Teoria: Princípios Básicos . . . . . . . . . . . . . . . . . . . 13

2.2 SAXS no Laboratório Nacional de Luz Síncrotron (LNLS) . . . . . . . . . . 15

$2.3 \quad$ Modelos para análise das curvas de SAXS $\ldots \ldots \ldots$. . . . . . . . . . . . . . 17

2.3.1 Modelo para análise de $N \geqslant 1$ lamelas infinitas . . . . . . . . . . . . 17

2.3 .2 Modelo de grupos $\ldots \ldots \ldots \ldots \ldots$. . . . . . . . . . . . . 20

2.3 .3 Modelo para análise de Proteínas . . . . . . . . . . . . . . . . . . . . 22

3 Caracterização de biomembranas de POPC, POPC:SM e POPC:SM:CO 23

3.1 Objetivo específico . . . . . . . . . . . . . . . . . . . . . . 24

3.2 Materiais e Métodos . . . . . . . . . . . . . . . . . . . . 25

3.2 .1 Materiais . . . . . . . . . . . . . . . . 25

xiii 
3.2.2 $\quad$ Preparação de Vesículas Unilamelamelares Grandes (LUVs) . . . . . . 26

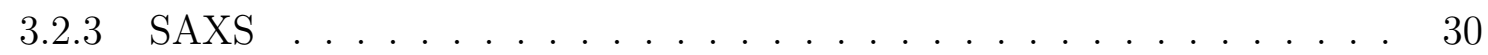

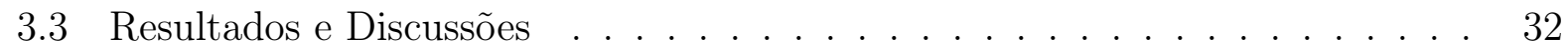

3.4 Conclusão . . . . . . . . . . . . . . . . . . . . . . . . . 41

4 Interação de fotossensibilizadores fenotiazínicos com membranas modelo 43

$4.1 \quad$ Objetivo específico $\ldots \ldots \ldots \ldots \ldots \ldots \ldots$

4.2 Materiais e Métodos $\ldots \ldots \ldots \ldots$. . . . . . . . . . . . . . . . . . 46

4.2 .1 Materiais . . . . . . . . . . . . . . . . . 46

4.2 .2 Métodos $\ldots \ldots \ldots \ldots$

4.3 Resultados e Discussões $\ldots \ldots \ldots \ldots \ldots \ldots$

$4.3 .1 \quad$ Incorporação de fotossensibilizadores em vesículas . . . . . . . . . . . 51

4.3.2 Análise por Espalhamento de raios-x a baixos ângulos (SAXS) . . . . 53

4.4 Conclusão $\ldots \ldots \ldots \ldots$

5 Mudanças estruturais impostas pela inclusão de lipídios oxidados em mem-

$\begin{array}{ll}\text { branas modelo } & 73\end{array}$

$5.1 \quad$ Objetivo específico $\ldots \ldots \ldots \ldots \ldots \ldots \ldots$

5.2 Materiais e Métodos . . . . . . . . . . . . . . . . . . . . 75

5.2 .1 Materiais . . . . . . . . . . . . . . . . . . 75

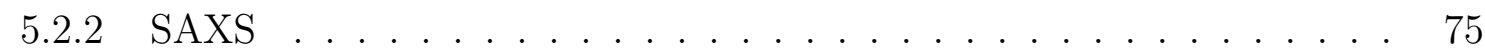

5.3 Resultados e Discussões $\ldots \ldots \ldots$. . . . . . . . . . . . . . . . . . . 77 
5.3.1 Caracterização inicial de membranas modelo contendo lipídios oxidados 78

5.3.2 Análise de membranas modelo compostas por POPC:POPC-OOH e POPC:PAzPC a partir do modelo de grupos químicos . . . . . . . . . 96

5.4 Conclusão . . . . . . . . . . . . . . . . . . . . 106

6 Estudo complementar - Análise da interação entre enzima GAPDH com

$\begin{array}{ll}\text { membranas modelo } & 109\end{array}$

6.1 Objetivo específico $\ldots \ldots \ldots \ldots \ldots \ldots$

6.2 Materiais e Métodos . . . . . . . . . . . . . . . . . . . . . 110

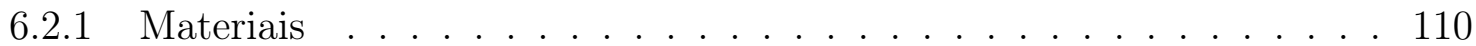

$6.2 .2 \mathrm{SAXS} \ldots \ldots \ldots \ldots \ldots \ldots \ldots$

6.3 Resultados e Discussões . . . . . . . . . . . . . . . . . . . . . 113

6.3.1 Parte 1 - Análise inicial (qualitativa) das curvas de SAXS . . . . . . . 113

6.3.2 Parte 2 - Análise quantitativa via ajuste teórico das curvas de SAXS 123

6.4 Conclusão . . . . . . . . . . . . . . . . . . . . 133

\begin{tabular}{lll}
\hline & Conclusão & 135
\end{tabular}

$\begin{array}{ll}\text { Referências } & 135\end{array}$

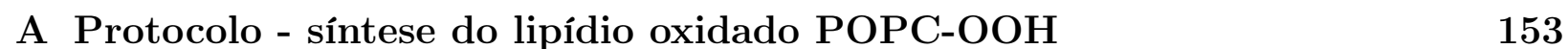

\begin{tabular}{lll}
\hline B Artigo publicado & 155
\end{tabular} 



\section{Lista de Figuras}

1.1 Ilustração esquemática do "modelo do mosaico fluido" para a estrutura da membrana plasmática. Imagem extraída da referência [1] . . . . . . . . . . . 2

1.2 Ilustração esquemática do modelo de membrana "Lipid Whisker". Imagem adaptada da referência $[6] \ldots \ldots \ldots$. . . . . . . . . . . . . . 3

1.3 Ilustração esquemática do processo de absorção de um fóton por um FS resultando na formação de espécies reativas de oxigênio. Mecanismo tipo I: ocorre a transferência de elétrons do FS no estado excitado triplete para biomoléculas formando radicais que reagem com o oxigênio levando a formação de ROS. Mecanismo tipo II: o FS no estado excitado triplete transfere energia diretamente para o oxigênio molecular formando oxigênio singlete $\left({ }^{1} \mathrm{O}_{2}\right)$. Imagem extraída das referências $[21,[26] . \ldots \ldots \ldots \ldots$. . . . . . . . . . . 5

1.4 Estrutura molecular do lipídio POPC-OOH (1-palmitoil-2-oleoil-sn-glicero-3fosfatidilcolina hidroperoxidado). Peso molecular 793,1g/mol (sintetizado em colaboração com as Dras. Yulia Moskalenko e Helena Junqueira - Laboratório de processos fotoinduzidos IQ - USP). Ver AnexdA| Figura extraída da referência [16]. 
1.5 Estrutura molecular do lipídio PAzPC (1-palmitoil-2-azelaoil-sn-glicero-3- fosfatidilcolina). Peso molecular 665,83g/mol (Avanti Polar Lipids, Inc.). . . . . 8

2.1 Representação do vetor espalhamento gerado pela interação do feixe de raioscom a amostra. . . . . . . . . . . . . . . . . . . . . . . . . . 14

2.2 Esquematização da linha de SAXS do LNLS. Figura extraída da referência [64] 16

2.3 Modelo de membrana com três regiões de diferentes densidades eletrônicas. .

$3.1 \quad$ Estrutura molecular do lipídio 1-palmitoil-2-oleoil-sn-glicero-3-fosfatidilcolina $(\mathrm{POPC}$ ou $\mathrm{PC})$

$3.2 \quad$ Estrutura molecular do lipídio Esfingomielina $(\mathrm{SM})$. . . . . . . . . . . . . . 26

$3.3 \quad$ Estrutura molecular do lipídio Colesterol $(\mathrm{CO})$. . . . . . . . . . . . . . 26

3.4 Ilustração do processo de formação de vesículas. Adaptado de www.avantilipids.com 28

3.5 Perfil de espalhamento de curvas de SAXS característico para estruturas uni-

lamelares (curva vermelha), estruturas multilamelares (curva verde) e coexis-

tência entre estruturas uni e multilamelares (curva azul). Neste exemplo, a amostra consistiu de membranas modelo de POPC $[10 \mathrm{mM}]$. . . . . . . . . . 30

$3.6 \quad$ Curvas de SAXS de LUVs compostas por POPC (curva vermelha), POPC:SM (curva verde) e POPC:SM:CO (curva azul) com concentração final de 10mM de lipídio medidos a $23^{\circ} \mathrm{C} . \ldots \ldots$. . . . . . . . . . . . . . . . . . . 33

3.7 Curvas de SAXS de vesículas grandes compostas por a) POPC, b) POPC:SM (1:1) com concentração inicial de $10 \mathrm{mM}(+)$ medidos a $23^{\circ} \mathrm{C}$ e melhor ajuste aos dados experimentais considerando o modelo de unilamela no caso de POPC e mistura de unilamela e multilamela no caso de POPC:SM (1:1). . . 35 
3.8 Curva de SAXS de LUVs compostas por POPC:SM:CO (1:1:1) com concentração inicial de $10 \mathrm{mM}(+)$ medidos a $23^{\circ} \mathrm{C}$ e ajuste aos dados experimentais. a) Comparação entre dois ajustes considerando o modelo de unilamela. O ajuste representado pela linha azul indica o caso em que foi considerada uma vesícula homogênea representada por apenas um fator de forma $I(q)=P(q)_{P C S M C O}$ e a linha verde representa dois fatores de forma $I(q)=x P(q)_{P O P C}+(1-x) P(q)_{S M C O}$. b) Melhor ajuste obtido a partir da consideração de 2 fatores de forma $\left(P(q)_{P O P C}\right.$ e $\left.P(q)_{S M C O}\right)$.

3.9 Perfil de densidade eletrônica ao longo do eixo $\mathrm{z}$, normal à superfície da bicamada lipídica, para vesículas compostas por: POPC (curva vermelha), POPC:SM (curva verde) e POPC:SM:CO (curvas vermelha e azul). A posição $0 \AA$ está localizada no centro da bicamada. . . . . . . . . . . . . . . . . 40

4.1 Imagem de microscopia óptica de contraste de fase apresentando as alterações morfológicas típicas de GUVs compostas por POPC ou DOPC (1,2-dioleoilsn-glicerol-3-fosfatidilcolina) dispersas em azul de metileno [40 $\mu \mathrm{M}]$ durante a foto-irradiação $(665 \mathrm{~nm})$. Imagem extraída da referência [19].] . . . . . . . . . 45

4.2 Fórmula estrutural das sondas fenotiazínicas (figura extraída da referência

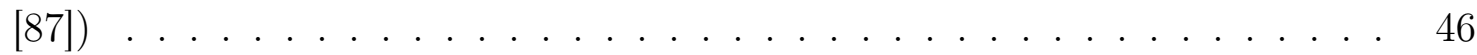

4.3 Valores referentes a porcentagem de incorporação dos fotossensibilizadores AA, AB, MB e Ti em diferentes composições lipídicas de membranas modelo: POPC (barra vermelha), POPC:SM (1:1) (barra verde) e POPC:SM:CO (1:1:1) (barra azul). Os dados utilizados neste histograma estão apresentados na tabela 4.2$] \ldots \ldots \ldots \ldots \ldots$ 
4.4 Perfil de SAXS para vesículas grandes compostas por POPC [5mM] na presença e ausência dos fotossensibilizadores MB, AA, AB e Ti a uma concentração de $20 \mu M$ medidos a $23^{\circ} \mathrm{C}$, com e sem exposição à radiação: $(+)$ Membrana modelo sem FS; $(+)$ Membrana modelo na presença dos diferentes FSs mas sem exposição à radiação (medida de controle do efeito do FS); (+) Membrana modelo na presença dos diferentes FSs após 2 horas de irradiação com LED vermelho $(\lambda=663 n m) . \ldots \ldots \ldots \ldots \ldots$

4.5 Perfil de SAXS para vesículas grandes compostas por POPC:SM (1:1) [5mM] na presença e ausência dos fotossensibilizadores MB, AA, AB e Ti a uma concentração de $20 \mu M$ medidos a $23^{\circ} \mathrm{C}$, com e sem exposição à radiação: $(+)$ Membrana modelo sem FS; $(+)$ Membrana modelo na presença dos diferentes FSs mas sem exposição à radiação (medida de controle do efeito do FS); (+) Membrana modelo na presença dos diferentes FSs após 2 horas de irradiação com LED vermelho $(\lambda=663 n m) . \quad \ldots \ldots \ldots$

4.6 Perfil de SAXS para vesículas grandes compostas por POPC:SM:CO (1:1:1) $[5 m M]$ na presença e ausência dos fotossensibilizadores MB, AA, AB e Ti a uma concentração de $20 \mu M$ medidos a $23^{\circ} \mathrm{C}$, com e sem exposição à radiação: $(+)$ Membrana modelo sem FS; $(+)$ Membrana modelo na presença dos diferentes FSs mas sem exposição à radiação (medida de controle do efeito do FS); (+) Membrana modelo na presença dos diferentes FSs após 2 horas de irradiação com LED vermelho $(\lambda=663 n m) . ~ \ldots . . . . . .57$ 
4.7 Curvas de SAXS de vesículas grandes compostas por POPC, POPC:SM (1:1) e POPC:SM:CO (1:1:1) com concentração igual a $5 m M(+)$ medidos a $23^{\circ} \mathrm{C}$ e melhor ajuste aos dados experimentais obtidos pelo software GENFIT (linha contínua verde) a partir do modelo de lamela infinita. . . . . . . . . . . . . 59

4.8 Perfil de densidade eletrônica ao longo do eixo z, normal à superfície da bicamada lipídica, para vesículas compostas por: a) POPC, b) POPC:SM, c) POPC:SM:CO e d) comparação entre todas as densidades. A legenda "outros" indica as composições lipídicas com possíveis alterações químicas investigadas neste capítulo. . . . . . . . . . . . . . . . . . . . . 62

4.9 Curvas de SAXS de vesículas grandes compostas por POPC $[5 m M](+)$ na presença dos FSs MB, AA, AB e Ti (concentração final de FS igual a $20 \mu M$ após 2horas de irradiação) medidos a $23^{\circ} \mathrm{C}$ e melhor ajuste aos dados experimentais obtidos pelo software GENFIT (linha contínua verde) a partir do modelo de lamela infinita. . . . . . . . . . . . . . . . . . . . . . . . . . 64

4.10 Curvas de SAXS de vesículas grandes compostas por POPC:SM (1:1) [5mM] $(+)$ na presença dos FSs MB, AA, AB e Ti (concentração final de FS igual a $20 \mu M$ após 2 horas de irradiação) medidos a $23^{\circ} \mathrm{C}$ e melhor ajuste aos dados experimentais obtidos pelo software GENFIT (linha contínua verde) a partir do modelo de lamela infinita. . . . . . . . . . . . . . . . . . 65

4.11 Curvas de SAXS de vesículas grandes compostas por POPC:SM:CO (1:1:1) $[5 m M](+)$ na presença dos FSs MB, AA, AB e Ti (concentração final de FS igual a $20 \mu M$ após 2 horas de irradiação) medidos a $23^{\circ} \mathrm{C}$ e melhor ajuste aos dados experimentais obtidos pelo software GENFIT (linha contínua verde) a

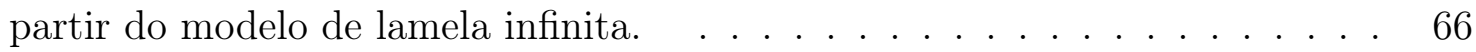


5.1 Curvas de SAXS de LUVs compostas por POPC:POPC-OOH com concentração inicial de lipídio igual a $10 \mathrm{mM}$ medidos a $23^{\circ} \mathrm{C}$. O insert apresenta as diferentes razões molares de POPC:POPC-OOH estudadas. . . . . . . . . . 79

5.2 Curvas de SAXS de vesículas grandes compostas por POPC:POPC-OOH com razões molares a) (0:100), b) (33:67) e c) (67:33) com concentração inicial de

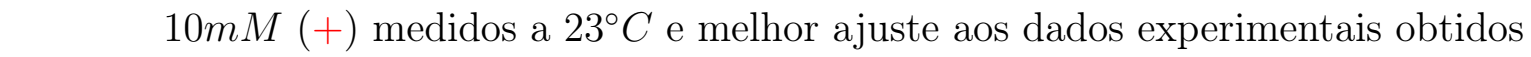
a partir do modelo de lamela infinita com três regiões de densidade eletrônica (ver seção 2.3 .1$). \ldots \ldots$. . . . . . . . . . . . . . . . . . 81

5.3 Distribuição da espessura da bicamada lipídica em função da quantidade de lipídio oxidado POPC-OOH na membrana e barra de erro obtida a partir de 10 iterações do ajuste. . . . . . . . . . . . . . . . . . . . . . . 83

5.4 Perfil de densidade eletrônica para as vesículas de POPC com e sem lipídio oxidado POPC-OOH. O insert apresenta as razões molares. . . . . . . . . . 84

5.5 Curvas de SAXS de LUVs compostas por POPC:PAzPC com concentração inicial de lipídio igual a $10 \mathrm{mM}$ medidos a $23^{\circ} \mathrm{C}$. O insert apresenta as diferentes razões molares de POPC:PAzPC estudadas. . . . . . . . . . . . . . . . 87

5.6 Curvas de SAXS de vesículas grandes compostas por POPC:PAzPC com ra\begin{tabular}{|c|c|}
\hline zões molares a) (90:10) e b) (67:33) com concentração inicial de $10 m M(+)$ \\
\hline
\end{tabular} \begin{tabular}{|c|}
\hline medidos a $23^{\circ} \mathrm{C}$ e melhor ajuste aos dados experimentais obtidos a partir do \\
\hline
\end{tabular} modelo de lamela infinita com três regiões de densidade eletrônica (ver seção

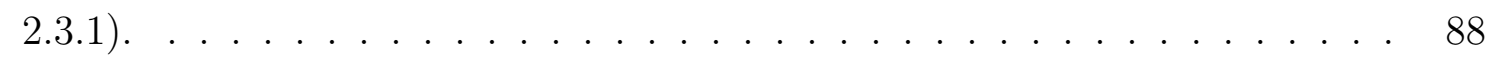

5.7 Perfil de densidade eletrônica para as vesículas de POPC com e sem lipídio oxidado PAzPC e vesículas compostas por POPC:POPC-OOH (67:33) (curva verde) para comparação de resultados. O insert apresenta as razões molares. 
5.8 Curvas de SAXS de LUVs compostas por POPC:POPC-OOH:PAzPC com concentração inicial de lipídio igual a $10 \mathrm{mM}$ medidos a $23^{\circ} \mathrm{C}$. O insert apresenta as diferentes razões molares estudadas. . . . . . . . . . . . . . . . . . . 93

5.9 Curvas de SAXS de vesículas grandes compostas por POPC:POPC-OOH:PAzPC com razões molares a) (60:25:15) e b) (47:25:28) com concentração inicial de $10 m M(+)$ medidos a $23^{\circ} \mathrm{C}$ e melhor ajuste aos dados experimentais obtidos a partir do modelo de lamela infinita com três regiões de densidade eletrônica (ver seção 2.3 .1$).$

5.10 Perfil de densidade eletrônica para as vesículas compostas por: POPC:POPC-

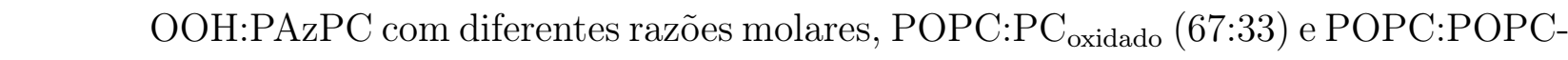
OOH (33:67). O insert apresenta as razões molares de cada composição lipídica. 96

5.11 Curvas de SAXS de vesículas grandes de POPC-OOH (imagem superior) e PAzPC (imagem inferior). Os pontos representam a curva experimental e a linha contínua preta o melhor ajuste obtido a partir do ajuste global. As curvas estão deslocadas entre si por um fator de 20 para facilitar a visualização. 101

5.12 Fração de volume dos grupos químicos obtidos a partir da análise das curvas \begin{tabular}{|l|l|l|l|l}
\hline de SAXS apresentadas na figura & 5.11 & em função da proporção $x$ de POPC-
\end{tabular} $\mathrm{OOH}$ (imagem à esquerda) e PAzPC (imagem à direita). A sombra colorida ao redor das linhas indicam o desvio padrão, obtido a partir de 20 iterações do ajuste global. . . . . . . . . . . . . . . . . . . . . . . . 103 
5.13 Dependência da posição de cada grupo químico $z_{i}$ em relação à fração de lipídio oxidado na membrana modelo $x$ para POPC-OOH (imagem à esquerda) e PAzPC (imagem à direita), obtidos a partir do ajuste global das curvas de SAXS apresentadas na figura $|5.11|$ A unidade de $z_{i}$ é Å. O índice X indica os grupos oxidados PX e CX para o POPC-OOH e o PAzPC, respectivamente. 104

5.14 Densidade eletrônica dos grupos químicos obtida a partir da análise das curvas de SAXS apresentadas na figura $|5.11|$ As cores são referentes a: $\mathrm{CH}_{2}$ (vermelho), $\mathrm{CH}_{3}$ (verde), $\mathrm{CH}$ (magenta), X (laranja), CG (grupo glicerol $(\mathrm{CH})\left[\left(\mathrm{CH}_{2}\right)(\mathrm{COO})\right]_{2}$, vermelho escuro), PCN (grupos fosfato e nitrogênio $\left(\mathrm{PO}_{4}^{-}\right)\left(\mathrm{CH}_{2}\right)_{2} \mathrm{~N}^{+}$, verde escuro), $\mathrm{CholCH}_{3}$ (metilenos do grupo colina $\left(\mathrm{CH}_{3}\right)_{3}$, azul escuro), $\mathrm{H}_{2} \mathrm{O}$ (azul). As linhas pretas no topo da imagem representam a densidade eletrônica do sistema. . . . . . . . . . . . . . . . . . . 105

5.15 Perfil de densidade eletrônica obtido a partir da análise das curvas de SAXS de membranas modelo compostas por $\mathrm{POPC}_{1-x} \mathrm{POPC}^{-\mathrm{OOH}_{x}}(\operatorname{com} x=0.00$,

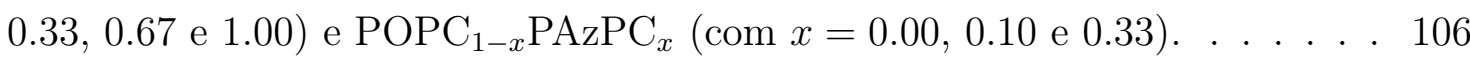

6.1 Estrutura cristalográfica da enzima GAPDH de coelho (PDB 1J0X extraído da referência [103]) . . . . . . . . . . . . . . . . . . . . . . 111

6.2 Curvas de SAXS da enzima GAPDH humana (curva vermelha) e GAPDH de coelho (curva verde) $[2 \mathrm{mg} / \mathrm{mL}=0.05 \mathrm{mM}]$ realizadas durante 100 segundos. Medidas realizadas a $37^{\circ} \mathrm{C} . \ldots \ldots \ldots \ldots$ 
6.3 Curvas de SAXS de medida cinética da enzima GAPDH de coelho $[2 \mathrm{mg} / \mathrm{mL}$ $=0.05 \mathrm{mM} \mid$. Foram realizadas 30 medidas de 40 seg de exposição à radiação com intervalo de $200 \mathrm{seg}$ entre cada medida, totalizando de $120 \mathrm{~min}$ de medida. Medidas realizadas a $37^{\circ} \mathrm{C}$. . . . . . . . . . . . . . . . . . . . . . . 115

6.4 Comparação entre o perfil de espalhamento das curvas de SAXS de: membrana modelo de POPC:POPC-OOH em diferentes proporções (curvas verdes) $(8.33 m M)$, enzima GAPDH (curva azul) $(0.05 \mathrm{mM})$, sistema membrana/proteína (curva vermelha) e a soma da curva da membrana com a curva da proteína (curva rosa); medidos a $37^{\circ} \mathrm{C}$. O insert apresenta o zoom para ângulo de

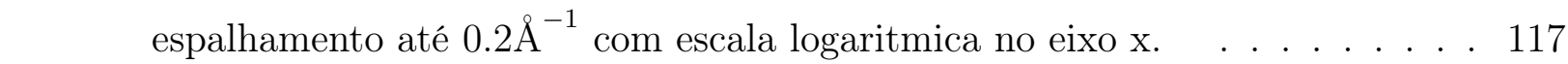

6.5 Comparação o perfil de espalhamento das curvas de SAXS de: membrana mo-

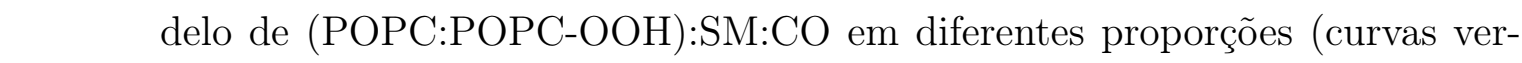
\begin{tabular}{|c|c|}
\hline des$)(8.33 m M)$, enzima GAPDH (curva azul) $[2 \mathrm{mg} / \mathrm{mL}=0.05 \mathrm{mM}]$, sistema \\
\hline
\end{tabular} membrana/proteína (curva vermelha) e a soma da curva da membrana modelo \begin{tabular}{|c|c|}
\hline com a curva da proteína (curva rosa); medidos a $37^{\circ} \mathrm{C}$. O insert apresenta o \\
\hline
\end{tabular} zoom para ângulo de espalhamento até $0.2 \AA^{-1}$ com escala logaritmica no eixo x. . . . . . . . . . . . . . . . . . . . 118

6.6 : Comparação entre as curvas de SAXS das vesículas $(8.33 m M)$ de: a) POPC; b) POPC:POPC-OOH (67:33); c) POPC:POPC-OOH (33:67) e d) POPCOOH com a enzima GAPDH $[2 \mathrm{mg} / \mathrm{mL}=0.05 \mathrm{mM}]$. A curva vermelha representa a medida realizada imediatamente após a mistura das soluções da vesícula e da proteína e a curva verde representa a medida realizada após $2 h$ de espera no banho térmico a $37^{\circ} \mathrm{C}$. . . . . . . . . . . . . . . . . 120 
6.7 : Comparação entre as curvas de SAXS das vesículas $(8.33 m M)$ de: a) POPC:SM:CO (1:1:1) e POPC-OOH:SM:CO (1:1:1) com a enzima GAPDH $[2 \mathrm{mg} / \mathrm{mL}=0.05 \mathrm{mM}]$. A curva vermelha representa a medida realizada imediatamente após a mistura das soluções da vesícula e da proteína e a curva verde representa a medida realizada após $2 h$ de espera no banho térmico a $37^{\circ} \mathrm{C}$.

6.8 : Comparação entre as curvas de SAXS das vesículas $(8.33 m M)$ de: POPC:POPCOOH $(1: 0)$ e $(0: 1)$ com a enzima GAPDH $[2 \mathrm{mg} / \mathrm{mL}=0.05 \mathrm{mM}]$. A curva vermelha representa a medida realizada imediatamente após a mistura das soluções da vesícula e da proteína e a curva verde representa a medida realizada após $24 h$ de espera no banho térmico a $37^{\circ} \mathrm{C} . \quad$. . . . . . . . . . . . . 122

6.9 Ajuste obtido para a curva de SAXS da enzima GAPDH (concentração $12 \mathrm{mg} / \mathrm{mL}$ medida a $\left.37^{\circ} \mathrm{C}\right)$ a partir do PDB de um tetrâmero. . . . . . . . . . . . . 125

6.10 Ajuste de vesículas compostas por POPC [8.33mM] com a enzima GAPDH $[2 \mathrm{mg} / \mathrm{mL}]$ a partir do PDB do tetrâmero, para medidas realizadas: a) logo após a mistura das soluções da proteína com a membrana modelo - 0h e b) após $2 h$ de espera em banho térmico a $37^{\circ} \mathrm{C}$. . . . . . . . . . . . . . . 126

6.11 Ajuste de vesículas compostas por POPC:POPC-OOH(67:33) [8.33mM] com a enzima GAPDH $[2 \mathrm{mg} / \mathrm{mL}]$ a partir do PDB do tetrâmero, para medidas realizadas: a) logo após a mistura das soluções da proteína com a membrana modelo - $0 h$ e b) após $2 h$ de espera em banho térmico a $37^{\circ} C . . . . .126$ 
6.12 Ajuste de vesículas compostas por POPC:POPC-OOH(33:67) [8.33mM] com a enzima GAPDH $[2 \mathrm{mg} / \mathrm{mL}]$ a partir do PDB do tetrâmero, para medidas realizadas: a) logo após a mistura das soluções da proteína com a membrana modelo - $0 h$ e b) após $2 h$ de espera em banho térmico a $37^{\circ} \mathrm{C}$. . . . . . . . . 127

6.13 Ajuste de vesículas compostas por POPC-OOH [8.33mM] com a enzima GAPDH [2mg/mL] a partir do PDB do tetrâmero, para medidas realizadas: a) logo após a mistura das soluções da proteína com a membrana modelo - 0h e b) após $2 h$ de espera em banho térmico a $37^{\circ} \mathrm{C}$. . . . . . . . . . . . . . . . . . 127

6.14 Ajuste de vesículas compostas por POPC:SM:CO(1:1:1) [8.33mM] com a enzima GAPDH $[2 \mathrm{mg} / \mathrm{mL}]$ a partir do PDB do tetrâmero, para medidas realizadas: a) logo após a mistura das soluções da proteína com a membrana - 0h e b) após $2 h$ de espera em banho térmico a $37^{\circ} C$. . . . . . . . . . . . . . . 128

6.15 Ajuste de vesículas compostas por POPC-OOH:SM:CO(1:1:1) [8.33mM] com a enzima GAPDH $[2 \mathrm{mg} / \mathrm{mL}]$ a partir do PDB do tetrâmero, para medidas realizadas: a) logo após a mistura das soluções da proteína com a membrana

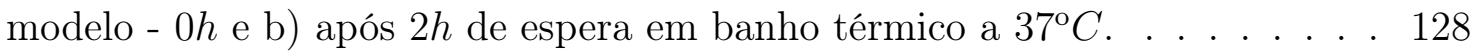

6.16 Ajuste de vesículas compostas por POPC [8.33mM] com a enzima GAPDH $[2 \mathrm{mg} / \mathrm{mL}]$ a partir de dois PDBs - tatrâmero/dímero (curva verde) e tetrâmero/monômero (curva azul), para medidas realizadas: a) logo após a mistura das soluções da proteína com a membrana modelo - 0h e b) após $2 h$ de espera em banho térmico a $37^{\circ} \mathrm{C}$. . . . . . . . . . . . . . . . . . . . . . . . 131 
6.17 Ajuste de vesículas compostas por POPC:POPC-OOH (67:33) [8.33mM] com a enzima GAPDH $[2 \mathrm{mg} / \mathrm{mL}]$ a partir de dois PDBs - tatrâmero/dímero (curva verde) e tetrâmero/monômero (curva azul), para medidas realizadas: a) logo após a mistura das soluções da proteína com a membrana modelo - 0h e b) após $2 h$ de espera em banho térmico a $37^{\circ} C$. . . . . . . . . . . . . . . . . 131

6.18 Ajuste de vesículas compostas por POPC:POPC-OOH (33:67) [8.33mM] com a enzima GAPDH $[2 \mathrm{mg} / \mathrm{mL}]$ a partir de dois PDBs - tatrâmero/dímero (curva verde) e tetrâmero/monômero (curva azul), para medidas realizadas: a) logo após a mistura das soluções da proteína com a membrana modelo - 0h e b) após $2 h$ de espera em banho térmico a $37^{\circ} \mathrm{C}$. . . . . . . . . . . . . . . . . . 132

6.19 Ajuste de vesículas compostas por POPC-OOH $[8.33 \mathrm{mM}]$ com a enzima GAPDH $[2 \mathrm{mg} / \mathrm{mL}]$ a partir de dois PDBs - tatrâmero/dímero (curva verde) e tetrâmero/monômero (curva azul), para medidas realizadas: a) logo após a mistura das soluções da proteína com a membrana modelo - $0 h$ e b) após $2 h$ de espera em banho térmico a $37^{\circ} \mathrm{C}$. . . . . . . . . . . . . . . . . . . . . . . . . 132 


\section{Lista de Tabelas}

3.1 Informações sobre as amostras medidas por SAXS para o estudo de "Caracterização de biomembranas compostas por POPC, POPC:SM e POPC:SM:CO". 31

3.2 Parâmetros de ajustes obtidos a partir dos resultados apresentados na figura

\begin{tabular}{|c|l|l|}
\hline & $R_{\text {pol }}, R_{\mathrm{CH}_{2}}$ e $R_{\mathrm{CH}_{3}}$ representam, respectivamente, a espessura da região \\
\hline
\end{tabular}
polar da membrana modelo, meio hidrofóbico contendo $\mathrm{CH}_{2}$ e $\mathrm{CH}_{3}$, enquanto

$\rho_{\text {pol }}, \rho_{\mathrm{CH}_{2}}$ e $\rho_{\mathrm{CH}_{3}}$ representam as densidades eletrônicas correspondentes. $\mathrm{O}$ parâmetro " $N$ " indica a quantidade de bicamadas lipídicas em uma vesícula multilamelar, "c" representa a distância entre os centros de duas bicamadas, "espessura" representa a espessura total da bicamada lipídica e $\eta_{\text {Caille é o }}$ parâmetro de Caillé. . . . . . . . . . . . . . . . . . . . . . 36

3.3 Parâmetros de ajustes obtidos a partir dos resultados apresentados na figura 3.8: $R_{\text {pol }}, R_{\mathrm{CH}_{2}}$ e $R_{\mathrm{CH}_{3}}$ representam, respectivamente, a espessura da região polar, meio hidrofóbico contendo $\mathrm{CH}_{2}$ e $\mathrm{CH}_{3}$, enquanto $\rho_{p o l}, \rho_{\mathrm{CH}_{2}}$ e $\rho_{\mathrm{CH}_{3}}$ as densidades eletrônicas correspondentes. O parâmetro "ratio" indica a porcentagem de cada um dos fatores de forma (membranas de ajuste) no sistema e "espessura" representa a espessura total da bicamada lipídica. . . . . . . . . 39 
4.1 Informações sobre as amostras medidas por SAXS para o estudo de fotossensibilização de vesículas grandes. . . . . . . . . . . . . . . . . . . . . . 50

4.2 Medida de incorporação dos fotossensibilizadores Azul de Metileno (MB), Azure A (AA), Azure B (AB) e Tionina (Ti) em vesículas compostas por POPC, POPC:SM (1:1) e POPC:SM:CO (1:1:1). . . . . . . . . . . . . . . 52

4.3 Parâmetros de ajustes obtidos a partir dos resultados apresentados na figura 4.7: $R_{\text {pol }}, R_{\mathrm{CH}_{2}}$ e $R_{\mathrm{CH}_{3}}$ representam, respectivamente, a espessura da região polar da membrana, meio hidrofóbico contendo $\mathrm{CH}_{2}$ e $\mathrm{CH}_{3}$, enquanto $\rho_{p o l}, \rho_{C H_{2}}$ e $\rho_{C H_{3}}$ representam as densidades eletrônicas correspondentes. O parâmetro "unilamela" representa a porcentagem de vesículas grandes unilamelares presentes na solução medida, "ratio" indica a porcentagem de cada uma das membranas no sistema (membrana com ou sem alteração química), "N" indica a quantidade de bicamadas lipídicas em uma vesícula multilamelar, "c" representa a distância entre os centros de duas bicamadas, "espessura" representa a espessura total da bicamada lipídica e $\eta_{\text {Caille }}$ é o parâmetro de Caillé.

4.4 Parâmetros de ajustes obtidos a partir dos resultados apresentados nas fi-

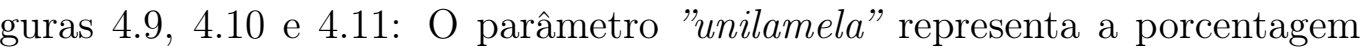
de vesículas grandes unilamelares presentas na solução medida, " $N$ " indica a quantidade de bicamadas lipídicas em uma vesícula multilamelar, "c" representa a distância entre os centros de duas bicamadas, $\eta_{\text {Caille é o parâmetro de }}$ Caillé, $K_{C}$ é o módulo de curvatura (eq. 2.7) e "ratio" indica a porcentagem de membrana considerada oxidada. Os parâmetros $R_{p o l}, R_{C_{2}}, R_{C H_{3}}, \rho_{\text {pol }}$, $\begin{array}{ll}\rho_{C H_{2}} \text { e } \rho_{C H_{3}} \text { foram mantidos com os valores apresentados na tabela } & 4.3 \text {. }\end{array}$. 
5.1 Amostras medidas por SAXS compostas por POPC e lipídio oxidado (POPC$\mathrm{OOH} \mathrm{e/ou} \mathrm{PAzPC).} \mathrm{.} \mathrm{.} \mathrm{.} \mathrm{.} \mathrm{.} \mathrm{.} \mathrm{.} \mathrm{.} \mathrm{.} \mathrm{.} \mathrm{.} \mathrm{.} \mathrm{.} \mathrm{.} \mathrm{.} \mathrm{.} \mathrm{.} \mathrm{.} 76$

5.2 Lista dos grupos químicos e seus respectivos volume molecular, peso molecular, número de elétrons e composição em cada um dos lipídios estudados (POPC, POPC-OOH e PAzPC). De acordo com Kucerka et al. [96], os grupos combinados são: o carbonil + glicerol $(\mathrm{CG})$, o fosfato $+\mathrm{CH}_{2} \mathrm{CH}_{2} \mathrm{~N}(\mathrm{PCN})$ e os três $\mathrm{CH}_{3}$ da colina $\left(\mathrm{CholCH}_{3}\right)$. Os grupos oxidados do POPC-OOH e do PAzPC são o conjunto insaturado CHCH + hidroperóxido CHOOH (PX) e a carboxila $\mathrm{COO}^{-}(\mathrm{CX})$, respectivamente. ${ }^{(\mathrm{a})}$ Standard literature data [97].] . . $\quad 77$

5.3 Parâmetros estruturais obtidos a partir dos ajustes apresentados na figura \begin{tabular}{|l|l|l}
\hline & $R_{\text {pol }}, R_{\mathrm{CH}_{2}}$ e $R_{\mathrm{CH}_{3}}$ representam, respectivamente, a espessura da região
\end{tabular} polar, meio hidrofóbico contendo $\mathrm{CH}_{2}$ e $\mathrm{CH}_{3}$, enquanto $\rho_{p o l}, \rho_{\mathrm{CH}_{2}}$ e $\rho_{\mathrm{CH}_{3}}$ as densidades eletrônicas correspondentes. . . . . . . . . . . . . . . 82

5.4 Parâmetros estruturais obtidos a partir dos ajustes apresentados na figura |5.6: $R_{\text {pol }}, R_{\mathrm{CH}_{2}}$ e $R_{\mathrm{CH}_{3}}$ representam, respectivamente, a espessura da região polar, meio hidrofóbico contendo $\mathrm{CH}_{2}$ e $\mathrm{CH}_{3}$, enquanto $\rho_{p o l}, \rho_{C H_{2}}$ e $\rho_{C H_{3}}$ as densidades eletrônicas correspondentes. $\ldots \ldots \ldots$. . . . . . . . . . . . . 89

5.5 Parâmetros estruturais obtidos a partir dos ajustes apresentados na figura |5.9: $R_{\text {pol }}, R_{\mathrm{CH}_{2}}$ e $R_{\mathrm{CH}_{3}}$ representam, respectivamente, a espessura da região polar, meio hidrofóbico contendo $\mathrm{CH}_{2}$ e $\mathrm{CH}_{3}$, enquanto $\rho_{p o l}, \rho_{C H_{2}}$ e $\rho_{\mathrm{CH}_{3}}$ as densidades eletrônicas correspondentes. . . . . . . . . . . . . . . . . . . . . 95

5.6 Parâmetros de ajuste obtidos a partir do ajuste global das curvas de SAXS apresentadas na figura $5.11 \mid$ As unidades de comprimento e área são respectivamente $\AA$ e $\AA^{2}$. . . . . . . . . . . . . . . . . . . . . . 102 
xxxii

6.1 Amostras medidas por SAXS em presença da enzima GAPDH. . . . . . . . 112

6.2 Porcentagem de cada PDB obtido para os ajustes dos sistemas de membrana/GAPDH para diferentes composições lipídicas (POPC, POPC:POPCOOH(67:33), POPC:POPC-OOH(33:67) e POPC-OOH). As medidas foram realizadas no tempo zero (legenda 0h) e após duas horas de descanso das amostras em banho térmico a $37^{\circ} \mathrm{C}$ (legenda $\left.2 \mathrm{~h}\right) . \quad \ldots . . . . . .130$ 


\section{Capítulo 1}

\section{Introdução}

Membranas celulares são estruturas biológicas muito importantes para o desenvolvimento e manutenção da vida. Elas funcionam como barreiras seletivas que separam o meio interno do meio externo das células e controlam a entrada e saída de componentes, sendo impermeáveis para a maioria dos solutos polares e permeáveis para os apolares [1, 2, 3]. Em 1972 Singer e Nicolson [4] propuseram o "modelo do mosaico fluido" (figura 1.1), no qual a membrana é formada por uma bicamada lipídica com proteínas inseridas ou ancoradas em sua superfície. O termo "fluido" vem da ideia de que as moléculas lipídicas e proteicas podem se movimentar conferindo, assim, mobilidade ao sistema [1, 3, 5]. Os avanços teóricos e experimentais no estudo de estrutura de membranas levaram à proposição do modelo denominado "Lipid Whisker" (figura 1.2 que descreve a influência das propriedades estruturais de lipídios oxidados nos aspectos físicos da membrana como espessura, fluidez e permeabilidade [6, 7, 8].

Dentre a grande variedade de lipídios que podem compor uma membrana biológica, os mais abundantes são os fosfolipídios e os esteróis sendo que, na maioria das membranas 
celulares, a fosfatidilcolina representa mais de $50 \%$ da sua composição [9]. A estrutura química de cada lipídio lhe confere características distintas como tamanho, geometria de empacotamento, temperatura de transição gel-fluído, as quais influenciam nas propriedades da membrana podendo alterar fatores como espessura da bicamada lipídica, fluidez e permeabilidade [1, 9, 10]. A presença de lipídios com diferentes características estruturais promove uma organização lateral na membrana celular podendo apresentar separação de fase [11, 12]. No caso de separação de fase líquido-desordenado(Ld)/líquido-ordenado(Lo) pode ocorrer a formação de domínios lipídicos, que podem afetar a interação entre proteína/membrana celular influenciando no processo de transmissão de informação entre os meios externo e interno da célula [13, 14, 15].

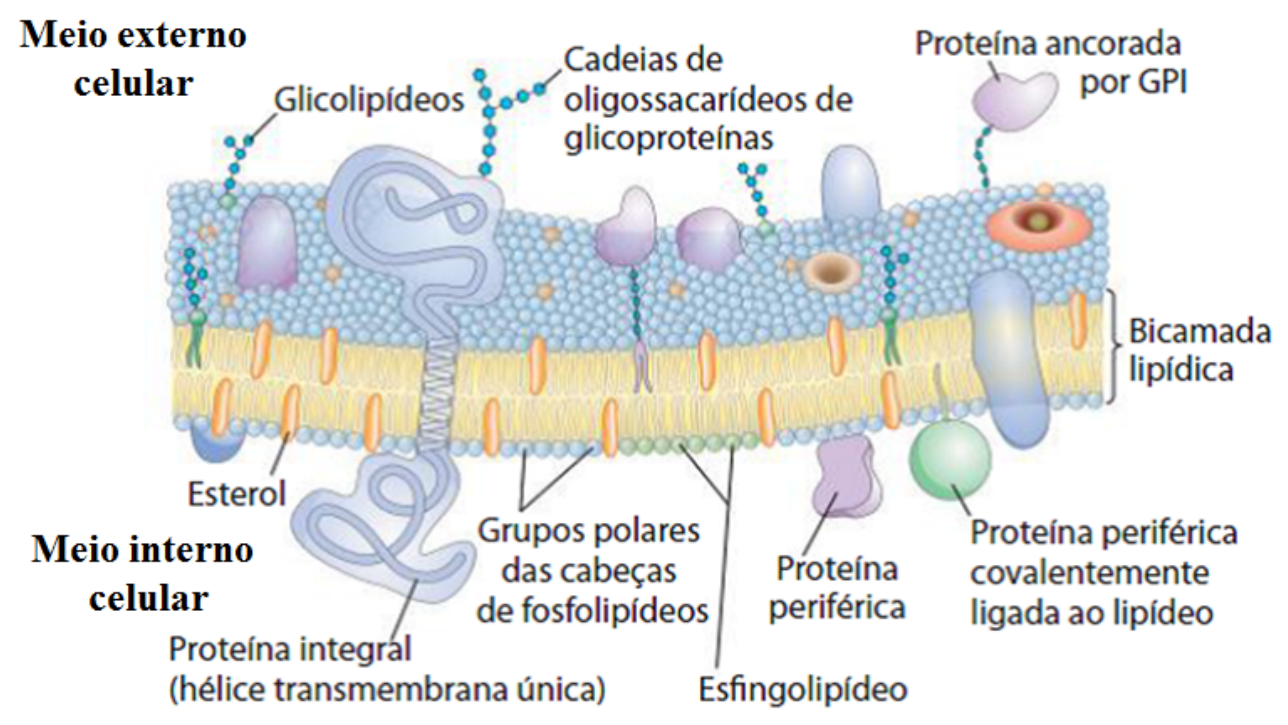

Figura 1.1: Ilustração esquemática do "modelo do mosaico fluido" para a estrutura da membrana plasmática. Imagem extraída da referência [1]

Muitos dos lipídios que compõem as membranas biológicas são insaturados sendo, portanto, suscetíveis à oxidação [16, 17, 18, 19]. Esse processo pode ocorrer espontaneamente 


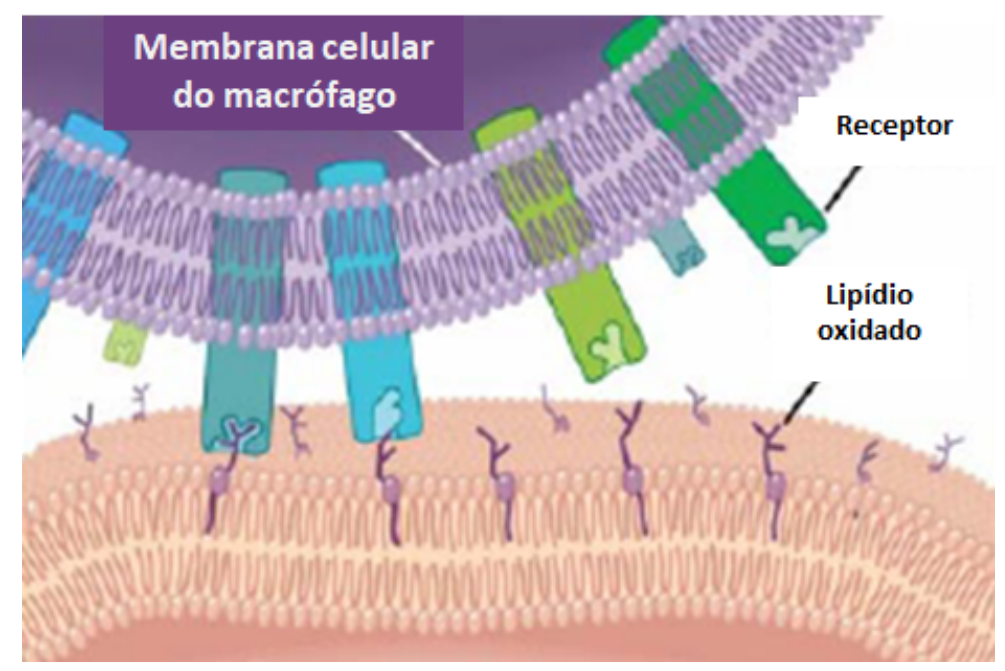

Figura 1.2: Ilustração esquemática do modelo de membrana "Lipid Whisker". Imagem adaptada da referência [6]

em lipídios poli-insaturados. Já fosfolipídios monoinsaturados e colesterol necessitam de um componente altamente oxidante para dar início à reação como, por exemplo, o oxigênio singlete $\left({ }^{1} \mathrm{O}_{2}\right)$ [10, 16]. Uma maneira de promover oxidação lipídica é através da foto-oxidação. Para este processo é necessário a presença de três elementos: molécula foto-ativa (fotossensibilizador - FS), fonte de luz e oxigênio molecular [16, 20, 21]. Em um estudo realizado com vesículas unilamelares gigantes (GUVs) na presença do FS porfirina [22], que possue alto rendimento quântico (da ordem de 60\%) na produção de ${ }^{1} \mathrm{O}_{2}$, Riske e colaboradores mostraram que a resposta de membrana modelo à foto-oxidação está diretamente ligada às insaturações presentes nos lipídios [22].

O processo de foto-oxidação ocorre quando o FS no estado fundamental absorve energia em um comprimento de onda específico (normalmente excita-se a molécula no comprimento de onda de máxima absorção) sendo então excitado para o estado singlete. A transição da molécula para o estado excitado triplete leva à formação de espécies reativas de oxigênio 
(ROS, do inglês, Reactive Oxygen Species) (figura 1.3). O FS decai do estado excitado triplete para o fundamental através de dois tipos de reações: mecanismos tipo I e tipo II [16, 17]. O mecanismo tipo I é caracterizado pela transferência de elétrons do FS no estado excitado triplete para biomoléculas. Esse processo resulta na formação de radicais que tendem a reagir instantaneamente com o oxigênio levando à formação de outras ROS (radicais hidroxila, superóxidos, etc). Já no mecanismo tipo II ocorre transferência de energia do FS no estado excitado triplete para o oxigênio no estado fundamental, resultando na formação do oxigênio singlete $\left({ }^{1} \mathrm{O}_{2}\right)$. O tipo de mecanismo de reação é determinado por fatores como as características do FS e proximidade do FS com alvo biológico. No caso em que há predominantemente reação tipo II, o oxigênio singlete tem como alvo as insaturações dos lipídios, ácidos nucleicos e proteínas levando a formação de peróxidos. Entretanto, no caso em que o FS também decai para o estado fundamental via mecanismo tipo I é possível que o FS no estado excitado triplete reaja diretamente com a dupla ligação, ou com hidroperóxido já formado, propagando a reação de peroxidação. Como produtos finais de oxidação podemos encontrar lipídios com cadeias alquilas truncadas [23, 24, 25]

Uma quantidade controlada de lipídio oxidado é necessária para sinalização celular, maturação e diferenciação, como no caso de apoptose. No entanto, se em excesso, a oxidação lipídica pode afetar negativamente o funcionamento da célula, e também estar envolvida em uma variedade de doenças [18, 27]. Os avanços metodológicos na detecção e identificação, em nível molecular, de espécies oxidativas proporcionaram insights a respeito das alterações lipídicas devido à estresse oxidativo bem como no seu envolvimento na sinalização celular relacionados às principais doenças e processos inflamatórios [28, 29, 30, 31, 32]. Estudos sugerem uma correlação entre a peroxidação lipídica e doenças neurodegenerativas como Parkinson e Alzheimer [33, 34, 35, 36], Huntington e Esclerose [37, 38] e Diabetes tipo 2 


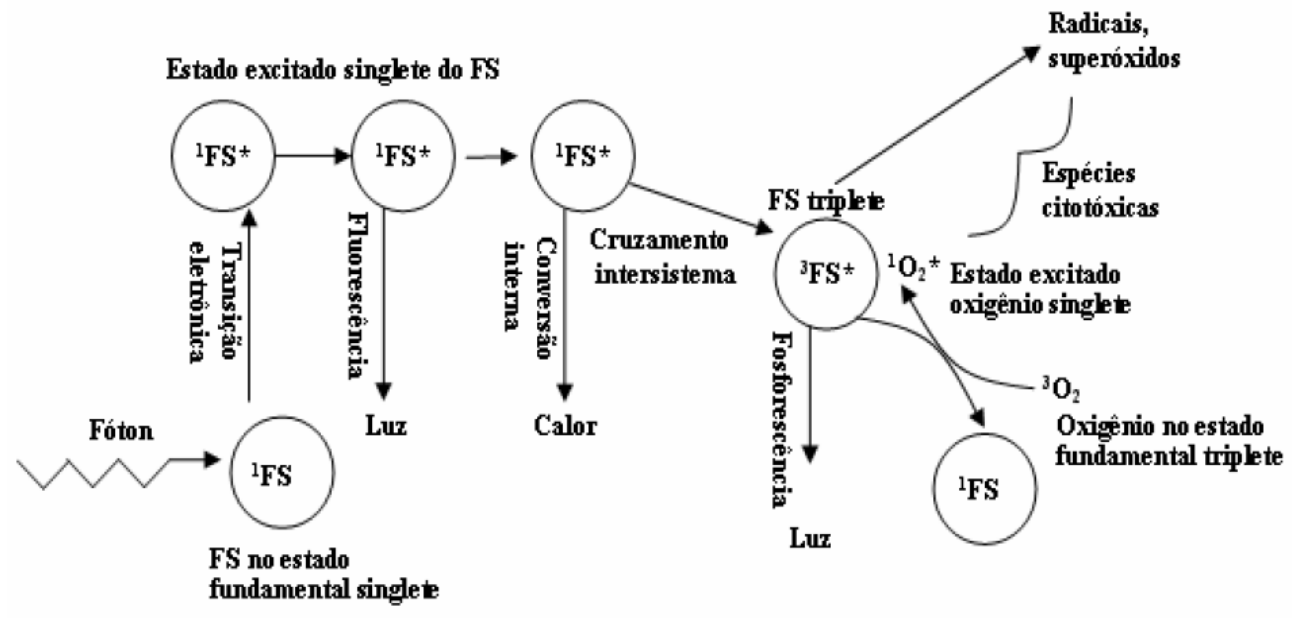

Figura 1.3: Ilustração esquemática do processo de absorção de um fóton por um FS resultando na formação de espécies reativas de oxigênio. Mecanismo tipo I: ocorre a transferência de elétrons do FS no estado excitado triplete para biomoléculas formando radicais que reagem com o oxigênio levando a formação de ROS. Mecanismo tipo II : o FS no estado excitado triplete transfere energia diretamente para o oxigênio molecular formando oxigênio singlete $\left({ }^{1} \mathrm{O}_{2}\right)$. Imagem extraída das referências [21, 26].

[39, 40]. Em paralelo, diversos estudos sugerem que os danos biofísicos causados devido à oxidação lipídica catalizam a formação de fibras amilóides levando à morte dos neurônios [37, 41, 42, 43, 44]. Depois do tecido adiposo, o cérebro é o sistema que possui maior concentração de lipídios, sendo uma grande parcela composta por fosfolipídios [41]. Um glicerofosfolipídio típico possui duas cadeias carbônicas podendo ter de uma à seis insaturações [41] tornando-o alvo fácil para oxidação lipídica e consequente desenvolvimento de doenças. Envelhecimento e carcinogênese induzida por UV e vários processos fisiológicos também estão relacionados à formação de espécies oxidativas [45, 29, 39]. Por outro lado, os efeitos do estresse oxidativo vem sendo utilizados com sucesso para o tratamento de doenças de pele, por exemplo, através da técnica de Terapia Fotodinâmica (PDT-do inglês photodynamic therapy) via morte celular foto-induzida [16]. 
Entretanto, apesar da indubitável relevância da necessidade de entendimento da base molecular relacionada a diversas doenças, o exato modo de ação dos lipídios oxidados em membranas requer estudos aprofundados.

Vários estudos de dinâmica molecular (MD) de bicamadas lipídicas modelo contendo diferentes lipídios oxidados foram desenvolvidos durante a última década (descritos por Jurkiewicz et al. [46] e, mais recentemente, por Siani et al. [10]). Em particular, resultados de simulação para hidroperóxidos lipídicos mostraram aumento na área lateral da bicamada lipídica acompanhada pela diminuição da espessura para lipídios com uma insaturação em uma das caudas lipídicas ou uma insaturação em cada cadeia alquílica [47, 10, 48]. A presença de grupos hidroperóxidos na bicamada lipídica não promove formação de poros independentemente do campo de força aplicado. No entanto, existe uma controvérsia na literatura sobre a localização do grupo hidroperoxidado na membrana prevista por MD. Alguns resultados apontam que os grupos hidroperóxidos tendem a se localizar preferencialmente perto do região da cabeça polar [47, 49, 10]. Por outro lado foram reportados resultados bimoidais de grupos hidroperóxidos localizados tanto na interface bicama-água quanto na região hidrofóbica [48]. Portanto, resultados de simulação computacional não são únicos uma vez que dependem do campo de força aplicado e metodologia escolhida.

Do ponto de vista experimental, resultados usando vesículas unilamelares gigantes (GUVs) como membranas modelo mostraram que o grupo hidroperóxido (figura 1.4 têm impacto significativo nas características estruturais da membrana como, por exemplo, aumento da área lateral [22] em bom acordo com os dados de MD, fluidez [50], elasticidade [20] e formação de domínios lipídicos [51, 52].

A continuidade do processo de oxidação que promove a formação de lipídios de cadeias truncadas também altera as propriedades da membrana. Pode-se observar aumento da 
permeabilidade da membrana, formação de poros [53, 54] e ruptura da membrana [55]. Khandelia e Mouritsen [56] simularam um sistema contendo o lipídio oxidado 1-palmitoil2-azelaoil-sn-glicero-3-fosfocololina (PAzPC) (figura 1.5) que possui um grupo carboxila no final de sua cadeia truncada. De acordo com resultados de MD, a cauda truncada do PAzPC sofre uma inversão completa expondo seu grupo carboxila à fase aquosa, em bom acordo com os resultados de FRET (do inglês Förster-type resonance energy transfer) obtidos para interação entre citocromo-c e membranas modelo de PAzPC marcadas com a sonda fluorescente [57] e perfis de densidade eletrônica obtidos a partir da técnica de refletividade de raios-X para bicamadas lipídicas contendo até 20mol\% de PAzPC [58]. Curiosamente, o PAzPC tem implicação em aterogênese [59].

Portanto, como resultado de um processo fisiológico ou derivado da foto-oxidação, a influência da oxidação lipídica nas propriedades físicas da membrana não é totalmente compreendida. De fato, a complexidade dos processos estudados e as limitações das ferramentas necessárias para caracterizar as modificações estruturais em membranas impostas pelo presença de lipídio oxidado dificulta nosso entendimento atual desse fenômeno. Embora as simulações de MD possam descrever qualitativamente algumas propriedades da bicamada lipídica, é de extrema importância o uso de técnicas experimentais adequadas para acessar a informação estrutural das membranas de forma quantitativa.

A composição lipídica da membrana celular apresenta um papel importante na relação com proteínas. A presença de microdomínios lipídicos e o aumento de estresse oxidativo na membrana influencia na relação entre os seus componentes como interação lipídio-lipídio e lipídio-proteína [10, 1, 9, 37]. A interação entre proteína/membrana pode alterar o estado da proteína a partir de formação de fibras amilóides e agregação, ao mesmo tempo que pode causar ruptura da membrana [37]. A formação de fibras milóides e a agregação de 
proteínas específicas têm sido correlacionadas à doenças neurodegenerativas como Parkinson, Alzheimer, Huntington, dentre outras [41, 37, 38]. Os processos de interação entre esses dois sistemas estão diretamente relacionados às características da proteína, como sequência de aminoácidos, à composição lipídica da membrana e características do meio em que estão inseridas, como pressão e pH [37].

Nesse contexto, investigar como a composição lipídica e também o estresse oxidativo impacta nas propriedades da membrana biológica e, por sua vez, em processos de interação com proteínas é de suma importância para melhor compreender os mecanismos envolvidos em doenças neurodegenerativas e consequente desenvolvimento de tratamentos clínicos.<smiles>[2H][C@@H](COC(=O)CCCCCCCCCCCCCCCCC)COP(=O)([O-])OCC[N+](C)(C)C</smiles>

Figura 1.4: Estrutura molecular do lipídio POPC-OOH (1-palmitoil-2-oleoil-sn-glicero-3fosfatidilcolina hidroperoxidado). Peso molecular 793,1g/mol (sintetizado em colaboração com as Dras. Yulia Moskalenko e Helena Junqueira - Laboratório de processos fotoinduzidos IQ - USP). Ver AnexdA. Figura extraída da referência [16].

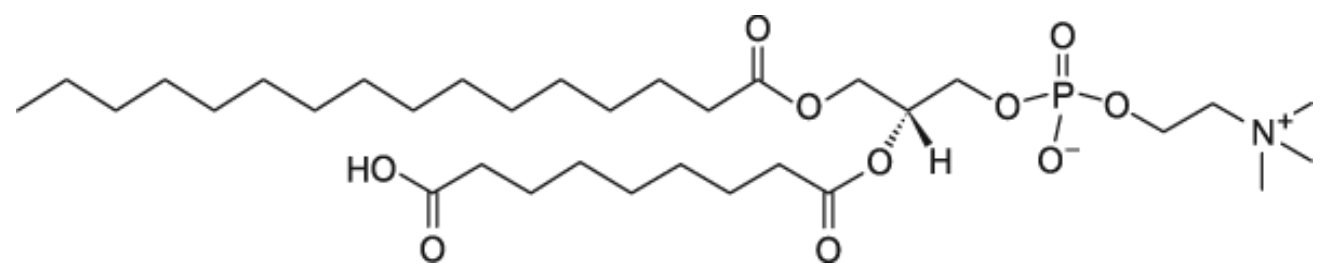

Figura 1.5: Estrutura molecular do lipídio PAzPC (1-palmitoil-2-azelaoil-sn-glicero-3- fosfatidilcolina). Peso molecular 665,83g/mol (Avanti Polar Lipids, Inc.). 


\section{$1.1 \quad$ Objetivos}

O objetivo desta tese de doutorado consistiu em investigar as alterações biofísicas causadas em membranas modelo devido à extresse oxidativo, e entender como essas alterações afetam a estrutura de proteínas específicas. A caracterização teve como técnica principal o espalhamento de raios-X a baixos ângulos (SAXS). Os objetivos específicos são:

i) Caracterizar a estrutura de membranas modelos por SAXS compostas por POPC, POPC:esfingomielina (SM) e POPC:SM:colesterol(CO), este último mimetizando membrana plasmática. Os parâmetros obtidos neste estudo servirão como base comparativa para os demais estudos apresentados nesta tese.

ii) Investigar a partir da técnica de SAXS os efeitos gerados em membranas modelo compostas por POPC, POPC:SM e POPC:SM:CO devido à fotossensibilização in situ. Para este estudo foram utilizadas vesículas grandes dispersas na presença de quatro diferentes fotossensibilizadores fenotiazínicos (FS): azul de metileno (MB), azure A (AA), azure B (AB) e tionina (Ti).

iii) Investigar do ponto de vista estrutural as alterações induzidas em membranas lipídicas

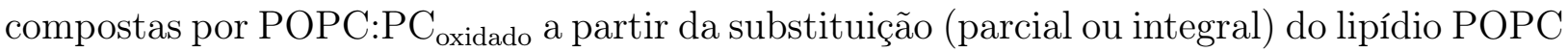
(1-palmitoil-2-oleoil-sn-glicero-3-fosfatidilcolina) pelos lipídios previamente oxidados POPC$\mathrm{OOH}$ (figura 1.4) e PAzPC (figura 1.5).

iv) Entender os mecanismos de interação e agregação de proteínas na superfície de membranas devido à presença de lipídio oxidado na membrana. Dada a relação entre processos oxidativos e doenças neurodegenerativas, para esse estudo foi utilizada a enzima GAPDH (gliceraldeido-3-fosfato-desidrogenase). 


\subsection{Estrutura da Tese}

Esta introdução apresenta uma visão geral da membrana celular e como os processos de oxidação lipídica podem afetar as suas caracterítias biofísicas bem como uma possível relação com doenças. O Capítulo 2 descreve a técnica de espalhamento de raios-X a baixos ângulos (SAXS) e os modelos teóricos aplicados às curvas de SAXS para descrição estrutural dos sistemas estudados. O Capítulo 3 está centrado na caracterização estrutural de membranas modelo compostas pelos lipídios POPC, SM e CO a partir do modelo de lamelas infinitas com três regiões de diferentes densidades eletrônicas (item i dos objetivos específicos). O Capítulo 4 apresenta o estudo de fotossensibilização em mebranas modelo de POPC, SM e CO devido à foto-irradiação in situ na presença dos corantes fenotiazínicos MB, AA, AB e Ti. A seção de resultados deste capítulo está separado em duas seções: na primeira discutimos o efeito de incorporação dos fotossensibilizadores nas membranas analisadas e no segundo apresentamos as possíveis alterações geradas devido à fotossensibilização a partir da análise das curvas de SAXS (item ii). No Capítulo 5 apresentamos a caracterização de membranas compostas por POPC a partir da substituição (parcial ou integral) do lipídio POPC por dois produtos lipídicos oxidados, o POPC-OOH e o PAzPC. Este capítulo constitui o principal capítulo desta tese, uma vez que este trabalho resultou na publicação de um artigo científico. Os resultados deste capítulo estão apresentados em duas seções: na primeira descrevemos as caracterização estrutural inicial realizada a partir do modelo de lamelas infinitas com três regiões de diferentes densidades eletrônicas, enquanto na segunda apresentamos as análises e resultados dos mesmos sistemas via modelo de grupos químicos que determina, como resultado principal, a posição preferencial dos grupos oxidados presentes em cada lipídio (item iii). O Capítulo 6 mostra o estudo da interação e agregação da enzima GAPDH na superfície de membranas modelo com diferentes composições lipídicas, incluindo lipídios oxidados 
(item iv). Em cada item/capítulo descrevemos os materias e metodologias empregadas, bem como as conclusões de cada sistema estudado. Após, nos Apêndices A e B encontram-se , respectivamente, o protocolo para produção do lipídio oxidado POPC-OOH e o artigo publicado como resultado do estudo apresentado nesta tese. 



\section{Capítulo 2}

\section{Espalhamento de Raios-X a Baixos}

\section{Ângulos (SAXS)}

\subsection{Teoria: Princípios Básicos}

A técnica experimental de espalhamento de raios-X a baixos ângulos (SAXS) é utilizada para a caracterização de materiais que tenham estrutura da ordem de dezenas a centenas de angstrons $(\AA)$ 60]. Fótons de raios-X interagem com os elétrons da amostra fazendo com que estes oscilem, originando assim o espalhamento Thompson, onde cada elétron se torna uma fonte de onda esférica de mesma frequência do feixe incidente [61]. A diferença entre o vetor de onda do feixe espalhado $\vec{k}$ e o vetor de onda do feixe transmitido $\overrightarrow{k_{0}}$, descritos na figura 2.1, representa o vetor de espalhamento $\vec{q}$, cujo módulo é dado por 2.1 .

$$
q=\frac{4 \pi}{\lambda} \operatorname{sen} \theta
$$


onde $\lambda$ é o comprimento de onda do feixe de raios-X incidente.

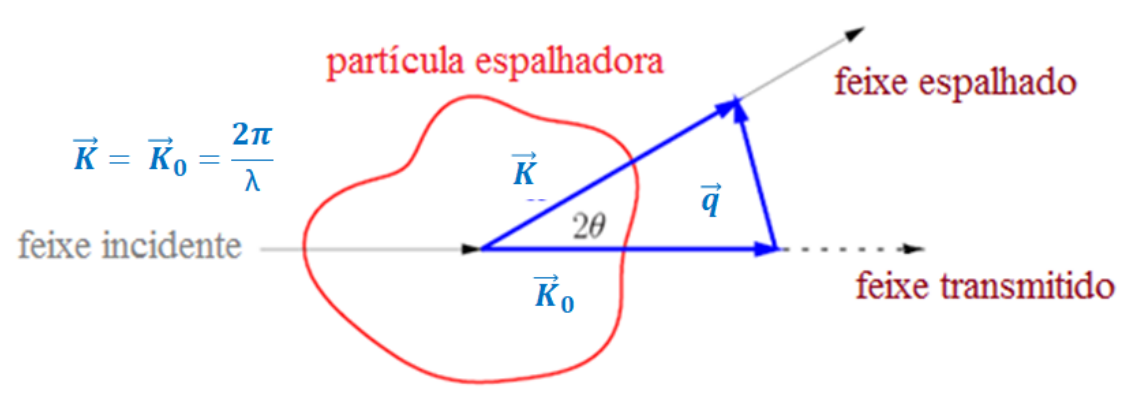

Figura 2.1: Representação do vetor espalhamento gerado pela interação do feixe de raios-X com a amostra.

A cada módulo do vetor espalhamento $(q)$ está relacionada uma intensidade de espalhamento $I(q)$, que representa a quantidade de fótons espalhados a um certo ângulo $\theta$ devido a interação do feixe de raios-X com a amostra. A intensidade de espalhamento é descrita por $2.260,62,63$

$$
I(q)=K n_{p} P(q) S(q)
$$

onde $K$ é uma constante relacionada ao arranjo experimental, $n_{p}$ representa a densidade numérica de partículas espalhadoras, $P(q)$ fator de forma da partícula espalhadora e $S(q)$ função de interferência, ou função de correlação, entre partículas espalhadoras. Para os casos em que não há correlação entre os centros espalhadores temos $S(q) \approx 1$ de modo que podemos reescrever a intensidade de espalhamento como

$$
I(q)=K n_{p} P(q)
$$




\subsection{SAXS no Laboratório Nacional de Luz Síncrotron (LNLS)}

Os resultados apresentados neste trabalho foram obtidos na linha de SAXS 1 do Laboratório Nacional de Luz Síncrotron (LNLS) em Campinas/SP. O tempo de cada medida variou de acordo com as características de cada amostra a fim de obtermos uma melhor relação sinal/ruído. Em geral, para medidas de lipossomos foram realizadas medidas de 300 seg de exposição à radiação à temperatura ambiente de $23^{\circ} \mathrm{C}$. Para proteínas, devido à possibilidade de degradação da amostra, o tempo de exposição foi reduzido para 40 seg. A medida das proteínas foi realizada em temperatura corporal de $37^{\circ} \mathrm{C}$. Observamos por SAXS que para as composições lipídicas estudas a alteração de temperatura de $23^{\circ} \mathrm{C}$ para $37^{\circ} \mathrm{C}$ não altera o perfil de espalhamento das dos lipossomos, de modo que os experimentos de sistemas vesículas(membranas modelo)/proteína foram realizados a $37^{\circ} \mathrm{C}$. As curvas foram corrigidas pelo espalhamento do solvente utilizado.

A figura 2.2 apresenta um esquema da linha de SAXS. Num experimento utilizando radiação síncrotron no LNLS, o feixe de elétrons é acelerado no anel de armazenamento em forma de polígono utilizando eletro-imãs e ondas de rádio frequência. As secções retas do anel são conectadas através de imãs que atuam de modo a alterar a direção da velocidade do feixe ocorrendo assim perda de energia em forma de radiação eletromagnética. O feixe emitido passa por um monocromador do feixe de raios-X $(\lambda=1,548 \AA)$ e um sistema de colimação, seguindo para o porta amostra acoplado a um banho térmico. No porta amostra o feixe de raios-X interage com os elétrons da amostra e é espalhado de forma elástica sendo recebido no detector (figura 2.2. 
A distância entre a amostra e o detector utilizados nos experimentos de SAXS apresentados neste trabalho foi de $90,20 \mathrm{~cm}$, resultando em um intervalo de espalhamento de $0,012 \leq q \leq 0,453 \AA^{-1}$.

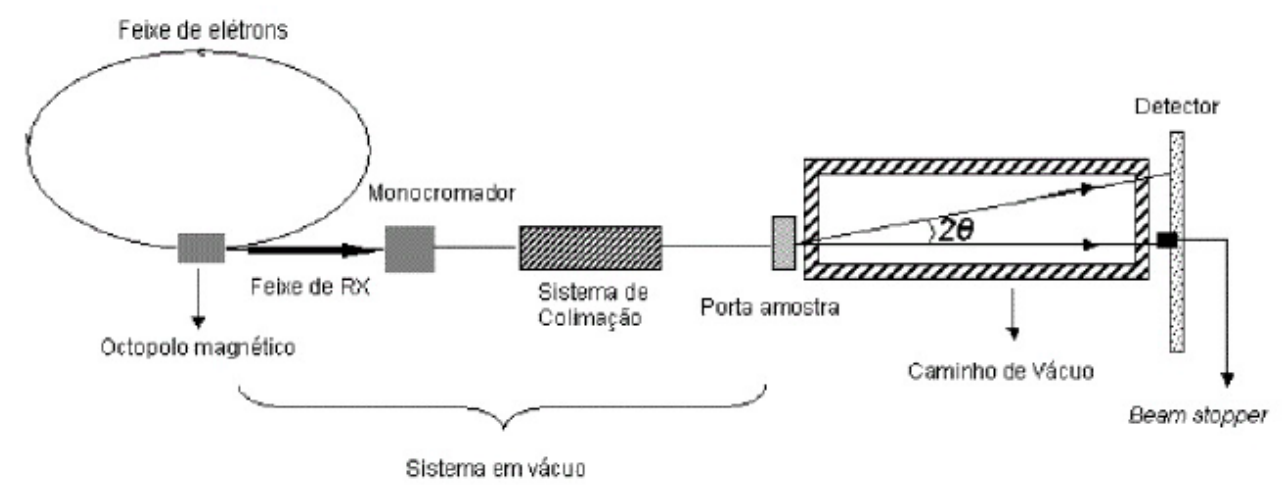

Figura 2.2: Esquematização da linha de SAXS do LNLS. Figura extraída da referência [64]

A dimensão máxima medida pela técnica de SAXS pode ser descrita pela equação 2.4 60]:

$$
D_{\operatorname{máx}}=\frac{\pi}{q_{\min }}
$$

Ou seja, a dimensão máxima observada com esse arranjo experimental foi

$$
D_{\text {máx }}=\frac{\pi}{q_{\min }}=\frac{\pi}{0,012} \approx 262 \AA
$$




\subsection{Modelos para análise das curvas de SAXS}

\subsubsection{Modelo para análise de $N \geqslant 1$ lamelas infinitas}

Como o diâmetro das vesículas (mínimo de $500 \AA ̊$ obtidos pelo método de extrusão - ver 3.2.2.1 é muito grande em comparação com a dimensão máxima que pode ser observada pela técnica de SAXS (da ordem de $262 \AA$ ), na análise dos dados de SAXS dos lipossomos consideramos o modelo de membrana infinita para cálculo de $P(q)$ (eq. 2.3). As curvas experimentais foram ajustadas pelo software GENFIT utilizando o modelo Infinit multilamella with smoothed scattering length density profile and MCT theory (modelo 35) [65]. Neste modelo cada multilamela é formada por $M=1$ bicamadas infinitas. O fator de estrutura $S(q)$ (eq. 2.6) de um empilhamento de multilamelas paralelas é descrito pela teoria de Caillé (MCT do inglês modified Caillé theory), a qual apresenta três parâmetros variáveis: número de multilamelas, $N$; a distância de repetição entre as bicamadas, $c$; e o parâmetro de Caillé $\eta_{\text {Caille }}$ (eq. 2.7) para quantificar as flutuações da bicamada [65, 66].

$$
\begin{gathered}
S(q)=N+2 \sum_{n=1}^{N-1}(N-n) \cos (q n c) e^{-0,0435 n q^{2} c^{2} \eta_{\text {Caille }}} \\
\eta_{\text {Caille }}=\frac{\pi \kappa_{B} T}{2 c^{2} \sqrt{K_{C} B}}
\end{gathered}
$$

onde $\kappa_{B}$ é a constante de Boltzmann $\left(\kappa_{B}=1.38 \cdot 10^{-16} \mathrm{ergK}^{-1}\right)$, $T$ representa a temperatura em Kelvin, $B$ é o módulo de compressibilidade do solvente entre as lamelas $(B=$ $15.10^{12} \mathrm{ergcm}^{-4}$ para $c$ entre $61 \AA$ e $65 \AA$ [67]) e $K_{C}$ é o módulo de curvatura de uma única bicamada lipídica (bending modulus), ou seja, independe de interações entre bicamadas. Este 
parâmetro está relacionado com a flutuação da membrana [66, 68].

No caso de vesículas grandes (area superficial muito maior que a espessura da bicamada), o fator de forma $P(q)$ apresentado na equação 2.2 pode ser reescrito como [69]:

$$
P(q)=\frac{2 \pi A}{q^{2}} P_{t}(q)
$$

onde $A$ é a área superficial da membrana, $q$ é o módulo vetor espalhamento e $P_{t}(q)$ representa o fator de forma da seção transversal (perpendicular ao plano da bicamada) dado pela equação 2.9. Para as análises, foi considerado o espalhamento da bicamada lipídica composta por 3 regiões de densidades eletrônicas diferentes em relação à solução. São elas (figura 2.3): cabeça polar hidrofílica, região hidrofóbica das cadeias de hidrocarbonetos $\mathrm{CH}_{2}$ e o grupo metil terminal $\mathrm{CH}_{3}$. A densidade eletrônica do solvente foi mantida constante. Os parâmetros de ajuste a serem determinados estão descritos abaixo:

$$
\begin{array}{r}
P_{t}(q)=\left\{\frac { 2 } { q } \left\{\Delta \rho_{C H_{3}} \operatorname{sen}\left(q R_{C_{3}}\right)+\Delta \rho_{C H_{2}}\left\{\operatorname{sen}\left[q\left(R_{C H_{2}}+R_{C H_{3}}\right)\right]-\operatorname{sen}\left(q R_{C H_{3}}\right)\right\}+\right.\right. \\
\left.\left.\Delta \rho_{p o l}\left\{\operatorname{sen}\left[q\left(R_{p o l}+R_{C H_{2}}+R_{C H_{3}}\right)\right]-\operatorname{sen}\left[q\left(R_{C H_{2}}+R_{C H_{3}}\right)\right]\right\}\right\}\right\}^{2}
\end{array}
$$

onde $\Delta \rho_{C H_{3}}=\rho_{C H_{3}}-\rho_{\text {sol }}\left(\rho_{\text {sol }}=0.33 e / \AA^{3}\right.$ para soluções em água $), \Delta \rho_{C H_{2}}=\rho_{C H_{2}}-\rho_{\text {sol }} \mathrm{e}$ $\Delta \rho_{\text {pol }}=\rho_{\text {pol }}-\rho_{\text {sol }}$ 


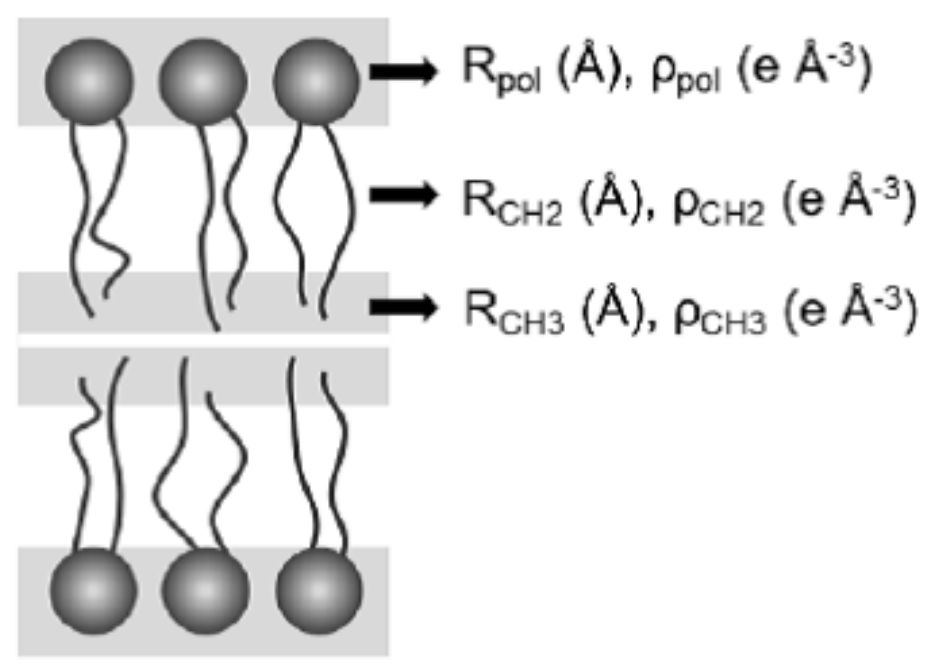

Figura 2.3: Modelo de membrana com três regiões de diferentes densidades eletrônicas.

Parâmetros de ajuste:

$R_{\text {pol }}$ - espessura da cabeça polar

$R_{\mathrm{CH}_{2}}$ - espessura das caudas parafínicas

$R_{\mathrm{CH}_{3}}$ - espessura da região do grupo $\mathrm{CH}_{3}$

$\rho_{\text {pol }}$ - densidade eletrônica da cabeça polar

$\rho_{\mathrm{CH}_{2}}$ - densidade eletrônica dos grupos $\mathrm{CH}_{2}$

$\rho_{\mathrm{CH}_{3}}$ - densidade eletrônica do grupo metil $\mathrm{CH}_{3}$

O perfil de densidade eletrônica ao longo do eixo z, eixo normal à superfície da bicamada lipídica, é descrito pela função $\operatorname{erro}(z)$ com transições suaves entre os quatro níveis (correspondente ao solvente, cabeça polar, cadeias de hidrocarbonetos $\mathrm{CH}_{2}$ e o grupo metil 
terminal $\mathrm{CH}_{3}$ ) conforme apresentado no artigo de Spinozzi e colaboradores [70, 71]:

$$
\begin{aligned}
& \rho(z)=\rho_{0}+ \frac{1}{2}\left\{\left[\rho_{0}-\rho_{p o l}\right] \times\left[\operatorname{erf}\left(\frac{z-Z_{1}}{\sqrt{2}}\right)-\operatorname{erf}\left(\frac{z+Z_{1}}{\sqrt{2}}\right)\right]+\right. \\
&+\left[\rho_{\text {pol }}-\rho_{C H_{2}}\right] \times\left[\operatorname{erf}\left(\frac{z-Z_{2}}{\sqrt{2}}\right)-\operatorname{erf}\left(\frac{z+Z_{2}}{\sqrt{2}}\right)\right]+ \\
&\left.+\left[\rho_{C H_{2}}-\rho_{C H_{3}}\right] \times\left[\operatorname{erf}\left(\frac{z-Z_{3}}{\sqrt{2}}\right)-\operatorname{erf}\left(\frac{z+Z_{3}}{\sqrt{2}}\right)\right]\right\}
\end{aligned}
$$

onde: $\mathrm{Z}_{1}=\mathrm{R}_{\text {pol }}+\mathrm{R}_{\mathrm{CH}_{2}}+\mathrm{R}_{\mathrm{CH}_{3}}$

$\mathrm{Z}_{2}=\mathrm{R}_{C_{2}}+\mathrm{R}_{C H_{3}}$

$\mathrm{Z}_{3}=\mathrm{R}_{C H_{3}}$

\subsubsection{Modelo de grupos}

Para o estudo da posição de grupos químicos em membranas modelo, foi utilizado o modelo Infinite Bilayer With SLD Based on Volume Probability Distributions and MCT Theory (modelo 71) [72] do software GENFIT desenvolvido pelo professor Francesco Spinozzi [65].

O conceito básico deste modelo consiste em descrever a distribuição da fração de volume de cada grupo químico presente em uma molécula a partir de funções analíticas elementares como Gaussianas e funções erro. Neste cenário, a distribuição da fração de volume para a água é obtida como complemento da unidade em relação à fração de volume total do lipídio. Com a finalidade de se obter o perfil de densidade eletrônica para sistemas mais complexos, neste modelo foi considerado que a distribuição de volume de cada grupo químico ao longo do eixo $z$ é dada pela combinação de duas funções erro (equação 2.11) ao invés de um único pico gaussiano. 


$$
E_{2}\left(z, z_{i}, w_{i}, \sigma_{i}\right)=\frac{1}{2}\left[\operatorname{erf}\left(\frac{z-z_{i}+w_{i}}{2^{1 / 2} \sigma_{i}}\right)-\operatorname{erf}\left(\frac{z-z_{i}-w_{i}}{2^{1 / 2} \sigma_{i}}\right)\right]
$$

onde $z_{i}$ representa a posição do pico do grupo químico $i, 2 w_{i}$ é a largura do pico e $\sigma_{i}$ é o desvio padrão da função erro. Para dois picos simetricamente opostos $\pm z_{i}$ a equação 2.11 pode ser reescrita como 2.12 .

$$
E_{2 s}\left(z, z_{i}, w_{i}, \sigma_{i}\right)=E_{2}\left(z, z_{i}, w_{i}, \sigma_{i}\right)+E_{2}\left(z,-z_{i}, w_{i}, \sigma_{i}\right)
$$

A distribuição da fração de volume para cada grupo químico $i$ é então dada por 2.13.

$$
\varphi_{i}(z)=\frac{\mathrm{n}_{i} \nu_{i}}{A} \frac{E_{2 s}\left(z, z_{i}, w_{i}, \sigma_{i}\right)}{2 w_{i}}
$$

onde $\nu_{i}$ é o volume molecular do grupo $i, \mathrm{n}_{i}$ é a quantidade de grupos $i$ no lipídio e $A=$ $V_{\text {hyd }} / D_{\text {hyd }}$ é a área por molécula com $V_{\text {hyd }}=\sum_{i=1}^{N_{\text {hyd }}} \mathrm{n}_{i} \nu_{i}$ e $D_{\text {hyd }}$ representando o volume total e a espessura da região hidrofóbica, respectivamente. Para água, temos 2.14 .

$$
\varphi_{N}(z)=1-\varphi_{\mathrm{hyd}}(z)-\sum_{i=N_{\mathrm{hyd}}+1}^{N-1} \varphi_{i}(z)
$$

cuja soma percorre os grupos apolares. Por fim, o perfil de densidade eletrônica da bicamada lipídica é descrito por 2.15 . 


$$
\rho(z)=\sum_{i=1}^{N} \varphi_{i}(z) b_{i} / \nu_{i}
$$

onde $b_{i}$ é o fator de espalhamento do grupo que, no caso da técnica SAXS, corresponde ao número de elétrons multiplicado pelo raio do elétron $\left(r_{\mathrm{e}}=0.28 \cdot 10^{-12} \mathrm{~cm}\right)$.

\subsubsection{Modelo para análise de Proteínas}

Para as análises de curvas de SAXS de proteínas, foi utilizado o modelo All-atoms form factor of a PDB structure with solvation shell of dummy atoms and multipole expansion average (modelo 15) do software GENFIT [65]. Neste modelo a contribuição de cada átomo presente no arquivo PDB (do inglês Protein Data Bank) é levado em consideração através do seu fator de estrutura atômica. A contribuição do solvente deslocado é calculada considerando esferas gaussianas fictícias centradas nas posições atômicas do PDB. As moléculas de solvente em contato com a macromolécula também são descritas por esféras gaussianas fictícias onde a quantidade e coordenadas geométricas são determinadas considerando a macromolécula em um conjunto tetraédrico de esferas fictícias [73]. 
Capítulo 3

Caracterização de biomembranas de

\section{POPC, POPC:SM e POPC:SM:CO}


Membranas biológicas possuem o importante papel de controlar a entrada e saída de componentes da célula [1, 2, 3]. Os lipídios que compõe a membrana apresentam características distintas como tamanho, geometria de empacotamento, temperatura de transição gel-fluído, que podem influenciar tanto suas propriedades estruturais como espessura da bicamada lipídica, fluidez e permeabilidade [1, 9, 10] quanto sua interação com outos biomaterias como proteínas, por exemplo [1, 13, 14, 15]. Neste caminho, o estudo apresentado neste capítulo teve como foco a caracterização estrutural de membranas modelo com diferentes composições lipídicas.

No caso do sistema ternário POPC:SM:CO (1:1:1), utilizado como mimético de membrana plasmática, pode ocorrer a formação de domínios lipídicos (Ld-Lo). Em 2007 Frazier e colaboradores [74] publicaram um estudo sobre a formação de domínios lipídicos (Ld-Lo) em vesículas compostas por POPC:SM:CO (30:35:35). O estudo foi realizado usando a técnica experimental FRET (do Inglês Föster Resonance Energy Transfer) e simulações de Monte Carlo. Eles observaram que há uma interação repulsiva entre os lipídios POPC/CO e POPC/SM, em contrapartida a interação é atrativa entre SM/CO [74]. Também utilizando FRET, Pathak e colaboradores [75] observaram nanodomínios lipídicos com raio de $80-100 \AA$ em sistemas compostos por POPC:SM:CO (1:1:1), à temperatura de $23^{\circ} \mathrm{C}$.

\subsection{Objetivo específico}

O objetivo deste capítulo consistiu na caracterização estrutural, via técnica de SAXS, de membranas modelo compostas por POPC, POPC:SM (1:1) e POPC:SM:CO (1:1:1), este último mimetizando membrana plasmática. Os parâmetros estruturais obtidos como resultado deste capítulo serão utilizados como base para os demais estudos apresentados 
nesta tese.

\subsection{Materiais e Métodos}

\subsubsection{Materiais}

Clorofórmio ( $\mathrm{CHCl}_{3}$ P.M. 119, 38 - adquirido da empresa Synth) utilizado para a diluição dos lipídios POPC, SM e CO (estruturas químicas apresentadas abaixo);

Água Milli-Q (Milli-Q plus ultra pure Type 1 water system - Milipore; resistividade 18,2M S.cm - pH 5) utilizada para hidratação dos filmes lipídicos.

\subsubsection{Lipídios}

1-palmitoil-2-oleoil-sn-glicero-3-fosfatidilcolina (POPC)

peso molecular 760, 10g/mol (Avanti Polar Lipids, Inc.).

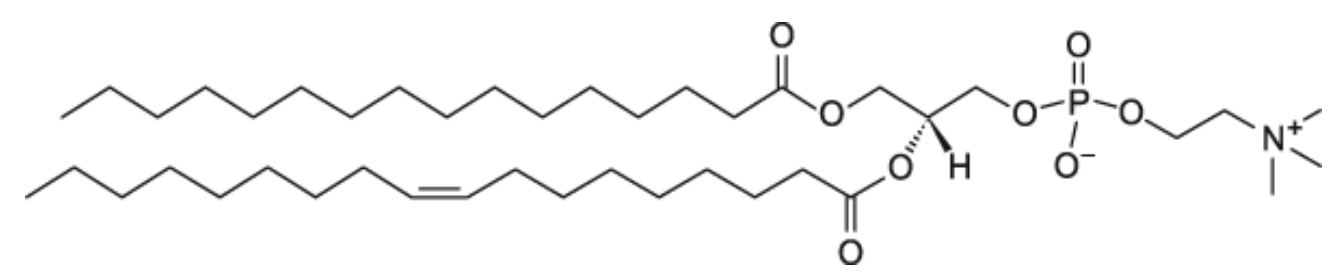

Figura 3.1: Estrutura molecular do lipídio 1-palmitoil-2-oleoil-sn-glicero-3-fosfatidilcolina (POPC ou PC)

Esfingomielina (Cérebro de porco) (SM)

peso molecular 731,09g/mol (Avanti Polar Lipids, Inc.). 


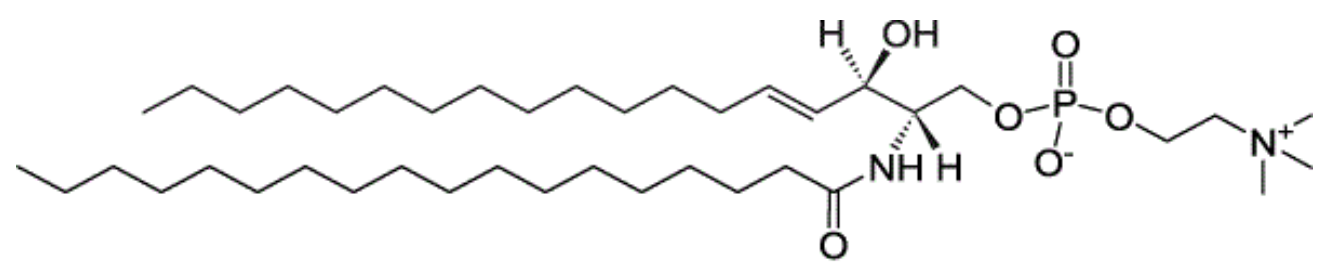

Figura 3.2: Estrutura molecular do lipídio Esfingomielina (SM)

Colesterol (Lã de ovelha) $(>98 \%)(\mathrm{CO})$

peso molecular 386,66g/mol (Avanti Polar Lipids, Inc.).

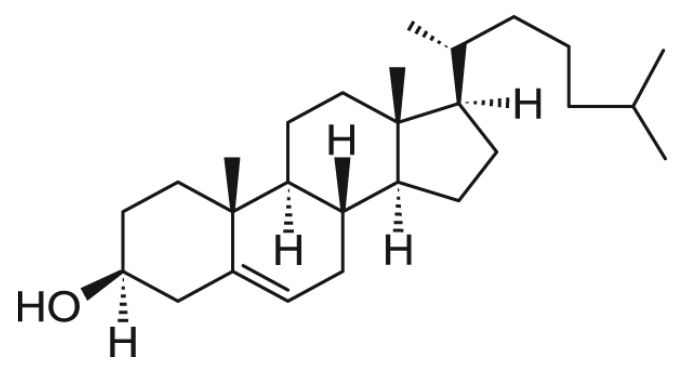

Figura 3.3: Estrutura molecular do lipídio Colesterol (CO)

\subsubsection{Preparação de Vesículas Unilamelamelares Grandes (LUVs)}

Para a preparação das vesículas, os lipídios POPC (figura 3.1), SM (figura 3.2) e CO (figura 3.3) foram primeiramente diluídos em clorofórmio $\left(\mathrm{CHCl}_{3}\right)$. Em seguida a solução foi submetida a um fluxo de nitrogênio $\left(N_{2}-99.999 \%\right.$ de pureza) o que levou à secagem do clorofórmio e consequente formação de um filme lipídico na parede do tubo de ensaio. Para garantir a completa evaporação do clorofórmio, os tubos de ensaio foram mantidos no dessecador por duas horas. Após a hidratação do filme, com tampão ou água, a solução foi agitada em vórtex até se obter uma solução homogênea. Para os casos em que a temperatura de transição gel-fluido do sistema é maior do que a temperatura ambiente (membranas 
modelo de POPC e POPC:CO contendo SM possue transição gel-fluído em torno de $35^{\circ} \mathrm{C}$ e $38^{\circ} \mathrm{C}$, respectivamente [76, 13, 77]), as soluções foram aquecidas em banho térmico acima da temperatura de transição.

\subsubsection{Processo de Extrusão de Vesículas}

O processo de extrusão consiste em passar a solução contendo vesículas recém-formadas por um filtro de policarbonato (Nuclepore) de tamanho definido, fazendo com que as mesmas se restruturem em tamanho. Para a obtenção de vesículas unilamelares esse procedimento deve ser repetido diversas vezes, sendo que o número de ciclos e diâmetro do filtro varia de acordo com a composição lipídica da solução (figura 3.4). Para que essa reestruturação aconteça, durante a extrusão a solução deve ser mantida acima da temperatura de transição de fase gel-fluido do sistema. As amostras analisadas no decorrer desta tese foram extrusadas com o equipamento da Avanti Polar Lipids utilizando filtros de 400nm, 100nm e 50nm de diâmetro, de acordo com a composição lipídica. O tamanho do filtro e quantidade de extrusão considerados para os sistemas estudados neste capítulo estão apresentados na tabela 3.1 . 


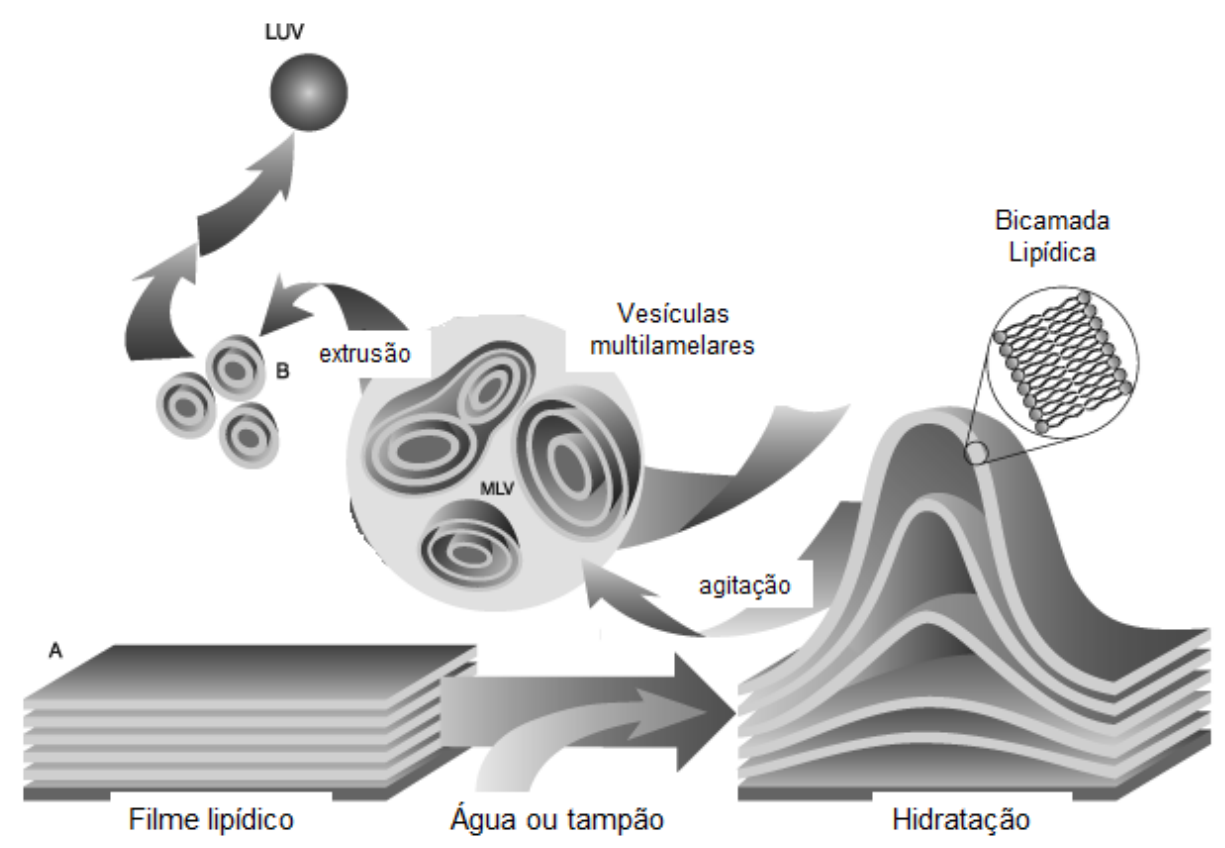

Figura 3.4: Ilustração do processo de formação de vesículas. Adaptado de www.avantilipids.com

Consideração inicial: Em todos os experimentos citados neste trabalho não foi considerada a perda de concentração de lipídios que pode ocorrer após o processo de extrusão. Portanto, os valores mencionados estão relacionados à concentração de lipídios inicial na preparação do filme lipídico. Tal consideração pode ser feita sem perda de generalidade pois, em nossos estudos, a variação na concentração final de vesículas em solução não afeta a estrutura da membrana modelo que será caracterizada.

A figura 3.5 apresenta um exemplo de curvas de SAXS características de estruturas unilamelares (curva vermelha), estruturas multilamelares (curva verde) e coexistência entre ambas as estruturas (curva azul). Pode-se observar na curva representativa de perfil multila- 
melar (curva verde) o aparecimento de picos de Bragg indicativo do padrão de repetição das bicamadas lipídicas. A posição de cada pico é descrita pela Lei de Bragg $n \lambda=2 D \operatorname{sen} \theta$, onde $D$ representa a distância de repetição entre as bicamadas e $n$ representa a ordem de difração. Por outro lado, como vesículas unilamelares não possuem padrão de repetição os picos não são observados (curva vermelha). Já sistemas compostos por vesículas unilamelares e multilamelares irão apresentar curvas de SAXS resultantes da composição dos espalhamentos de ambas estruturas (uni e multilamelar). Por isso, a curva azul apresenta uma tendência ao aparecimento de um pico de Bragg em $q \simeq 0,08 \AA^{-1}$, indicado pela seta. . A definição de picos de Bragg em sistemas mistos é determida pela quantidade de estruturas multilamelares presentes na amostra [78]. 


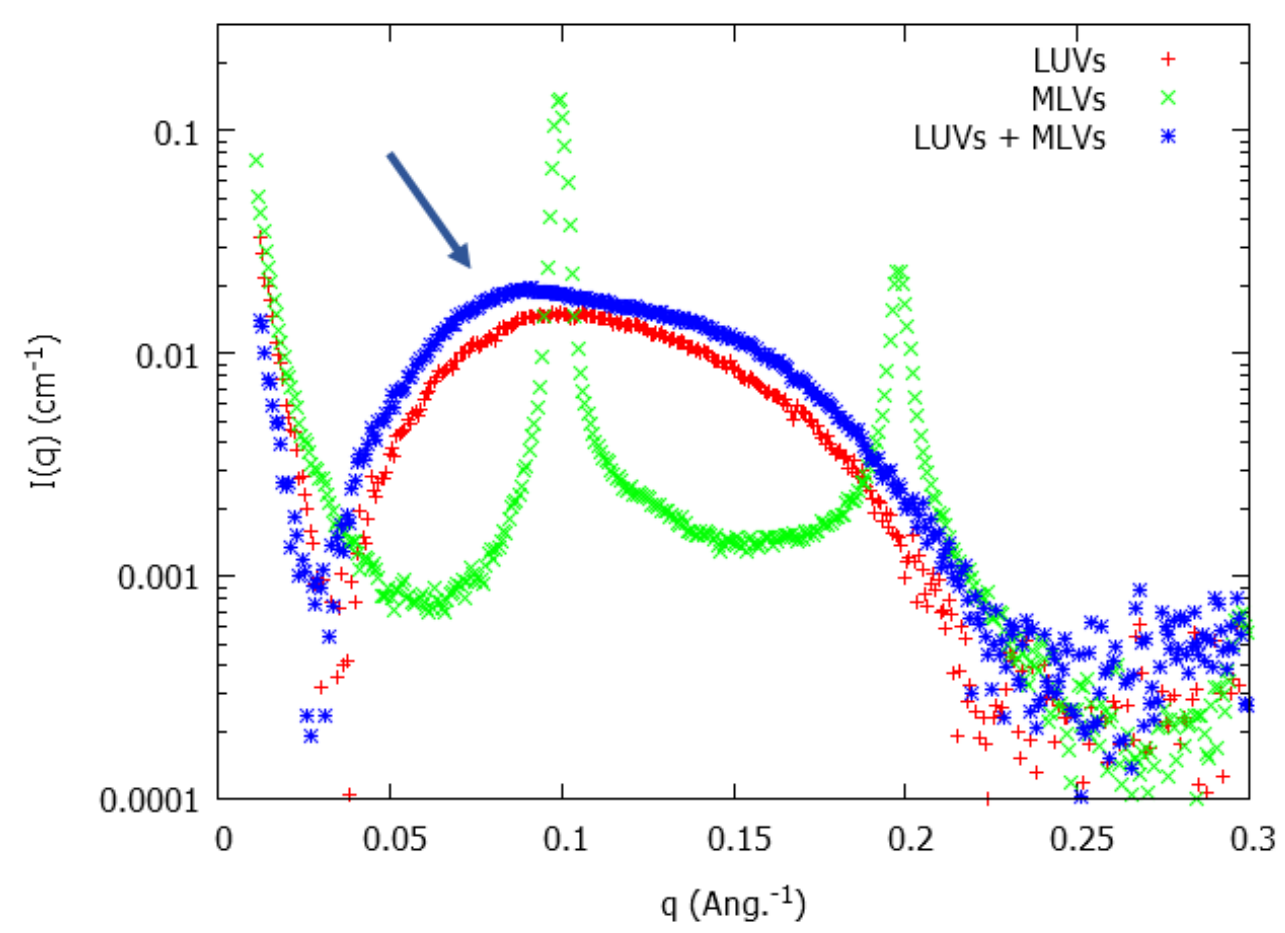

Figura 3.5: Perfil de espalhamento de curvas de SAXS característico para estruturas unilamelares (curva vermelha), estruturas multilamelares (curva verde) e coexistência entre estruturas uni e multilamelares (curva azul). Neste exemplo, a amostra consistiu de membranas modelo de POPC [10mM].

\subsubsection{SAXS}

A caracterização de vesículas grandes compostas por POPC, POPC:SM e POPC:SM:CO foi realizada a partir da técnica de SAXS com o intuito de se obter os parâmetros estruturais dessas membranas modelo que serão consideradas base para os estudos seguintes de interação com outros biomateriais (porteína e corantes fenotiazínicos).

As vesículas grandes foram preparadas segundo o protocolo descrito na seção 3.2.2. A tabela 3.1 apresenta as informações sobre composição lipídica, concentração inicial de lipídios, 
quantidade de extrusões e tamanhos de poro utilizados para a obtenção de unilamelas e a temperatura em que a solução foi mantida durante o processo de hidratação do filme lipídico. Bicamadas lipídicas compostas unicamente por POPC possuem temperatura de transição em $-2,5^{\circ} \mathrm{C}$ [79, 80], permitindo assim temperaturas de extrusão mais baixas, diferentemente dos outros dois sistemas POPC:SM e POPC:SM:CO que necessitam de mais energia para que haja uma mudança de estado. Em vesículas compostas por POPC:SM a transição de fase ocorre em $35^{\circ} \mathrm{C}$ [76, 13]. Para a composição ternária POPC:SM:CO (1:1:1), estudos realizados por Pokorny et al evidenciaram maior porcentagem de fase líquido-desordenada $\left(L_{d}\right)$ para temperaturas abaixo de $22^{\circ} \mathrm{C}$ ou acima de $38^{\circ} \mathrm{C}$ [77]. Essa característica de maior rigidez dos sistemas compostos por POPC:SM e POPC:SM:CO, se comparado ao sistema puro POPC, também influenciou no total de extrusões necessárias para se obter uma maior quantidade de vesículas unilamelares na solução.

As análises das curvas de SAXS dos sistemas apresentados neste capítulo foram realizadas utilizando o modelo de multilamelas infinitas descrito na seção 2.3.1. No caso de unilamela, o parâmetro referente ao número de multilamelas é dado por $N=1$.

Tabela 3.1: Informações sobre as amostras medidas por SAXS para o estudo de "Caracterização de biomembranas compostas por POPC, POPC:SM e POPC:SM:CO”.

\begin{tabular}{ccccc}
\hline \multicolumn{5}{c}{ Medidas de SAXS } \\
\hline Composição & Concentração & $\mathrm{n}^{\circ}$ de extrusão das vesículas & filtro $(\mathrm{nm})$ & $\mathrm{T}\left({ }^{\circ} \mathrm{C}\right)$ \\
\hline POPC & \multirow{2}{*}{$10 \mathrm{mM}$} & 31 & 100 & 30 \\
& & 19 & 400 & 45 \\
POPC:SM (1:1) & \multirow{2}{*}{$10 \mathrm{mM}$} & 31 & 100 & \\
& & 19 & 400 & \multirow{2}{*}{45} \\
POPC:SM:CO (1:1:1) & \multirow{2}{*}{$10 \mathrm{mM}$} & 31 & 100 & \\
\hline
\end{tabular}




\subsection{Resultados e Discussões}

O estudo de caracterização de membranas modelo teve início com sistemas compostos por POPC, POPC:SM e POPC:SM:CO, este último mimetizando membrana plasmática [1]. As curvas de SAXS apresentadas na figura 3.6 mostram os diferentes perfis de espalhamento a medida que alteramos a composição lipídica da membrana modelo. Podem ser observadas alterações no perfil de espalhamento das curvas de SAXS a medida que incluímos os lipídios esfingomielina (SM) e colesterol (CO) na composição das vesículas. Em particular, a curva experimental referente à composição lipídica POPC:SM indica presença de multilamelas (ver figura 3.6 curva verde - região indicada pela seta), similar ao exemplo descrito na figura 3.5 (curva azul) onde há coexistência entre estruturas uni e multilamelares. Para os demais sistemas, POPC e POPC:SM:CO, as curvas de SAXS indicaram presença predominante de estruturas unilamelares. Mesmo após o processo de extrusão, pode ocorrer a presença de multilamelas devido à reorganização das vesículas ou mesmo à vesículas multilamelares com diâmetro menor do que o tamanho do poro utilizado para a extrusão. As definições dos tipos de estruturas presentes em cada sistema são apresentados a seguir a partir da análise das curvas de SAXS via o modelo de lamelas infinitas (ver seção 2.3.1).

A figura 3.7 apresenta o melhor ajuste obtido para as vesículas compostas por POPC e POPC:SM (1:1) e a tabela 3.2 apresenta os respectivos parâmetros de ajuste. Para o sistema composto apenas por POPC consideramos apenas a presença de LUVs $(N=1)$. No caso do sistema binário POPC:SM a suposição foi de que os lipídios POPC e SM estão distribuídos homogeneamente pela vesícula, de modo que consideramos apenas um modelo de lamela infinita para o cálculo do fator de forma $P(q)$. Para este sistema foi evidenciada presença de multilamela de modo que $N>1$ foi determinado a partir do ajuste (tabela 3.2 ). 


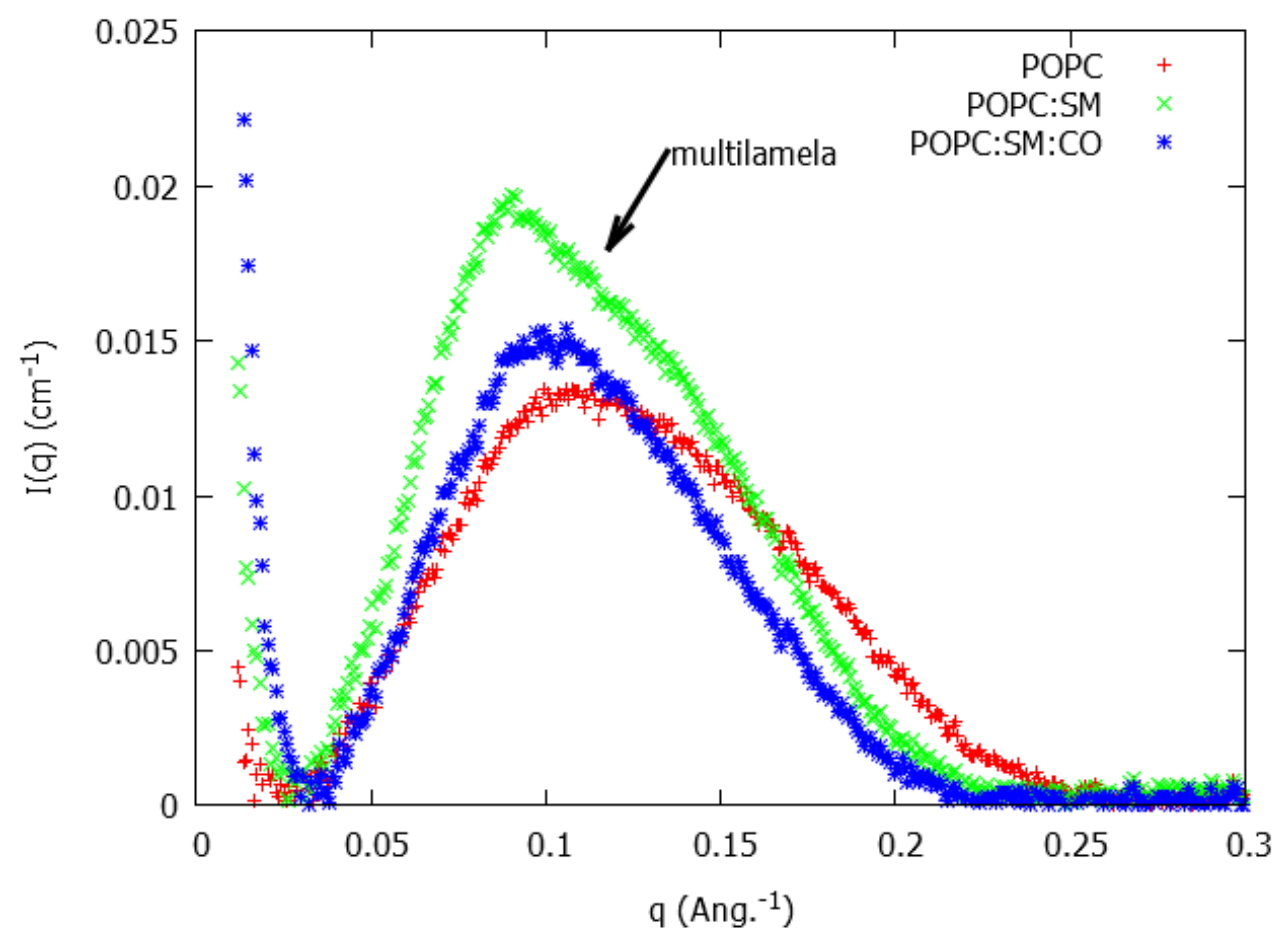

Figura 3.6: Curvas de SAXS de LUVs compostas por POPC (curva vermelha), POPC:SM (curva verde) e POPC:SM:CO (curva azul) com concentração final de $10 \mathrm{mM}$ de lipídio medidos a $23^{\circ} \mathrm{C}$.

Conforme pode-se observar, lipossomos de POPC foram caracterizados como LUVs, apresentando espessura de bicamada lipídica de 46.4(6) $\AA$, em bom acordo com resultados descritos na literatura [69]. Por outro lado, vesículas de POPC:SM (1:1) apresentaram perfil característico de coexistência de estrutura uni e multilamelares (ver figura 3.6). Neste caso, o ajuste aos dados experimentais foi feito considerando que $I(q)=$ $x P(q)_{u n i}+(1-x) P(q)_{m u l t} S(q)$. Os parâmetros de espessura $(R)$ e densidade $(\rho)$ são os mesmos para $P(q)_{\text {uni }}$ e $P(q)_{\text {mult }}$. Já os parâmetros relativos ao fator de estrutura $S(q)(N$, $c$ e $\left.\eta_{\text {Caille }}\right)$ foram determinados apenas para os sistemas multilamelares uma vez que para unilamelas $S(q)=1$. Os parâmetros resultantes do ajuste estão apresentados na tabela 3.2 . 
A partir da análise para os sistema compostos por POPC:SM (1:1), foi possível verificar que cerca de $20 \%$ das vesículas possuem estruturas multilamerares, com distância de repetição entre as bicamadas lipídicas de $77(1) \AA$ (tabela 3.2). A inclusão do lipídio SM na composição da vesícula causa um maior efeito na espessura média da região hidrofóbica que, resulta em um aumento de $2.8 \AA$ em $R_{\mathrm{CH}_{2}}$ se comparado à vesícula composta apenas por POPC. Este resultado era esperado uma vez que a esfingomielina (figura 3.2 apresenta maior quantidade de carbonos na cauda hidrofóbica se comparada ao POPC (figura 3.1). Com relação à espessura total da bicamada lipídica, vesículas compostas por POPC:SM apresentaram valor igual a $53(1) \AA$, ou seja, $7 \AA$ maior que a espessura obtida para vesículas compostas apenas por POPC (espessura de 46.4(6)Å). O aumento na espessura da bicamada lipídica devido a inclusão do lipídio SM era esperado pois sua estrutura química apresenta duas caudas saturadas (figura 3.2 de modo que, à temperatura ambiente, a SM deve tender ao empacotamento com estiramento das caudas de hidrocarboneto ("fase gel") [81]. O parâmetro de Caillé obtido para esse sistema $\left(\eta_{\text {Caille }}=0.13\right)$ indica a flutuação das bicamadas que apresentam estrutura multilamelar, sendo que valores menores desse parâmetro (da ordem de $10^{-2}$ ) indicam estruturas altamente correlacionadas [82, 83]. 


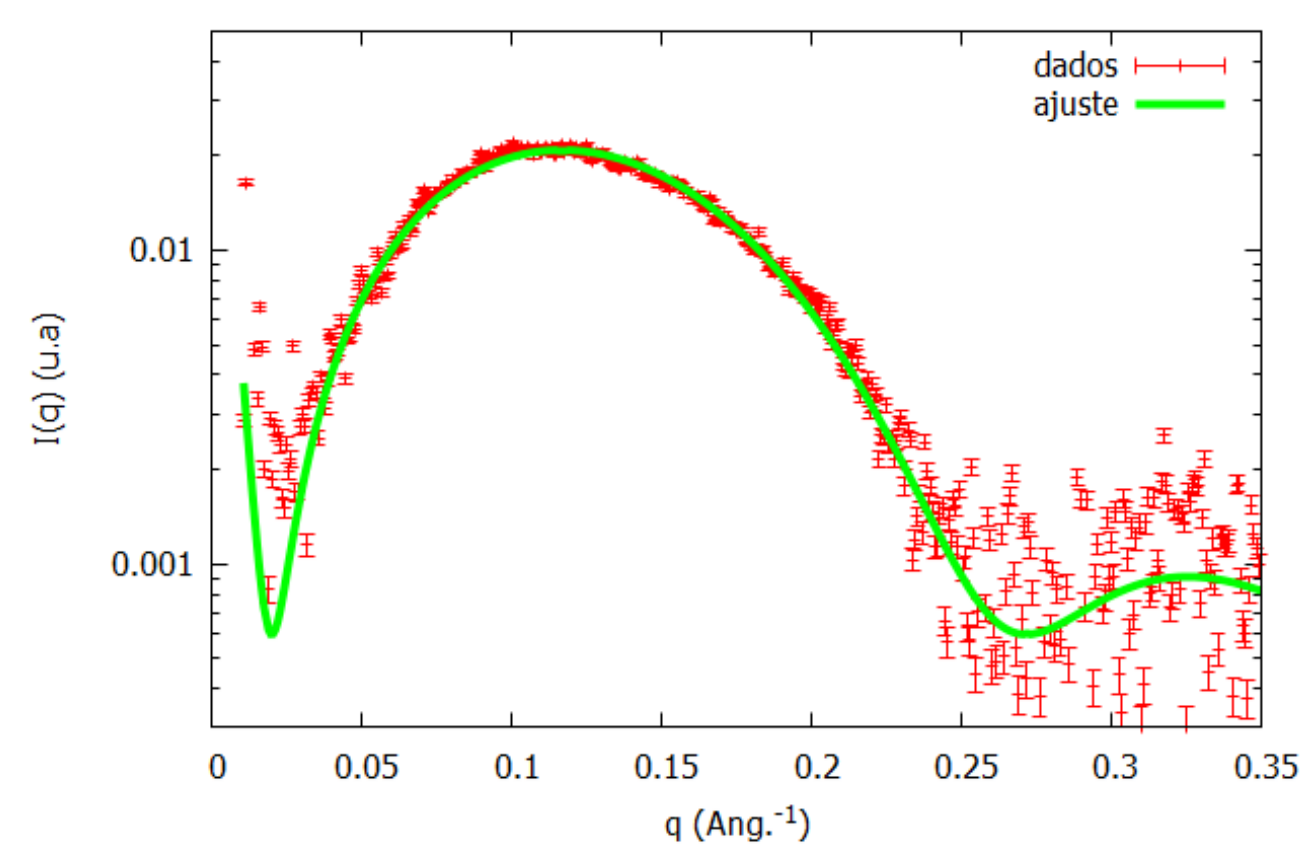

(a) POPC

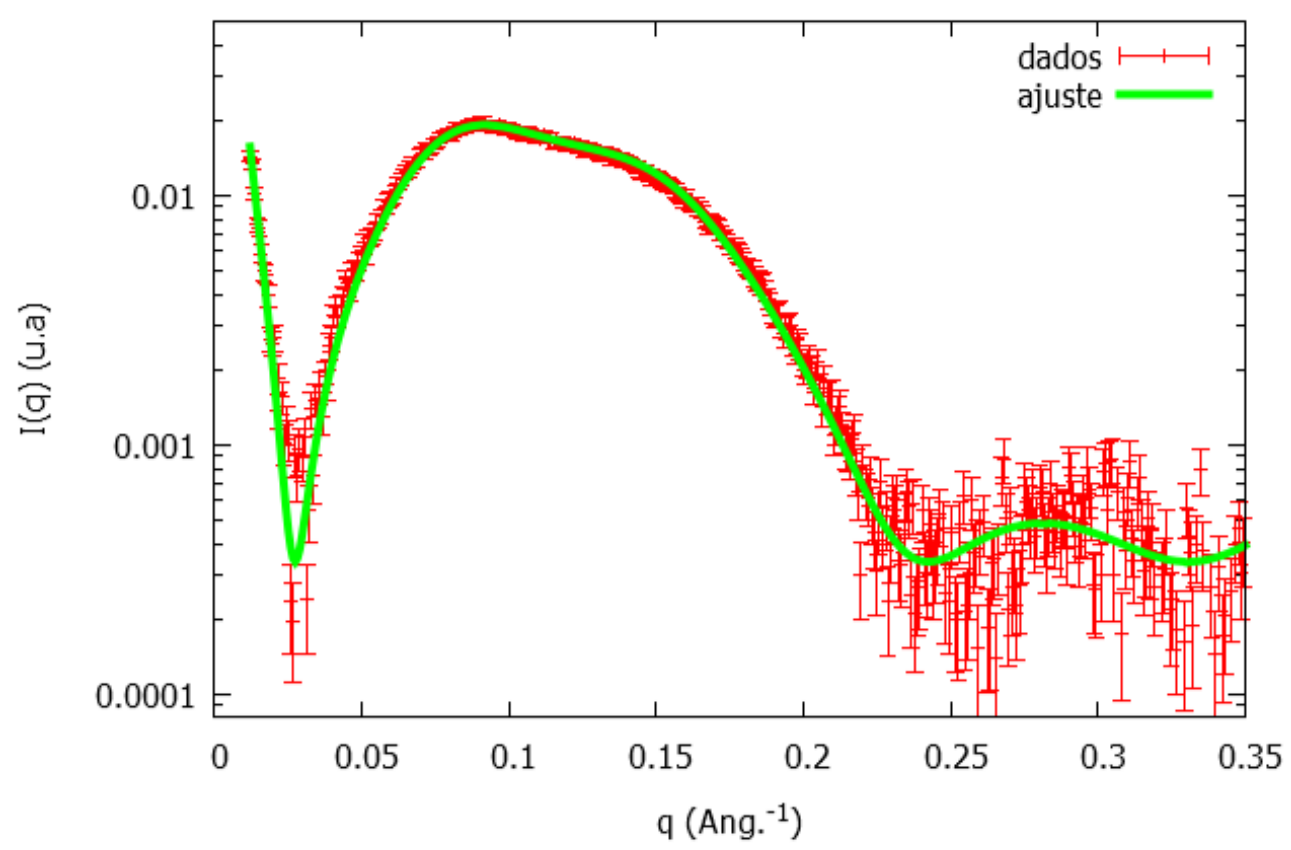

(b) POPC:SM(1:1)

Figura 3.7: Curvas de SAXS de vesículas grandes compostas por a) POPC, b) POPC:SM (1:1) com concentração inicial de $10 \mathrm{mM}(+)$ medidos a $23^{\circ} \mathrm{C}$ e melhor ajuste aos dados experimentais considerando o modelo de unilamela no caso de POPC e mistura de unilamela e multilamela no caso de POPC:SM (1:1). 
Tabela 3.2: Parâmetros de ajustes obtidos a partir dos resultados apresentados na figura 3.7. $R_{\text {pol }}, R_{\mathrm{CH}_{2}}$ e $R_{\mathrm{CH}_{3}}$ representam, respectivamente, a espessura da região polar da membrana modelo, meio hidrofóbico contendo $\mathrm{CH}_{2}$ e $\mathrm{CH}_{3}$, enquanto $\rho_{p o l}, \rho_{\mathrm{CH}_{2}}$ e $\rho_{\mathrm{CH}_{3}}$ representam as densidades eletrônicas correspondentes. O parâmetro " $N$ " indica a quantidade de bicamadas lipídicas em uma vesícula multilamelar, "c" representa a distância entre os centros de duas bicamadas, "espessura" representa a espessura total da bicamada lipídica e $\eta_{\text {Caille é o }}$ parâmetro de Caillé.

\begin{tabular}{ccc}
\hline \multicolumn{3}{c}{ Parâmetros de Ajuste } \\
\hline & POPC & POPC:SM $(1: 1)$ \\
\hline unilamela $(\%)$ & 100 & $81(5)$ \\
$R_{\text {pol }}(\AA)$ & $9.3(6)$ & $9.4(9)$ \\
$R_{C H_{2}}(\AA)$ & $10.9(4)$ & $13.7(5)$ \\
$R_{C H_{3}}(\AA)$ & $3.0(3)$ & $3.4(2)$ \\
$\rho_{\text {pol }}\left(e / \AA^{3}\right)$ & $0.417(4)$ & $0.408(8)$ \\
$\rho_{C H_{2}}\left(e / \AA^{3}\right)$ & $0.297(3)$ & $0.317(2)$ \\
$\rho_{C H_{3}}\left(e / \AA^{3}\right)$ & $0.198(7)$ & $0.200(6)$ \\
espessura $(\AA)$ & $46.4(6)$ & $53(1)$ \\
$N$ & - & $2(1)$ \\
$c(\AA)$ & - & $77(1)$ \\
$\eta_{\text {Caille }}$ & - & $0.13(3)$ \\
\hline
\end{tabular}

Em LUVS de POPC:SM:CO pode ocorrer formação de domínios lipídicos Ld-Lo dependendo da razão molar entre os componentes [74, 84, 75, 12]. No caso das curvas de SAXS para o sistema composto por POPC:SM:CO (1:1:1), conseguimos melhor ajuste quando utilizamos dois modelos de membrana para representar o espalhamento total da bicamada lipídica: um modelo para a membrana de POPC e outro para membrana composta por SM e CO (figura 3.8). A utilização de dois modelos de membrana para o ajuste significa que foram considerados dois fatores de forma ponderados (um para POPC apenas e outro para uma mistura homogênea de SM e CO), tal que $I(q)=x P(q)_{P O P C}+(1-x) P(q)_{S M C O}$, sendo $P(q)_{P O P C}$ igual aos valores apresentados na tabela 3.2 e $P(q)_{S M C O}$ desconhecido. A figura 3.8 apresenta os melhores ajustes obtidos considerando apenas uma unilamela homogênea 
de POPC:SM:CO e unilamela não homogênea composta por domínios de POPC e domínios de SM:CO. Conforme podemos observar, o último modelo é mais efetivo em representar o primeiro mínimo de $I(q)$ em $q \simeq 0,04 \AA^{-1}$. A partir dos parâmetros de ajuste obtidos em ambas análises, descritos na tabela 3.3 , pode-se notar que os resultados obtidos quando consideramos apenas um fator de forma $P(q)_{P C S M C O}$ são similares aos observavdos para o domínio composto por SMCO $\left(P(q)_{S M C O}\right)$. A melhora na qualidade do ajuste evidênciada em $q \simeq 0,04$ é devido à $P(q)_{P O P C}$. A continuação da discussão será feita com base nos resultados obtidos a partir da utilização de dois modelos de ajuste.

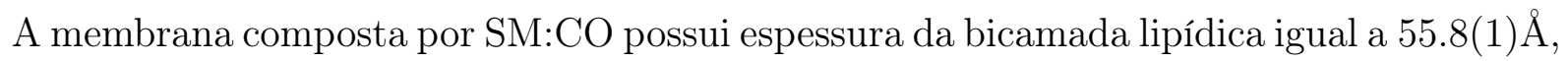
ou seja $9.4 \AA$ maior do que a espessura de bicamada obtida para a membrana composta por POPC (46.4(6)A). Resultado semelhante foi obtido por Rinia e colaboradores [85] através da técnica de microscopia de força atômica ( $A F M$ do Inglês Atomic Force Microscope) em sistemas compostos por DOPC:SM (1:1) com $25 \mathrm{~mol} \%$ de colesterol, os quais observaram um aumento de 8.0Å na espessura da bicamada lipídica dos domínios lipídicos de SM:CO em relação à bicamada de DOPC. 


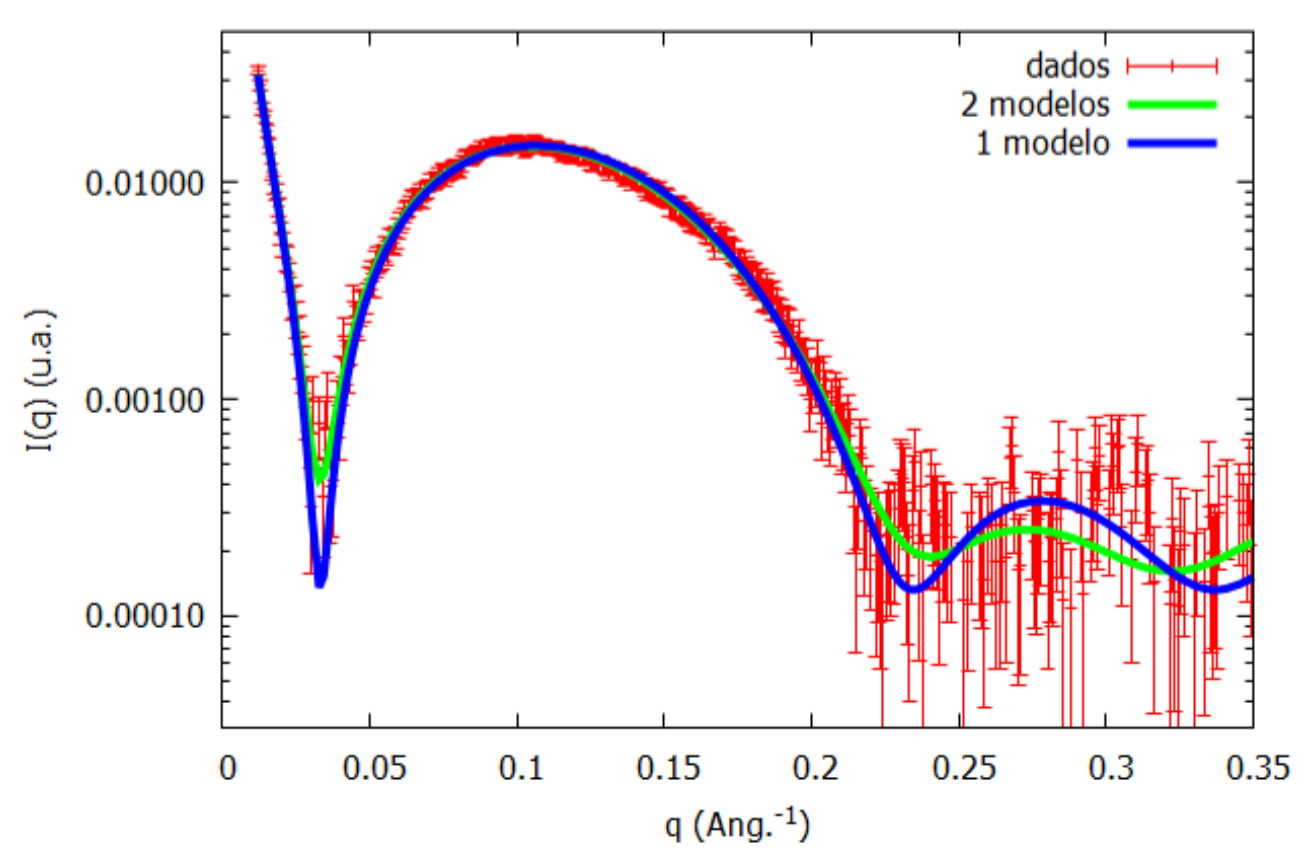

(a) Comparação entre modelos de ajuste

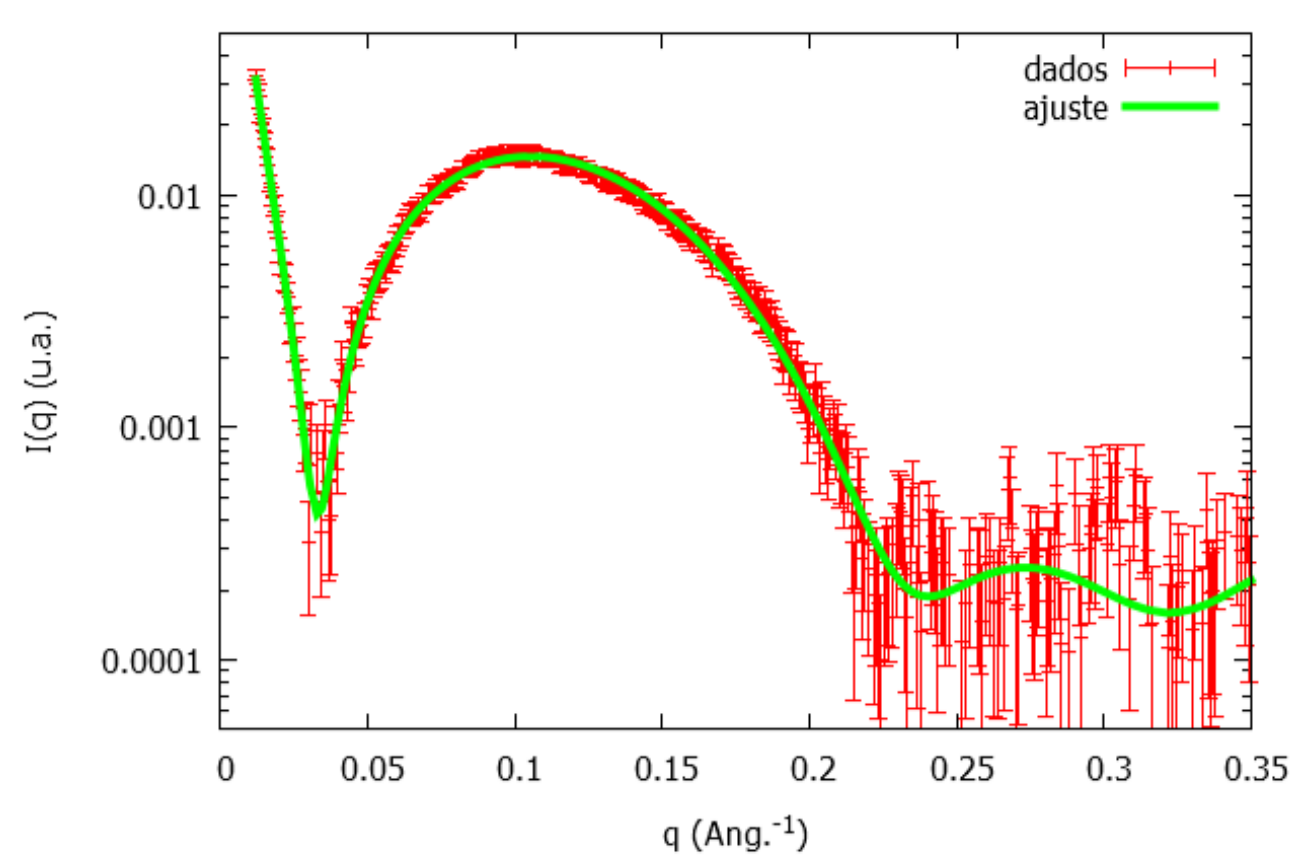

(b) Melhor ajuste - POPC:SM:CO(1:1:1)

Figura 3.8: Curva de SAXS de LUVs compostas por POPC:SM:CO (1:1:1) com concentração inicial de $10 \mathrm{mM}(+)$ medidos a $23^{\circ} \mathrm{C}$ e ajuste aos dados experimentais. a) Comparação entre dois ajustes considerando o modelo de unilamela. O ajuste representado pela linha azul indica o caso em que foi considerada uma vesícula homogênea representada por apenas um fator de forma $I(q)=P(q)_{P C S M C O}$ e a linha verde representa dois fatores de forma $I(q)=x P(q)_{P O P C}+(1-x) P(q)_{S M C O}$. b) Melhor ajuste obtido a partir da consideração de 2 fatores de forma $\left(P(q)_{P O P C}\right.$ e $\left.P(q)_{S M C O}\right)$. 
Tabela 3.3: Parâmetros de ajustes obtidos a partir dos resultados apresentados na figura 3.8. $R_{\text {pol }}, R_{\mathrm{CH}_{2}}$ e $R_{\mathrm{CH}_{3}}$ representam, respectivamente, a espessura da região polar, meio hidrofóbico contendo $\mathrm{CH}_{2}$ e $\mathrm{CH}_{3}$, enquanto $\rho_{\text {pol }}, \rho_{\mathrm{CH}_{2}}$ e $\rho_{\mathrm{CH}_{3}}$ as densidades eletrônicas correspondentes. O parâmetro "ratio" indica a porcentagem de cada um dos fatores de forma (membranas de ajuste) no sistema e "espessura" representa a espessura total da bicamada lipídica.

\begin{tabular}{|c|c|c|c|}
\hline \multicolumn{4}{|c|}{ Parâmetros de Ajuste - POPC:SM:CO (1:1:1) } \\
\hline & \multicolumn{2}{|c|}{2 modelos } & 1 modelo \\
\hline & POPC & SMCO & PCSMCO \\
\hline unilamela $(\%)$ & \multicolumn{2}{|c|}{100} & 100 \\
\hline ratio $(\%)$ & $37(4)$ & $63(4)$ & - \\
\hline$R_{\text {pol }}(\AA)$ & $9.3(6)$ & $10.2(2)$ & $10.8(4)$ \\
\hline$R_{\mathrm{CH}_{2}}(\AA)$ & $10.9(4)$ & $14.2(2)$ & $13.5(2)$ \\
\hline$R_{\mathrm{CH}_{3}}(\AA)$ & $3.0(3)$ & $3.5(2)$ & $2.9(3)$ \\
\hline$\rho_{\text {pol }}\left(e / \AA^{3}\right)$ & $0.417(4)$ & $0.437(6)$ & $0.416(3)$ \\
\hline$\rho_{\mathrm{CH}_{2}}\left(e / \AA^{3}\right)$ & $0.297(3)$ & $0.313(5)$ & $0.308(5)$ \\
\hline$\rho_{C H_{3}}\left(e / \AA^{3}\right)$ & $0.198(7)$ & $0.172(9)$ & $0.187(6)$ \\
\hline espessura $(\AA)$ & $46.4(6)$ & $55.8(1)$ & $54.4(9)$ \\
\hline
\end{tabular}

Tendo como base os parâmetros apresentados nas tabelas 3.2 e 3.3 , foi obtido para cada uma das membranas modleo estudadas, o perfil de densidade eletrônica ao longo do eixo z, normal à superfície da bicamada lipídica, segundo a equação 2.10 (ver seção 2.3.1). O resultado apresentado na figura 3.9 mostra as diferenças no perfil de densidade de acordo com a variação da composição lipídica. Para a vesícula composta por POPC:SM:CO, como foi mencionado anteriormente, é preciso considerar a existência de duas membranas, POPC e SMCO.

Analisando os perfis de densidade eletrônica, pode-se observar que o sistema composto por POPC:SM (curva verde) apresentou aumento na espessura da cadeia hidrocarbônica $\mathrm{CH}_{2}$, se comparados às vesículas compostas apenas por POPC (curva vermelha). Resultado semelhante foi observado para a membrana de SM:CO, referente aos domínios lipídicos nas 
vesículas compostas por POPC:SM:CO. O aumento de espessura na região hidrofóbica em relação à membrana de POPC para ambos os casos (POPC:SM e SM:CO) foi da ordem de $3 \AA$ (ver tabelas 3.2 e 3.3 . Esse resultado é um indicativo de que o estiramento das caudas $\mathrm{CH}_{2}$, nos dois casos observados, foi prioritariamente determinada pela presença do lipídio SM na composição da vesícula. Para o domínio lipídico SM:CO foi evidenciado aumento de densidade eletrônica na região da cabeça polar, o qual pode ser explicado pela presença do grupo hidroxila $(O H)$, do colesterol, na região polar [86].

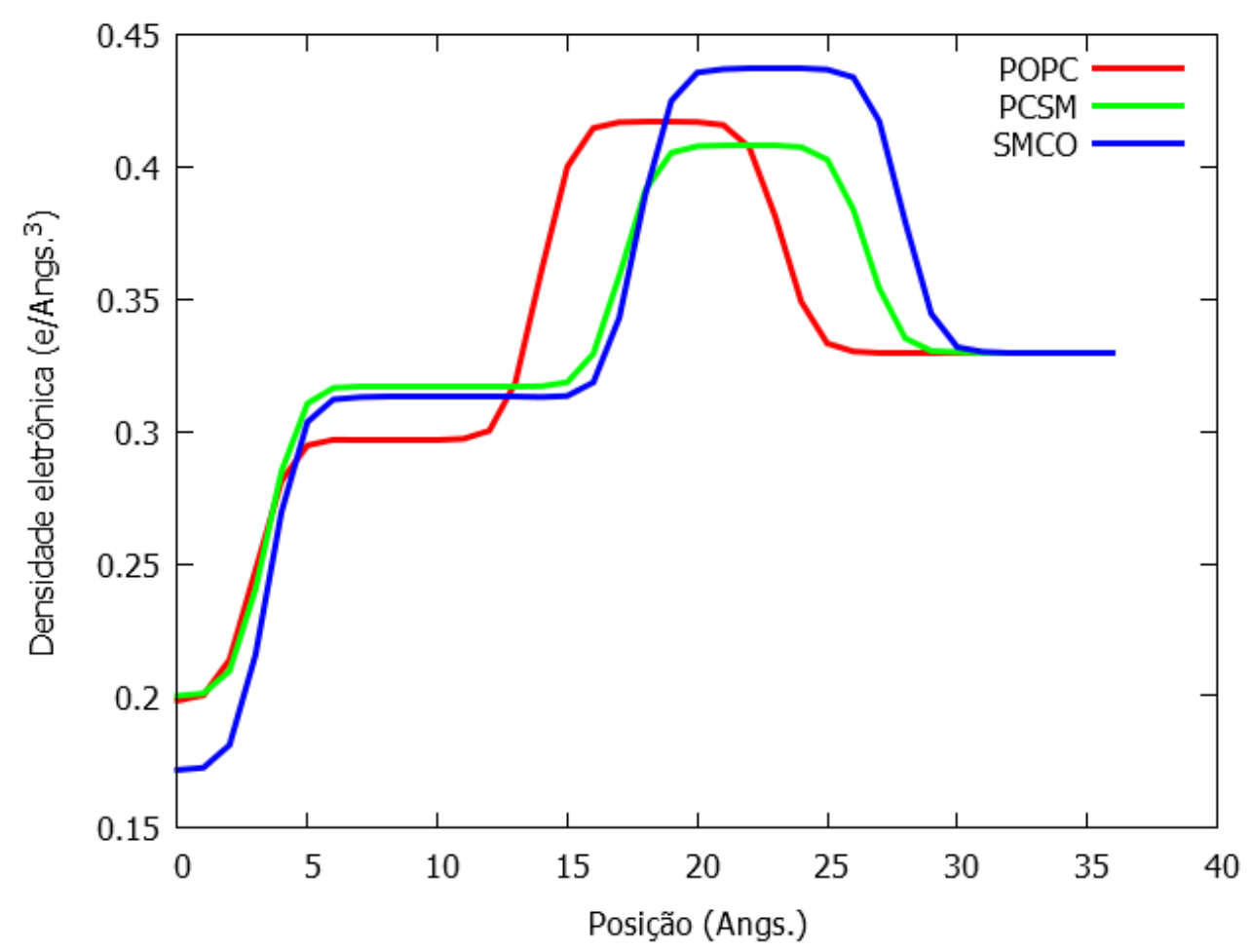

Figura 3.9: Perfil de densidade eletrônica ao longo do eixo z, normal à superfície da bicamada lipídica, para vesículas compostas por: POPC (curva vermelha), POPC:SM (curva verde) e POPC:SM:CO (curvas vermelha e azul). A posição $0 \AA$ está localizada no centro da bicamada. 


\subsection{Conclusão}

O estudo de vesículas grandes compostas por POPC, POPC:SM e POPC:SM:CO mostrou que a composição lipídica influencia nas características estruturais de membranas modelo tais como espessura e distribuição de densidade eletrônica. Ajustes de curvas de SAXS de

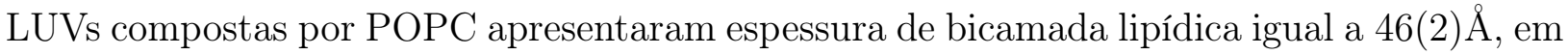
bom acordo com os resultados descritos na literatura [69, 72]. Por outro lado, com relação aos sistemas compostos por POPC:SM foi evidenciado aumento de $6.6 \AA$ na espessura da bicamada se comparado ao obtido para vesículas de POPC. Por fim, em nosso estudo de miméticos de membrana plasmática compostos por POPC:SM:CO, a necessidade da utilização de dois modelos de membrana para o cálculo do fator de forma $P(q)$ reflete a existência da formação de domínios lipídicos Ld-Lo nanométricos compostos por esfingomielina e colesterol [74, 75, 84. 

Capítulo 4

Interação de fotossensibilizadores fenotiazínicos com membranas modelo 
Com relação ao estudo de oxidação in situ, experimentos realizados anteriormente pelo grupo de pesquisa da prof $^{a}$ Rosangela Itri apresentaram resultados interessantes em vesículas dispersas em solução contendo o FS azul de metileno (MB) cujo rendimento quântico de produção de oxigênio singlete é de 50\%. Os experimentos foram realizados com GUVs de POPC e DOPC (1,2-dioleoil-sn-glicerol-3-fosfatidilcolina) na presença de diferentes concentrações de MB. As imagens obtidas por microscopia óptica de contraste de fase mostraram que durante a foto-irradiação as vesículas sofreram alterações morfológicas, podendo ser resumidas em 4 etapas (figura 4.1): $1^{\mathrm{a}}$ ) inicialmente vesículas de forma esférica eram estáveis; $2^{\mathrm{a}}$ ) começam a flutuar sofrendo alteração na forma; a magnitude da flutuação era dependente da concentração de MB e indicam aumento de área superficial da membrana modelo; $3^{\mathrm{a}}$ ) as vesículas retornavam à forma esférica inicial e recuperavam a estabilidade, seguido por um início de perda de contraste; $4^{\mathrm{a}}$ ) lentamente a vesícula perdia totalmente o contraste. Tal variação de contraste ótico indica troca de fluidos entre os meios interno e externo à vesícula, sugerindo formação de defeitos e/ou poros na bicamada lipídica [19]. Em paralelo, através da técnica de aspiração por micropipeta, foi quantificado o aumento de área em vesículas compostas por POPC e DOPC utilizando o FS Clorina ancorado na membrana modelo (este FS, denominado Clorina-12, foi sintetizado pelo grupo na qual uma clorina foi ligada a 2 caudas de 12 Carbonos e apresenta um rendimento quântico de produção de oxigênio singlete de 70\%) [20]. Os resultados mostraram um aumento de área de 15.6\% para a vesícula de POPC e 19.1\% para DOPC. Vesículas compostas pelo lipídio saturado DMPC não apesentaram alteração. Neste mesmo trabalho os autores quantificaram o módulo de estiramento elástico em $50 \mathrm{mN} . \mathrm{m}^{-} 1$ para vesículas compostas por $100 \%$ de hidroperóxido lipídico de POPC (POPC-OOH), cujo valor resultou ser igual ao obtido para as vesículas de POPC hidroperoxidadas in situ com $2 \%$ mol de Clorina-12, indicando que nessas condições houve total conversão dos lipídios POPC em hidroperóxidos POPC-OOH [20]. 
Com base nos estudos previamente desenvolvidos com GUVs e microscopia ótica, uma parte deste projeto de doutoramento é dedicada ao estudo da foto-oxidação in situ de sistemas miméticos de membrana celular, usando a técnica de SAXS.
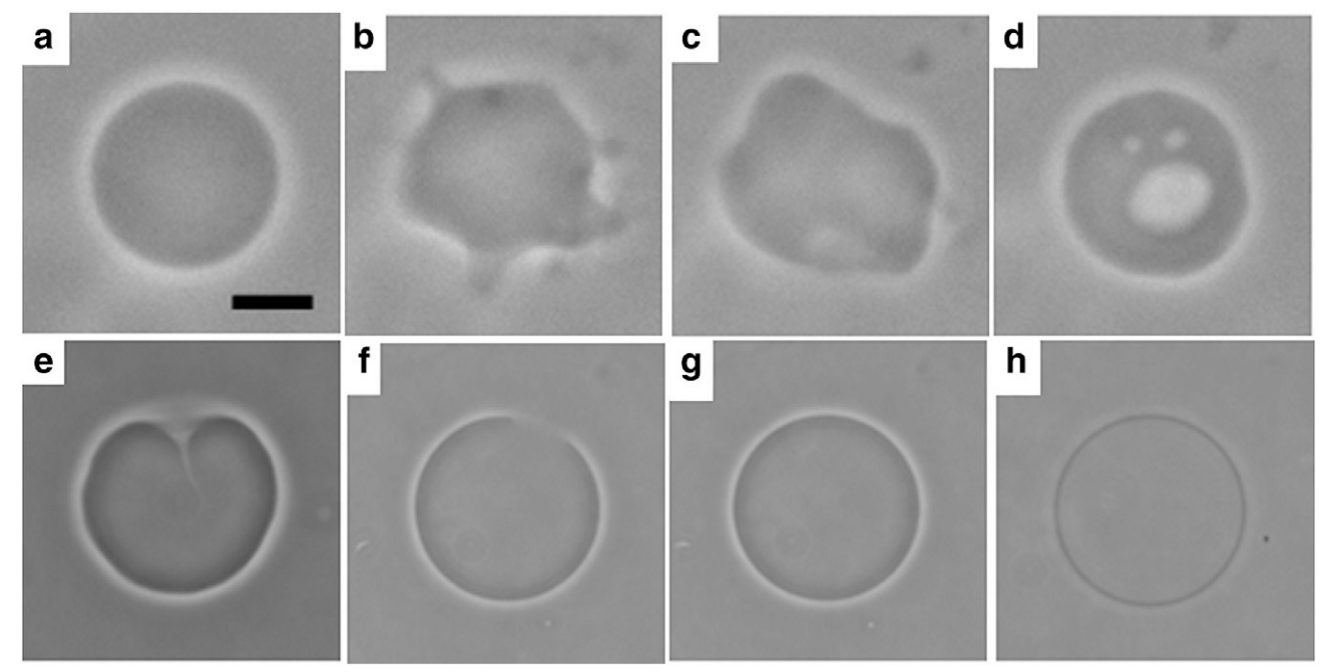

Figura 4.1: Imagem de microscopia óptica de contraste de fase apresentando as alterações morfológicas típicas de GUVs compostas por POPC ou DOPC (1,2-dioleoil-sn-glicerol-3fosfatidilcolina) dispersas em azul de metileno $[40 \mu \mathrm{M}]$ durante a foto-irradiação $(665 \mathrm{~nm})$. Imagem extraída da referência [19].

\subsection{Objetivo específico}

O estudo descrito neste capítulo teve como objetivo avaliar os possíveis danos estruturais causados em membranas modelo devido ao processo de foto-oxidação. As análises foram realizadas em membranas modelo compostas por POPC, POPC:SM(1:1) e POPC:SM:CO(1:1:1) com e sem fotossensibilizador, na presença e ausência de irradiação. 


\subsection{Materiais e Métodos}

\subsubsection{Materiais}

Para o estudo de fotossensibilização de vesículas foram utilizados os lipídios POPC, SM e CO cujas estruturas químicas estão apresentadas nas figuras $3.1,3.2$ e 3.3 , respectivamente. No preparo das amostras, tanto os filmes lipídicos quanto os corantes fenotiazínicos foram hidratados em água Milli-Q (Milli-Q plus ultra pure Type 1 water system - Milipore; resistividade 18,2M $\Omega . c m-\mathrm{pH} 5)$.

\subsubsection{Corantes Fenotiazínicos - Fotossensibilizadores}

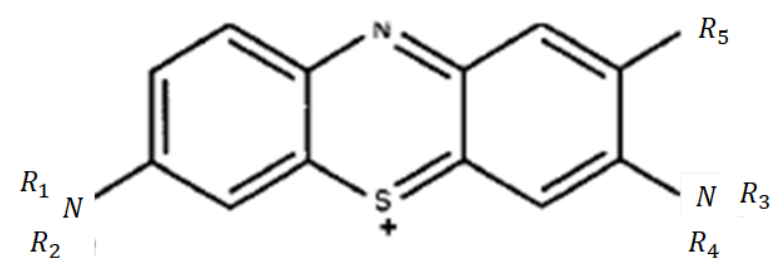

Figura 4.2: Fórmula estrutural das sondas fenotiazínicas (figura extraída da referência [87])

Azul de metileno (MB): $R_{1}=R_{2}=R_{3}=R_{4}=C_{3}$ e $R_{5}=H$

Azure B (AB): $R_{1}=R_{2}=R_{3}=C_{3}$ e $R_{4}=R_{5}=H$

Azure A (AA): $R_{1}=R_{2}=C H_{3}$ e $R_{3}=R_{4}=R_{5}=H$

Tionina (Ti): $R_{1}=R_{2}=R_{3}=R_{4}=R_{5}=H$

Os comprimentos de onda de absorção de máxima dos fotossensibilizadores utilizados são 
[87]:

MB: $\lambda_{\text {máx }}=665 \mathrm{~nm}$

AB: $\lambda_{m a ́ x}=647 n m$

AA: $\lambda_{m a ́ x}=633 n m$

Ti: $\lambda_{\text {máx }}=598 \mathrm{~nm}$

\subsubsection{Métodos}

O estudo da caracterização de vesículas grandes foto-irradiadas foi realizada a partir de doi processos: Incorporação de fotossensibilizadores em membranas modelo e Espalhamento de raios- $X$ a baixos ângulos $(S A X S)$. As seções a seguir apresentam as características principais das amostras e análises empregadas em cada técnica.

\subsubsection{Incorporação de Fotossensibilizadores na Membrana}

Neste trabalho a avaliação da incorporação do FS na membrana foi feita a partir do estudo de equilíbrio entre vesículas e FS ligado e livre, utilizando o método de centrifugação para a separação entre vesículas e sobrenadante [88, 89], segundo o protocolo descrito a seguir. Esta análise fornece uma boa aproximação qualitativa para entender a relação de afinidade entre o FS e a membrana modelo. Contudo, para a obtenção de valores precisos dessa ligação é necessária a realização de experimentos direto na membrana [90].

Foram preparadas vesículas multilamelares grandes (MLVs) de POPC, POPC:SM (1:1) e POPC:SM:CO (1:1:1) em água com concentração final de $5 m M$ pelo método descrito na 
seção 3.2.2. As soluções de vesículas foram centrifugadas durante 3 min com rotação de 13.500rpm. Após a centrifugação o sobrenadante contendo vesículas menores foi descartado e as vesículas maiores que haviam precipitado foram ressuspensas no mesmo volume de água (aproximadamente $1 \mathrm{~mL}$ ). Devido a esta necessidade de separação entre vesículas e sobrenadante o estudo foi realizado com vesículas não extrusadas. Esse processo foi repetido por três vezes. Em seguida foi acrescentada à solução das vesículas o FS que também estava em água. O volume de FS acrescentado foi calculado de modo a se obter uma concentração final de $20 \mu M$ de FSs para $5 m M$ de lipídios em $1 m L$ de solução. Os FSs ficaram incubados durante 30min e em seguida a solução vesículas/FSs foi centrifugada nas condições já mencionadas onde as vesículas decantaram carregando os FSs incorporados. Os sobrenadantes foram retirados e medidos. Para garantir que os FSs não agregassem, todas as medidas foram realizadas com $200 \mu L$ de solução vesículas/FS e $200 \mu L$ de etanol.

As medidas dos espectros de absorção foram realizadas em triplicatas no espectrofotômetro UV-2401PC Shimadzu Co. do Laboratório de Processos Foto-Induzidos (IQ-USP).

A porcentagem de incorporação do FS nas vesículas foi calculada segundo a equação 4.1 . sendo que para cada sistema foi utilizado o valor de absorção obtido a partir do cálculo da média das três curvas medidas.

$$
\% \text { Inc }=100-100 \frac{A b s_{\text {depois }}}{A b s_{\text {antes }}}
$$

onde \%Inc representa a porcentagem de incorporação do FS, Abs depois representa o valor da absorção medido no $\lambda_{\text {máx }}$ de absorção do sobrenadante medido após a incorporação na membrana modelo e $A b s_{\text {antes }}$ é valor da absorção medido no $\lambda_{\text {máx }}$ de absorção para a medida 
do fotossensibilizador sozinho (solução mãe sem interação com a membrana modelo).

\subsubsection{Método de foto-irradiação de vesículas}

O processo de foto-irradiação consitiu em mantermos as soluções de vesículas/FSs durante duas horas sob um sistema de LEDs vermelhos (LED do inglês Light-Emitting Diode) com comprimento de onda $\lambda=663 \mathrm{~nm}$ e irradiância $I=68 \mathrm{~W} \cdot \mathrm{m}^{-2}$ a $10 \mathrm{~cm}$ de distância, segundo protocolo descrito na literatura [91, 89]. O comprimeto de onda dos LEDs foi escolhido com base na banda de absorção dos fotossensibilizadores utilizados no estudo: entre $550-700 \mathrm{~nm}$ [87.

\subsubsection{SAXS}

O estudo de fotossensibilização de vesículas via técnica de SAXS foi realizado com vesículas grandes preparadas segundo protocolo descrito na seção 3.2 .2 e foto-irradiadas segundo o processo descrito na seção 4.2 .2 .2 .

A tabela 4.1 apresenta as informações sobre composição lipídica, concentração inicial de lipídios, quantidade de extrusões e tamanho do poro utilizados para a obtenção de unilamelas e a temperatura em que o foi mantida a solução durante o processo de hidratação do filme lipídico e de extrusão. 
Tabela 4.1: Informações sobre as amostras medidas por SAXS para o estudo de fotossensibilização de vesículas grandes.

\begin{tabular}{|c|c|c|c|c|}
\hline \multicolumn{5}{|c|}{ Medidas de SAXS } \\
\hline Composição & Concentração & $\mathrm{n}^{\circ}$ de extrusão & filtro (nm) & $\mathrm{T}\left({ }^{\circ} C\right)$ \\
\hline POPC & $5 m M$ & 31 & 100 & 30 \\
\hline $\mathrm{POPC} / \mathrm{AA}$ & $5 m M / 20 \mu M$ & 31 & 100 & 30 \\
\hline $\mathrm{POPC} / \mathrm{AB}$ & $5 m M / 20 \mu M$ & 31 & 100 & 30 \\
\hline $\mathrm{POPC} / \mathrm{MB}$ & $5 m M / 20 \mu M$ & 31 & 100 & 30 \\
\hline $\mathrm{POPC} / \mathrm{Ti}$ & $5 m M / 20 \mu M$ & 31 & 100 & 30 \\
\hline POPC:SM (1:1) & $5 m M$ & $\begin{array}{l}19 \\
31\end{array}$ & $\begin{array}{l}400 \\
100\end{array}$ & 45 \\
\hline POPC:SM (1:1)/AA & $5 m M / 20 \mu M$ & $\begin{array}{l}19 \\
31\end{array}$ & $\begin{array}{l}400 \\
100\end{array}$ & 45 \\
\hline POPC:SM $(1: 1) / \mathrm{AB}$ & $5 m M / 20 \mu M$ & $\begin{array}{l}19 \\
31\end{array}$ & $\begin{array}{l}400 \\
100\end{array}$ & 45 \\
\hline POPC:SM (1:1)/MB & $5 m M / 20 \mu M$ & $\begin{array}{l}19 \\
31\end{array}$ & $\begin{array}{l}400 \\
100\end{array}$ & 45 \\
\hline POPC:SM (1:1)/Ti & $5 m M / 20 \mu M$ & $\begin{array}{l}19 \\
31\end{array}$ & $\begin{array}{l}400 \\
100\end{array}$ & 45 \\
\hline POPC:SM:CO (1:1:1) & $5 m M$ & $\begin{array}{l}19 \\
31\end{array}$ & $\begin{array}{l}400 \\
100\end{array}$ & 45 \\
\hline POPC:SM:CO (1:1:1)/AA & $5 m M / 20 \mu M$ & $\begin{array}{l}19 \\
31\end{array}$ & $\begin{array}{l}400 \\
100\end{array}$ & 45 \\
\hline POPC:SM:CO (1:1:1)/AB & $5 m M / 20 \mu M$ & $\begin{array}{l}19 \\
31\end{array}$ & $\begin{array}{l}400 \\
100\end{array}$ & 45 \\
\hline POPC:SM:CO (1:1:1)/MB & $5 m M / 20 \mu M$ & $\begin{array}{l}19 \\
31\end{array}$ & $\begin{array}{l}400 \\
100\end{array}$ & 45 \\
\hline POPC:SM:CO (1:1:1)/Ti & $5 m M / 20 \mu M$ & $\begin{array}{l}19 \\
31\end{array}$ & $\begin{array}{l}400 \\
100\end{array}$ & 45 \\
\hline $\begin{array}{l}\text { Obs: As vesiculas foram in } \\
\text { Para controle, também foi }\end{array}$ & $\begin{array}{l}\text { liadas na pres } \\
\text { lizada medida }\end{array}$ & $\begin{array}{l}\text { ça dos FSs dur } \\
\text { as vesículas cor }\end{array}$ & $\begin{array}{l}\text { te 2horas ( } \\
\text { FSs sem fot }\end{array}$ & $\begin{array}{l}663 n m) . \\
\text { rradiação }\end{array}$ \\
\hline
\end{tabular}




\subsection{Resultados e Discussões}

\subsubsection{Incorporação de fotossensibilizadores em vesículas}

Para o estudo de incorporação de fotossensibilizadores em vesículas grandes, foram preparadas vesículas compostas por POPC, POPC:SM (1:1) e POPC:SM:CO (1:1:1) na presença dos fotossensibilizadores MB, AA, AB e Ti segundo o protocolo descrito na seção 4.2.2.1.

A partir dos resultados obtidos, apresentados na tabela 4.2 e figura 4.3 , foi possível constatar dois pontos principais:

a) Analisando a influência da composição lipídica para cada FS individualmente, verificouse que a membrana modelo composta por POPC:SM:CO (1:1:1) (curva azul - figura 4.3) foi a que apresentou menor resultado de incorporação. Por outro lado, seguindo essa mesma análise, a maior incorporação foi obtida para vesículas de POPC:SM (1:1) (curva verde figura 4.3.

b) Analisando a incorporação de cada um dos FSs para uma dada composição lipídica, observou-se que o fotossensibilizador Ti foi o que apresentou maior incorporação para a três composições lipídicas.

Em sua tese de doutoramento, Helena Junqueira [88] investigou a incorporação dos mesmos FSs (MB, AA, AB e Ti) em vesículas compostas por DSPC:CL (8:2). Os valores por ela obtidos foram: MB (39(4)\%); AA (56(1)\%); AB (47(6)\%); Ti (38(4)\%). A grande diferença entre valores de incorporação obtidos pela Dra. Helena e os apresentados neste estudo (tabela 4.2 mostram que a composição lipídica bem como a resultante de cargas da vesícula são características de grande importância para o entendimento de processos de interação entre corantes fenotiazínicos e biomembranas. Por outro lado, os baixos valores de incorporação dos FSs AA, AB, MB e Ti nas membranas modelo de POPC, POPC:SM (1:1) 
e POPC:SM:CO (1:1:1) obtidos em nosso estudo podem ser responsáveis por não termos observado efeitos significativos de foto-oxidação para esses sistemas via análises de SAXS, que será apresentada a seguir.

Tabela 4.2: Medida de incorporação dos fotossensibilizadores Azul de Metileno (MB), Azure A (AA), Azure B (AB) e Tionina (Ti) em vesículas compostas por POPC, POPC:SM (1:1) e POPC:SM:CO (1:1:1).

\begin{tabular}{c|cccc}
\hline & \multicolumn{4}{|c}{ \% de Incorporação de FSs em vesículas } \\
\hline Composição lipídica & $A A$ & $A B$ & $M B$ & $T i$ \\
\hline POPC & $5.18(7)$ & $6.09(16)$ & $2.22(8)$ & $11.22(47)$ \\
POPC:SM (1:1) & $13.52(8)$ & $6.29(15)$ & $7.19(9)$ & $19.40(24)$ \\
POPC:SM:CO (1:1:1) & $2.91(29)$ & $1.34(15)$ & $2.26(18)$ & $7.04(35)$ \\
\hline
\end{tabular}




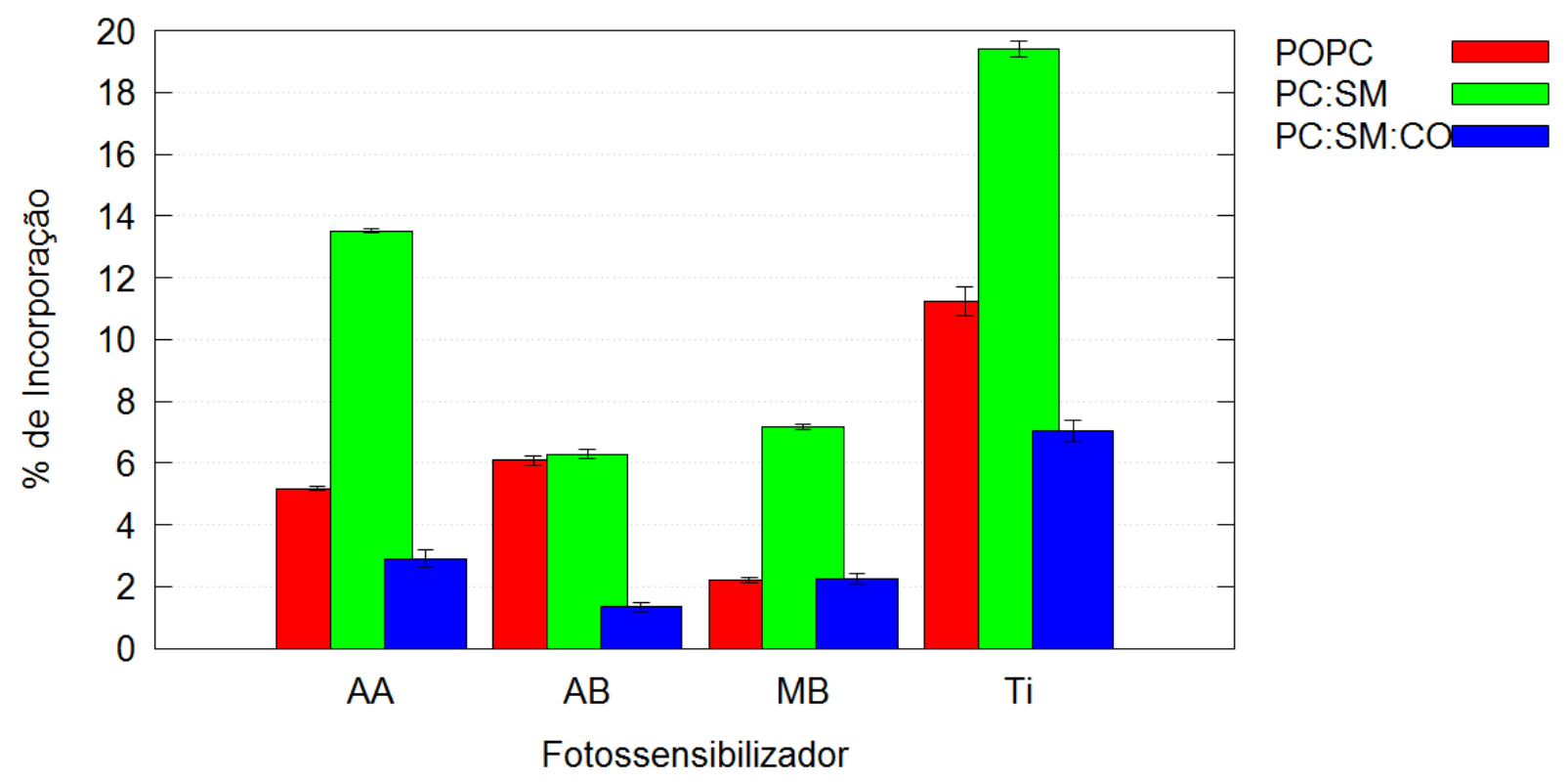

Figura 4.3: Valores referentes a porcentagem de incorporação dos fotossensibilizadores AA, $\mathrm{AB}, \mathrm{MB}$ e Ti em diferentes composições lipídicas de membranas modelo: POPC (barra vermelha), POPC:SM (1:1) (barra verde) e POPC:SM:CO (1:1:1) (barra azul). Os dados utilizados neste histograma estão apresentados na tabela 4.2

\subsubsection{Análise por Espalhamento de raios-x a baixos ângulos (SAXS)}

A caracterização estrutural de membranas modelo foto-irradiadas foi realizada via técnica de SAXS a partir de vesículas grandes compostas por POPC, POPC:SM (1:1) e POPC:SM:CO (1:1:1) na presença e ausência dos fotossensibilizadores MB, AA, AB e Ti. No caso das vesículas com FS, foram realizadas medidas de controle para verificar o efeito da inclusão do FS, ou seja, membranas modelo com o FS mas sem exposição à irradiação. Já a análise do efeito de foto-oxidação da membrana modelo foi realizado a partir de medidas de SAXS de membranas modelo com FS após 2 horas de foto-irradiação com LED vermelho $(\lambda=663 \mathrm{~nm})$ (ver a preparação das amostras na seção 4.2.2.3). Os resultados obtidos por SAXS para os 
sistemas compostos por POPC, POPC:SM (1:1) e POPC:SM:CO (1:1:1) estão apresentados respectivamente nas figuras 4.4, 4.5 e 4.6. Foi observado que a simples inclusão do FS à solução das vesículas gerou alterações nas curvas de SAXS onde o perfil de espalhamento das membranas modelo com FS sem exposição à irradiação (curvas verdes + ) apresentaram maior intensidade de espalhamento $I(q)$ na região do pico se comparado às curvas obtidas para as medidas controle da membrana modelo sem FS (curvas vermelhas + ). Por outro lado, após o procedimento de foto-irradiação dos sistemas membrana modelo/FS (curvas azuis + ) foi observado, além do aumento de intensidade na região do pico, indução à formação de multilamelas ( ver exemplo na figura 3.5) e perfil indicativo de polidispersão ou vesícula não homogênea, evidenciado pelo aumento na intensidade de espalhamento $I(q)$ na região de baixos ângulos (aproximadamente $0.03 \AA^{-1}$ ) [78]. Esse efeito de polidispersão pode ser atribuido à danos físicos causados nas LUVs devido à foto-irradição, como observado por Mertins e colaboradores em seu estudo intitulado "Physical Damage on Giant Vesicles Membrane as a Result of Methylene Blue Photoirradiation"[19]. Em outro estudo realizado por Bacellar e colaboradores [89], foi observado efeito semelhante de aumento de intensidade de espalhamento na região de baixo ângulo para vesículas de lecitina de soja (com concentração lipídica de $1.6 \mathrm{mM})$ irradiadas durante 5 h na presença do FS DO15 $(30 \mu M)$, bem como vazamento da sonda carboxifluoresceina indicando dano na estrutura da membrana modelo. Neste experimento foi observada, após 5 h de foto-irradiação, redução na espessura da bicamada lipídica de $\sim 6 \AA$.

Como foram observadas apenas pequenas alterações nos perfis de SAXS na presença de FS com e sem irradiação, optamos por analisar aqui a resposta de fotossensibilização nas propriedades estruturais das membranas modelo. 


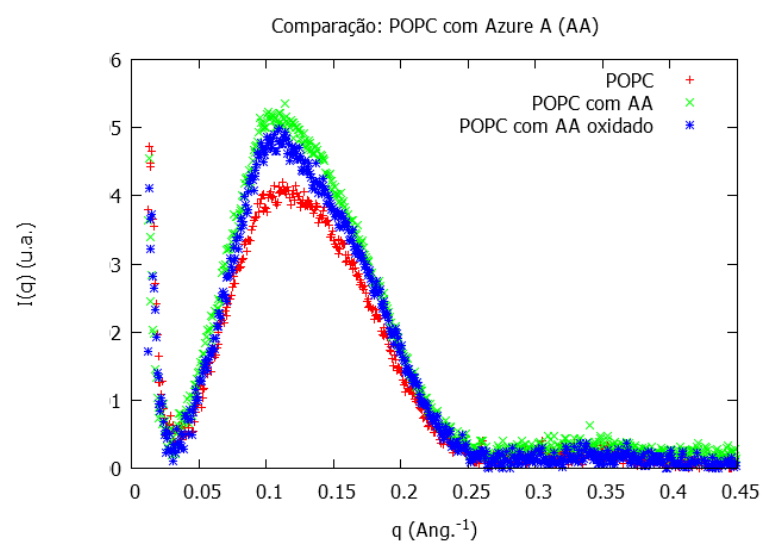

(a) $\mathrm{POPC} / \mathrm{AA}$

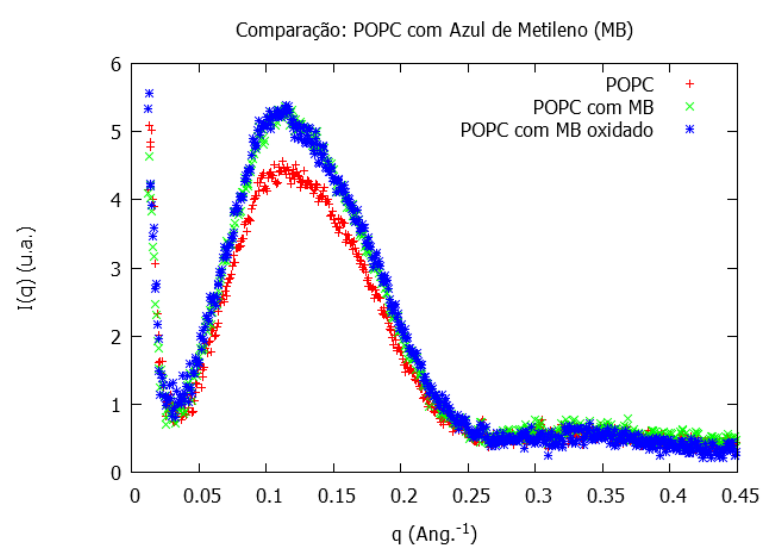

(c) $\mathrm{POPC} / \mathrm{MB}$

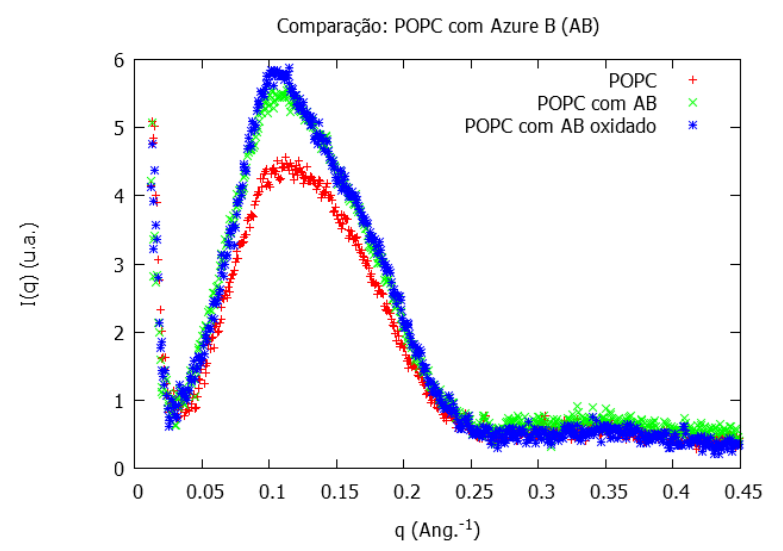

(b) $\mathrm{POPC} / \mathrm{AB}$

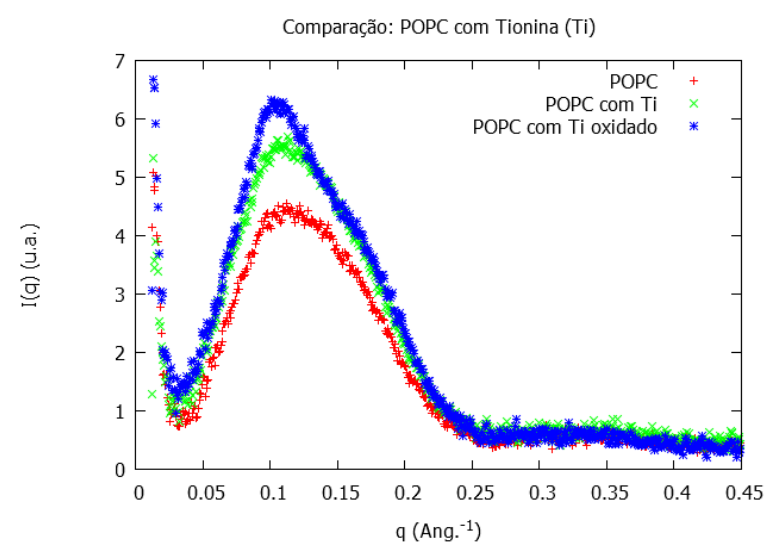

(d) $\mathrm{POPC} / \mathrm{Ti}$

Figura 4.4: Perfil de SAXS para vesículas grandes compostas por POPC [5mM] na presença e ausência dos fotossensibilizadores MB, AA, AB e Ti a uma concentração de $20 \mu M$ medidos a $23^{\circ} \mathrm{C}$, com e sem exposição à radiação: $(+)$ Membrana modelo sem FS; $(+)$ Membrana modelo na presença dos diferentes FSs mas sem exposição à radiação (medida de controle do efeito do FS); (+) Membrana modelo na presença dos diferentes FSs após 2 horas de irradiação com LED vermelho $(\lambda=663 \mathrm{~nm})$. 


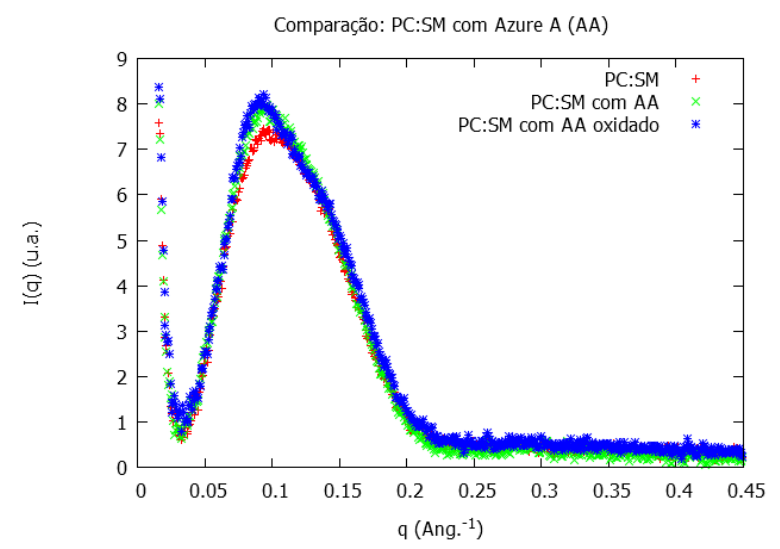

(a) POPC:SM/AA

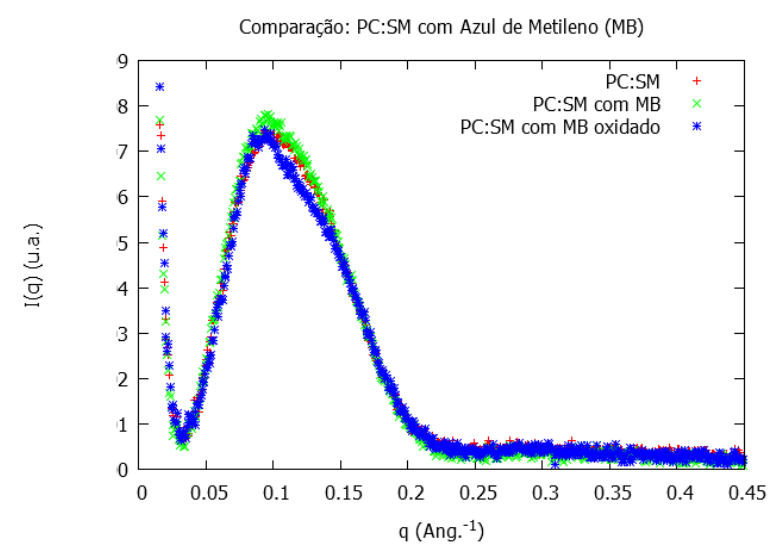

(c) POPC:SM/MB

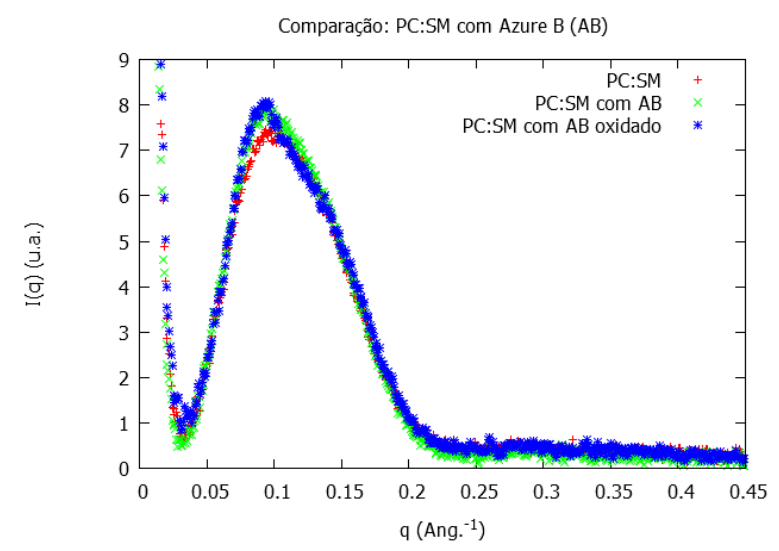

(b) POPC:SM/AB

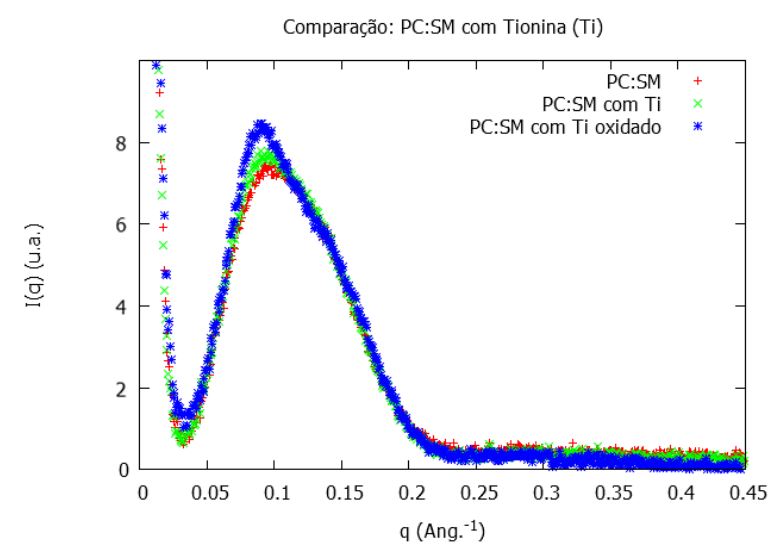

(d) POPC:SM/Ti

Figura 4.5: Perfil de SAXS para vesículas grandes compostas por POPC:SM (1:1) [5mM] na presença e ausência dos fotossensibilizadores $\mathrm{MB}, \mathrm{AA}, \mathrm{AB}$ e Ti a uma concentração de $20 \mu M$ medidos a $23^{\circ} \mathrm{C}$, com e sem exposição à radiação: $(+)$ Membrana modelo sem FS; $(+)$ Membrana modelo na presença dos diferentes FSs mas sem exposição à radiação (medida de controle do efeito do FS); (+) Membrana modelo na presença dos diferentes FSs após 2 horas de irradiação com LED vermelho $(\lambda=663 \mathrm{~nm})$. 


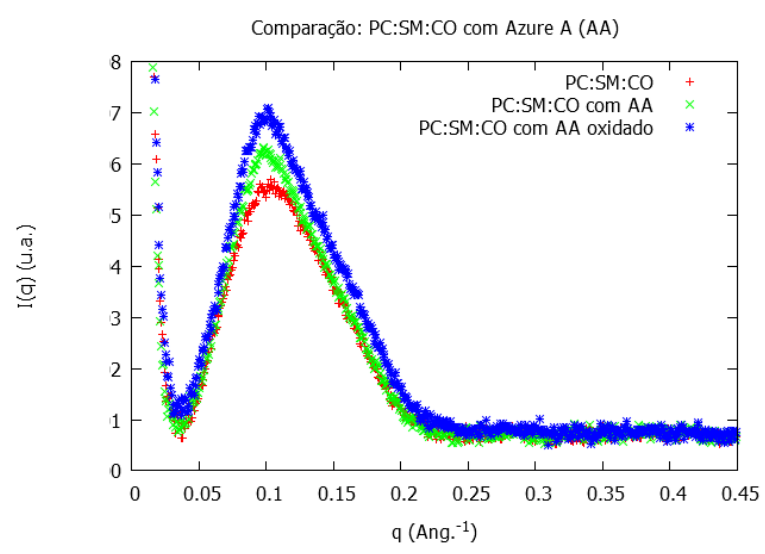

(a) POPC:SM:CO/AA

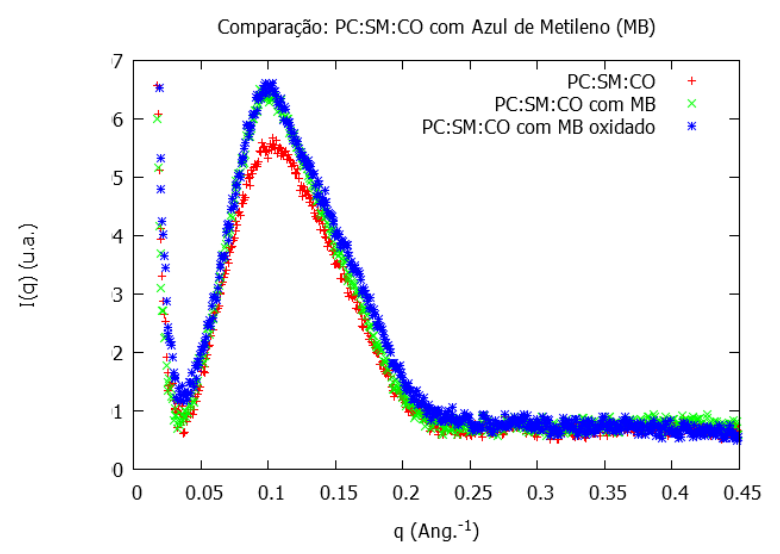

(c) POPC:SM:CO/MB

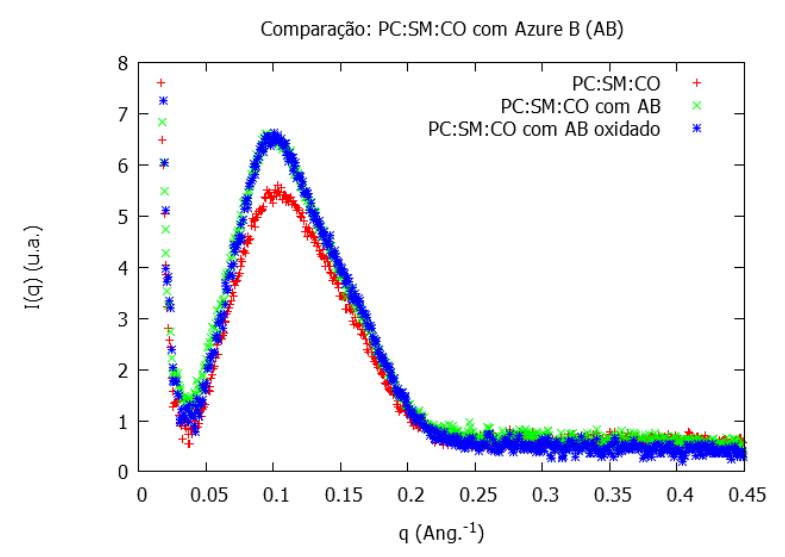

(b) POPC:SM:CO/AB

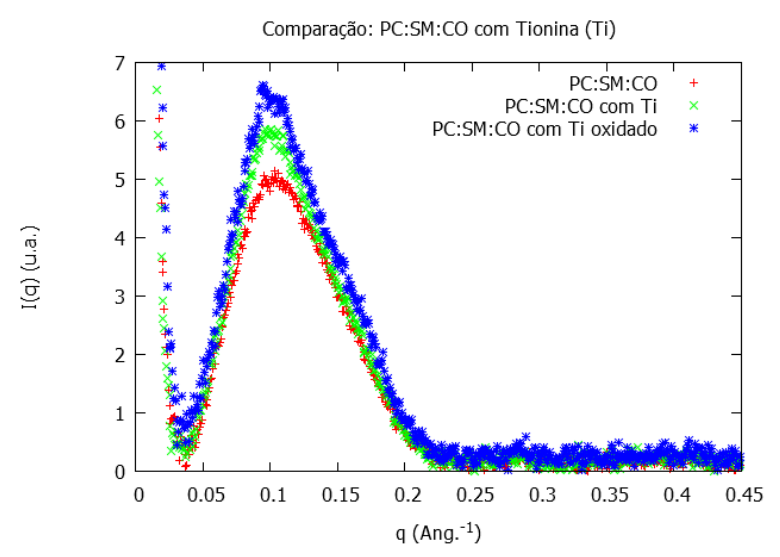

(d) POPC:SM:CO $/ \mathrm{Ti}$

Figura 4.6: Perfil de SAXS para vesículas grandes compostas por POPC:SM:CO (1:1:1) $[5 m M]$ na presença e ausência dos fotossensibilizadores MB, AA, AB e Ti a uma concentração de $20 \mu M$ medidos a $23^{\circ} \mathrm{C}$, com e sem exposição à radiação: (+) Membrana modelo sem FS; $(+)$ Membrana modelo na presença dos diferentes FSs mas sem exposição à radiação (medida de controle do efeito do FS); (+) Membrana modelo na presença dos diferentes FSs após 2 horas de irradiação com LED vermelho $(\lambda=663 \mathrm{~nm})$.

Para avaliarmos de forma quantitativa os efeitos de fotossensibilização, foram realizados os ajustes teóricos das membranas modelo puras (sem FS e sem exposição à radiação) e das membranas foto-irradiadas. Foi observado que as membranas modelo compostas por POPC e 
POPC:SM apresentaram um decréscimo do primeiro vale de espalhamento se comparadas as curvas obtidas para as mesmas composições e medidas anteriormente (apresentada na figura 3.6). Nossa hipótese é de que os lipídios utilizados poderiam ter um certo grau de oxidação inicial. Devido às duplas ligações presentes em lipídios como POPC, a interação com o oxigênio pode facilmente causar a oxidação desses lipídios tornando o manuseio de lipídios insaturados extremamente delicado [16]. Apesar de todo o cuidado tomado na preparação das amostras, as curvas de SAXS sugerem que alguns dos lipídios utilizados devem ter sofrido alterações químicas devido à oxidação, gerando alterações nos perfis de SAXS.

Nesse cenário, para a análise dos efeitos causados unicamente devido à fotossensibilização na presença do FS, foi necessária a caracterização das membranas modelo sem o FS (figura 4.7) utilizadas como amostra mãe considerando a possível presença de outros produtos lipídicos na composição da membrana modelo.

O ajuste das vesículas que apresentaram alteração (POPC e POPC:SM) foi realizado a partir de dois modelos de unilamelas para o cálculo do fator de forma $P(q)$, semelhante ao ajuste apresentado na figura 3.8 para vesículas compostas por POPC:SM:CO. Em cada um dos casos foi considerado que uma parte da vesícula é composta pela membrana do lipídio base (valores apresentados nas tabelas 3.2 e 3.3 ) sem oxidação ( $1^{\circ}$ modelo) e uma outra parte composta por uma membrana de lipídios não definidos gerados devido à alterações químicas $\left(2^{\circ}\right.$ modelo - outros). Para o $1^{\circ}$ modelo foram considerados os valores apresentados na tabela 3.2 , nos quais as membranas não apresentaram alteração química.

Os parâmetros de ajuste obtidos e a representação gráfica do perfil de densidade eletrônica para cada membrana modelo estão apresentados, respectivamente, na tabela 4.3 e figura 4.8 . 


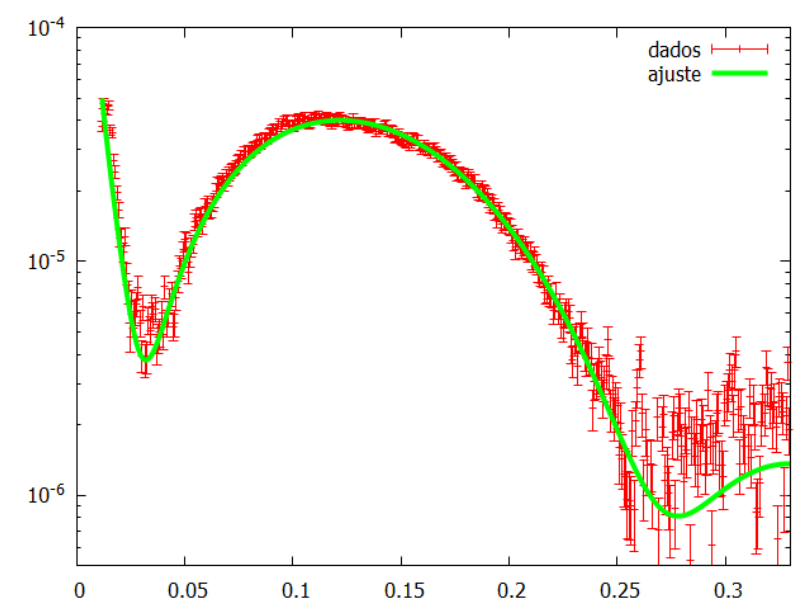

(a)

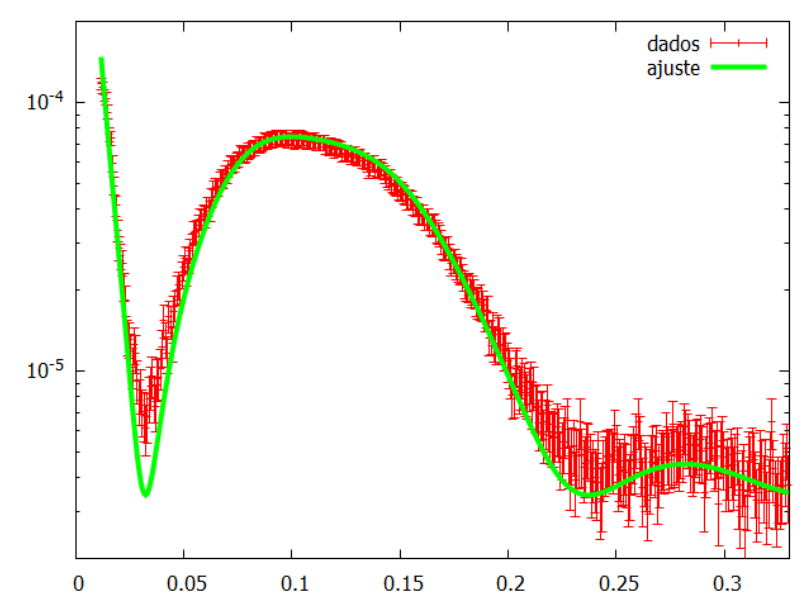

(b)

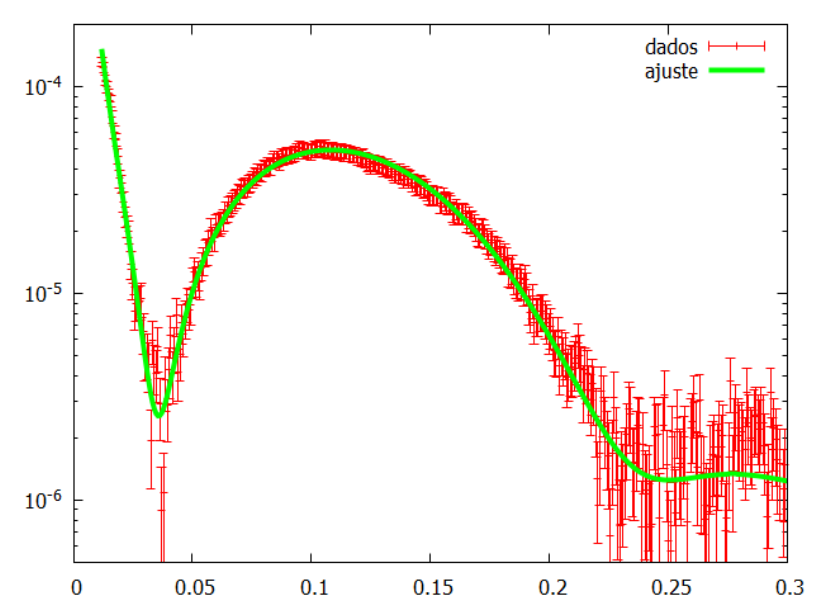

(c)

Figura 4.7: Curvas de SAXS de vesículas grandes compostas por POPC, POPC:SM (1:1) e POPC:SM:CO (1:1:1) com concentração igual a $5 \mathrm{mM}(+)$ medidos a $23^{\circ} \mathrm{C}$ e melhor ajuste aos dados experimentais obtidos pelo software GENFIT (linha contínua verde) a partir do modelo de lamela infinita. 
Tabela 4.3: Parâmetros de ajustes obtidos a partir dos resultados apresentados na figura 4.7 $R_{\text {pol }}, R_{\mathrm{CH}_{2}}$ e $R_{\mathrm{CH}_{3}}$ representam, respectivamente, a espessura da região polar da membrana, meio hidrofóbico contendo $\mathrm{CH}_{2}$ e $\mathrm{CH}_{3}$, enquanto $\rho_{\text {pol }}, \rho_{\mathrm{CH}_{2}}$ e $\rho_{\mathrm{CH}_{3}}$ representam as densidades eletrônicas correspondentes. O parâmetro "unilamela" representa a porcentagem de vesículas grandes unilamelares presentes na solução medida, "ratio" indica a porcentagem de cada uma das membranas no sistema (membrana com ou sem alteração química), " $N$ " indica a quantidade de bicamadas lipídicas em uma vesícula multilamelar, "c" representa a distância entre os centros de duas bicamadas, "espessura" representa a espessura total da bicamada lipídica e $\eta_{\text {Caille }}$ é o parâmetro de Caillé.

\begin{tabular}{|c|c|c|c|c|c|c|}
\hline \multirow[b]{3}{*}{ modelo } & \multicolumn{6}{|c|}{ Parâmetros de Ajuste - Membranas sem FS } \\
\hline & \multicolumn{2}{|c|}{ POPC } & \multicolumn{2}{|c|}{ POPC:SM $(1: 1)$} & \multicolumn{2}{|c|}{ POPC:SM:CO (1:1:1) } \\
\hline & $1^{\circ}-\mathrm{POPC}$ & $2^{\circ}-$ Outros & $1^{\circ}-\mathrm{POPC}: \mathrm{S}$ & $2^{\circ}-$ Outros & $1^{\circ}-\mathrm{POPC}$ & $2^{\circ}-\mathrm{SMCO}$ \\
\hline unilamela $(\%)$ & \multicolumn{2}{|c|}{100} & \multicolumn{2}{|c|}{$91 \pm 3$} & \multicolumn{2}{|c|}{100} \\
\hline ratio $(\%)$ & $81(2)$ & $19(2)$ & $78(3)$ & $22(3)$ & $37(4)$ & $63(4)$ \\
\hline$R_{p o l}(\AA)$ & $9.3(6)$ & $7.0(2)$ & $9.4(9)$ & $10.2(2)$ & $9.3(6)$ & $10.2(2)$ \\
\hline $\mathrm{R}_{\mathrm{CH}_{2}}(\AA)$ & $10.9(4)$ & $9.9(2)$ & $13.7(5)$ & $12.5(3)$ & $10.9(4)$ & $14.2(2)$ \\
\hline$R_{\mathrm{CH}_{3}}(\AA)$ & $3.0(3)$ & $2.7(2)$ & $3.4(3)$ & $2.9(3)$ & $3.0(3)$ & $3.5(2)$ \\
\hline$\rho_{p o l}\left(e / \AA^{3}\right)$ & $0.417(4)$ & $0.413(16)$ & $0.408(8)$ & $0.433(1)$ & $0.417(4)$ & $0.437(6)$ \\
\hline$\rho_{C H_{2}}\left(e / \AA^{3}\right)$ & $0.297(3)$ & $0.323(23)$ & $0.317(2)$ & $0.299(11)$ & $0.297(3)$ & $0.313(5)$ \\
\hline$\rho_{\mathrm{CH}_{3}}\left(e / \AA^{3}\right)$ & $0.198(7)$ & $0.218(20)$ & $0.200(6)$ & $0.218(8)$ & $0.198(7)$ & $0.172(13)$ \\
\hline$N$ & - & - & \multicolumn{2}{|c|}{$2(1)$} & - & - \\
\hline$c(\AA)$ & - & - & \multicolumn{2}{|c|}{$80.6(17)$} & - & - \\
\hline espessura $(\AA)$ & $46(2)$ & $39(1)$ & $53(2)$ & $51(2)$ & $46(2)$ & $56(1)$ \\
\hline$\eta_{\text {Caille }}$ & - & - & \multicolumn{2}{|c|}{$0.11(3)$} & - & - \\
\hline
\end{tabular}

Comparando os valores apresentados na tabela 4.3 com os ajustes obtidos para as membranas de POPC, POPC:SM e POPC:SM:CO sem alteração química, apresentados nas tabelas 3.2 e 3.3 , pode-se observar que as vesículas compostas por POPC e POPC:SM usadas no experimento de fotossensibilização apresentam características estruturais diferentes da obtida na caracterização inicial para as mesmas composições lipídicas (ver Capítulo 3 . Para a nova vesícula de POPC foi identificado 19\% de membrana com alteração química, com espessura de bicamada lipídica igual a 39(1)A. Conforme veremos na seção 5.3.1.1, a segunda membrana apresentada na tabela 4.3 na composição de POPC pode corresponder à membrana com composição lipídica POPC:POPC-OOH (33:67) (ver tabela 5.3), indicando 
possível oxidação do lipídio POPC. Neste cenário, a diminuição de espessura está em bom acordo com o esperado devido a localização do grupo $O O H$ na interface bicamada lipídicaágua [72]. Já as vesículas compostas por POPC:SM apresentaram 22\% de membrana com composição química diferente. Neste caso a espessura da bicamada foi de 51(2)Å. A composição POPC:SM:CO não apresentou alteração, como pode ser observado pela comparação dos parâmetros apresentados nas tabelas 3.3 e 4.3 . 


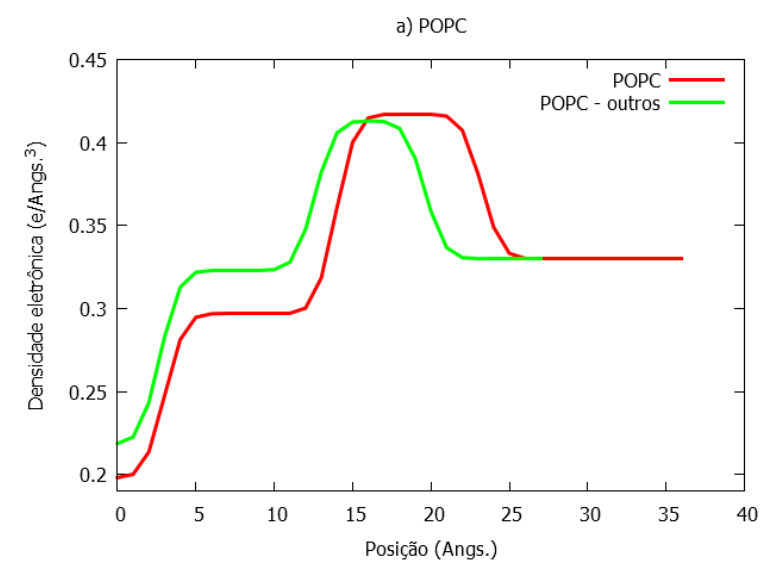

(a)

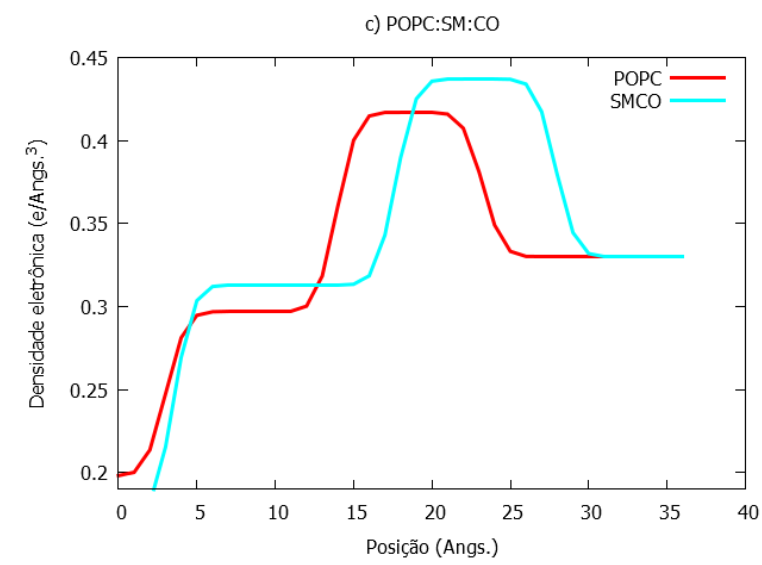

(c)

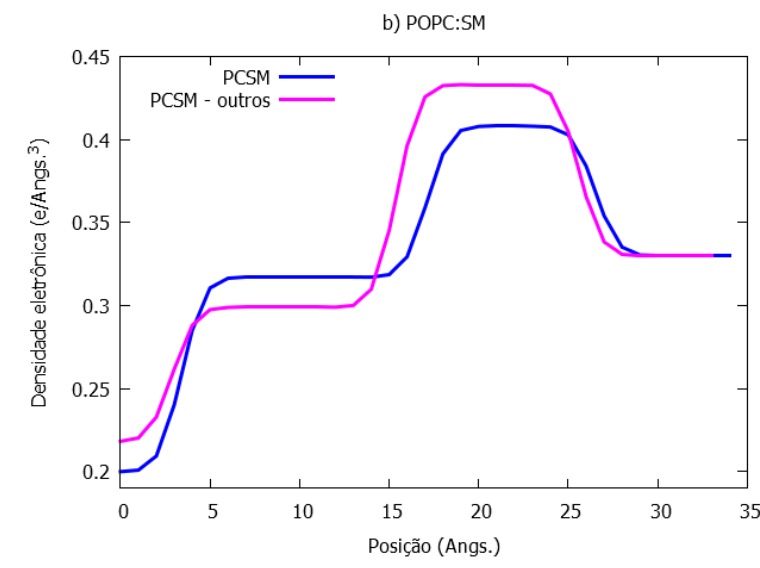

(b)

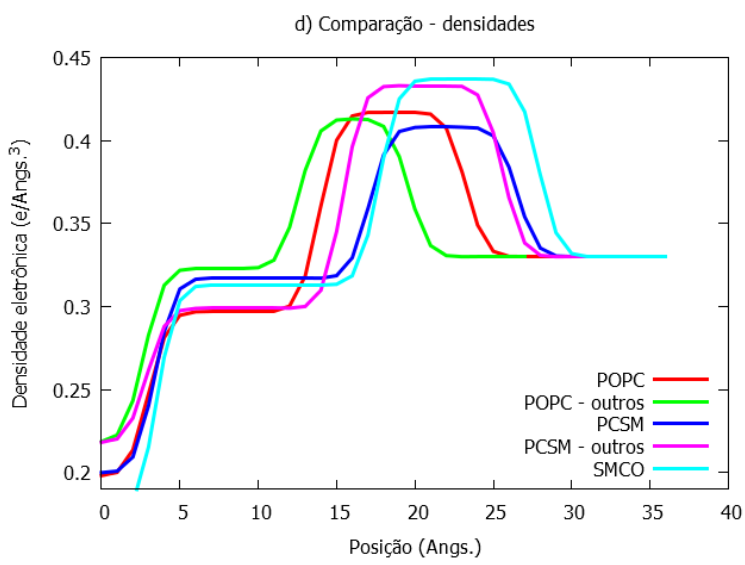

(d)

Figura 4.8: Perfil de densidade eletrônica ao longo do eixo z, normal à superfície da bicamada lipídica, para vesículas compostas por: a) POPC, b) POPC:SM, c) POPC:SM:CO e d) comparação entre todas as densidades. A legenda "outros" indica as composições lipídicas com possíveis alterações químicas investigadas neste capítulo.

Em seguida foi realizada a caracterização estrutural, via análise das curvas de SAXS, das vesículas foto-irradiadas. Os melhores ajustes aos dados experimentais estão apresentados nas figuras 4.9, 4.10 e 4.11 e os respectivos parâmetros estruturais estão apresentados na tabela 4.4 
Após a foto-irradiação das vesículas não foi observado, através dos ajustes, aparecimento de membrana com composição lipídica diferente da inicial (antes da foto-irradiação), ou seja, os parâmetros referentes à espessura e densidade eletrônica da bicamada lipídica foram os mesmos que os obtidos para as membranas não foto-irradiasdas (tabela 4.3). Por outro lado, as análises apresentaram variação na porcentagem de membrana considerada "oxidada"com alterações no perfil de empilhamento das bicamadas. Os parâmetros de ajuste obtidos estão descritos na tabela 4.4. A análise das alterações físicas observadas em cada composição lipídica está descrita a seguir: 


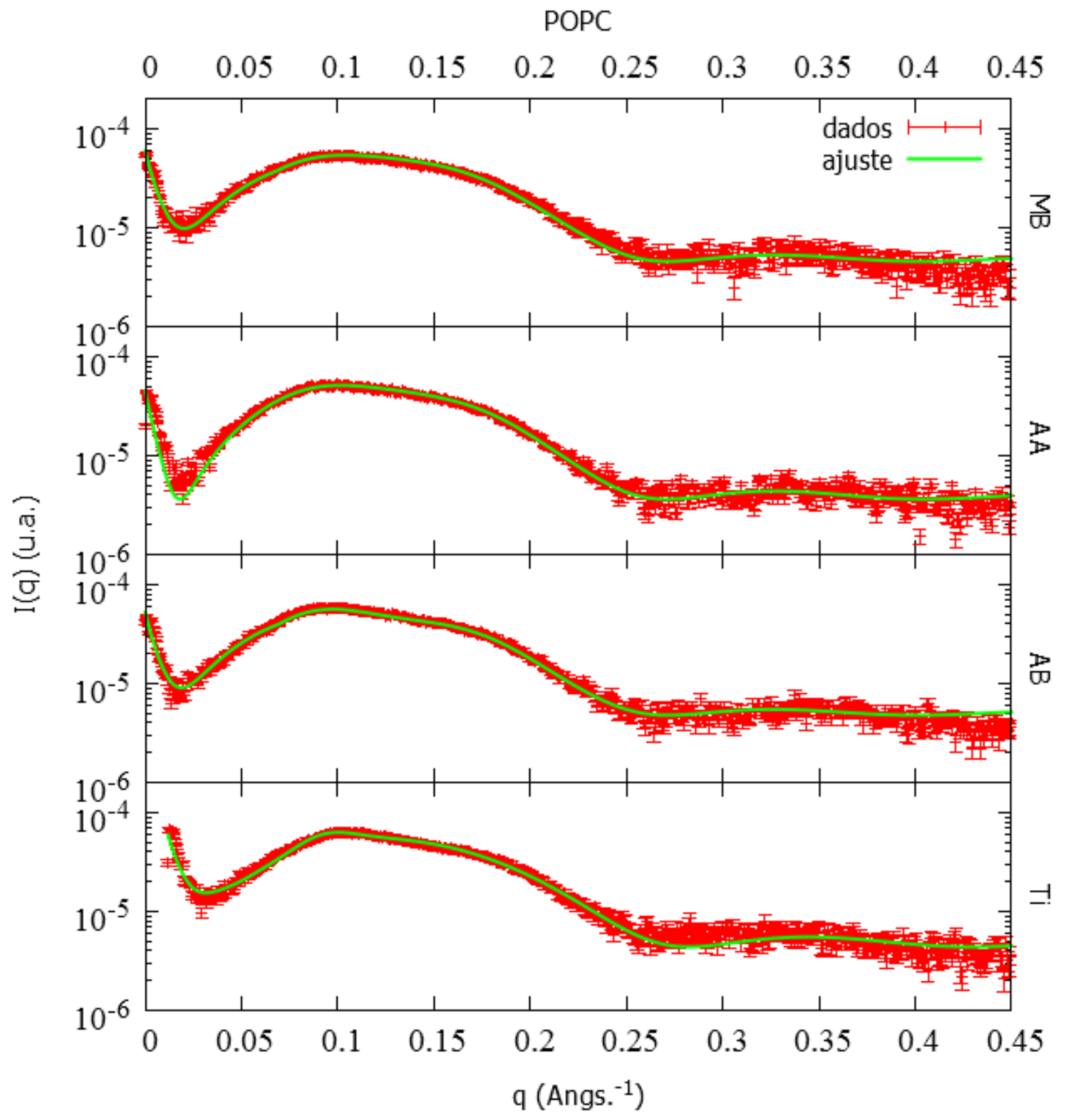

Figura 4.9: Curvas de SAXS de vesículas grandes compostas por POPC $[5 m M](+)$ na presença dos FSs MB, AA, AB e Ti (concentração final de FS igual a $20 \mu M$ após 2 horas de irradiação) medidos a $23^{\circ} \mathrm{C}$ e melhor ajuste aos dados experimentais obtidos pelo software GENFIT (linha contínua verde) a partir do modelo de lamela infinita. 


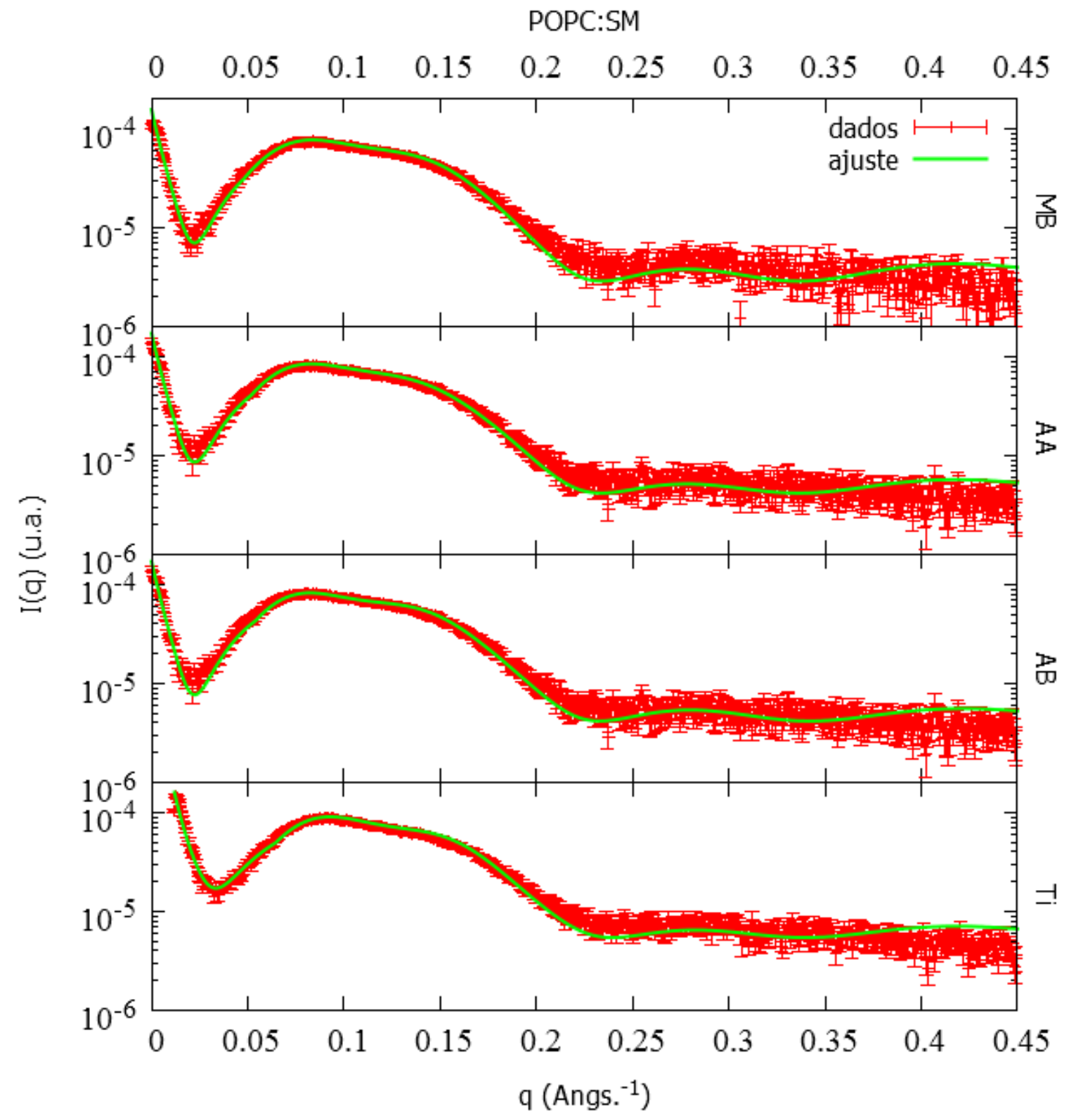

Figura 4.10: Curvas de SAXS de vesículas grandes compostas por POPC:SM (1:1) [5mM] (+) na presença dos FSs MB, AA, AB e Ti (concentração final de FS igual a $20 \mu M$ após 2horas de irradiação) medidos a $23^{\circ} \mathrm{C}$ e melhor ajuste aos dados experimentais obtidos pelo software GENFIT (linha contínua verde) a partir do modelo de lamela infinita. 


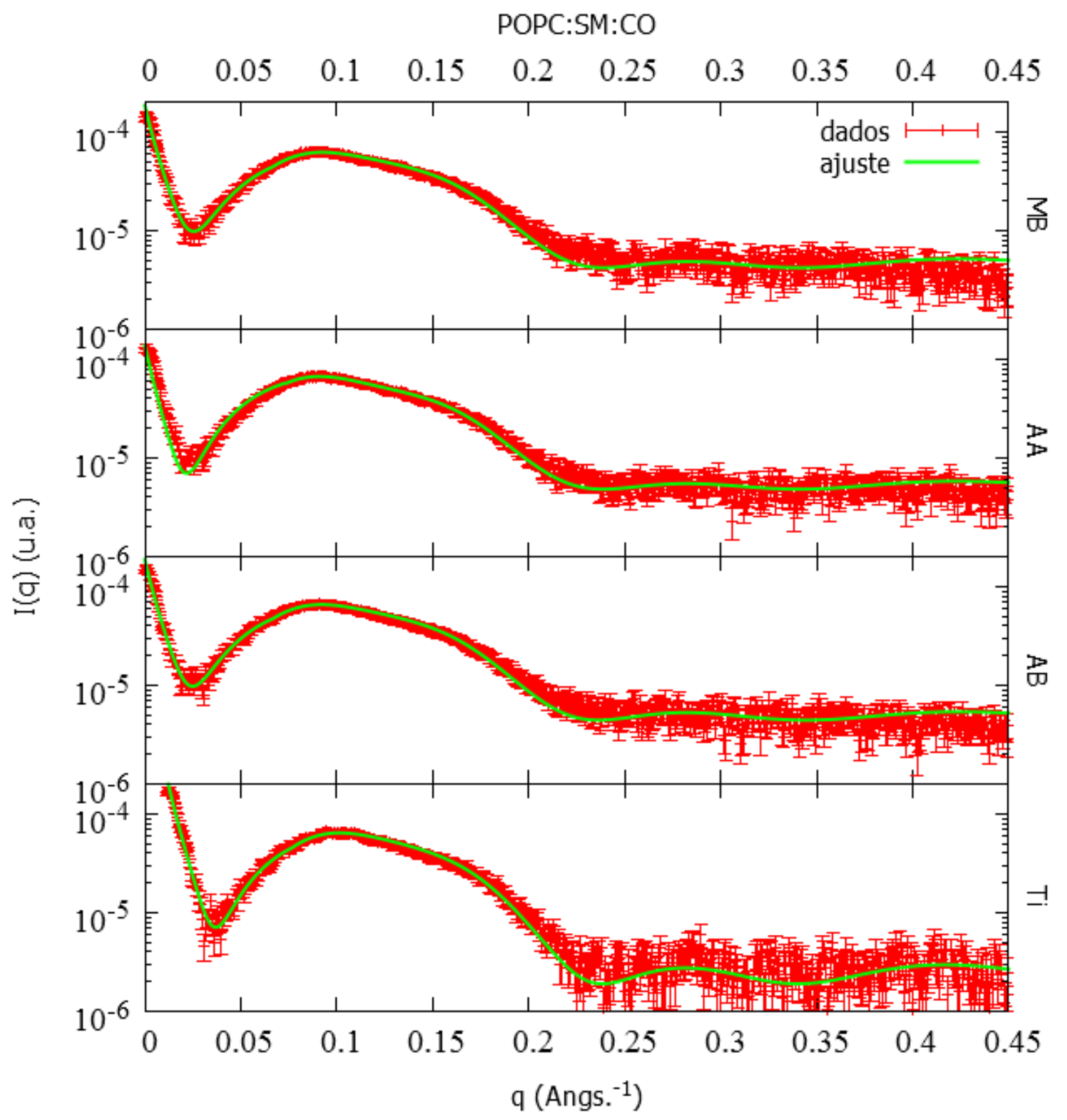

Figura 4.11: Curvas de SAXS de vesículas grandes compostas por POPC:SM:CO (1:1:1) $[5 m M](+)$ na presença dos FSs MB, AA, AB e Ti (concentração final de FS igual a $20 \mu M$ após 2horas de irradiação) medidos a $23^{\circ} \mathrm{C}$ e melhor ajuste aos dados experimentais obtidos pelo software GENFIT (linha contínua verde) a partir do modelo de lamela infinita. 
Tabela 4.4: Parâmetros de ajustes obtidos a partir dos resultados apresentados nas figuras 4.9. 4.10 e 4.11. O parâmetro "unilamela" representa a porcentagem de vesículas grandes unilamelares presentas na solução medida, "N"indica a quantidade de bicamadas lipídicas em uma vesícula multilamelar, "c" representa a distância entre os centros de duas bicamadas,

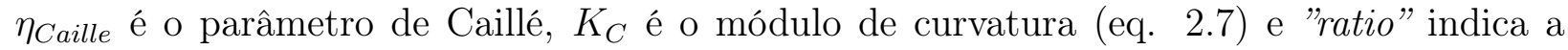
porcentagem de membrana considerada oxidada. Os parâmetros $R_{\text {pol }}, R_{\mathrm{CH}_{2}}, R_{\mathrm{CH}_{3}}, \rho_{\text {pol }}$, $\rho_{\mathrm{CH}_{2}}$ e $\rho_{\mathrm{CH}_{3}}$ foram mantidos com os valores apresentados na tabela 4.3 .

\begin{tabular}{|c|c|c|c|c|c|c|c|}
\hline \multicolumn{8}{|c|}{ Parâmetros de Ajuste - Vesículas grandes irradiadas com FSs } \\
\hline & & unilamela $(\%)$ & $N$ & $c(\AA)$ & $\eta_{\text {Caille }}$ & $K_{C}\left(10^{-13} \mathrm{erg}\right)$ & ratio(\%) \\
\hline \multirow{5}{*}{ POPC } & sem FS & 100 & - & - & - & - & $18(2)$ \\
\hline & $M B$ & 93(9) & $2(1)$ & $68(4)$ & $0.10(5)$ & 1 & $39(4)$ \\
\hline & $A A$ & $90(2)$ & $3(1)$ & $66(1)$ & $0.10(1)$ & 1 & 10(3) \\
\hline & $A B$ & $80(4)$ & $2(1)$ & $65(1)$ & $0.12(4)$ & 1 & $43(3)$ \\
\hline & $T i$ & $23(5)$ & $3(1)$ & $62(3)$ & $0.32(1)$ & 0.2 & $59(1)$ \\
\hline \multirow{5}{*}{ POPC:SM } & sem FS & $91(3)$ & $2(1)$ & $81(2)$ & $0.11(3)$ & 0.5 & $22(3)$ \\
\hline & $M B$ & $80(5)$ & $2(1)$ & $76(1)$ & $0.12(3)$ & 0.6 & $22(3)$ \\
\hline & $A A$ & $69(7)$ & $2(1)$ & $75(1)$ & $0.17(2)$ & 0.3 & $22(3)$ \\
\hline & $A B$ & $72(11)$ & $2(1)$ & $77(1)$ & $0.14(3)$ & 0.4 & $22(3)$ \\
\hline & $T i$ & $79(7)$ & $2(1)$ & $76(1)$ & $0.11(3)$ & 0.7 & $39(8)$ \\
\hline \multirow{5}{*}{ POPC:SM:CO } & sem FS & 100 & - & - & - & - & 0 \\
\hline & $M B$ & $87(3)$ & $2(1)$ & $70(4)$ & $0.11(2)$ & 1 & 0 \\
\hline & $A A$ & $84(2)$ & $2(1)$ & $69(1)$ & $0.11(5)$ & 1 & 0 \\
\hline & $A B$ & $87(2)$ & $2(1)$ & $70(1)$ & $0.11(4)$ & 1 & 0 \\
\hline & $T i$ & $88(4)$ & $2(1)$ & $80(1)$ & $0.10(2)$ & 0.7 & 0 \\
\hline
\end{tabular}

Vesículas de POPC: Após a foto-irradiação, no que diz respeito à oxidação das membranas, foi observado que os fotossensibilizadores MB, AB e Ti apresentaram uma porcentagem maior da membrana considerada oxidada ( $2^{\circ}$ modelo - outros) se comparada as vesículas de POPC sem FS e irradiada com AA. O percentual de membrana oxidada na presença dos FSs Ti, AB e MB foram respectivamente 59\%, $43 \%$ e $39 \%$ contra $18 \%$ e $10 \%$ para POPC sem FS e irradiada com AA. Esse resultado indica que a irradiação realizada com MB, AB e Ti resultou em uma maior porcentagem de membranas foto-oxidadas do que o obtido com 
AA. Dados os valores de incorporação de FS na membrana apresentados na seção 4.3.1 figura 4.3. o esperado seria que para esta composição lipídica os FSs Ti, AB, AA e MB, nessa ordem, apresentassem maior efeito de oxidação. Embora a incorporação de MB na membrana de POPC tenha sido baixa se comparada aos demais FSs (ver tabela 4.2), experimentos de rendimento quântico mostraram que Ti e MB possuem maior produção de oxigênio singlete, respectivamente $60 \%$ e $52 \%$ se comparado aos azures A (45\%) e B (31\%) [92, 93, 94, 88, podendo ser esse um fator para o maior efeito de foto-oxidação observado para MB se comparado ao FS AA que apresentou maior incorporação.

Outro resultado observado após a foto-irradiação na presença dos quatro FSs foi a formação de multilamelas, com maior efeito gerado pelo FS Tionina que apresentou aumento de $77 \%$ em estruturas multilamelares. Os FSs MB, AA e AB também apresentaram indução à formação de multilamelas porém promovendo a formação máxima de $20 \%$ de multilamelas. É interessante notar que o parâmetro de Caillé $\left(\eta_{\text {Caille }}\right)$ observado para o sistema POPC/Ti é maior do que o obtido para as demais composições. Dado que este sistema apresenta grande proporção de estruturas multilamelares, seria esperado que para este caso o $\eta_{\text {Caille }}$ fosse menor do que o obtido para os FSs MB, AA e AB. [82]. Com relação à flutuação da membrana, verificou-se que nos sistemas com $\mathrm{MB}, \mathrm{AA}$ e $\mathrm{AB}$ os valores de módulo de curvatura $\left(K_{C}\right)$ obtidos são similares ao observado para membranas puras de POPC $\left(K_{C}\right.$ entre $1-20.10^{-13} \mathrm{erg}$ ) [95]. Já o sistema com Ti apresentou $K_{C} \sim 10^{-14} \mathrm{erg}$ indicando que a membrana apresenta menor módulo de curvatura.

Vesículas de POPC:SM: Para as vesículas compostas por POPC:SM também foi observado formação de multilamelas, sendo os maiores efeitos obtidos na presença dos FSs AA, AB e Ti com um aumento de $\sim 22 \%$ de multilamelas. Com relação à foto-oxidação dos 
lipídios, as vesículas irradiadas com MB, AA e AB não apresentaram efeito. Já as vesículas irradiadas na presença de Ti apresentaram um aumento de 17\% de membrana considerada oxidada em acordo com o resultado obtido no estudo de incorporação, onde a Tionina apresentou maior efeito (seção 4.3.1 - figura 4.3). Vale observar que embora a Tionina tenha apresentado maior efeito de incorporação em vesículas compostas por POPC:SM, o resultado de oxidação foi maior em vesículas compostas apenas por POPC. Esse efeito pode se dar ao a fato de que em vesículas compostas apenas por POPC há uma maior chance de oxidação devido às duplas ligações presentes nesse lipídio. Quando ocorre a inclusão de outro lipídio no sistema, o volume de insaturações disponíveis será menor, desfavorecendo assim o efeito oxidativo. Isto explica porque o sistema POPC:SM possui maior incorporação dos FSs, porém menor efeito de oxidação em relação a membranas puras de POPC. É interessante notar que a composição POPC:SM apresentou grande flutuação de membrana para os quatro FSs estudados $\left(K_{C} \sim 10^{-14} \mathrm{erg}\right)$.

Vesículas de POPC:SM:CO: Para esta composição não foi observado efeito de fotooxidação lipídica para nenhum dos fotossensibilizadores. Dois fatores podem ser considerados aqui: 1 - A composição POPC:SM:CO (1:1:1) apresentou baixos resultados de incorporação (seção 4.3.1- figura 4.3) se comparados aos sistemas POPC e POPC:SM (1:1). 2 - Somado a isso tem-se a baixa disponibilidade de lipídios POPC disponíveis para oxidação. Após a foto-irradiação o único efeito observado foi o aparecimento de multilamelas, da ordem de $15 \%$ para todos os FSs. O parâmetro $K_{C}$ se manteve similar ao observado para vesículas de POPC (da ordem de $\sim 10^{-13} \mathrm{erg}$ ) com exceção do sistema foto-irradiado com Ti que apresentou maior flutuação com $K_{C} \sim 10^{-14} \mathrm{erg}$. 
Os experimentos de rendimento quântico de produção de oxigênio singlete descritos na literatura, cujos valores obtidos paras os FSs MB, AA, AB e Ti são respectivamente 52\%, $45 \%, 31 \%$ e $60 \%$, indicam que, assim como verificado em nossos resultados de SAXS, o FS Tionina apresenta maior efeito de oxidação de membrana via oxigênio singlete [92, 93, 94]. Entretanto, considerando os valores de rendimento quântico apresentados, era esperado que o grau de oxidação das membranas aqui analisadas, tanto para a Ti quanto para os demais FSs, fosse mais significativo. Portanto, a foto-oxidação induzida na membrana não depende apenas da característica do FS em relação ao rendimento quântico na produção de ${ }^{1} \mathrm{O}_{2}$, mas de sua localização/ligação na membrana.

\subsection{Conclusão}

Os resultados de SAXS mostraram que, dentre as três composições lipídicas estudadas, o sistema composto por POPC:SM:CO (1:1:1) foi o que apresentou menor efeito de alteração estrutural devido à fotossensibilização, que pode ser explicado devido a baixa proporção de lipídios POPC disponíveis para oxidação e aos baixos valores de incorporação dos FSs. Portanto, parece que domínios lipídicos de SM:CO dificultam a incorporação das fenotiazínas, provavelmente devido ao maior grau de empacotamento (packing) lipídico. Para as vesículas compostas por POPC e POPC:SM (1:1), verificou-se que o FS Tionina foi o que promoveu maior foto-dano na membrana em bom acordo tanto com os resultados de incorporação observados neste estudo como com os valores de rendimento quântico de produção do oxigênio singlete descritos na literatura. O resultado de incorporação em bom acordo com o obtido por SAXS funciona como um validador das análises aplicadas. O efeito de indução à formação de multilamelas foi observado para todas as composições com FSs, mesmo antes da exposição à irradiação, sugerindo assim que o fotossensibilizadror por si só, nas composi- 
ções estudadas, promove formação de multilamelas. Este efeito pode também ser um fator atrelado ao pequeno efeito oxidativo observado.

De um modo geral, os efeitos de fotossensibilização observados neste trabalho não foram significativos no que se refere à danos físicos em membranas levando à destruição das mesmas. Esse efeito pode ser explicado pelos baixos valores de incorporação obtidos para os sistemas estudados se comparados aos descritos na literatura para outros sistemas [88], bem como à redução de lipídios insaturados disponíveis como alvo de reações foto-oxidativas. 



\section{Capítulo 5}

Mudanças estruturais impostas pela inclusão de lipídios oxidados em membranas modelo 
Neste capítulo vamos determinar os efeitos gerados devido à oxidação da membrana a partir da substituição (parcial ou integral) controlada do lipídio POPC pelos lipídios oxidados POPC-OOH e PAzPC em mebranas compostas por POPC:PC $\mathrm{P}_{\text {oxidado }}$. Uma vez que os efeitos de fotossensibilização in situ descritos no capítulo anterior (Capítulo 4) foram baixos, a inclusão controlada de lipídios previamente oxidados garantem a oxidação da membrana de modo que possamos avaliar as possíveis alterações estruturais devido à oxidação lipídica.

Vale a pena ressaltar que o estudo apresentado neste capítulo resultou na publicação de um artigo científico intitulado Hydroperoxide and carboxyl groups preferential location in oxidized biomembranes experimentally determined by small angle X-ray scattering: Implications in membrane structure [72] desenvolvido em colaboração com o professor Francesco Spinozzi da Universidade Politécnica de Marche (Ancona - Itália).

Para melhor compreensão do texto, optamos por descrever primeiramente as análises que serviram como base para estudo apresentado no artigo e em segundo momento os resultados principais publicados.

\subsection{Objetivo específico}

O objetivo deste capítulo consistiu em:

1 - Quantificar as alterações estruturais em membranas modelo impostas pela inclusão controlada de lipídios oxidados POPC-OOH e PAzPC.

2 - Identificar, a partir de curvas experimentais de SAXS, a posição preferencial dos grupos oxidados $\mathrm{OOH}$ e $\mathrm{COO}^{-}$dos lipídios POPC-OOH e PAzPC, respectivamente, em membranas modelo de POPC. 


\subsection{Materiais e Métodos}

\subsubsection{Materiais}

Os filmes lipídicos foram hidratados em água Milli-Q (Milli-Q plus ultra pure Type 1 water system - Milipore; resistividade 18,2M $\Omega . c m$ - pH 5). A estrutura química dos lipídios POPC, POPC-OOH e PAzPC utilizados neste capítulo estão apresentadas nas figuras 3.1, 1.4 e 1.5 , respectivamente.

\subsubsection{SAXS}

A caracterização da propriedades físicas das vesículas foi realizada a partir da técnica de SAXS, cujas informações referente aos parâmetros de aquisição dos dados obtidos no LNLS estão descritos na seção 2.2 .

As LUVs foram preparadas a partir do método de extrusão segundo o protocolo descrito na seção 3.2.2. As informações sobre composição lipídica, concentração final de lipídios, quantidade de extrusões e tamanho do poro utilizados para a obtenção de unilamelas e a temperatura em que a solução foi mantida durante o processo de hidratação do filme lipídico estão descritas na tabela 5.1

As proporções de lipídio utilizadas em cada sistema estudo foram determinadas de modo a substituir gradativamente a porcentagem referente ao lipídio POPC por lipídio oxidado (POPC-OOH ou PAzPC).

A utilização de poros de 50nm para extrusão das amostras compostas por POPC:PC $\mathrm{Pxidado}_{\text {o }}$ ocorreu devido à indisponibilidade de filtros de $100 \mathrm{~nm}$ no ato das medidas. Essa troca pôde ser realizada sem perda de generalidade pois, como descrito na seção 2.2 , o diâmetro obtido 
para estas amostras (mínimo de $500 \AA ̊$ ) é muito grande em comparação com a dimensão máxima que pode ser observada pela técnica de SAXS na configuração utilizada (da ordem de $262 \AA)$.

Tabela 5.1: Amostras medidas por SAXS compostas por POPC e lipídio oxidado (POPC$\mathrm{OOH}$ e/ou PAzPC).

\begin{tabular}{|c|c|c|c|c|}
\hline \multicolumn{5}{|c|}{ Medidas de SAXS - POPC:PC oxidado } \\
\hline Composição & Concentração & $\mathrm{n}^{\circ}$ de extrusão & filtro $(\mathrm{nm})$ & $\mathrm{T}\left({ }^{\circ} C\right)$ \\
\hline POPC:POPC-OOH (0:1) & $10 \mathrm{mM}$ & 31 & 50 & 30 \\
\hline POPC:POPC-OOH (33:67) & $10 \mathrm{mM}$ & 31 & 50 & 30 \\
\hline POPC:POPC-OOH (67:33) & $10 \mathrm{mM}$ & 31 & 50 & 30 \\
\hline POPC:POPC-OOH (1:0) & $10 \mathrm{mM}$ & 31 & 50 & 30 \\
\hline POPC:PAzPC (90:10) & $10 \mathrm{mM}$ & 31 & 50 & 30 \\
\hline POPC:PAzPC (67:33) & $10 \mathrm{mM}$ & 31 & 50 & 30 \\
\hline POPC:POPC-OOH:PAzPC (60:25:15) & $10 \mathrm{mM}$ & 31 & 50 & 30 \\
\hline POPC:POPC-OOH:PAzPC (47:25:28) & $10 \mathrm{mM}$ & 31 & 50 & 30 \\
\hline
\end{tabular}

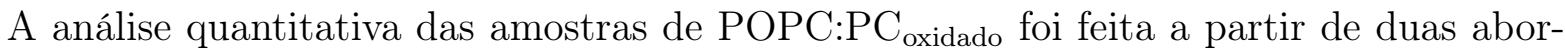
dagens diferentes, de acordo com a profundidade de detalhamento desejada:

1- Modelo de lamelas infinitas com três regiões de densidade eletrônica diferentes, descrito na seção 2.3.1. No caso de unilamela, o parâmetro referente ao número de multilamelas N é dado por $N=1$.

2- Modelo de grupos químicos, o qual leva em consideração a distribuição da fração de volume de cada grupo químico presente nos lipídio que compõe a bicamada (ver seção 2.3.2). Os grupos químicos presentes em cada lipídio e água do meio (bulk) bem como suas principais propriedades e quantidade $\left(\mathrm{n}_{i}\right)$ em cada um dos três lipídios (POPC, POPC-OOH 
e PAzPC) estão apresentados na tabela 5.2 .

Tabela 5.2: Lista dos grupos químicos e seus respectivos volume molecular, peso molecular, número de elétrons e composição em cada um dos lipídios estudados (POPC, POPC-OOH e PAzPC). De acordo com Kucerka et al. [96], os grupos combinados são: o carbonil + glicerol (CG), o fosfato $+\mathrm{CH}_{2} \mathrm{CH}_{2} \mathrm{~N}(\mathrm{PCN})$ e os três $\mathrm{CH}_{3}$ da colina $\left(\mathrm{CholCH}_{3}\right)$. Os grupos oxidados do POPC-OOH e do PAzPC são o conjunto insaturado $\mathrm{CHCH}+$ hidroperóxido $\mathrm{CHOOH}(\mathrm{PX})$ e a carboxila $\mathrm{COO}^{-}(\mathrm{CX})$, respectivamente. ${ }^{\left({ }^{a}\right)}$ Standard literature data [97].

\begin{tabular}{lrrrrrr}
\hline$i$-group & $\begin{array}{r}\nu_{i}^{(\mathrm{a})} \\
\left(\AA^{3}\right)\end{array}$ & $\begin{array}{r}M_{i} \\
\left(\mathrm{~g} \mathrm{~mol}^{-1}\right)\end{array}$ & $\begin{array}{r}Z_{i} \\
\left(q_{\mathrm{e}}\right)\end{array}$ & $\mathrm{n}_{i}$ - POPC & $\mathrm{n}_{i}$ - POPC-OOH & $\mathrm{n}_{i}$ - PazePC \\
\hline $\mathrm{CH}_{2}$ & 27.7 & 14.03 & 8 & 28 & 27 & 21 \\
$\mathrm{CH}_{3}$ & 52.9 & 15.04 & 9 & 2 & 2 & 1 \\
$\mathrm{CH}$ & 21.5 & 13.02 & 7 & 2 & 1 & \\
$\mathrm{CG}$ & 143.3 & 129.09 & 67 & 1 & 1 & 1 \\
$\mathrm{PCN}$ & 87.8 & 137.03 & 70 & 1 & 1 & 1 \\
$\mathrm{CholCH}$ & 99.9 & 45.11 & 27 & 1 & 1 & \\
$\mathrm{PX}$ & 94.8 & 72.03 & 38 & & & \\
$\mathrm{CX}$ & 51.0 & 44.01 & 23 & & & \\
$\mathrm{H}_{2} \mathrm{O}$ & 29.9 & 18.02 & 10 & & & \\
\hline
\end{tabular}

\subsection{Resultados e Discussões}

A apresentação dos resultados e discussão deste capítulo foi feita em duas partes:

1 - Caracterização inicial de vesículas compostas por POPC:PC $\mathrm{Pxidado}_{\text {a }}$ partir do modelo de de lamela infinita com três regiões de densidade eletrônica (ver seção 2.3.1). Neste estudo $\mathrm{PC}_{\text {oxidado }}$ é dado por POPC-OOH e/ou PAzPC.

2 - Resultados obtidos a partir da análise via modelo de grupos químicos (ver seção 2.3.2) para as composições POPC:POPC-OOH e POPC:PAzPC que resultou na publicação do artigo intitulado Hydroperoxide and carboxyl groups preferential location in oxidized biomembranes experimentally determined by small angle X-ray scattering: Implications in membrane structure [72]. 


\subsubsection{Caracterização inicial de membranas modelo contendo lipí- dios oxidados}

\subsubsection{POPC:POPC-OOH}

A figura 5.1 apresenta o perfil de espalhamento de vesículas compostas por POPC:POPCOOH variando o percentual de lipídio oxidado POPC-OOH de 0 a 100\%. Foi observado um deslocamento do primeiro vale para maiores ângulos de espalhamento a medida em que aumentamos a proporção de lipídio oxidado no sistema, indicando diminuição da bicamada lipídica.

A partir dos ajustes teóricos das curvas de SAXS através do modelo de três regiões de diferentes densidades eletrônicas (polar, regiões de CH2 e CH3) (ver seção 2.3.1) apresentados na figura 5.2 foi possível quantificar as variações na espessura e densidade eletrônica ao longo da bicamada devido à inclusão de POPC-OOH. Os parâmetros estruturais obtidos obtidos estão apresentados na tabela 5.3. Já a figura 5.3 apresenta a distribuição das espessuras total da bicamada lipídica a medida em que aumentamos a quantidade do lipídio oxidado na membrana modelo.

Do ponto de vista teórico, existe na literatura uma variedade de estudos de simulação computacional mostrando que o grupo OOH do lipídio oxidado POPC-OOH tende a migrar para a interface bicamada-água gerando aumento na área ocupada por cada lipídio e consequente diminuição na espessura da bicamada lipídica. [10, 49, 98, 172]. O efeito de aumento de área, diminuição de espessura e alteração na permeabilidade da membrana também foram observados experimentalmente em estudos com vesículas gigantes [16, 20, 22, 23, 99 . 


\section{Comparação entre POPC e POPC-OOH}

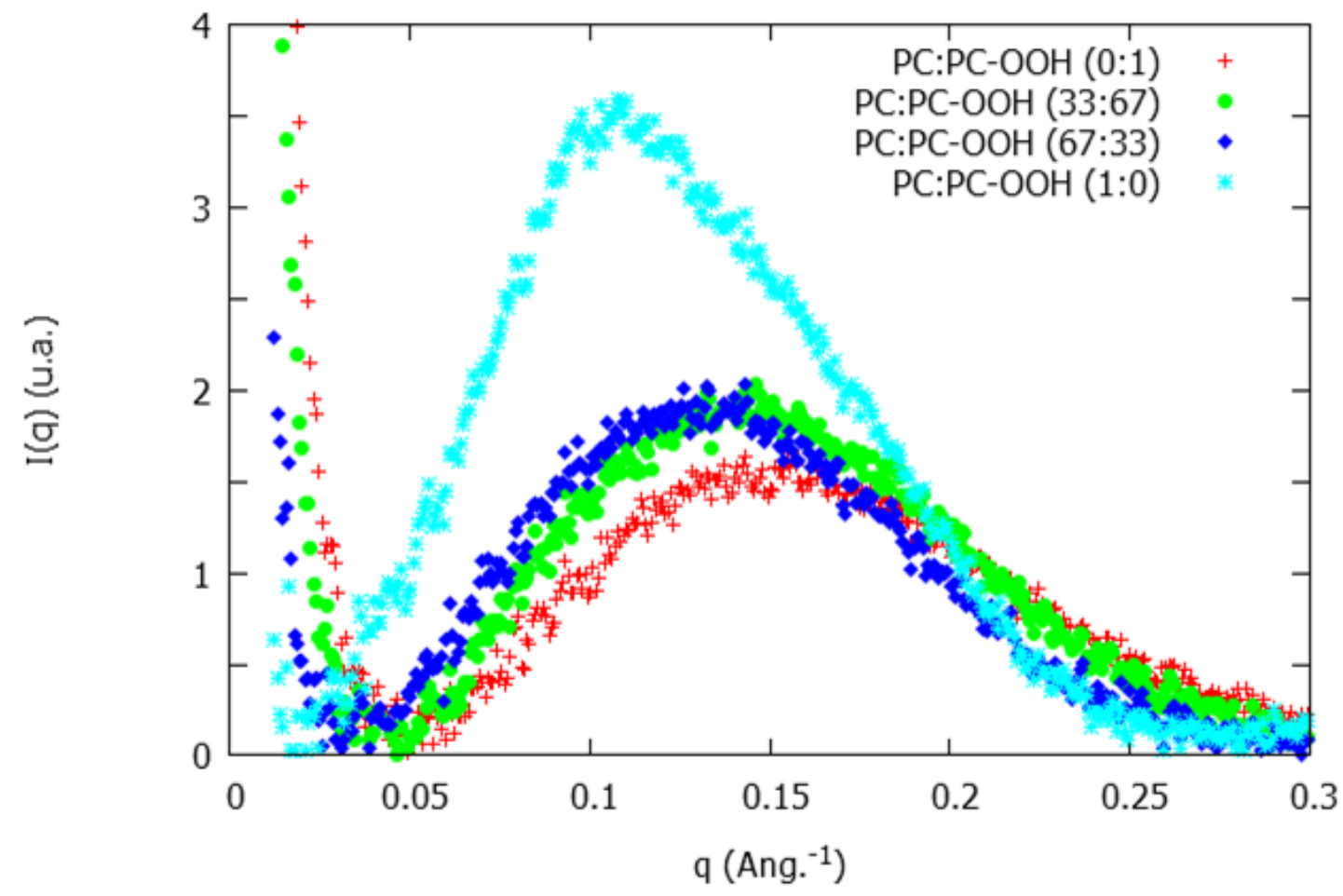

Figura 5.1: Curvas de SAXS de LUVs compostas por POPC:POPC-OOH com concentração inicial de lipídio igual a $10 \mathrm{mM}$ medidos a $23^{\circ} \mathrm{C}$. O insert apresenta as diferentes razões molares de POPC:POPC-OOH estudadas.

Analisando os resultados de SAXS para membranas modelo com lipídio oxidado POPC$\mathrm{OOH}$, foi observado um decréscimo significativo da espessura da bicamada que diminui de

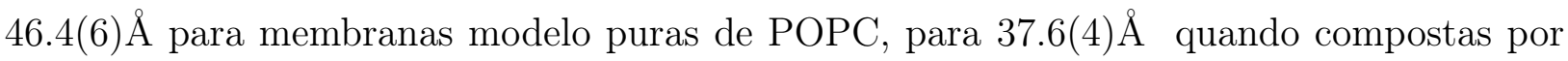
100\% de POPC-OOH , representando uma variação de 8.8(7) ^. Para as composições lipídicas intermediárias, com 33\% e 67\% de POPC-OOH, as espessuras obtidas foram respectivamente

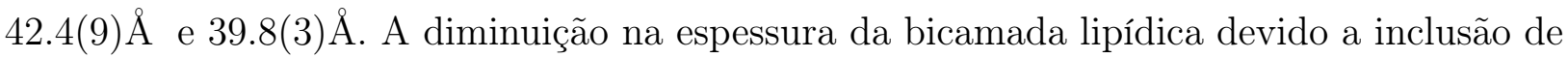
lipídio oxidado está em bom acordo com os resultados de dinâmica molecular descritos na literaturua [49, 98]. A variação de espessura observada está atrelada aos parâmetros $R_{\text {pol }}$, 
$R_{\mathrm{CH}_{2}}$ e $R_{\mathrm{CH}_{3}}$ que também sofrem redução com o aumento de POPC-OOH. É interesante notar que os parâmetros de espessura observados para a composição lipídica POPC:POPCOOH (33:67) (tabela 5.3) são similares aos observados no estudo de fotossensibilização (seção 4.3.2 para a membrana modelo de POPC considerada oxidada (tabela 4.3).

Observando os perfis de densidade eletrônica apresentados na figura 5.4, foi observado um aumento de densidade nas regiões $\mathrm{CH}_{2}$ e $\mathrm{CH}_{3}$. A continuidade deste estudo, que será apresentada no decorrer deste trabalho (seção 5.3.2), mostrou que o grupo $\mathrm{CH}_{3}$ do lipídio POPC-OOH tende a se localizar na região central da membrana modelo entre $0 \AA$ e $5 \AA$ assim como ocorre para o mesmo grupo referente ao lipídio POPC. Contudo, o aumento de POPC-OOH na composição lipídica da membrana modelo leva a uma diminuição na fração de volume ocupado pelo grupo $\mathrm{CH}_{3}$ acarretando assim no aumento de densidade eletrônica na região [72]. Já o aumento de densidade eletrônica na região das caudas parafínicas pode ser explicado pela presença do grupo $\mathrm{OOH}$ na região de interface com a água e consequente redução na espessura [49, 72].

Os resultados apresentados nesta seção juntamente com os obtidos para vesículas compostas por POPC:PAzPC, que serão descritos na seção a seguir 5.3.1.2, foram de extrema importância para entendermos do ponto de vista experimental como a oxidação lipídica afeta a estrutura física de bicamada lipídica servindo como insumo para o aprofundamento das análises através do modelo de grupos químicos (ver seção 5.3.2). 


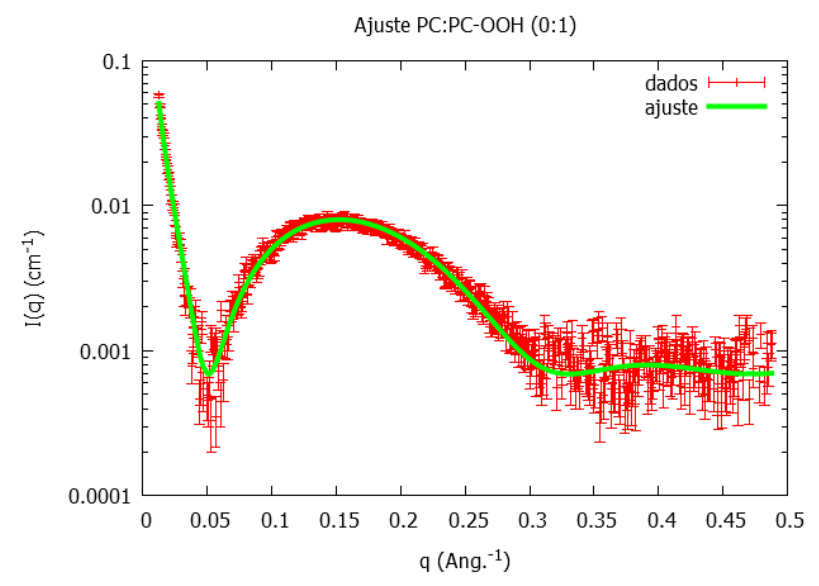

(a)

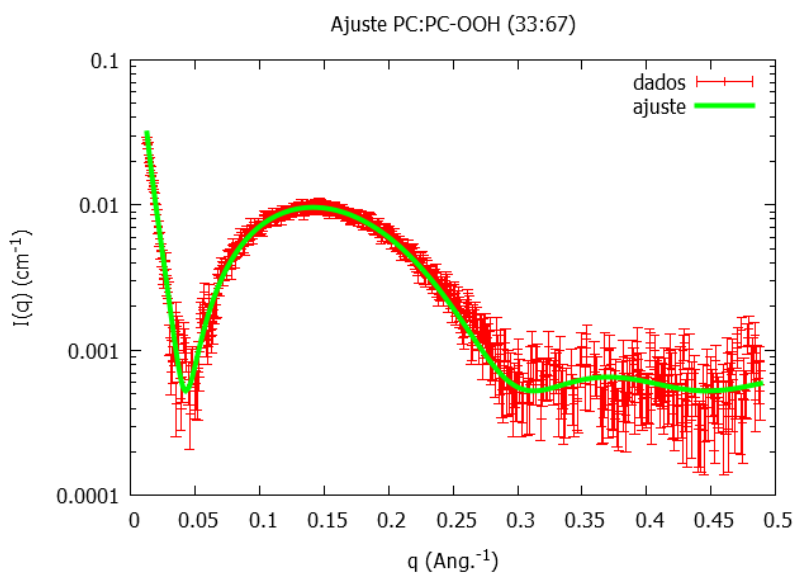

(b)

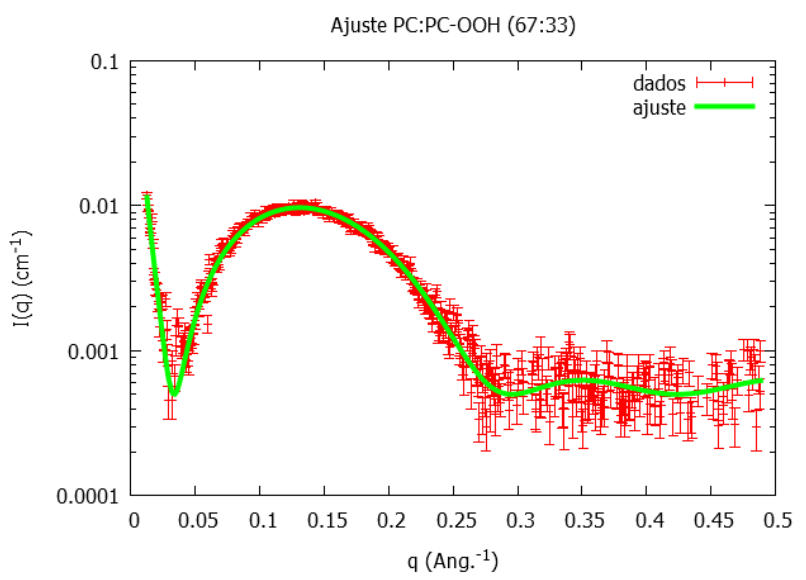

(c)

Figura 5.2: Curvas de SAXS de vesículas grandes compostas por POPC:POPC-OOH com razões molares a) (0:100), b) (33:67) e c) (67:33) com concentração inicial de $10 \mathrm{mM}(+)$ medidos a $23^{\circ} \mathrm{C}$ e melhor ajuste aos dados experimentais obtidos a partir do modelo de lamela infinita com três regiões de densidade eletrônica (ver seção 2.3.1. 
Tabela 5.3: Parâmetros estruturais obtidos a partir dos ajustes apresentados na figura 5.2 ; $R_{p o l}, R_{\mathrm{CH}_{2}}$ e $R_{\mathrm{CH}_{3}}$ representam, respectivamente, a espessura da região polar, meio hidrofóbico contendo $\mathrm{CH}_{2}$ e $\mathrm{CH}_{3}$, enquanto $\rho_{\text {pol }}, \rho_{\mathrm{CH}_{2}}$ e $\rho_{\mathrm{CH}_{3}}$ as densidades eletrônicas correspondentes.

\begin{tabular}{ccccc}
\hline \multicolumn{5}{c}{ Parâmetros de Ajuste } \\
\hline & POPC & PC:PC-OOH $(67: 33)$ & PC:PC-OOH $(33: 67)$ & PC:PC-OOH $(0: 1)$ \\
\hline$R_{\text {pol }}(\AA)$ & $9.3(6)$ & $7.7(8)$ & $7.1(4)$ & $6.6(5)$ \\
$R_{C H_{2}}(\AA)$ & $10.9(4)$ & $10.6(5)$ & $10.1(3)$ & $9.7(3)$ \\
$R_{C H_{3}}(\AA)$ & $3.0(3)$ & $2.9(2)$ & $2.7(1)$ & $2.5(2)$ \\
$\rho_{\text {pol }}\left(e / \AA^{3}\right)$ & $0.417(4)$ & $0.403(7)$ & $0.407(3)$ & $0.412(8)$ \\
$\rho_{C H_{2}}\left(e / \AA^{3}\right)$ & $0.297(3)$ & $0.313(8)$ & $0.315(4)$ & $0.318(6)$ \\
$\rho_{C H_{3}}\left(e / \AA^{3}\right)$ & $0.198(7)$ & $0.226(8)$ & $0.225(4)$ & $0.224(9)$ \\
espessura $(\AA)$ & $46.4(6)$ & $42.4(9)$ & $39.8(3)$ & $37.6(4)$ \\
\hline
\end{tabular}




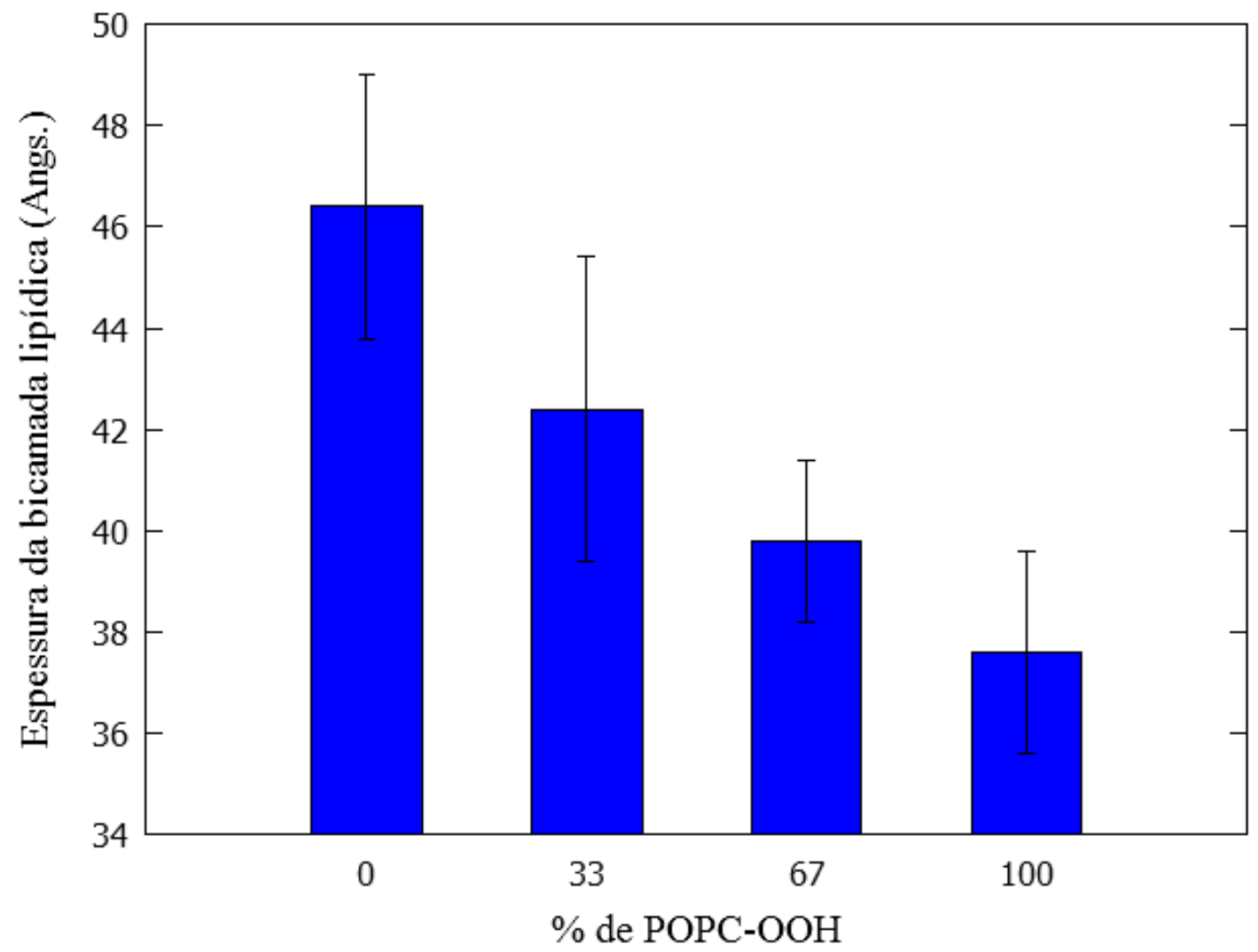

Figura 5.3: Distribuição da espessura da bicamada lipídica em função da quantidade de lipídio oxidado POPC-OOH na membrana e barra de erro obtida a partir de 10 iterações do ajuste. 


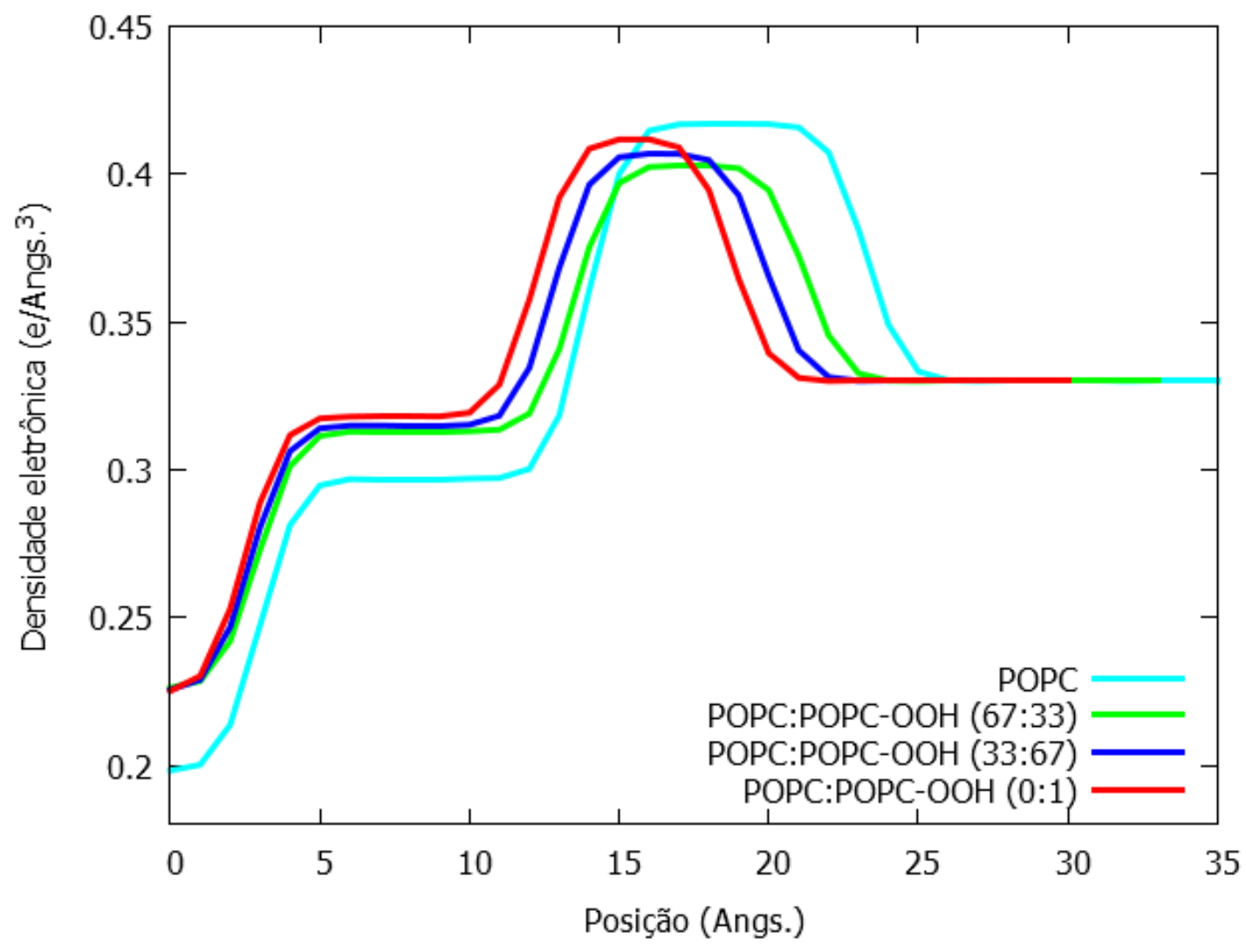

Figura 5.4: Perfil de densidade eletrônica para as vesículas de POPC com e sem lipídio oxidado POPC-OOH. O insert apresenta as razões molares.

\subsubsection{POPC:PAzPC}

Dependendo do mecanismo envolvido no processo de oxidação lipídica pode haver a formação de um produto de oxidação lipídica com truncamento das cadeias carbônicas, alterando assim a estrutura química do lipídio [16, 17, 99]. O lipídio oxidado PAzPC apresenta uma cadeia alquila truncada na região do carbono 9 contendo grupo terminal carboxila (ver figura 1.5 apresentando assim uma estrutura cônica que dificulta a interação entre carbonos levando a uma consequente instabilidade para a formação de vesículas grandes [56, 58, 99]. 
Neste caminho, foram realizadas análises de espalhameto de luz dinâmico (DLS) para vesículas extrusadas com filtro de 50nm compostas por POPC:PAzPC (50:50) e (33:67). Para essas composições foram obtidos tamanhos de vesículas entre $10 \mathrm{~nm}$ e $15 \mathrm{~nm}$ indicando possível ruptura das mesmas. Dado esse resultado, a continuidade deste estudo foi feita a partir de composições lipídicas com limite máximo de 33mol\% de PAzPC, cujos resultados de DLS indicaram formação de vesículas grandes entre 50nm e 100nm.

Em continuidade com a caracterização de vesículas grandes por SAXS, foram analisados sistemas binários compostos por POPC:PAzPC nas proporções (100:0), (90:10) e (67:33). O perfil de espalhamento para cada composição lipídica está apresentado na figura 5.5 .

Assim como observado na seção anterior para vesículas compostas pelo lipídio oxidado POPC-OOH, o aumento da proporção de PAzPC na membrana modelo gera um deslocamento no primeiro vale da curva de SAXS para maiores ângulos de espalhamento $(q)$, indicando diminuição na espessura total da bicamada lipídica. A quantificação das possíveis alterações estruturais de espessura e densidade eletrônica foram realizadas a partir dos ajustes das curvas de SAXS através do modelo de três regiões de diferentes densidades eletrônicas (polar, regiões de CH2 e CH3) (ver seção 2.3.1). Os resultados estão apresentados na figura 5.6 e tabela 5.4 .

Foi observado um decréscimo da espessura da bicamada lipídica que diminui de 46.4(6) $\AA$

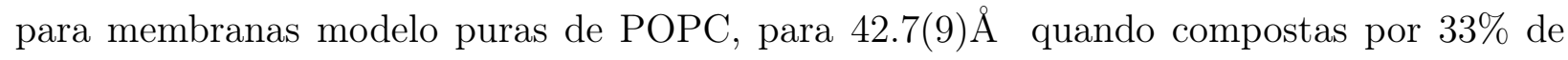

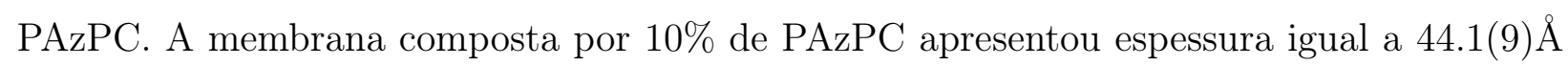
indicando que a concentração do lipídio oxidado PAzPC na composição lipídica da membrana modelo é um fator importante na condição estrutural da membrana. Resultados da literatura mostram efeito semelhante em membranas modelo de POPC com 20\% de PAzPC a partir da técnica de reflectometria de raios-x [58]. 
Vale notar que a espessura total da bicamada lipídica encontrada para vesículas contendo $33 \%$ de PAzPC é similar ao valor obtido para membranas modelo compostas por

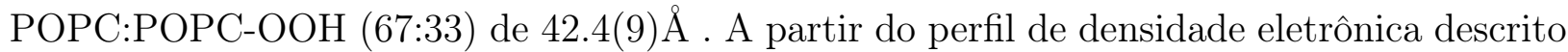
na figura 5.7 é possível perceber que a inclusão de lipídio oxidado (PAzPC ou POPC-OOH), ainda que em baixa quantidade como observado para POPC:PAzPC (90:10) (curva azul), altera claramente os parâmetros de espessura e densidade eletrônica se comparados aos obtidos para vesículas não oxidadas de POPC.

Resultados de dinâmica molecular descritos por Khandélia e colaboradores [56] mostraram que para bicamadas lipídicas de POPC:PAzPC com 25\% de PAzPC o grupo carboxil $\mathrm{COO}^{-}$apresenta duas possíveis localizações na membrana, uma na região de interface bicamada-água e a outra na região hidrofílica ao redor do grupo fosfato. No decorrer desta tese será apresentada a continuidade deste estudo a partir das análises de SAXS via modelo de grupos químicos (ver seção 5.3.2), a qual confirmou a posição do grupo $C O O^{-}$nas regiões hidrofóbica e hidrofílica da membrana modelo [72]. A posição dos grupos oxidados presentes em uma das caudas afeta as interações hidrofóbicas entre carbonos e consequentemente empacotamento dos lipídios, explicando assim a redução na espessura total da bicamada lipídica observada no presente estudo. Uma possível consequência desse efeito é o aumento na fluidez da membrana para composições lipídicas mais oxidadas [1] bem como o aumento de área superficial da membrana [72]. 


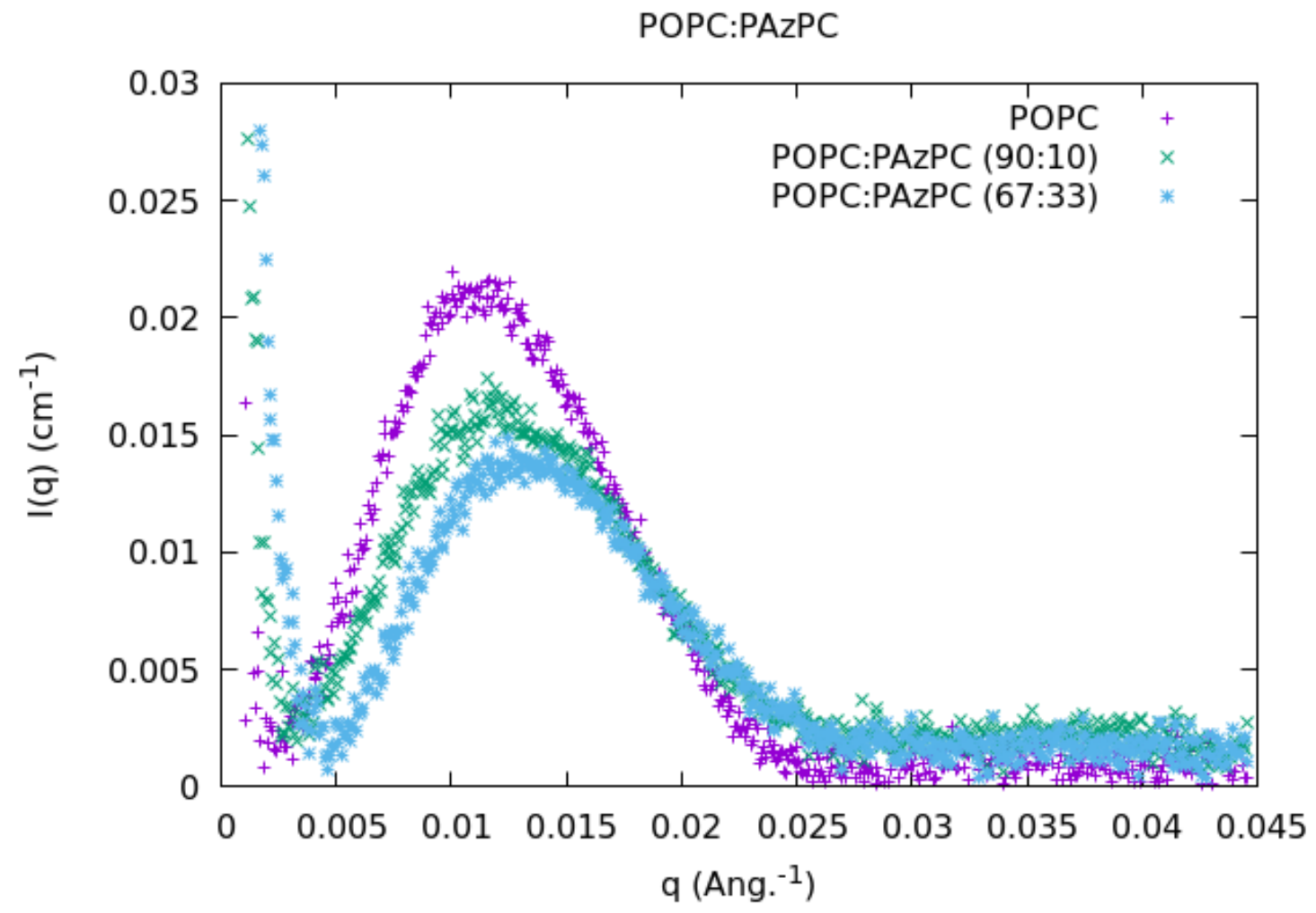

Figura 5.5: Curvas de SAXS de LUVs compostas por POPC:PAzPC com concentração inicial de lipídio igual a $10 \mathrm{mM}$ medidos a $23^{\circ} \mathrm{C}$. O insert apresenta as diferentes razões molares de POPC:PAzPC estudadas. 


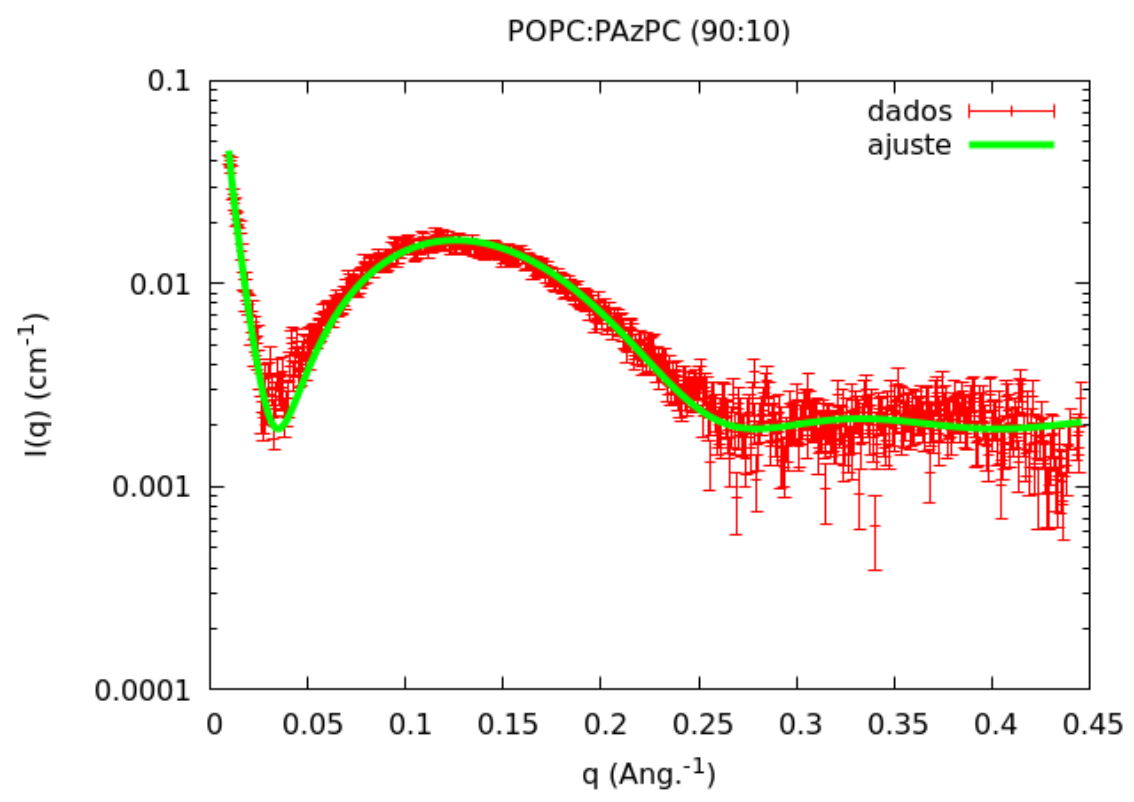

(a)

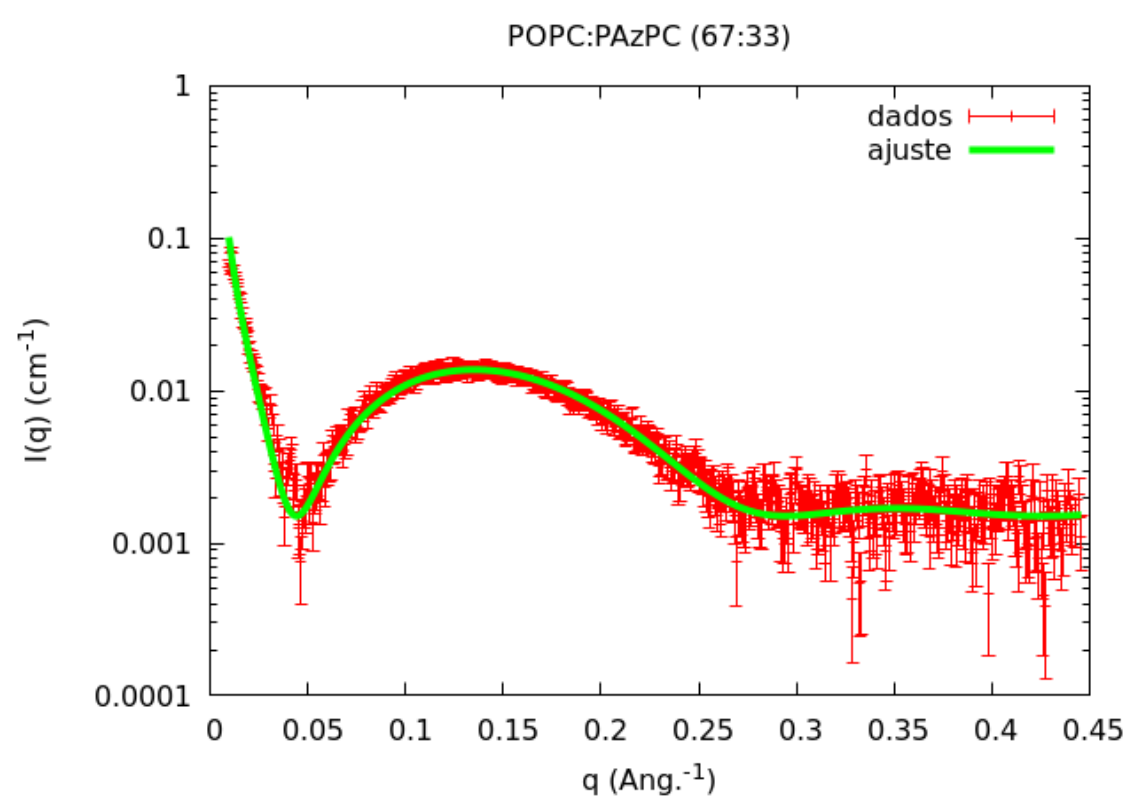

(b)

Figura 5.6: Curvas de SAXS de vesículas grandes compostas por POPC:PAzPC com razões molares a) (90:10) e b) (67:33) com concentração inicial de $10 \mathrm{mM}(+)$ medidos a $23^{\circ} \mathrm{C}$ e melhor ajuste aos dados experimentais obtidos a partir do modelo de lamela infinita com três regiões de densidade eletrônica (ver seção 2.3.1). 
Tabela 5.4: Parâmetros estruturais obtidos a partir dos ajustes apresentados na figura 5.6 . $R_{p o l}, R_{\mathrm{CH}_{2}}$ e $R_{\mathrm{CH}_{3}}$ representam, respectivamente, a espessura da região polar, meio hidrofóbico contendo $\mathrm{CH}_{2}$ e $\mathrm{CH}_{3}$, enquanto $\rho_{\text {pol }}, \rho_{\mathrm{CH}_{2}}$ e $\rho_{\mathrm{CH}_{3}}$ as densidades eletrônicas correspondentes.

\begin{tabular}{cccc}
\hline \multicolumn{4}{c}{ Parâmetros de Ajuste } \\
\hline & POPC & PC:PAzPC $(90: 10)$ & PC:PAzPC (67:33) \\
\hline$R_{\text {pol }}(\AA)$ & $9.3(6)$ & $7.6(5)$ & $8.1(5)$ \\
$R_{C H_{2}}(\AA)$ & $10.9(4)$ & $11.9(3)$ & $10.4(4)$ \\
$R_{C H_{3}}(\AA)$ & $3.0(3)$ & $2.5(1)$ & $2.8(1)$ \\
$\rho_{\text {pol }}\left(e / \AA^{3}\right)$ & $0.417(4)$ & $0.404(4)$ & $0.407(3)$ \\
$\rho_{C H_{2}}\left(e / \AA^{3}\right)$ & $0.297(3)$ & $0.314(2)$ & $0.314(2)$ \\
$\rho_{C H_{3}}\left(e / \AA^{3}\right)$ & $0.198(7)$ & $0.221(5)$ & $0.225(5)$ \\
espessura $(\AA)$ & $46.4(6)$ & $44.1(9)$ & $42.7(9)$ \\
\hline
\end{tabular}




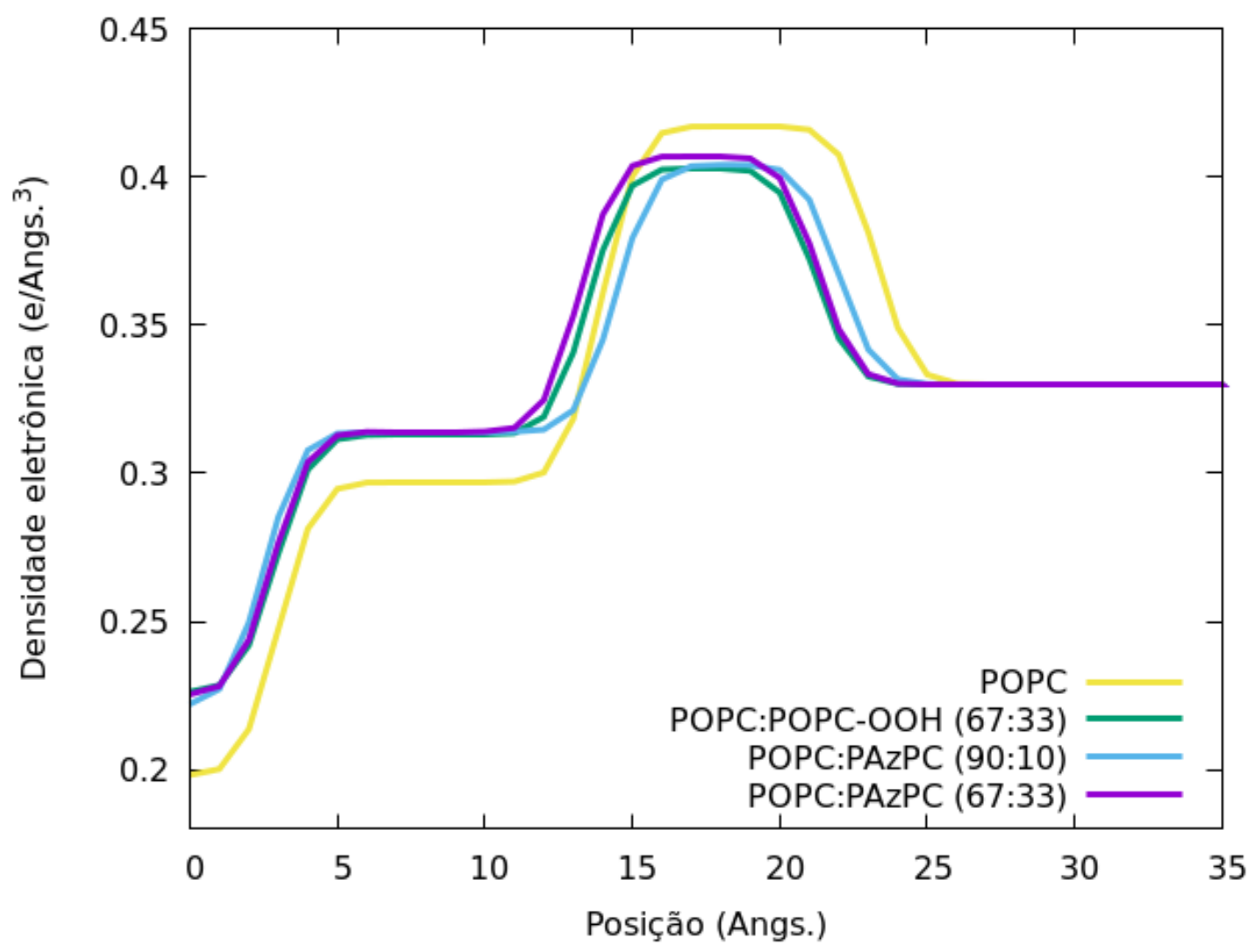

Figura 5.7: Perfil de densidade eletrônica para as vesículas de POPC com e sem lipídio oxidado PAzPC e vesículas compostas por POPC:POPC-OOH (67:33) (curva verde) para comparação de resultados. O insert apresenta as razões molares.

\subsubsection{POPC:POPC-OOH:PAzPC}

Após analisarmos separadamente a influência dos lipídios oxidados POPC-OOH (5.3.1.1) e PAzPC 5.3.1.2 na estrutura física da bicamada lipídica, foi dada continuidade ao estudo a partir de vesículas compostas por POPC na presença de ambos os lipídios oxidados (POPC$\mathrm{OOH}$ e PAzPC).

Seguindo a mesma sequência de análises, foram avaliadas a partir da técnica de SAXS vesículas grandes compostas por POPC:POPC-OOH:PAzPC (60:25:15) e (47:25:28). Como 
pode ser observado a proporção de $\mathrm{PAzPC}$ foi limitada ao valor máximo evidenciado por DLS para formação de vesículas grandes de 33mol\%. Para efeitos de comparação com os resultados obtidos anteriormente, optou-se por manter fixa a quantidade de POPC-OOH em $25 \%$.

Dadas as composições analisadas, temos 2 cenários a serem observados: 1) influência da quantidade de lipídio oxidado na membrana, neste caso representando $40 \%$ e $53 \%$ da bicamada e 2) influência do aumento de PAzPC em membranas contendo uma quantidade fixa de POPC-OOH.

O perfil de espalhamento das curvas de SAXS para as composições em questão, apresentado na figura 5.8, mostram um pequeno deslocamento do primeiro vale para maiores ângulos de espalhamento $(q)$ a medida em que aumentamos a proporção do total de lipídios oxidados na membrana modelo.

Os ajustes teóricos realizados a partir do modelo de lamela infinita com três regiões de densidade eletrônica, apresentados na figura 5.9 e tabela 5.5 , mostraram que os parâmetros de ajuste obtidos para as membranas modelo de POPC/PAzPC contendo $25 \mathrm{~mol} \%$ de POPC-

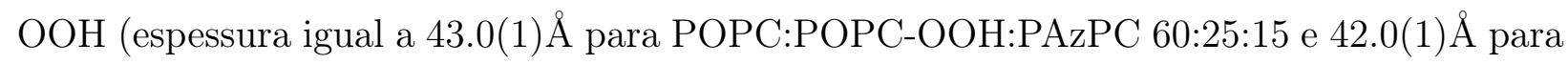
POPC:POPC-OOH:PAzPC 47:25:28) apresentados na tabela 5.5 são similares aos resultados

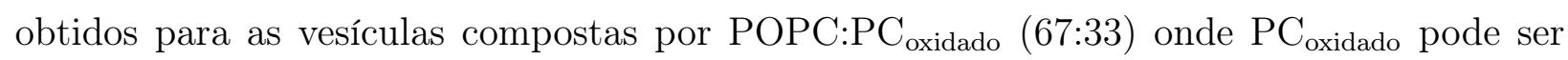
POPC-OOH ou PAzPC. As espessuras obtidas para POPC:POPC-OOH e POPC:PAzPC

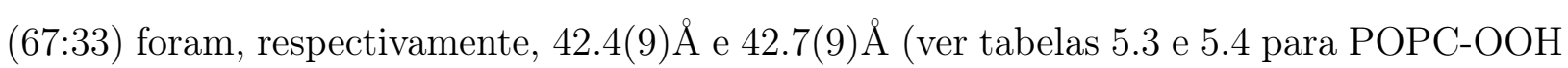
e PAzPC, respectivamente).

A partir da distribuição de densidade eletrônica, apresentada na figura 5.10, é possível notar que as composições ternárias apresentaram menor densidade eletrônica na região do

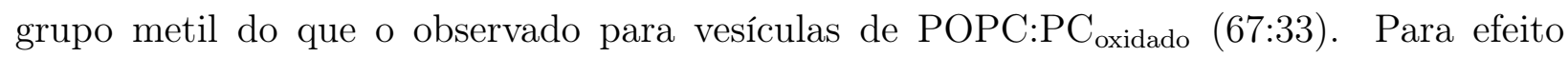


de comparação, incluimos também o perfil de densidade eletrônica da composição binária POPC:POPC-OOH (33:67), cuja razão molar de lipídio oxidado (67mol\%) é mais próxima do máximo considerado em nosso sistema ternário (53mol\%). Para vesículas compostas por POPC:POPC-OOH (33:67) a densidade eletrônica da região $\mathrm{CH}_{3}$ foi a mesma que a

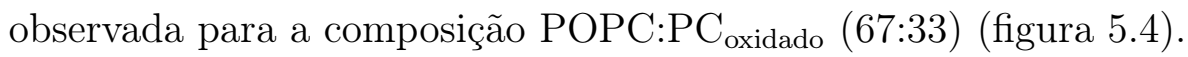

Em síntese, os dois sistemas ternários analisados apresentam parâmetros de espessura equivalentes aos obtidos para os sistemas binários de POPC com 33\% de lipídio oxidado, contudo apresentaram menor densidade eletrônica na região do grupo metil ainda que comparado ao sistema POPC com $67 \%$ de POPC-OOH. Tal resultado indica que a variação de densidade eletrônica na região $\mathrm{CH}_{3}$ é devida a presença dos dois lipídios oxidados POPC$\mathrm{OOH}$ e PAzPC na membrana modelo. 
Vesículas de POPC com 2 lipídios oxidados

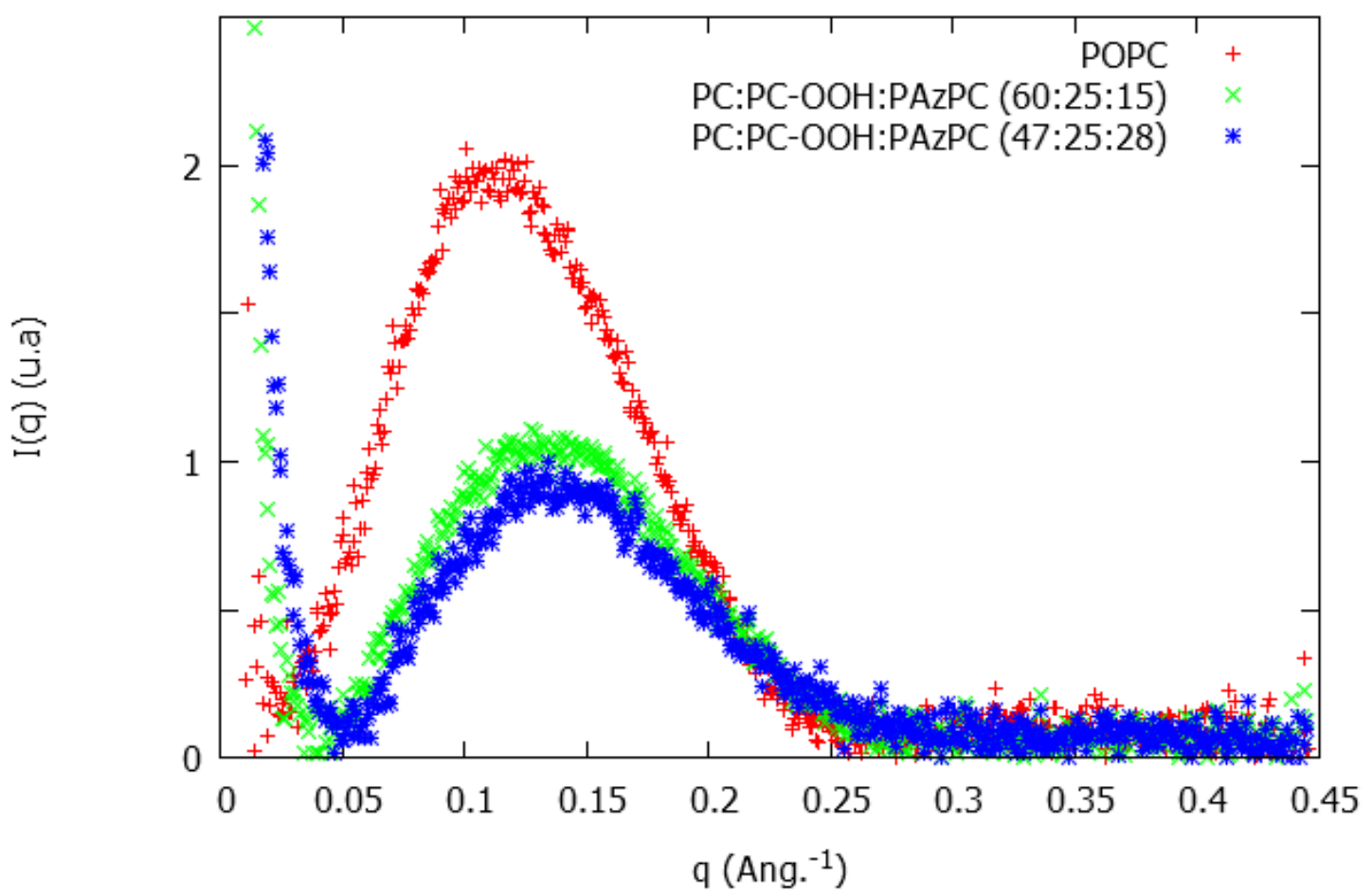

Figura 5.8: Curvas de SAXS de LUVs compostas por POPC:POPC-OOH:PAzPC com concentração inicial de lipídio igual a $10 \mathrm{mM}$ medidos a $23^{\circ} \mathrm{C}$. O insert apresenta as diferentes razões molares estudadas. 


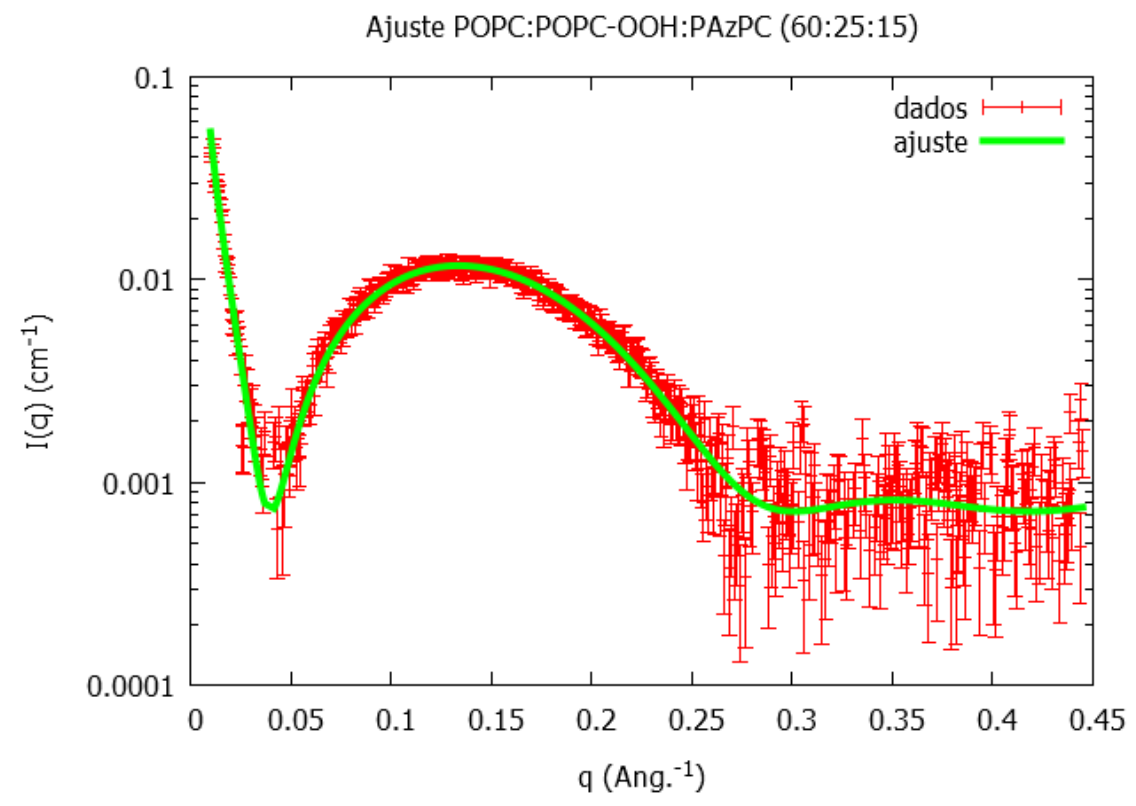

(a)

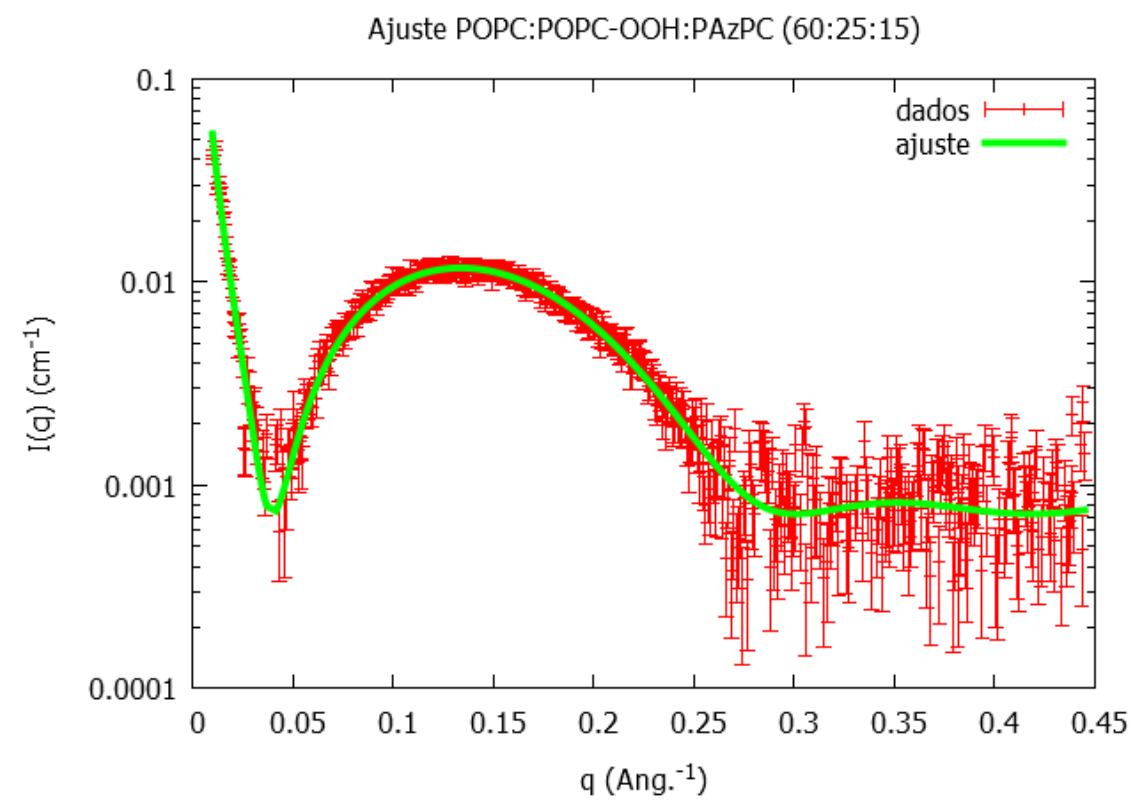

(b)

Figura 5.9: Curvas de SAXS de vesículas grandes compostas por POPC:POPCOOH:PAzPC com razões molares a) (60:25:15) e b) (47:25:28) com concentração inicial de $10 \mathrm{mM}(+)$ medidos a $23^{\circ} \mathrm{C}$ e melhor ajuste aos dados experimentais obtidos a partir do modelo de lamela infinita com três regiões de densidade eletrônica (ver seção 2.3.1). 
Tabela 5.5: Parâmetros estruturais obtidos a partir dos ajustes apresentados na figura 5.9. $R_{p o l}, R_{\mathrm{CH}_{2}}$ e $R_{\mathrm{CH}_{3}}$ representam, respectivamente, a espessura da região polar, meio hidrofóbico contendo $\mathrm{CH}_{2}$ e $\mathrm{CH}_{3}$, enquanto $\rho_{\text {pol }}, \rho_{\mathrm{CH}_{2}}$ e $\rho_{\mathrm{CH}_{3}}$ as densidades eletrônicas correspondentes.

\begin{tabular}{cccc}
\hline & Parâmetros de Ajuste \\
\hline & POPC & POPC:POPC-OOH:PAzPC & POPC:POPC-OOH:PAzPC \\
& $(100: 0: 0)$ & $(60: 25: 15)$ & $(47: 25: 28)$ \\
\hline$R_{\text {pol }}(\AA)$ & $9.3(6)$ & $8.3(2)$ & $8.0(3)$ \\
$R_{C H_{2}}(\AA)$ & $10.9(4)$ & $10.3(2)$ & $10.2(2)$ \\
$R_{C H_{3}}(\AA)$ & $3.0(3)$ & $2.9(1)$ & $2.8(1)$ \\
$\rho_{\text {pol }}\left(e / \AA^{3}\right)$ & $0.417(4)$ & $0.410(2)$ & $0.408(3)$ \\
$\rho_{C H_{2}}\left(e / \AA^{3}\right)$ & $0.297(3)$ & $0.314(1)$ & $0.320(2)$ \\
$\rho_{C H_{3}}\left(e / \AA^{3}\right)$ & $0.198(7)$ & $0.204(3)$ & $0.208(4)$ \\
espessura $(\AA)$ & $46.4(6)$ & $43.0(1)$ & $42.0(1)$ \\
\hline
\end{tabular}


Mudanças estruturais impostas pela inclusão de lipídios oxidados em membranas modelo

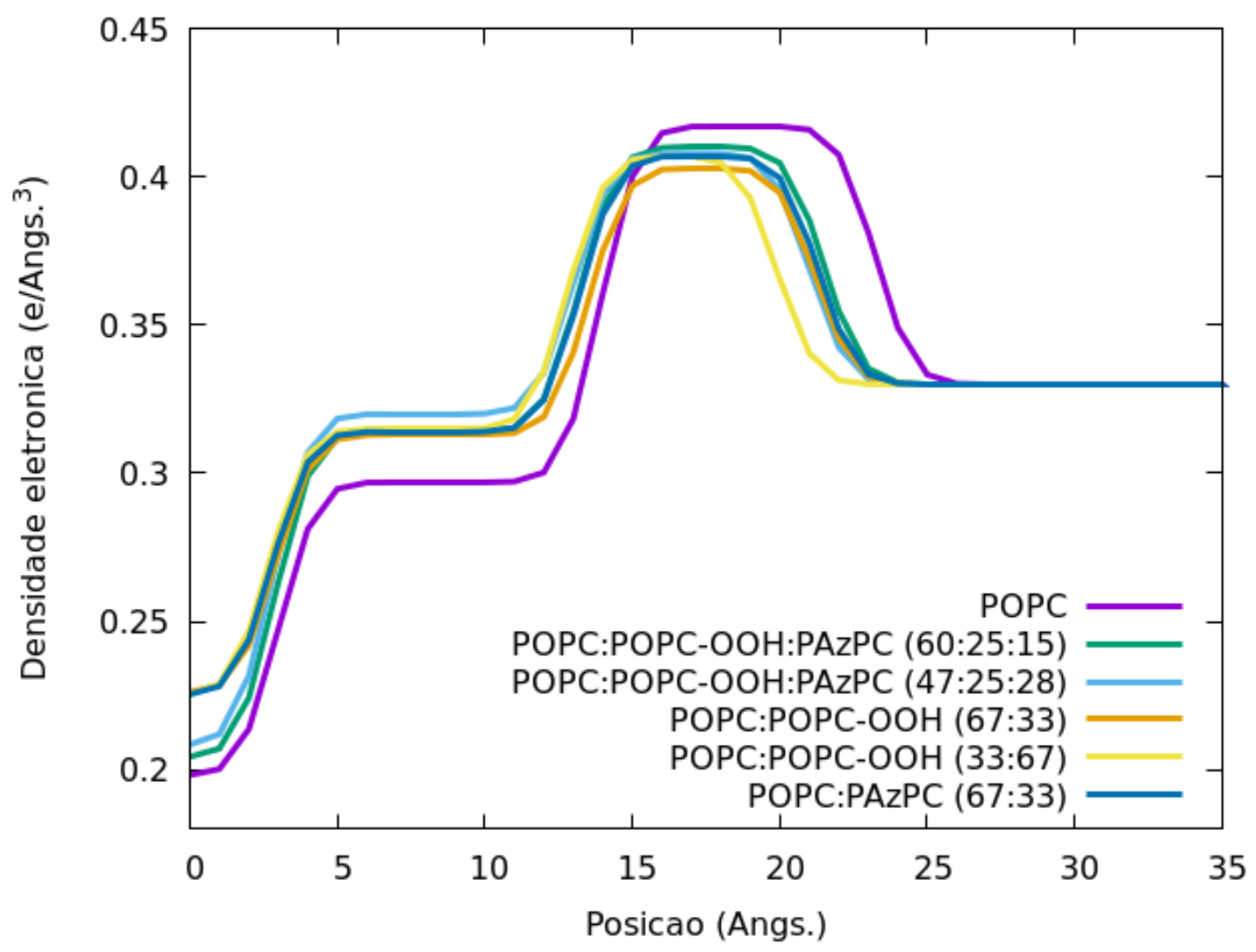

Figura 5.10: Perfil de densidade eletrônica para as vesículas compostas por: POPC:POPC-

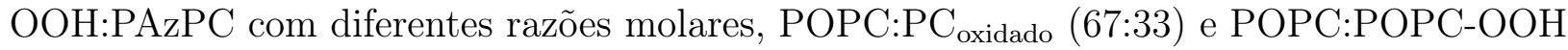
(33:67). O insert apresenta as razões molares de cada composição lipídica.

\subsubsection{Análise de membranas modelo compostas por POPC:POPC-} OOH e POPC:PAzPC a partir do modelo de grupos químicos

Nesta seção serão apresentados os resultados e discussão referente às análises das curvas de SAXS dos sistemas compostos por POPC:POPC-OOH e POPC:PAzPC a partir do modelo de grupos químicos do software GENFIT [65], descrito na seção 2.3.2. 
O perfil de espalhamento das curvas de SAXS, bem como o melhor ajuste aos dados experimentais obtido a partir do ajuste global estão apresentados na figura 5.11. Em primeira análise, observa-se que os perfis de espalhamento para as diferentes composições são similares, com pico central posicionado em $q \approx 0.12 \AA^{-1}$. Os dois vales observados apresentam aproximadamente mesma intensidade de espalhamento $I(q)$ indicando a falta de poros ou domínios [100], ou seja, os sistemas podem ser considerados homogêneos [60, 78] de modo que podemos utilizar um único fator de forma $P(q)$ para as análises.

Os grupos químicos dos lipídios utilizados nesse estudo (seção 5.2) podem ser separados a partir da sua localização nas regiões polar e apolar da bicamada lipídica. Na região polar se encontram os grupos $\mathrm{CG}, \mathrm{PCN}$ e $\mathrm{CholCH}_{3}$, já na região hidrofóbica temos os grupos $\mathrm{CH}_{2}, \mathrm{CH}_{3}$ e $\mathrm{CH}$. Com relação aos grupos oxidados do POPC-OOH (referido como PX o qual inclui também os cabonos insaturados $\mathrm{CHCH}$ ) e PAzPC (referido como $\mathrm{CX}$ ) até o momento da finalização deste trabalho ainda não haviam evidências experimentais das suas localizações na membrana, sendo assim, para os ajustes foi considerada a possibilidade de os mesmos serem encontrados em ambas as regiões hidrofóbica (referido como $\mathrm{PX}_{\text {hyd }}$ ou $\mathrm{CX}_{\text {hyd }}$ ) e polar $\left(\mathrm{PX}_{\mathrm{pol}}\right.$ ou $\left.\mathrm{CX}_{\mathrm{pol}}\right)$. Neste caminho, definimos $x_{\mathrm{pol}}$ como a fração do total de grupos oxidados $(\mathrm{X}=\mathrm{PX}$ ou $\mathrm{X}=\mathrm{CX})$ que se localiza na região polar.

A tabela 5.6 apresenta os parâmetros obtidos a partir do ajuste global onde: $\kappa$ indica o fator de escala, adicionado para corrigir possíveis erros de calibração do instrumento; $A$ representa a área por lipídio; $x_{\text {pol }}$ é a fração de grupo oxidado na região polar; $D_{\text {hyd }}$ respresenta a espessura da monocamada hidrofóbica e $f_{i}$ é um fator multiplicativo sendo esse o real parâmetro de ajuste. A posição do pico de cada grupo químico é descrita a partir dos parâmetros de ajuste como $z_{i}=f_{i} D_{\text {hyd }}$, exceto o grupo terminal $\mathrm{CH}_{3}$ que foi mantido fixo em $z=0$. 
Apesar da grande quantidade de parâmetros ajustados, é importante notar que o ajuste global foi realizado a partir de dois únicos fatores de escala $\kappa$ (apresentado na tabela 5.6), reduzindo assim o intervalo possível de parâmetros que poderiam gerar um bom ajuste. Outra consideração importante foi o ajuste da membrana composta por POPC puro, cujos parâmetros são comuns para as membranas modelo oxidadas. Essas restrições foram necessárias para garantirmos a robustês do ajuste com resultados de relevância física.

A representação gráfica dos resultados obtidos (tabela 5.6) estão apresentados nas figuras 5.12, 5.13 e 5.14. Na figura 5.12 estão apresentadas a fração de volume da cada grupo químico em função da proporção $x$ de lipído oxidado. Para os grupos oxidados $(\mathrm{X}=\mathrm{PX}$ ou $\mathrm{X}=\mathrm{CX}$ ) o volume apresentado é composto pela contribuição das regiões polar e apolar de modo que $\varphi_{\mathrm{X}}(z)=\varphi_{\mathrm{X}_{\mathrm{hyd}}}(z)+\varphi_{\mathrm{X}_{\mathrm{pol}}}(z)$. A figura 5.13 apresenta a dependência da posição de cada grupo químico $\left(z_{i}\right)$ em relação à fração de lipídio oxidado $(x)$ para as duas misturas $\mathrm{POPC}_{1-x} \mathrm{POPC} \mathrm{OOH}_{x}$ (imagem à direita) e $\mathrm{POPC}_{1-x} \mathrm{PAzPC}_{x}$ (imagem à esquerda). Por fim, as figuras 5.14 e 5.15 mostram, respectivamente, a distribuição de densidade eletrônica de cada grupo e densidade total longo da bicamada lipídica $(z)$ e o comparativo entre as densidades totais variando a concentração e tipo de lipídio oxidado.

A partir dos resultados apresentados na tabela 5.6 pode-se verificar que $0.95 \pm 0.02$ dos grupos oxidados das vesículas compostas por $\mathrm{POPC}_{1-x} \mathrm{POPC}^{-} \mathrm{OOH}_{x} x_{\mathrm{pol}}$ se encontram na região polar $\left(x_{\text {pol }}\right)$, enquanto apenas $5 \%$ permanece na parte hidrofóbica da membrana modelo, mais especificamente na interface bicamada-água $\left(f_{\mathrm{PX}_{\mathrm{hyd}}}=0.96 \pm 0.02\right)$. Este resultado difere do reportado por Guo et al. que observou a partir de dinâmica molecular [48] uma distribuição bimodal para o grupo hidroperóxido com localizações na região interna da bicamada lipídica e na interface bicamada-água. Pode ser observado, a partir da figura 
5.12 e 5.13 , que a posição do grupo do hidroperóxido na região polar $z_{\mathrm{PX}_{\mathrm{pol}}}$ variou de 16 a $14 \AA$ a medida em que aumentamos razão molar de POPC-OOH na membrana de $33 \%$ para 100\%. Como consequência, é observado um decréscimo na espessura da região hidrofóbica $D_{\text {hyd }}$ que varia de $14.5 \AA$ para membranas modelo puras de POPC para $11.2 \AA$ para membranas modelo com $100 \%$ de POPC-OOH. O resultado obtido para $D_{\text {hyd }}$ está em bom acordo com dados da literatura [96]. Portanto, o deslocamento do grupo hidroperóxido para valores menores de posição $z$ está diretamente relacionado à diminuição na espessura da bicamada lipídica devido à oxidação. Tal característica também pode ser obervada a partir do deslocamento dos grupos $\mathrm{CG}, \mathrm{PCN}, \mathrm{CholCH}_{3}$ e $\mathrm{CH}_{2}$ com o aumento da proporção de POPC-OOH na membrana (figuras 5.12 e 5.13). Como consequência, houve uma redução de aproximadamente $20 \%$ na distância entre as duas monocamadas, dada pela posição z do pico de máxima densidade eletrônica do grupo PCN (figura 5.14) a medida em ocorre o aumento de POPC-OOH na composição. Vale ressaltar que essa dimiuição de espessura já havia sido prevista em simulações de dinâmica molecular [10, 48] porém em menor grau $(\sim 10 \%)$ do que o observado experimentalmente neste trabalho.

Foi observado também aumento de área $A$ por lipídio, que variou de $65.4 \pm 0.4 \AA^{2}$ para $78 \pm 2 \AA^{2}$ com o aumento de POPC-OOH na membrana (tabela 5.6). Embora o resultado obtido para POPC $\left(A=65.4 \pm 0.4 \AA^{2}\right)$ seja um pouco maior do que o reportado na literatura a partir de evidências experimentais $62.7 \AA^{2}$ [101], está em bom acordo com os descritos a partir de simulação de MD [47, 48]. Com relação às membranas oxidadas, o aumento de área observado está em acordo com a expansão observada em GUVs via técnica de microaspiração [20] e simulações de MD [10, 48].

Considerando agora os resultados obtidos para vesículas compostas por $\mathrm{POPC}_{1-x} \mathrm{PAzPC}_{x}$, 
foi observado valor de $x_{\mathrm{pol}}=0.59 \pm 0.04$, indicando que grande parte do grupo caboxila do PAzPC (descrito como CX) se localiza na região hidrofóbica da membrana. A partir da posição $z$ apresentada nas figuras 5.12 e 5.13 é possível verificar que, similar ao observado para POPC-OOH, o grupo $\mathrm{CX}_{\text {pol }}$ apresenta afinidade pelos grupos $\mathrm{CG}$ e PCN, por outro lado a parcela oxidada $\mathrm{CX}_{\text {hyd }}$ se encontra no meio da região hidrofóbica $\left(f_{\mathrm{CX}_{\mathrm{hyd}}}=0.57 \pm 0.09\right.$ recordando que $\left.z_{\mathrm{CX}_{\mathrm{hyd}}}=f_{\mathrm{CX}_{\mathrm{hyd}}} D_{\text {hyd }}\right)$. Essa característica bimodal da posição $z$ do grupo CX fica evidente na figura 5.12. Khandélia e Mouritsen [56] observaram a partir de simulações de MD uma completa reversão da orientação da cadeia truncada do PAzPC, expondo assim o grupo carboxil na região polar, resultado esse dependente da concentração do referido lipídio oxidado. Por outro lado, nossos resultados mostraram que para concentrações de até 33 mol \% de PAzPC a partição do grupo CX é a mesma. É interessante notar que embora os valores de espessura $D_{\text {hyd }}, D_{B} / 2$ e $D$ sejam similares aos observados para membranas modelo de $\mathrm{POPC}_{1-x} \mathrm{POPC}-\mathrm{OOH}_{x}$ com $x=0.33$, o aumento de área foi significantemente menor: $73 \pm 3 \AA^{2}$ e $67 \pm 2 \AA^{2}$ (tabela 5.6 ) para membranas modelo contendo $33 \%$ de POPC$\mathrm{OOH}$ e PAzPC, respectivamente. Esse resultado mostra que a geometria do lipídio possui um papel importante na na área ocupada pelo mesmo, e consequentemente na estrutura da membrana. Vale ressaltar que a oxidação lipídica nos sistemas analisados não promove a penetração profunda de água no interior da bicamada lipídica com relação ao observado para POPC puro (figura 5.12), em acordo com o observado em experimentos de GUVs compostas por POPC e POPC-OOH [20]. Por outro lado, resultados da literatura indicam alterações na permeabilidade de membranas modelo em sistemas contendo lipídios de cadeia truncada [55, 53, 54], contudo tal efeito não foi observado neste trabalho. 

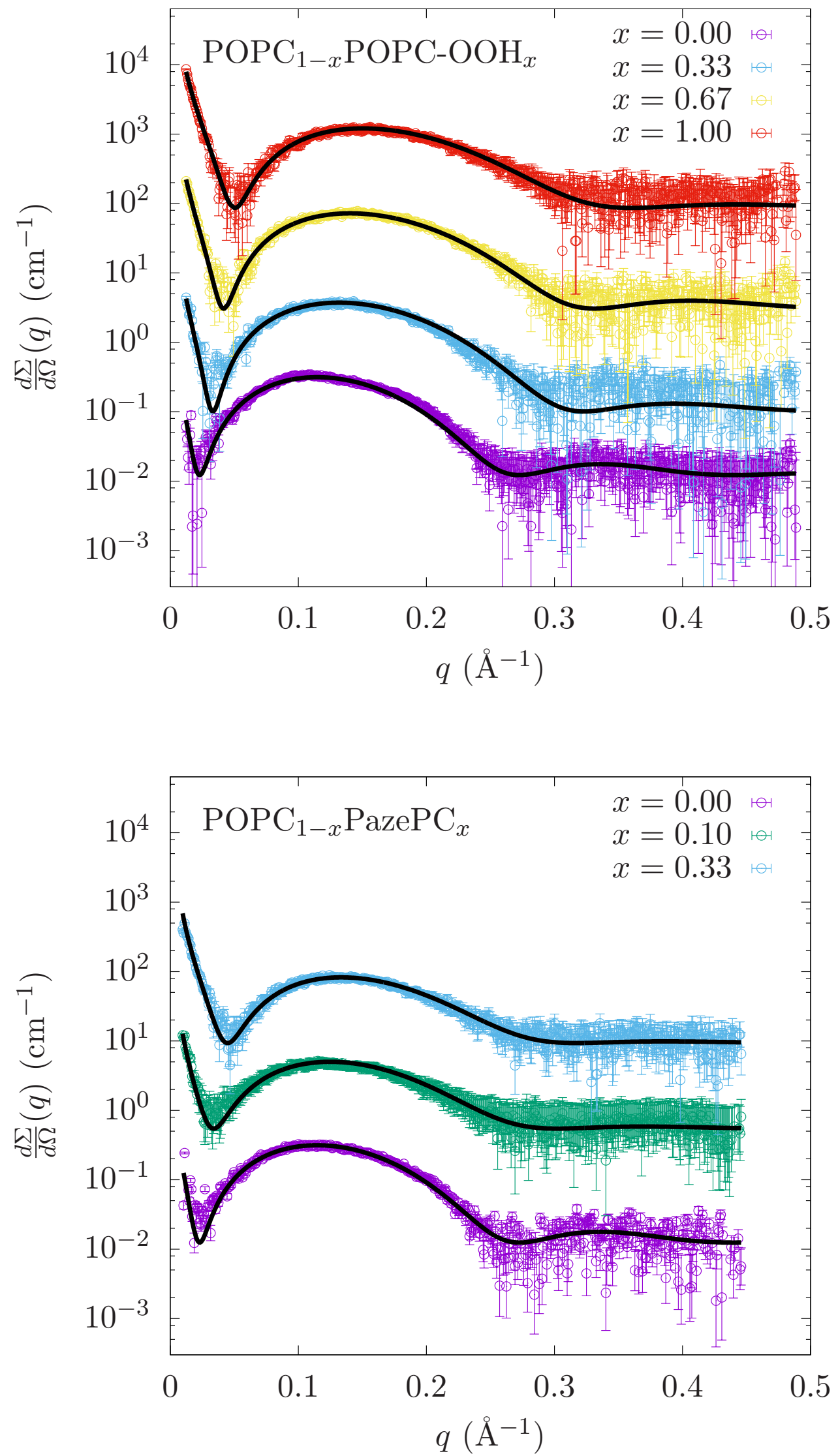

Figura 5.11: Curvas de SAXS de vesículas grandes de POPC-OOH (imagem superior) e PAzPC (imagem inferior). Os pontos representam a curva experimental e a linha contínua preta o melhor ajuste obtido a partir do ajuste global. As curvas estão deslocadas entre si por um fator de 20 para facilitar a visualização. 
Tabela 5.6: Parâmetros de ajuste obtidos a partir do ajuste global das curvas de SAXS apresentadas na figura 5.11. As unidades de comprimento e área são respectivamente $\AA$ e $\AA^{2}$.

\begin{tabular}{|c|c|c|c|c|c|c|c|}
\hline & \multicolumn{4}{|c|}{ POPC $_{1-x}$ POPC-OOH $_{x}$} & \multicolumn{3}{|c|}{ POPC $_{1-x}$ PAzPC $_{x}$} \\
\hline$\kappa$ & \multicolumn{4}{|c|}{$5.4 \pm 0.2$} & \multicolumn{3}{|c|}{$6.7 \pm 0.3$} \\
\hline$x$ & 0.00 & 0.33 & 0.67 & 1.00 & 0.00 & 0.10 & 0.33 \\
\hline$A$ & $65.4(4)$ & $73(1)$ & $73(3)$ & $78(2)$ & $65.4(4)$ & $69(1)$ & $67(2)$ \\
\hline$x_{\mathrm{pol}}$ & - & $0.95(2)$ & $0.95(2)$ & $0.95(2)$ & - & $0.59(4)$ & $0.59(4)$ \\
\hline$f_{\mathrm{CH}}$ & $0.65(2)$ & $0.64(2)$ & $0.65(3)$ & - & $0.65(2)$ & $0.65(2)$ & $0.65(2)$ \\
\hline$f_{\mathrm{X}_{\mathrm{hyd}}}$ & - & $0.96(2)$ & $0.97(2)$ & $0.97(2)$ & - & $0.57(9)$ & $0.57(9)$ \\
\hline$f_{\mathrm{CG}}$ & $1.22(3)$ & $1.20(2)$ & $1.21(6)$ & $1.22(5)$ & $1.22(3)$ & $1.19(2)$ & $1.19(3)$ \\
\hline$f_{\mathrm{PCN}}$ & $1.27(4)$ & $1.20(3)$ & $1.22(8)$ & $1.22(8)$ & $1.27(4)$ & $1.22(4)$ & $1.22(6)$ \\
\hline$f_{\mathrm{CholCH}_{3}}$ & $1.49(7)$ & $1.40(5)$ & $1.5(1)$ & $1.5(1)$ & $1.49(7)$ & $1.41(7)$ & $1.4(1)$ \\
\hline$f_{\mathrm{X}_{\mathrm{pol}}}$ & - & $1.26(9)$ & $1.25(8)$ & $1.24(9)$ & - & $1.3(2)$ & $1.3(2)$ \\
\hline $2 D_{\text {hyd }}$ & $28.9(2)$ & $25.3(5)$ & $24(1)$ & $22.4(7)$ & $28.9(2)$ & $26.7(5)$ & $25.3(7)$ \\
\hline$D_{B}$ & $39.0(2)$ & $35.1(6)$ & $35(2)$ & $33(1)$ & $39.0(2)$ & $36.4(6)$ & $35.4(9)$ \\
\hline $2 D$ & $59(2)$ & $53(2)$ & $52(2)$ & $50(2)$ & $59(2)$ & $55(2)$ & $54(2)$ \\
\hline
\end{tabular}




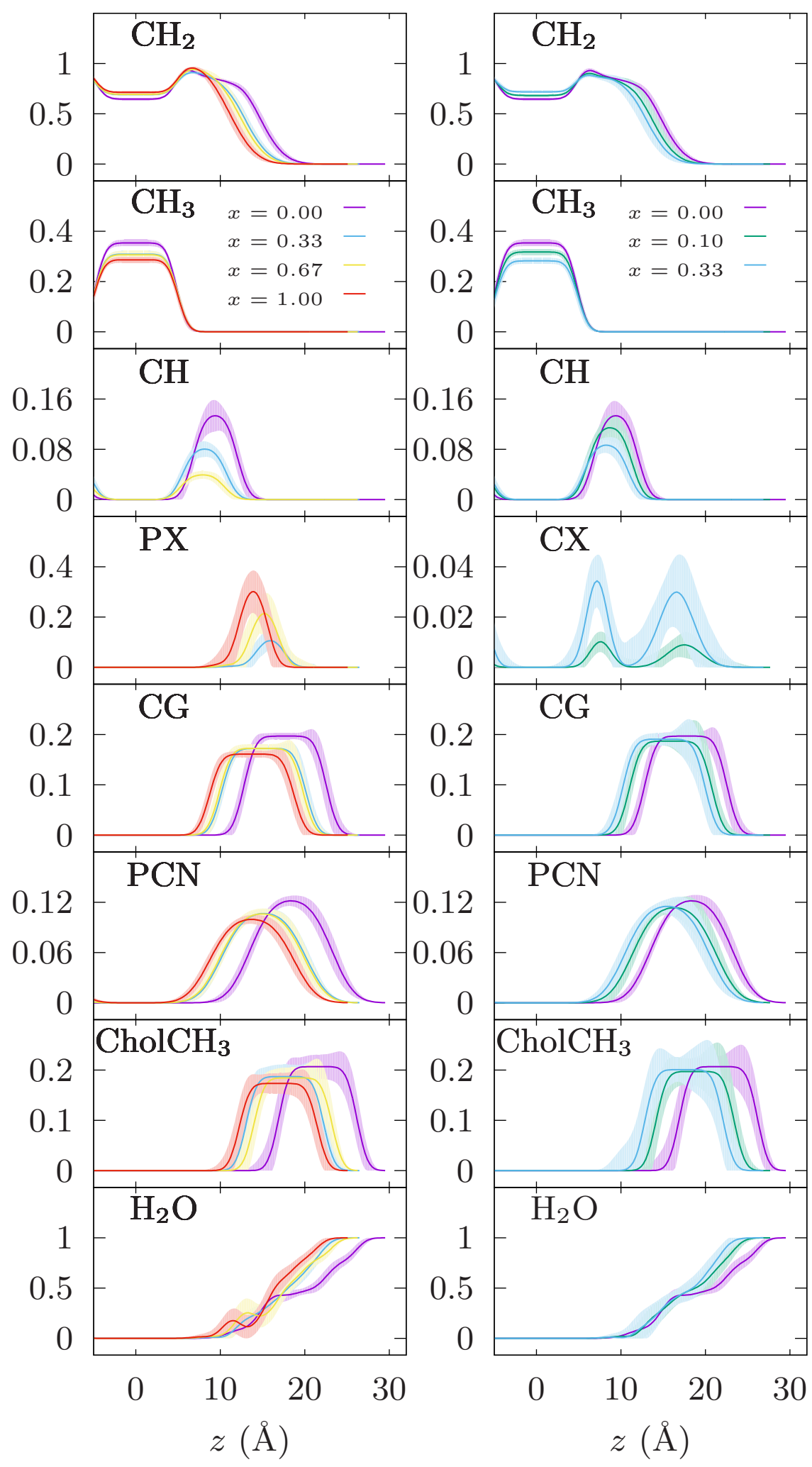

Figura 5.12: Fração de volume dos grupos químicos obtidos a partir da análise das curvas de SAXS apresentadas na figura 5.11 em função da proporção $x$ de POPC-OOH (imagem à esquerda) e PAzPC (imagem à direita). A sombra colorida ao redor das linhas indicam o desvio padrão, obtido a partir de 20 iterações do ajuste global. 


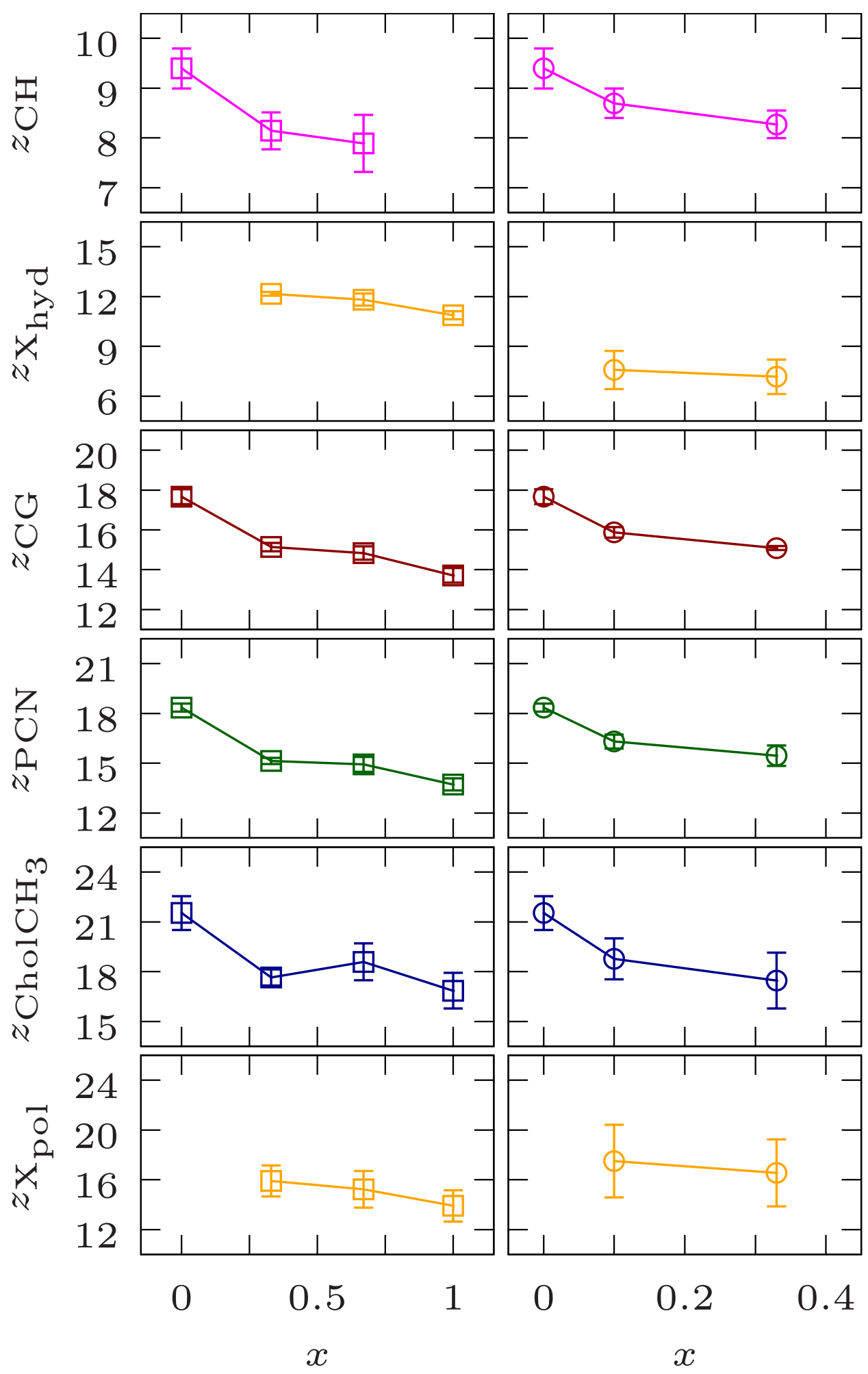

Figura 5.13: Dependência da posição de cada grupo químico $z_{i}$ em relação à fração de lipídio oxidado na membrana modelo $x$ para $\mathrm{POPC}-\mathrm{OOH}$ (imagem à esquerda) e PAzPC (imagem à direita), obtidos a partir do ajuste global das curvas de SAXS apresentadas na figura 5.11. A unidade de $z_{i}$ é $\AA$. O índice $\mathrm{X}$ indica os grupos oxidados PX e CX para o $\mathrm{POPC}-\mathrm{OOH}$ e o $\mathrm{PAzPC}$, respectivamente. 

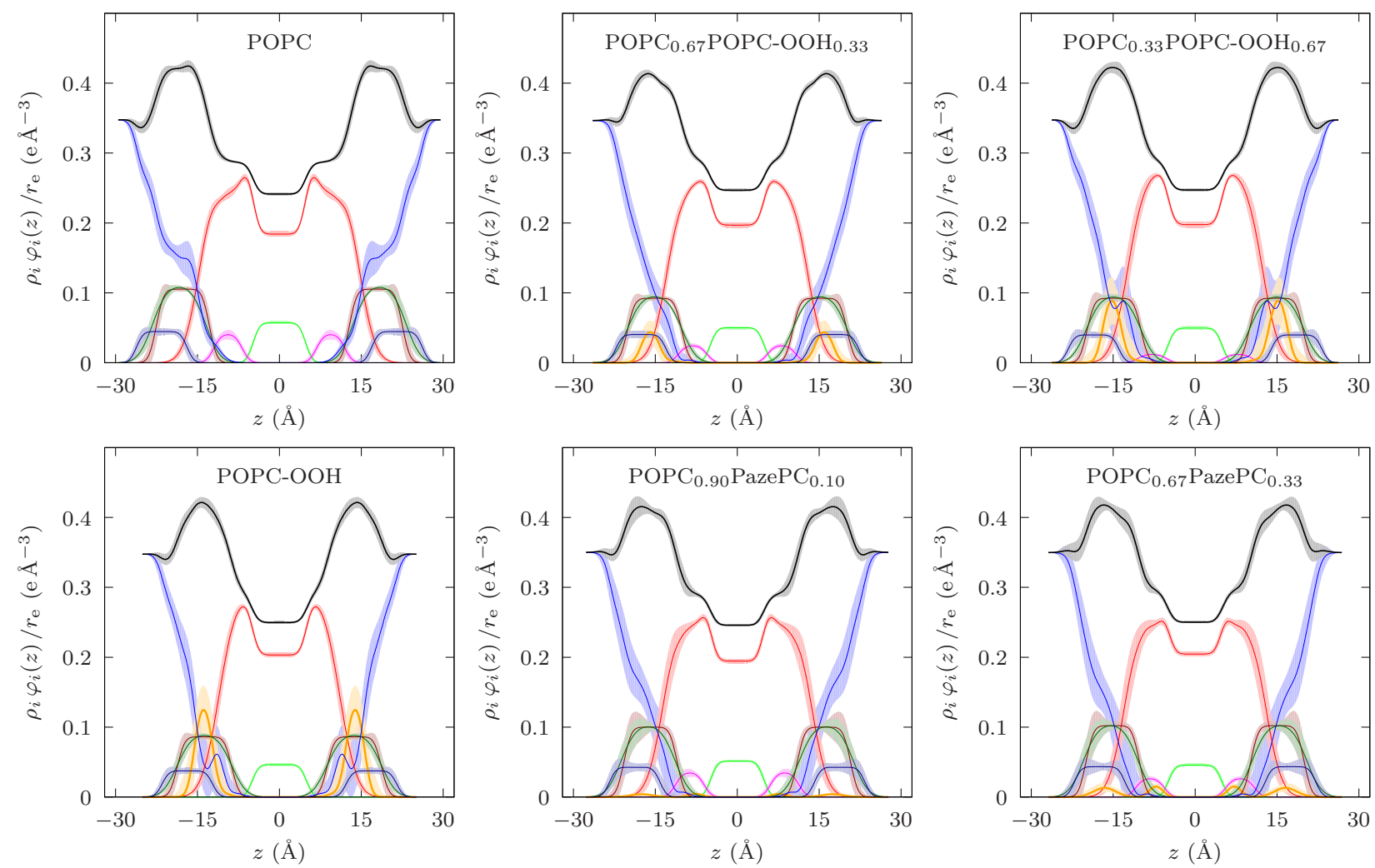

Figura 5.14: Densidade eletrônica dos grupos químicos obtida a partir da análise das curvas de SAXS apresentadas na figura 5.11. As cores são referentes a: $\mathrm{CH}_{2}$ (vermelho), $\mathrm{CH}_{3}$ (verde), $\mathrm{CH}$ (magenta), X (laranja), $\mathrm{CG}$ (grupo glicerol $(\mathrm{CH})\left[\left(\mathrm{CH}_{2}\right)(\mathrm{COO})\right]_{2}$, vermelho escuro), PCN (grupos fosfato e nitrogênio $\left(\mathrm{PO}_{4}^{-}\right)\left(\mathrm{CH}_{2}\right)_{2} \mathrm{~N}^{+}$, verde escuro), $\mathrm{CholCH}_{3}$ (metilenos do grupo colina $\left(\mathrm{CH}_{3}\right)_{3}$, azul escuro), $\mathrm{H}_{2} \mathrm{O}$ (azul). As linhas pretas no topo da imagem representam a densidade eletrônica do sistema. 


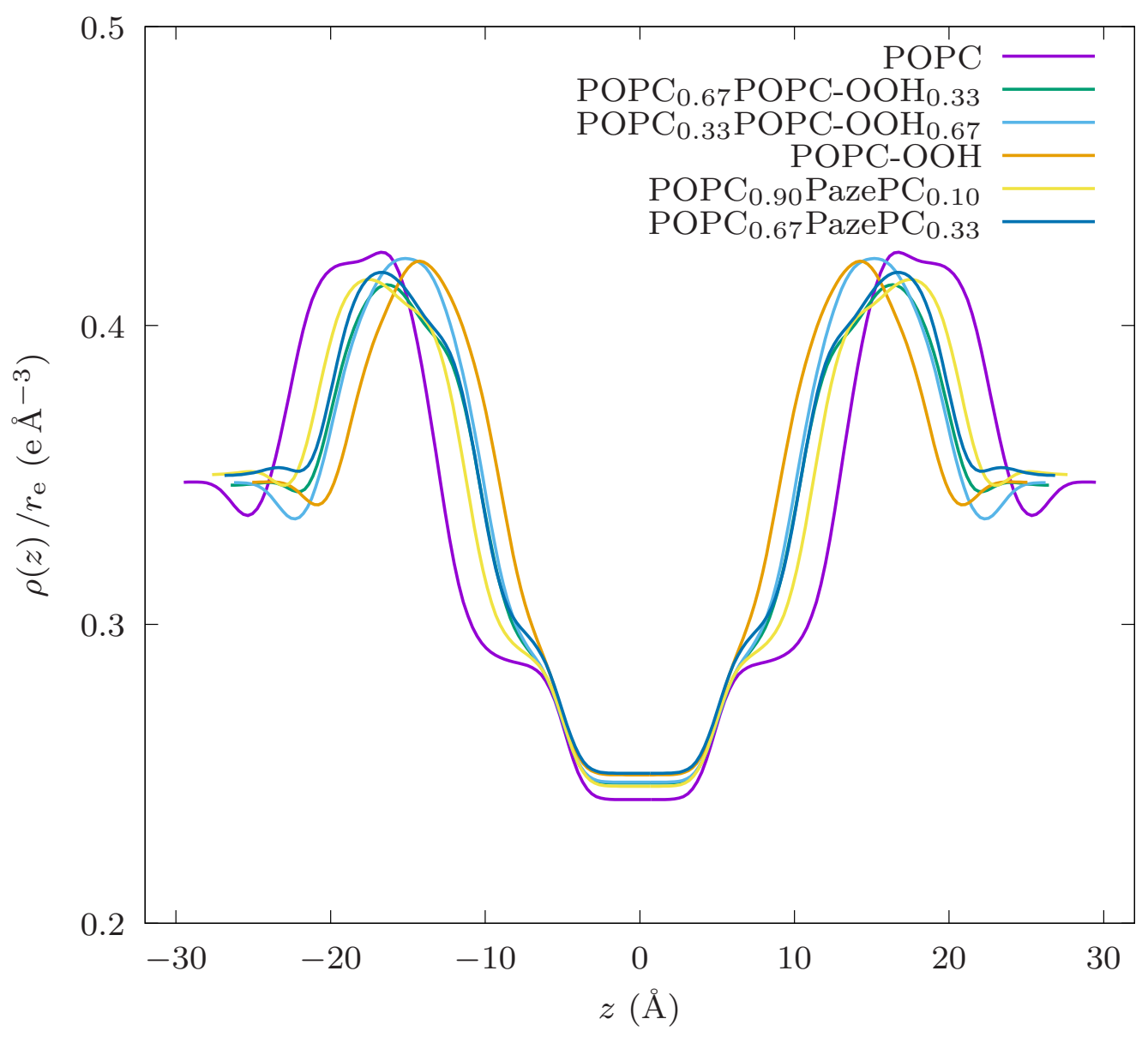

Figura 5.15: Perfil de densidade eletrônica obtido a partir da análise das curvas de SAXS de membranas modelo compostas por $\mathrm{POPC}_{1-x} \mathrm{POPC}^{-\mathrm{OOH}_{x}}(\operatorname{com} x=0.00,0.33,0.67 \mathrm{e}$ $1.00)$ e $\mathrm{POPC}_{1-x} \mathrm{PAzPC}_{x}(\operatorname{com} x=0.00,0.10$ e 0.33$)$.

\subsection{Conclusão}

O estudo de caracterização de membranas modelo compostas por lipídio oxidado a partir do modelo de três niveis de diferente densidade eletrônica mostrou que, no caso de sistemas compostos por POPC e lipídio oxidado POPC-OOH, o aumento da proporção de POPCOOH na membrana modelo leva a um decréscimo significativo da espessura da bicamada

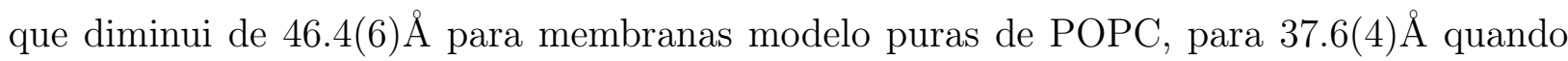


compostas por $100 \%$ de POPC-OOH , representando uma variação de 8.8(7) ̊. Para as composições lipídicas intermediárias, com 33\% e 67\% de POPC-OOH, as espessuras obtidas

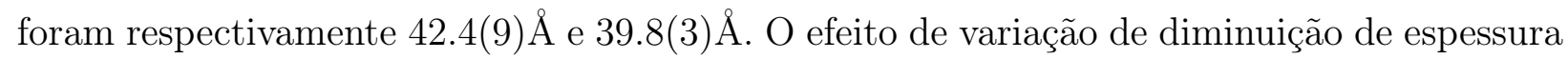
observado está em bom acordo com resultados de dinâmica molecular descritos na literaturua [49, 98, 72]. Em sequência, a análise via modelo de grupos químicos mostrou que o grupo hidroperóxido do POPC-OOH se encontra preferencialmente na região polar da membrana, próximos aos grupos carbonil e fosfato. Membranas modelo com maior grau de oxidação apresentaram também aumento na área por lipídio com variação de $A=65.4 \pm 0.4 \AA^{2}$ para POPC puro e $A=78 \pm 2 \AA^{2}$ para $100 \%$ de POPC-OOH e diminuição da espessura total de hidratação $2 D_{\text {hyd }}$ que variou de $28.9 \pm 0.2 \AA$ para $22.4 \pm 0.7 \AA$. A relação entre oxidação lipídica e aumento de área já havia sido observada em trabalhos anteriores com GUVs [22, 20]. Por outro lado, o decréscimo da espessura da bicamada lipídica devido à oxidação foi quantificado pela primeira vez neste trabalho, o que resultou na publicação do artigo científico intitulado Hydroperoxide and carboxyl groups preferential location in oxidized biomembranes experimentally determined by small angle X-ray scattering: Implications in membrane structure [72] desenvolvido em colaboração com o professor Francesco Spinozzi da Universidade Politécnica de Marche (Ancona - Itália).

Com relação aos resultados para vesículas compostas por POPC e PAzPC, os ajustes via modelo de três regiões mostraram um decréscimo na espussura da bicamada lipídica que va-

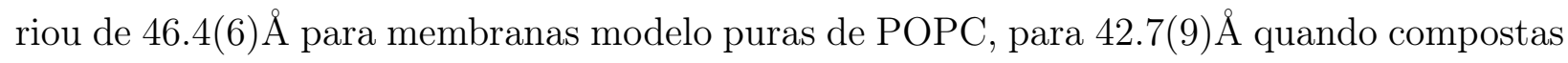
por 33\%de PAzPC. Vale notar que a espessura total da bicamada lipídica encontrada para vesículas contendo 33\% de PAzPC é similar ao valor obtido para membranas modelo compostas por POPC:POPC-OOH (67:33) de 42.4(9)Å. Diferente do observado para o sistema POPC:POPC-OOH, a análise via modelo de grupos químicos para POPC:PAzPC apresen- 
tou uma distribuição bimodal para o grupo oxidado carboxila do PAzPC com localização nas regiões hidrofóbica e hidrofílica da membrana modelo. Também foi observado aumento de área por lipídio com o aumento de oxidação porém em menor intensidade $A=67 \pm 2 \AA^{2}$ para 33\% de PAzPC, como consequência houve diminuição na espessura total de hidratação para $54 \pm 2 \AA$ com $33 \%$ de oxidação, em bom acordo com o observado em sistemas compostos por POPC com $20 \%$ de PAzPC [58].

Por fim, o estudo de sistemas ternários de POPC contendo os dois lipídios oxidados POPC-OOH e PAzPC nas proporções POPC:POPC-OOH:PAzPC (60:25:15) e (47:25:28) mostrou que ambos os sistemas apresentam parâmetros de espessura equivalentes aos obtidos para os sistemas binários de POPC com 33\% de lipídio oxidado (POPC-OOH ou

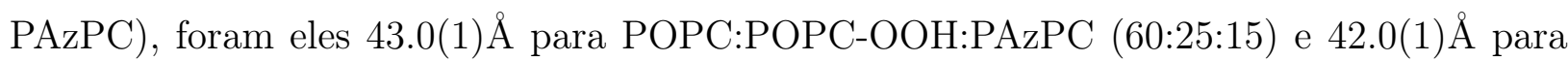
POPC:POPC-OOH:PAzPC (47:25:28). Por outro lado, a densidade eletrônica da região $\mathrm{CH}_{3}$ para os sistemas ternários se mostrou menor do que o obtido para membranas modelo de POPC com 33\% de lipídio oxidado e POPC:POPC-OOH (33:67)e POPC-OOH puro. Este resultado indica que a variação de densidade eletrônica na região do grupo metil é devida às características dos lipídios oxidados POPC-OOH e PAzPC. 
Capítulo 6

Estudo complementar - Análise da interação entre enzima GAPDH com membranas modelo 
A enzima GAPDH tem sido extensivamente estudada devido a sua importante função na produção de energia para a célula. De maneira interessante, foi mostrado que a GAPDH pode se associar em membranas contendo lipídios negativos, formando agregados tipo-amilóides [102]. Com o intuito de contribuir para o entendimento de como membranas lipídicas podem catalisar a formação de agregados proteicos elaboramos o estudo da interação entre a enzima GAPDH e membranas modelos contendo lipídios oxidados e não oxidados. O objetivo é estudar se a inclusão de lipídio oxidado impacta na formação de oligômeros de GAPDH em relação a membranas não oxidadas.

\subsection{Objetivo específico}

O objetivo deste capítulo consistiu em investigarmos, a partir da técnica de SAXS, os mecanismos de interação, dissociação e agregação de proteínas na superfície de membranas modelo devido à presença de lipídio oxidado na membrana e de domínios lipídicos.

\subsection{Materiais e Métodos}

\subsubsection{Materiais}

Para este estudo foram utilizados os lipídios POPC (figura 3.1) , POPC-OOH (figura 1.4), SM (figura 3.2 e CO (figura 3.3) e a enzima gliceraldeido-3-fosfato-desidrogenase de músculo de coelho $(\mathrm{GAPDH})$ apresentada na figura 6.1 .

Os filmes lipídicos e a enzima foram hidratados em água Milli-Q (Milli-Q plus ultra pure Type 1 water system - Milipore; resistividade 18,2M $\Omega . c m$ - pH 5). 
GAPDH de coelho (gliceraldeido-3-fosfato-desidrogenase de músculo de coelho) - peso molecular 36kDa (G2267- Sigma-Aldrich). Potencial isoelétrico (pI) 8,51.

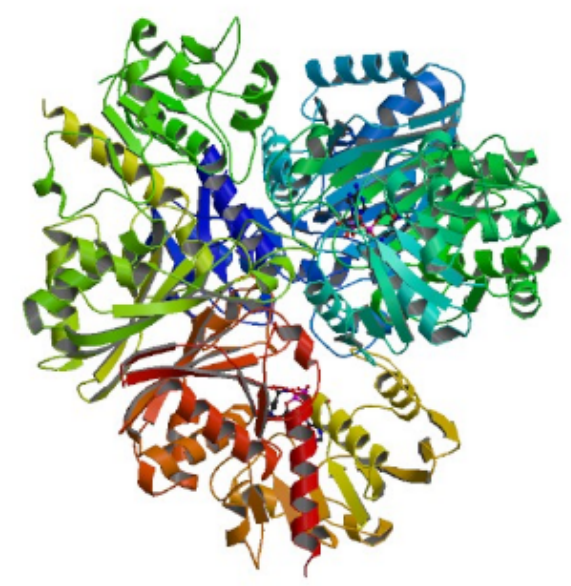

Figura 6.1: Estrutura cristalográfica da enzima GAPDH de coelho (PDB 1J0X extraído da referência [103])

\subsubsection{SAXS}

A caracterização da propriedades físicas referentes aos sistemas membrana modelo/enzima foi realizada a partir da técnica de SAXS, cujas informações referente aos parâmetros de aquisição dos dados obtidos no LNLS estão descritos na seção 2.2

A preparação das vesículas grandes foi realizada pelo método de extrusão (3.2.2.1) de acordo com o protocolo descrito na seção 3.2.2. As informações sobre composição lipídica, concentração final de lipídios, quantidade de extrusões e tamanho do poro utilizados para a obtenção de unilamelas e a temperatura em que a solução foi mantida durante o processo de hidratação do filme lipídico estão descritas na tabela 6.1

Para as medidas de SAXS na presença de enzima GAPDH, as vesículas foram extrusadas 
a $10 \mathrm{~m} M$ e diluídas para $8.33 \mathrm{~m} M$ no momento da medida. A enzima GAPDH foi medida a $2 \mathrm{mg} / \mathrm{mL}(0.05 \mathrm{mM})$ sendo que para os estudos de interação, a mistura das soluções da membrana modelo e da enzima foi efetuada instantes antes da realização das medidas, garantindo assim a obervação do sistema desde o príncípio da interação. Os sistemas membrana/enzima foram medidos a $37^{\circ} \mathrm{C}$ durante 100 seg de exposição contínua à radiação. Nos estudos de interação em função do tempo, o sistema membrana/enzima foi mantido em repouso em banho térmico a $37^{\circ} \mathrm{C}$ durante 2 horas pré medida experimental para comparação com o sistema medido diretamente após a mistura das soluções de LUVs e GAPDH.

A mensuração dos resultados foi realizada a partir de ajustes teóricos através do software Genfit [65]. Para o ajuste da enzima foi utilizado o modelo de PDB (All-atoms form factor of a PDB structure with solvation shell of dummy atoms and multipole expansion average), descrito na seção 2.3.3, que leva em consideração a contribuição de cada átomo presente no arquivo PDB (do inglês Protein Data Bank). Já para o ajuste das membranas modelo, utilizou-se o modelo de $\mathrm{N}$ lamelas infitas com três regiões de diferentes densidades eletrônicas (seção 2.3.1).

Tabela 6.1: Amostras medidas por SAXS em presença da enzima GAPDH.

\begin{tabular}{|c|c|c|c|c|}
\hline \multicolumn{5}{|c|}{ Medidas de SAXS } \\
\hline Composição & Concentração & $\mathrm{n}^{\circ}$ de extrusão das vesículas & filtro $(\mathrm{nm})$ & $\mathrm{T}\left({ }^{\circ} \mathrm{C}\right)$ \\
\hline POPC:POPC-OOH (1:0)/GAPDH & $8.33 \mathrm{mM} / 0.05 \mathrm{mM}$ & 31 & 100 & 30 \\
\hline POPC:POPC-OOH (67:33)/GAPDH & $8.33 \mathrm{mM} / 0.05 \mathrm{mM}$ & 31 & 100 & 30 \\
\hline POPC:POPC-OOH (33:67)/GAPDH & $8.33 \mathrm{mM} / 0.05 \mathrm{mM}$ & 31 & 100 & 30 \\
\hline POPC:POPC-OOH (0:1)/GAPDH & $8.33 \mathrm{mM} / 0.05 \mathrm{mM}$ & 31 & 100 & 30 \\
\hline POPC:SM:CO (1:1:1)/GAPDH & $8.33 \mathrm{mM} / 0.05 \mathrm{mM}$ & $\begin{array}{l}19 \\
31\end{array}$ & $\begin{array}{l}400 \\
100\end{array}$ & 45 \\
\hline POPC-OOH:SM:CO (1:1:1)/GAPDH & $8.33 \mathrm{mM} / 0.05 \mathrm{mM}$ & $\begin{array}{l}19 \\
31\end{array}$ & $\begin{array}{l}400 \\
100\end{array}$ & 45 \\
\hline
\end{tabular}




\subsection{Resultados e Discussões}

A apresentação e discussão dos resultados desta seção será realizada em duas partes: na primeira parte serão apresentados os resultados experimentais obtidos e uma análise qualitativa que serviram como insumo para o desenvolvimento dos experimentos; na segunda serão apresentados os ajustes teóricos das curvas de maior relevância apresentadas na primeira parte acompanhado de uma discussão sobre a qualidade dos ajustes, bem como os resultados quantitativos obtidos.

\subsubsection{Parte 1 - Análise inicial (qualitativa) das curvas de SAXS}

Iniciamos o estudo de interação da GAPDH com membranas modelo a partir da comparação entre o perfil de espalhamento das curvas de SAXS para as enzimas GAPDH extraída de coelho (GAPDH de coelho figura 6.1) e extraída de seres humanos (GAPDH humana, obtida em colaboração com a prof ${ }^{a}$ Rosana N. Chehín do Instituto de Química del Noroeste Argentino - INQUINOA - CONICET). A partir do resultado apresentado na figura 6.2 foi possível verificar que, para a técnica de SAXS, ambas as enzimas apresentam mesmo perfil indicando estruturas quaternárias semelhantes. Com base neste resultado, a continuidade do estudo proposto neste capítulo foi dada com a GAPDH de coelho devido ao menor custo e maior facilidade de obtenção do material para análise, dada a complexidade de extração da proteína humana.

A fim de garantir que os resultados observados nos ensaios seguintes não eram devido ao efeito de radiação sobre a enzima, foram realizadas medidas de SAXS da GAPDH durante 120 min a $37^{\circ} \mathrm{C}$, apresentados na figura 6.3. Foi observado que não há alteração no perfil de espalhamento da enzima com o passar do tempo, o que indica que não houve mudança 


\section{4 \\ Estudo complementar - Análise da interação entre enzima GAPDH com membranas modelo}

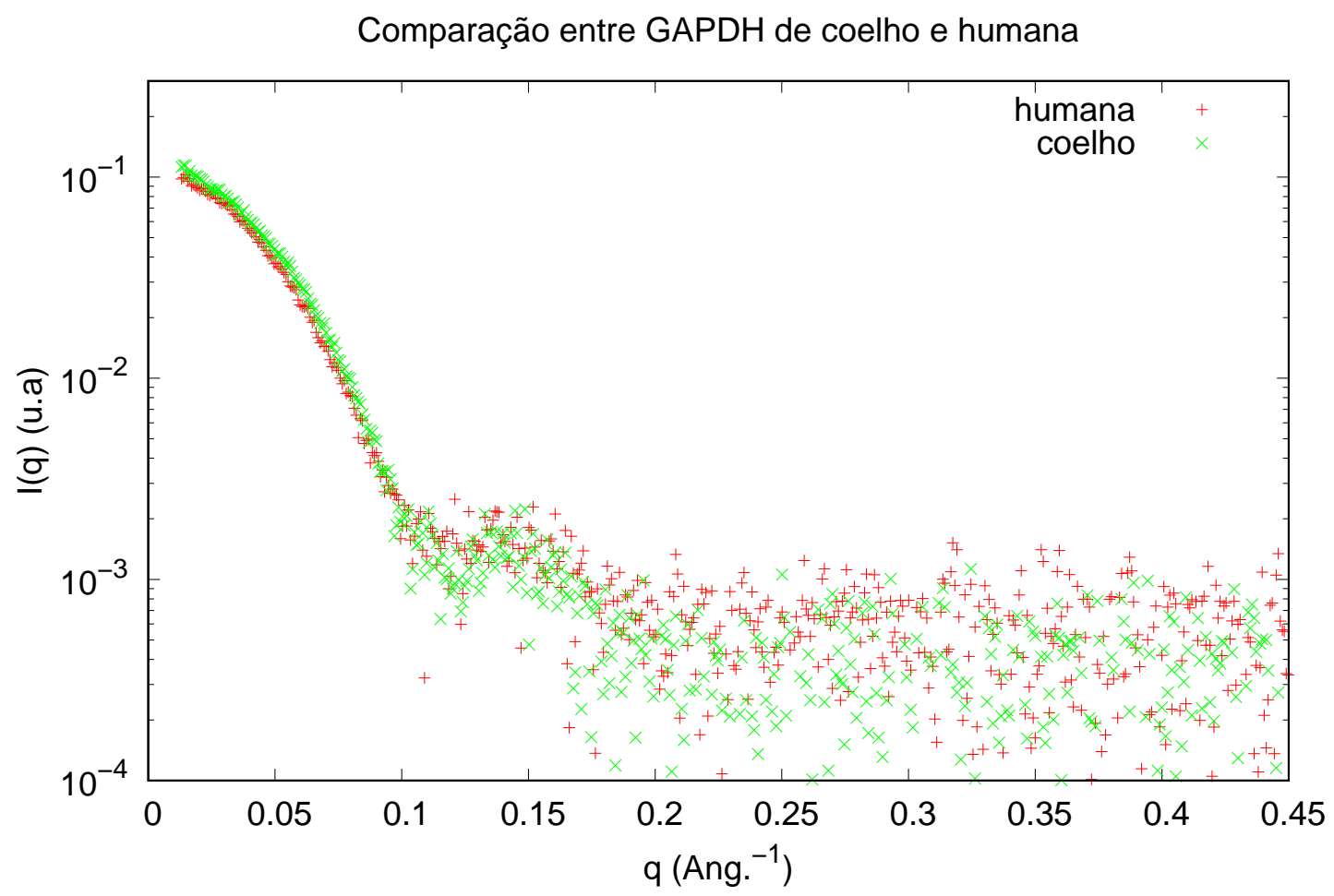

Figura 6.2: Curvas de SAXS da enzima GAPDH humana (curva vermelha) e GAPDH de coelho (curva verde) $[2 \mathrm{mg} / \mathrm{mL}=0.05 \mathrm{mM}]$ realizadas durante 100 segundos. Medidas realizadas a $37^{\circ} \mathrm{C}$.

estrutural na proteína devido a efeito de radiação durante o tempo medido (120 min), em bom acordo com resultados da literatura [38]. A curva azul claro apresentada na figura 6.3 representa a média das curvas obtidas. Como durante os 120 min a estrutura da enzima não sofreu alteração, para as próximas as análises iremos considerar apenas a média das curvas de SAXS. Nota-se apenas uma pequena agregação da enzima na região de ângulos pequenos (figura 6.3).

Resultados da literatura mostram que a composição lipídica da membrana pode estar diretamente associada à agregação e formação de fibras amilóides em proteínas relacionadas à diversas doenças [37, 38, 34, 41]. Iniciamos o estudo da interação entre a GAPDH e 


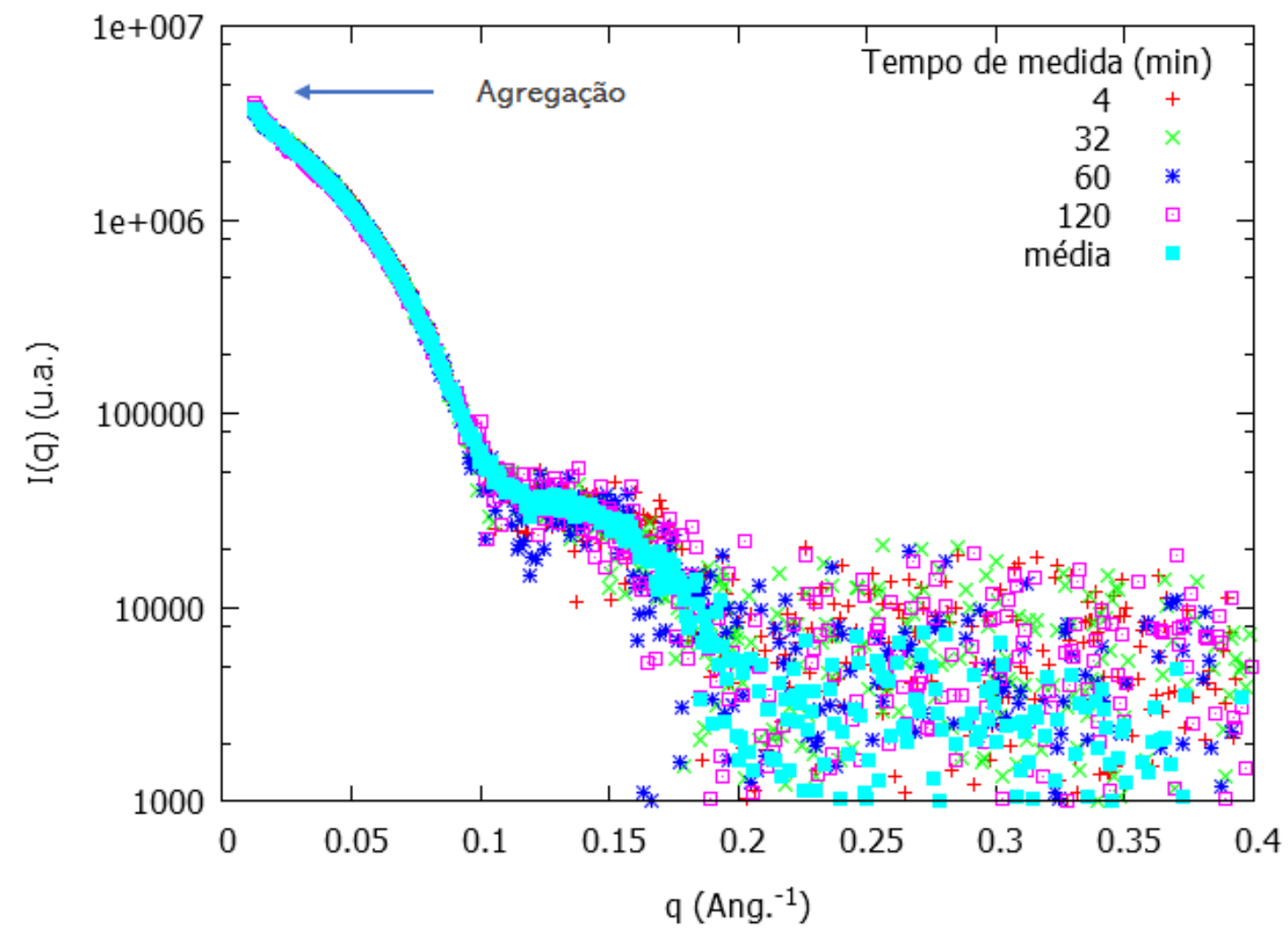

Figura 6.3: Curvas de SAXS de medida cinética da enzima GAPDH de coelho $[2 \mathrm{mg} / \mathrm{mL}=$ $0.05 \mathrm{mM}$ ]. Foram realizadas 30 medidas de 40seg de exposição à radiação com intervalo de $200 \mathrm{seg}$ entre cada medida, totalizando de $120 \mathrm{~min}$ de medida. Medidas realizadas a $37^{\circ} \mathrm{C}$.

membrana modelo oxidada a partir da caracterização de sistemas binários compostos por POPC e POPC-OOH. Os sistemas estudados foram: POPC:POPC-OOH (1:0), (67:33), (33:67) e (0:1). A figura 6.4 apresenta a comparação entre as curvas de SAXS das membranas modelo de POPC com e sem lipídio oxidado (POPC-OOH), da enzima GAPDH, do sistema membrana/enzima e a curva resultante da soma simples da curva da enzima com a curva da membrana modelo. O dado experimental foi adquirido imediatamente após a mistura das LUVs com GAPDH.

Foi observado que as curvas de SAXS das vesículas compostas por POPC:POPC-OOH 
(1:0), (33:67) e (0:1) apresentaram um aumento na intensidade de espalhamento $I(q)$ para a região de baixos ângulos $\left(q\right.$ até $0.1 \AA^{-1}$ ) se comparadas com a curva resultante da soma dos espalhamentos da LUV e da enzima. Segundo a equação $D_{\max }=\pi / q_{\min }$ [60] temos que estruturas maiores são observadas na região de menor ângulo de espalhamento. No caso de sistemas proteicos, esse aumento na intensidade de espalhamento indica que a proteína sofreu agregação. Inesperadamente o sistema composto por vesículas de POPC:POPC-OOH (67:33) não apresentou alteração, de modo que a curva experimental da membrana/GAPDH é igual à curva resultante da soma da curva da enzima com a curva da membrana modelo. Dentre os 4 sistemas apresentados na figura 6.4 as composições POPC:POPC-OOH (1:0) e (0:1) foram remedidas e o efeito de agregação pode ser confirmado, tal procedimento não pode ser aplicado para as demais composições. Por outro lado, é possível perceber que para $q>0.1 \AA^{-1}$ a curva de espahamento do sistema GAPDH/membrana é dada pela soma dos espalhamentos da proteína e da membrana modelo separadamente, indicando que não houve alteração na estrutura da membrana.

Com base no resultado apresentado na figura 6.4 foi possível inferir que a agregação da enzima GAPDH independe da presença de lipídio oxidado POPC-OOH na membrana modelo, pois efeito semelhante de agregação foi observado para o sistema composto vesículas puras de POPC, ou seja, sem oxidação. O resultado obtido para vesículas compostas por $33 \%$ de POPC-OOH, cujo sistema não apresentou efeito de agregação, precisaria ser medido novamente para verificarmos se o resultado observado se trata de um caso especial no qual essa proporção específica de POPC-OOH inibe, de alguma forma, a agregação da GAPDH. Dada a impossibilidade de confirmação deste resultado, o mesmo será considerado como inconclusivo. Efeito similar de aumento na intensidade de espalhamento na região de baixo ângulo $\left(q 0.02 \AA^{-1}\right)$, indicativo de agregação da GAPDH, foi observado na presença das 
composições lipídicas POPC:SM:CO (1:1:1) e POPC-OOH:SM:CO (1:1:1) (ver figura 6.5, reforçando que tal efeito não pode ser atribuido unicamente à oxidação da membrana modelo.

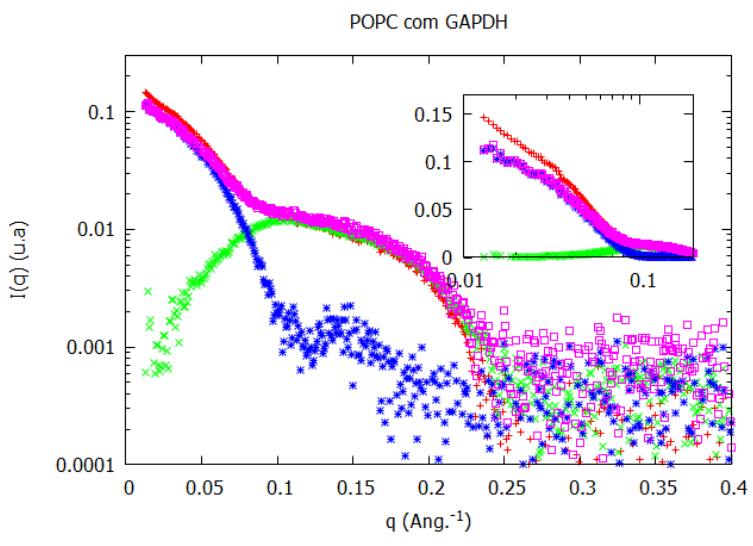

(a) POPC/GAPDH

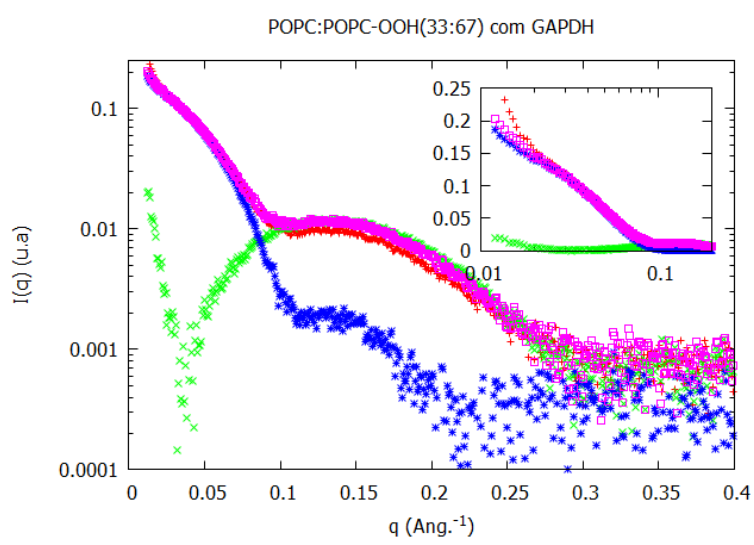

(c) POPC:POPC-OOH(33:67)/GAPDH

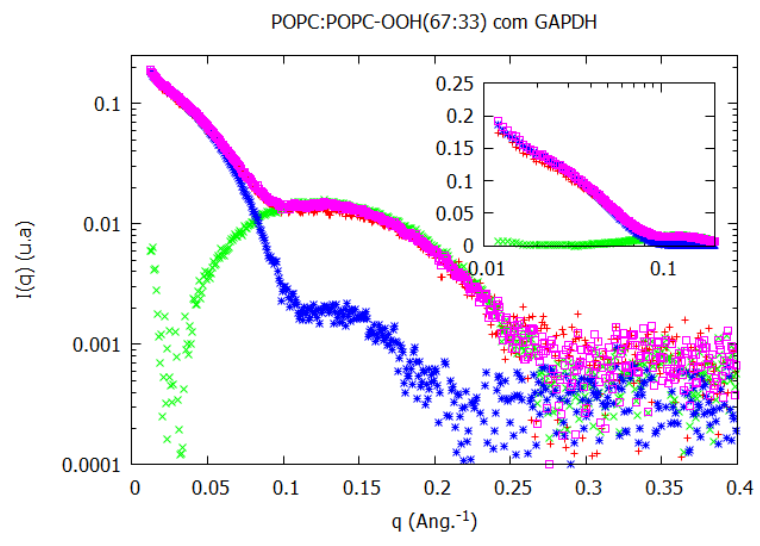

(b) POPC:POPC-OOH(67:33)/GAPDH

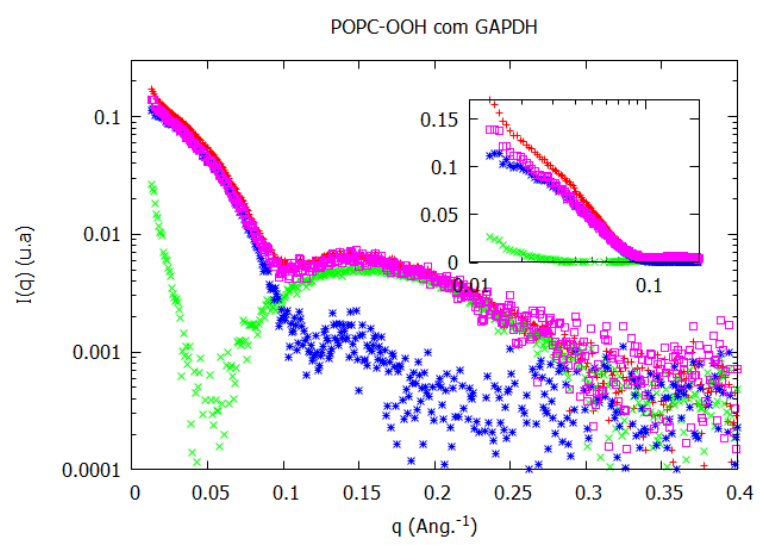

(d) POPC-OOH/GAPDH

Figura 6.4: Comparação entre o perfil de espalhamento das curvas de SAXS de: membrana modelo de POPC:POPC-OOH em diferentes proporções (curvas verdes) (8.33m $\mathrm{M}$ ), enzima GAPDH (curva azul) (0.05mM), sistema membrana/proteína (curva vermelha) e a soma da curva da membrana com a curva da proteína (curva rosa); medidos a $37^{\circ} \mathrm{C}$. O insert apresenta o zoom para ângulo de espalhamento até $0.2 \AA^{-1}$ com escala logaritmica no eixo $\mathrm{x}$. 

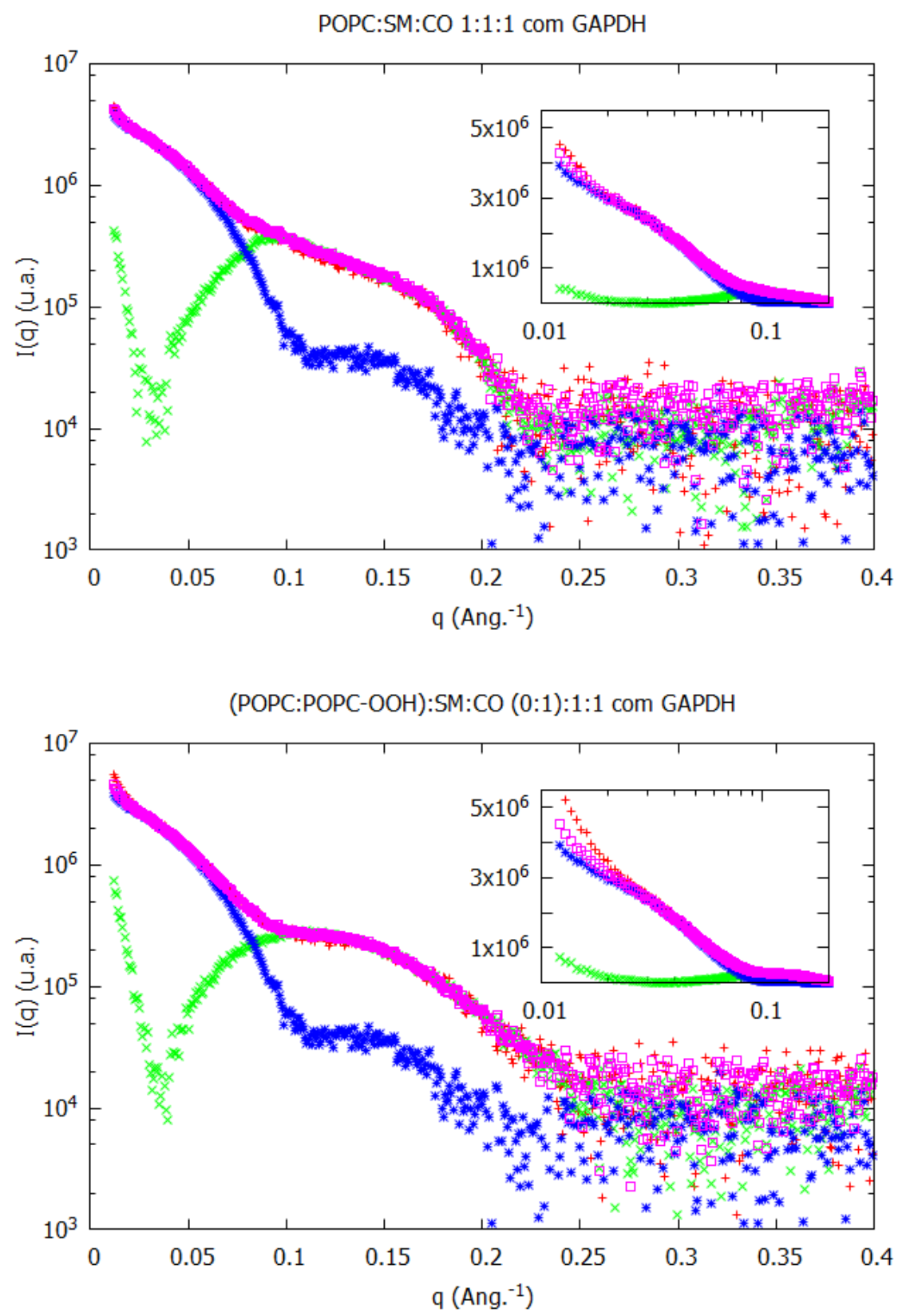

Figura 6.5: Comparação o perfil de espalhamento das curvas de SAXS de: membrana modelo de (POPC:POPC-OOH):SM:CO em diferentes proporções (curvas verdes) (8.33mM), enzima GAPDH (curva azul) $[2 \mathrm{mg} / \mathrm{mL}=0.05 \mathrm{mM}]$, sistema membrana/proteína (curva vermelha) e a soma da curva da membrana modelo com a curva da proteína (curva rosa); medidos a $37^{\circ} \mathrm{C}$. O insert apresenta o zoom para ângulo de espalhamento até $0.2 \AA^{-1}$ com escala logaritmica no eixo $\mathrm{x}$. 
Uma vez verificada que interação entre a enzima e a membrana modelo não afetou a estrutura desta última, demos sequência aos ensaios a partir da investigação de interação dos sistemas em função do tempo. Foram realizadas medidas de SAXS das membranas modelo na presença da enzima GAPDH levando em consideração um tempo de espera de duas horas durante o qual a amostra ficou em banho térmico a $37^{\circ} \mathrm{C}$. A figura 6.6 apresenta os resultados obtidos para as membranas modelo compostas POPC:POPC-OOH (1:0), (67:33), (33:67) e (0:1). Para todos os sistemas foi observado um aumento na intensidade de espalhamento na região de baixo ângulo após o tempo de espera de duas horas indicando que a GAPDH sofreu alteração estrutural. Como mencionado anteriormente (ver figura 6.3) a enzima sozinha após 120 minutos de medida não apresentou alteração no perfil de espalhamento de SAXS, portanto o efeito de agregação observado está vinculado à interação com a membrana modelo ao longo das duas horas. Resultado similar foi observado para os sistemas com membranas modelo compostas por POPC:SM:CO (1:1:1) e POPC-OOH:SM:CO (1:1:1) medidos nas mesmas condições (figura 6.7).

Com base no efeito observado após duas horas de interação do sistema GAPDH/membrana, realizamos um estudo complementar para entender os efeitos na GAPDH após um período maior de interação, 24 horas. Para esse estudo foram selecionadas, estratégicamente, as composições lipídicas POPC:POPC-OOH (1:0) e (0:1). Os resultados obtidos, apresentados na figura 6.8, mostram que mesmo após as 24h, para ambos os sistemas, o efeito de interação levando à agregação da proteína ainda é pequeno. 

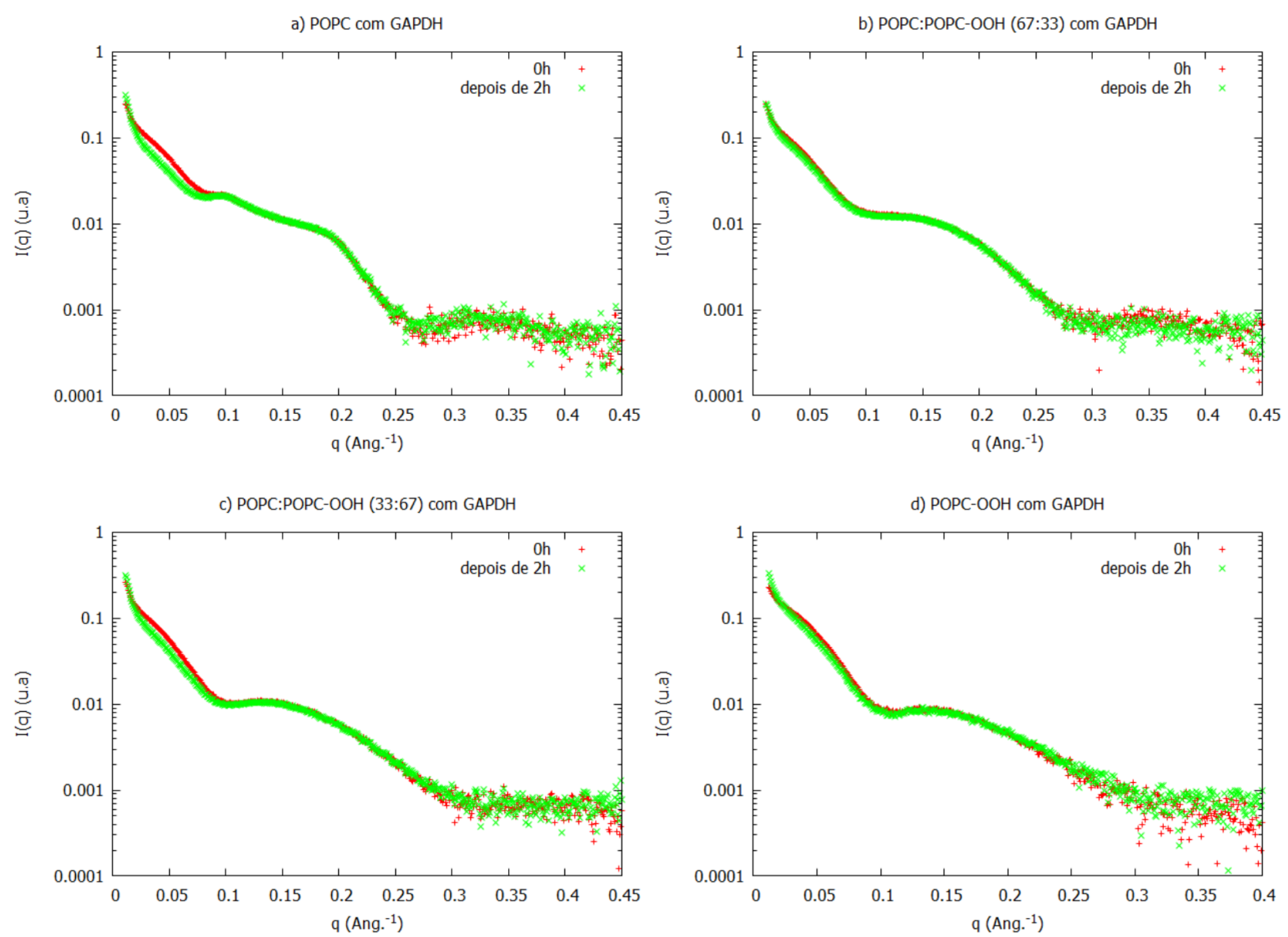

Figura 6.6: : Comparação entre as curvas de SAXS das vesículas (8.33mM) de: a) POPC; b) POPC:POPC-OOH (67:33); c) POPC:POPC-OOH (33:67) e d) POPC-OOH com a enzima GAPDH $[2 \mathrm{mg} / \mathrm{mL}=0.05 \mathrm{mM}]$. A curva vermelha representa a medida realizada imediatamente após a mistura das soluções da vesícula e da proteína e a curva verde representa a medida realizada após $2 h$ de espera no banho térmico a $37^{\circ} \mathrm{C}$. 
a) POPC:SM:CO (1:1:1) com GAPDH

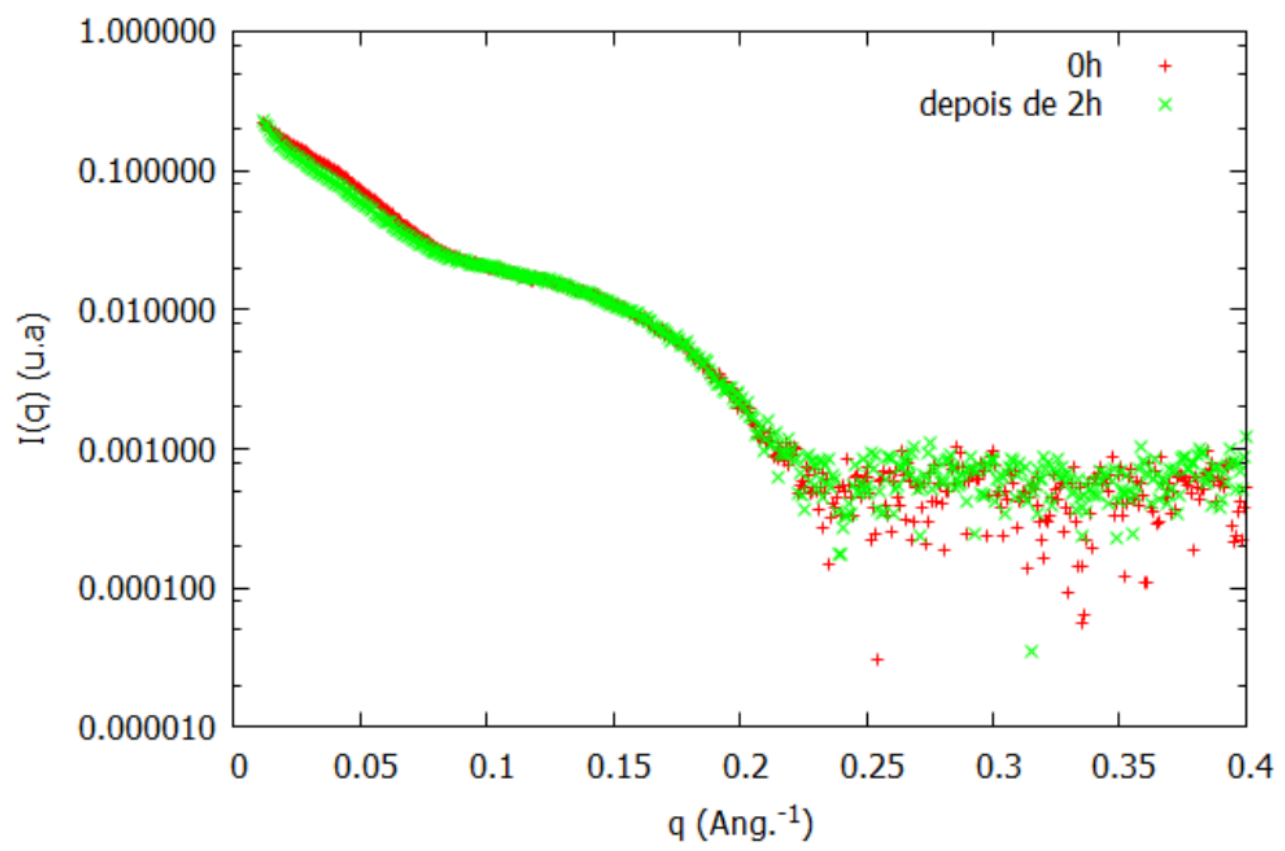

b) POPC-OOH:SM:CO (1:1:1) com GAPDH

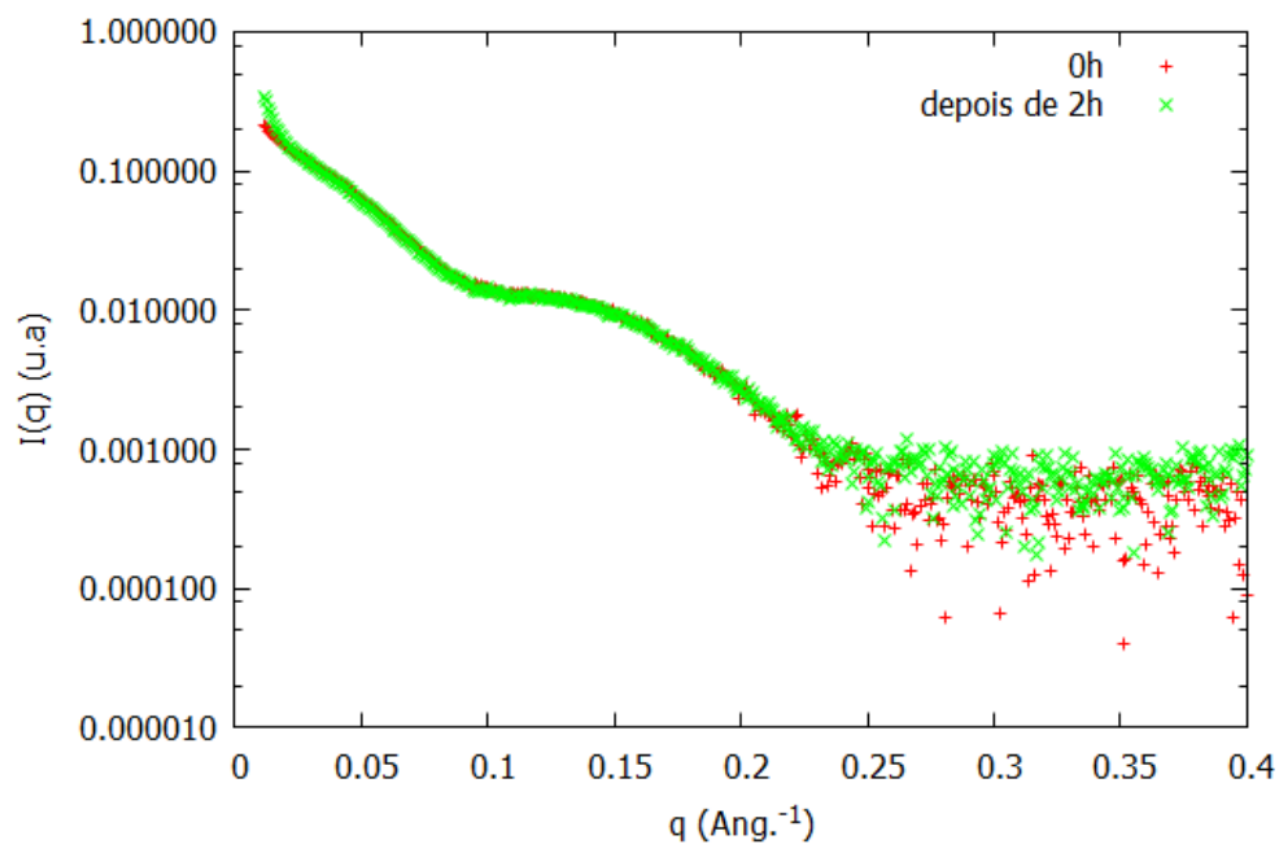

Figura 6.7: : Comparação entre as curvas de SAXS das vesículas (8.33mM) de: a) POPC:SM:CO (1:1:1) e POPC-OOH:SM:CO (1:1:1) com a enzima GAPDH $[2 \mathrm{mg} / \mathrm{mL}=$ $0.05 \mathrm{mM}]$. A curva vermelha representa a medida realizada imediatamente após a mistura das soluções da vesícula e da proteína e a curva verde representa a medida realizada após $2 h$ de espera no banho térmico a $37^{\circ} \mathrm{C}$. 

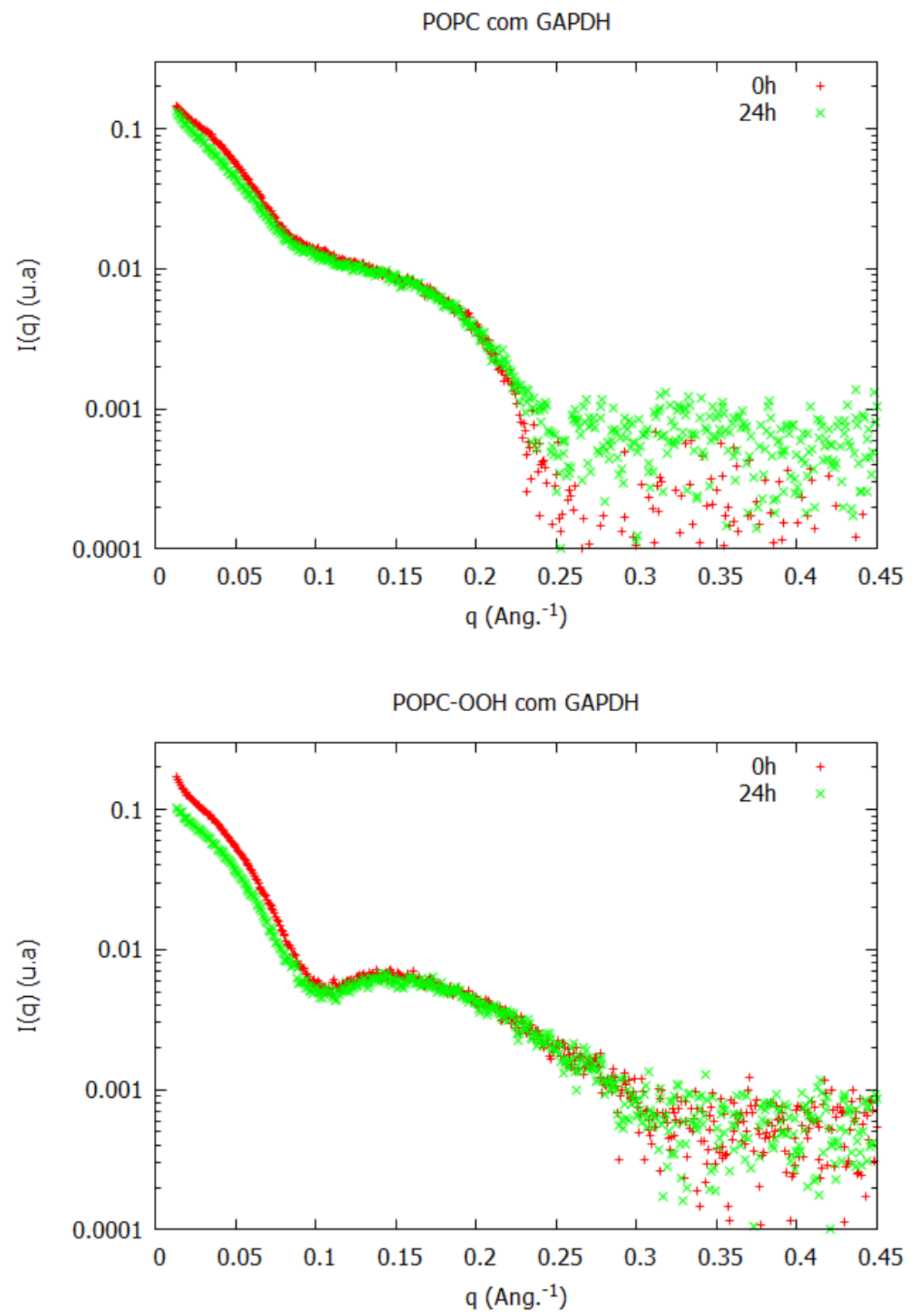

Figura 6.8: : Comparação entre as curvas de SAXS das vesículas $(8.33 m M)$ de: POPC:POPC-OOH (1:0) e (0:1) com a enzima GAPDH $[2 \mathrm{mg} / \mathrm{mL}=0.05 \mathrm{mM}]$. A curva vermelha representa a medida realizada imediatamente após a mistura das soluções da vesícula e da proteína e a curva verde representa a medida realizada após $24 h$ de espera no banho térmico a $37^{\circ} \mathrm{C}$. 


\subsubsection{Parte 2 - Análise quantitativa via ajuste teórico das curvas de SAXS}

Nesta seção serão apresentados tanto os resultados finais das análises quanto os processos intermediários que serviram como aprendizado e guia para o desenvolvimento deste estudo.

Primeiramente foi analisada a curva de SAXS para a enzima GAPDH sozinha a partir do modelo que considera o fator de forma da estrutura critalográfica do PDB da proteína, descrito na seção 2.3.3. Para esta análise, foi considerado que nas condições medidas a GAPDH possui estrutura tetramérica [103]. A figura 6.9 apresenta o ajuste obtido, cuja boa qualidade mostra que em solução a GAPDH apresenta estrutura de tetrâmero.

Como descrito na análise qualitativa das curvas de SAXS (subseção 6.3.1), os sistemas membrana/GAPDH apresentaram alteração significativa apenas na região de menor ângulo de espalhamento da curva de SAXS (até $q=0.1 \AA^{-1}$ ) onde a contribuição na intensidade de espalhamento $I(q)$ é prioritariamente dada pela estrutura quaternária da enzima, de modo que os parâmetros de ajuste das vesículas não são relevantes para as análises a seguir. Sendo assim, os resultados e discussões desta seção serão desenvovidos unicamente a partir das possíveis alterações no estado conformacional enzima GAPDH devido à interação com diferentes composições lipídica e variação no tempo de interação.

Partindo do resultado obtido para a análise da GAPDH, demos sequência às análises dos sistemas membrana/proteína considerando para a proteína apenas o PDB do tetrâmero e para a membrana o modelo de lamela infinita 2.3.1. As figuras 6.10, 6.11, 6.12, 6.13, 6.14 e 6.15 apresentam, respectivamente, os ajustes obtidos para a GAPDH na presença das vesículas compostas por POPC, POPC:POPC-OOH (67:33), POPC:POPC-OOH (33:67), 
POPC-OOH, POPC:SM:CO e POPC-OOH:SM:CO (1:1:1) medidas logo após a mistura das soluções da membrana modelo com a proteína e a medida realizada após duas horas de espera em banho térmico a $37^{\circ} \mathrm{C}$ a partir da consideração de forma tetramérica para a enzima. A partir dos resultados de ajuste, foi observado que a forma de tetrâmero claramente não se ajusta bem aos dados experimentais para as composições de vesículas parcialmente oxidadas de POPC:POPC-OOH (67:33) e POPC:POPC-OOH (33:67) em $0 h$ e $2 h$. A tentativa de ajustar esse sistema usando apenas o PDB do tetrâmero levou a um maior distanciamento da curva de ajuste para os pontos experimentais na região de maior contribuição da membrana $\left(q>0.1 \AA^{-1}\right)$, figuras 6.11 para POPC:POPC-OOH (67:33) e 6.12 para POPC:POPC-OOH (33:67). Ou seja, para os sistemas de vesículas compostas por POPC com $33 \%$ e $67 \%$ de POPC-OOH há a necessidade de se incluir outro modelo de ajuste considerando uma possível dissociação da proteína. Para as composições puras de POPC e POPC-OOH, os ajustes a partir do PDB do tetrâmero se mostraram satifatórios na maior parte das curvas com possibilidade de melhora na região de menor ângulo de espalhamento $\left(q<=0.1 \AA^{-1}\right)$, indicados pela seta azul nas figuras 6.10 para POPC e 6.13 para POPC-OOH. Por outro lado, na presença de vesículas compostas por POPC:SM:CO e POPC-OOH:SM:CO (1:1:1) o ajuste teórico a partir do PBD do tetrâmero representou bem os dados experimentais (figura 6.14 para POPC:SM:CO e figura 6.15 para POPC-OOH:SM:CO) indicando que na presença dessas composições lipídicas a enzima GAPDH manteve a estrutura inicial de tetrâmero [103. Dado esse resultado, não se pode atribuir o efeito de alteração estrutural da enzima à oxidação da membrana modelo. No entanto, os sistemas compostos por SM e CO foram os únicos que se mativeram constantes após $2 h$ de interação sugerindo que a formação de domínios lipídicos dada pela interação entre SM e CO [74, 84, 75, 12] preserva a estrutura inicial da GAPDH. 


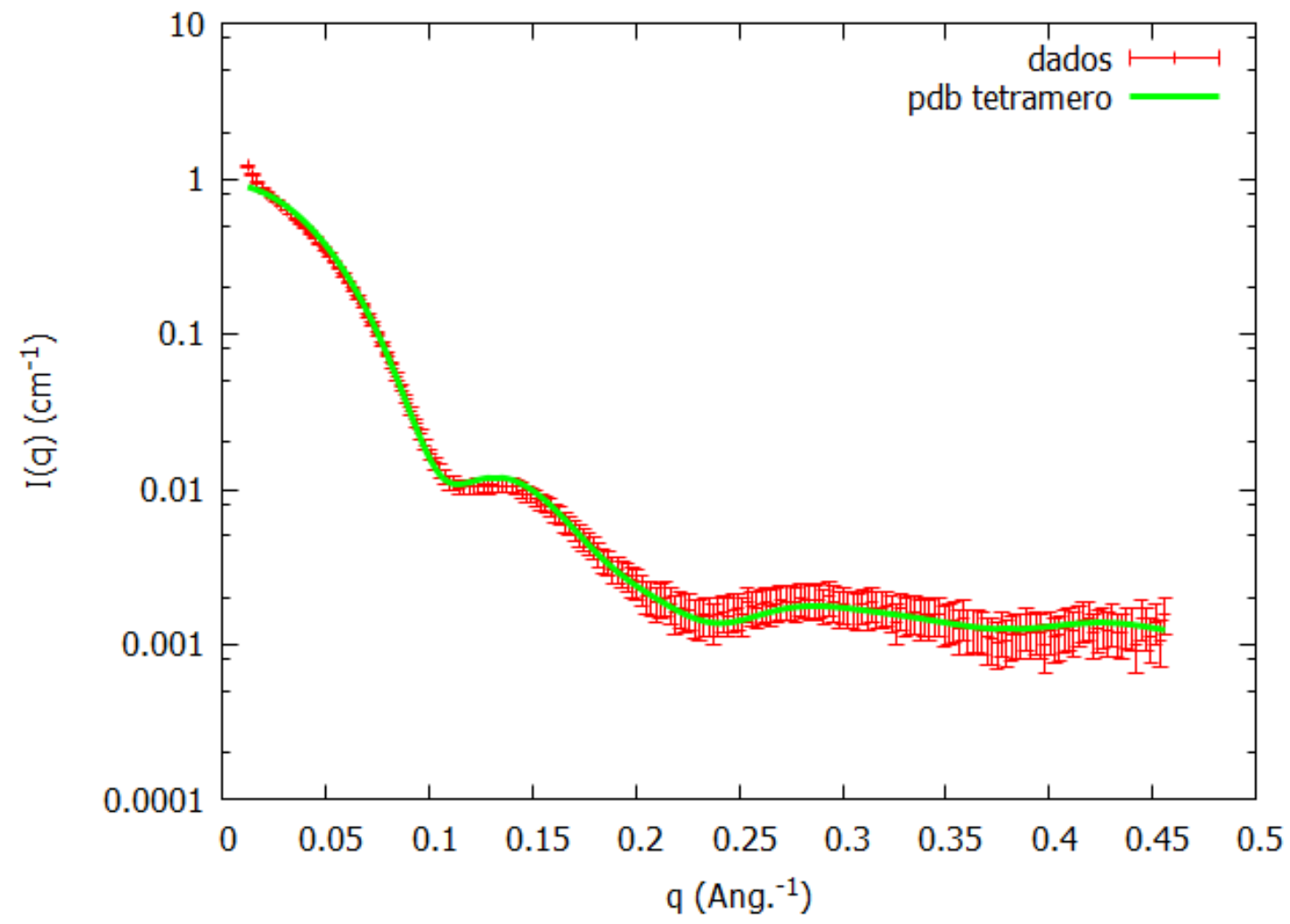

Figura 6.9: Ajuste obtido para a curva de SAXS da enzima GAPDH (concentração $12 \mathrm{mg} / \mathrm{mL}$ medida a $37^{\circ} \mathrm{C}$ ) a partir do PDB de um tetrâmero. 


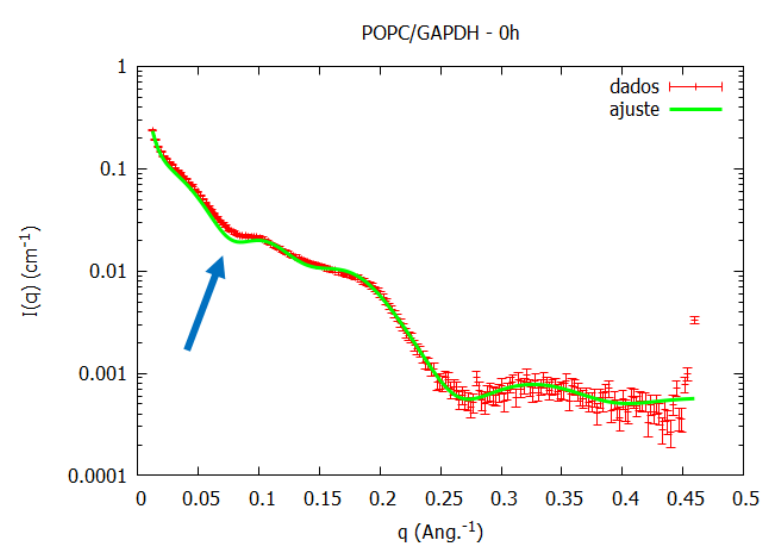

(a) Medida 0h

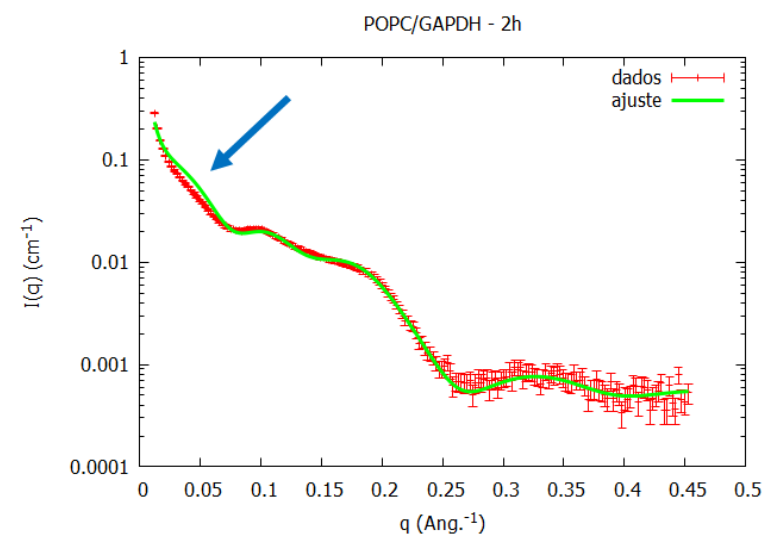

(b) Medida após $2 \mathrm{~h}$

Figura 6.10: Ajuste de vesículas compostas por POPC [8.33mM] com a enzima GAPDH $[2 \mathrm{mg} / \mathrm{mL}]$ a partir do PDB do tetrâmero, para medidas realizadas: a) logo após a mistura das soluções da proteína com a membrana modelo - $0 h$ e b) após $2 h$ de espera em banho térmico a $37^{\circ} \mathrm{C}$.

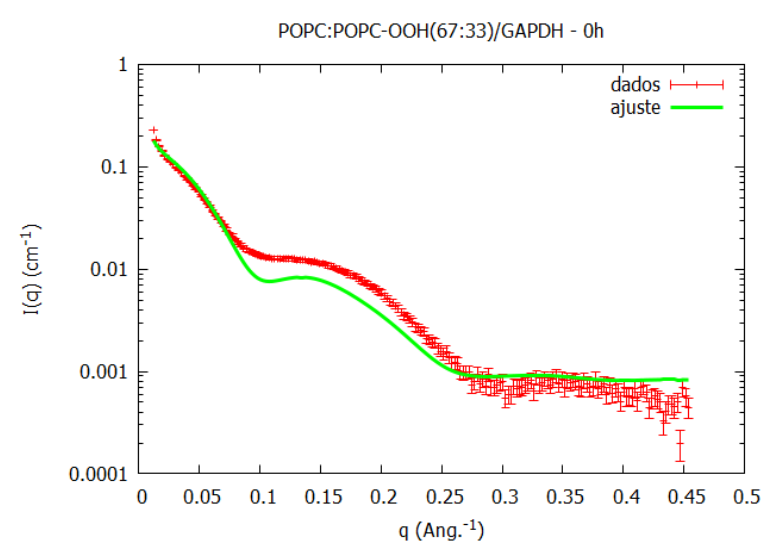

(a) Medida $0 \mathrm{~h}$

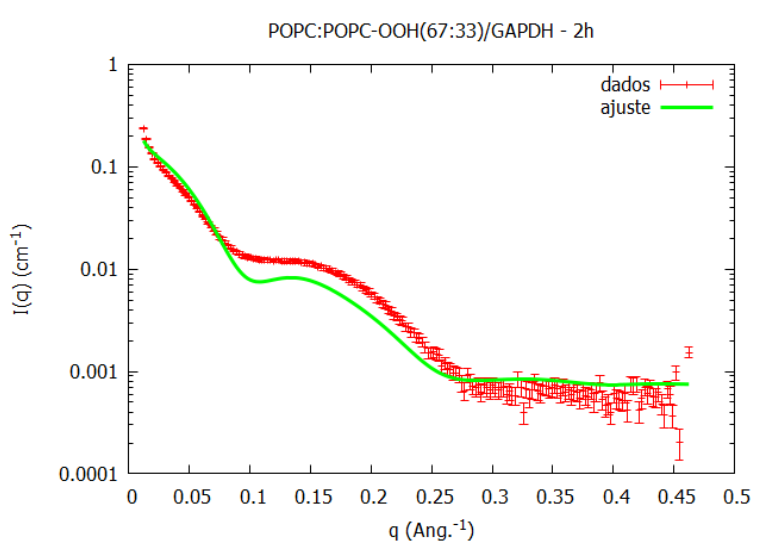

(b) Medida após $2 \mathrm{~h}$

Figura 6.11: Ajuste de vesículas compostas por POPC:POPC-OOH(67:33) [8.33mM] com a enzima GAPDH [2mg/mL] a partir do PDB do tetrâmero, para medidas realizadas: a) logo após a mistura das soluções da proteína com a membrana modelo - $0 h$ e b) após $2 h$ de espera em banho térmico a $37^{\circ} \mathrm{C}$. 


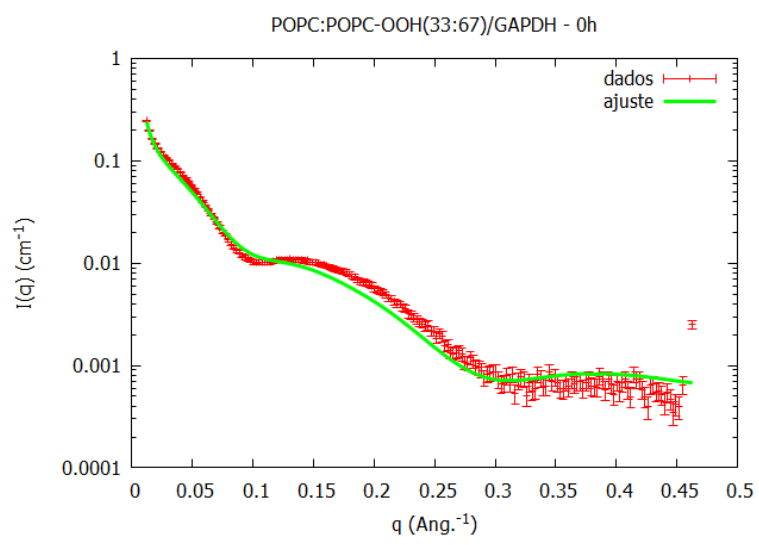

(a) Medida $0 \mathrm{~h}$

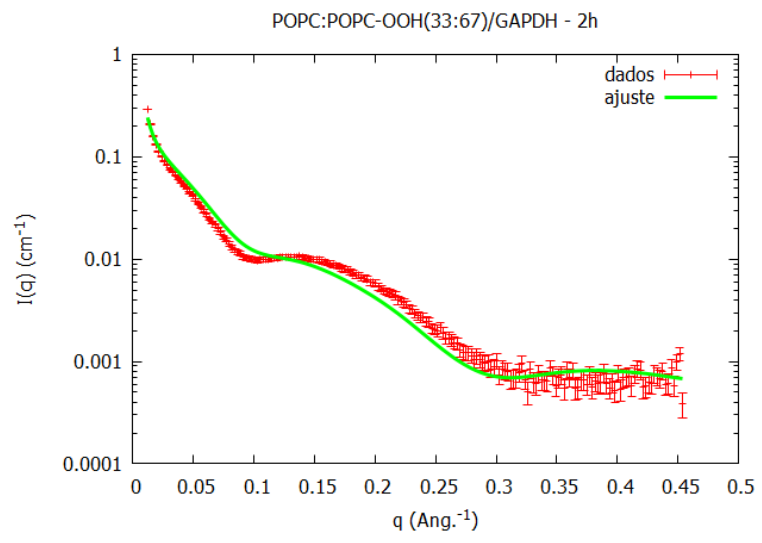

(b) Medida após $2 \mathrm{~h}$

Figura 6.12: Ajuste de vesículas compostas por POPC:POPC-OOH(33:67) [8.33mM] com a enzima GAPDH [2mg/mL] a partir do PDB do tetrâmero, para medidas realizadas: a) logo após a mistura das soluções da proteína com a membrana modelo - $0 h$ e b) após $2 h$ de espera em banho térmico a $37^{\circ} \mathrm{C}$.

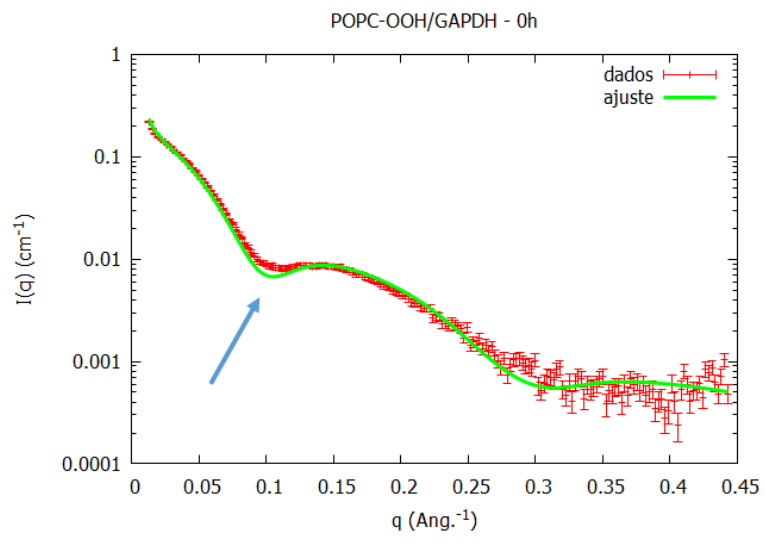

(a) Medida $0 \mathrm{~h}$

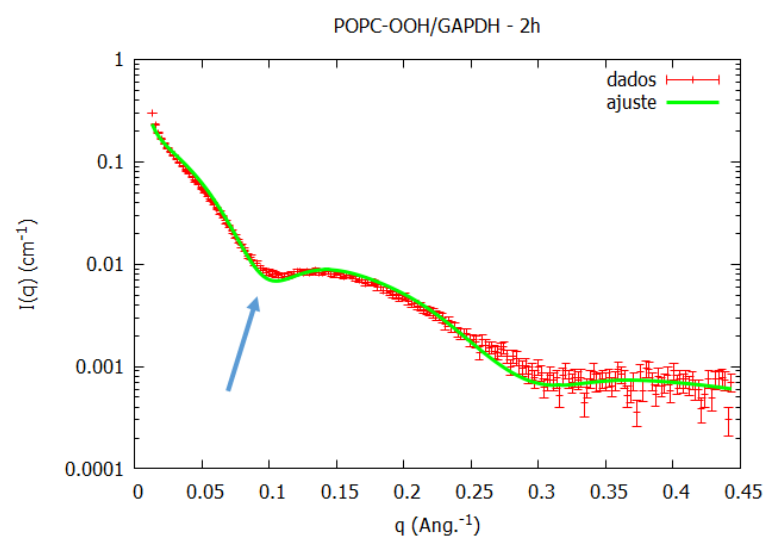

(b) Medida após $2 \mathrm{~h}$

Figura 6.13: Ajuste de vesículas compostas por POPC-OOH $[8.33 \mathrm{mM}]$ com a enzima GAPDH $[2 \mathrm{mg} / \mathrm{mL}]$ a partir do PDB do tetrâmero, para medidas realizadas: a) logo após a mistura das soluções da proteína com a membrana modelo - $0 h$ e b) após $2 h$ de espera em banho térmico a $37^{\circ} \mathrm{C}$. 


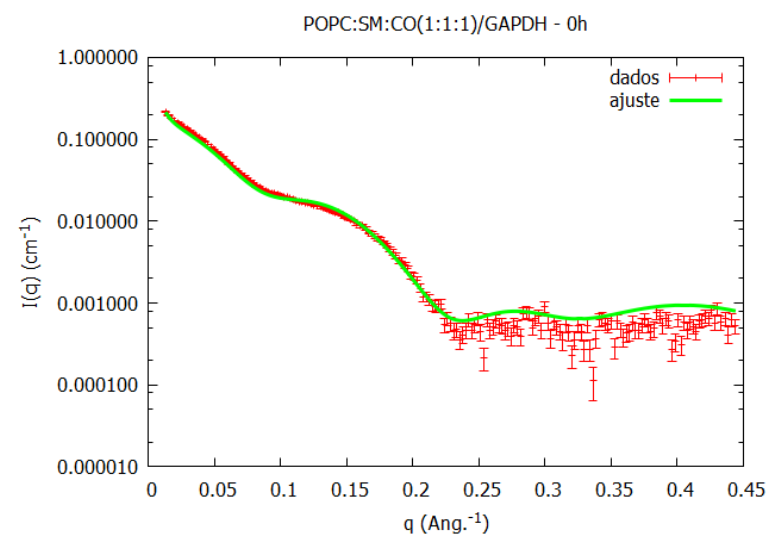

(a) Medida $0 \mathrm{~h}$

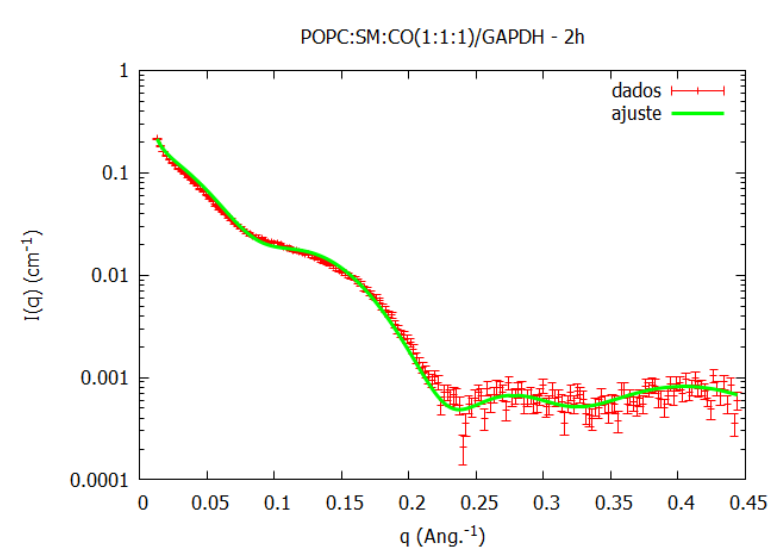

(b) Medida após $2 \mathrm{~h}$

Figura 6.14: Ajuste de vesículas compostas por POPC:SM:CO(1:1:1) [8.33mM] com a enzima GAPDH $[2 \mathrm{mg} / \mathrm{mL}]$ a partir do PDB do tetrâmero, para medidas realizadas: a) logo após a mistura das soluções da proteína com a membrana - $0 h$ e b) após $2 h$ de espera em banho térmico a $37^{\circ} \mathrm{C}$.

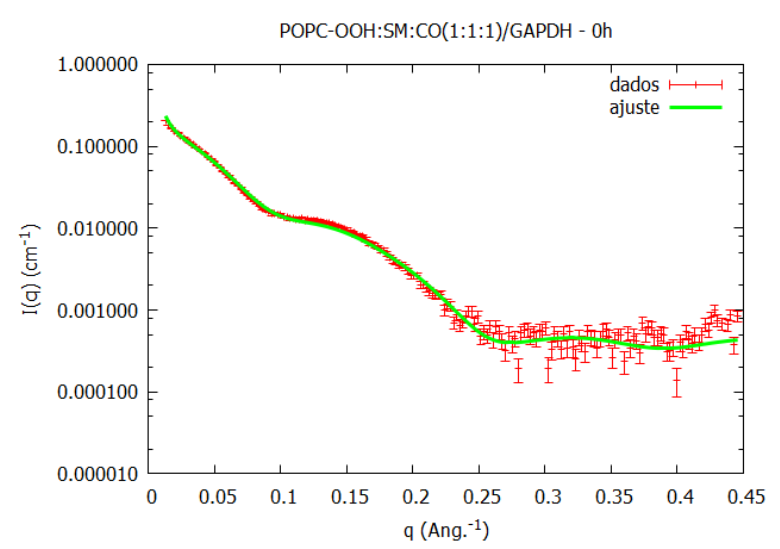

(a) Medida $0 \mathrm{~h}$

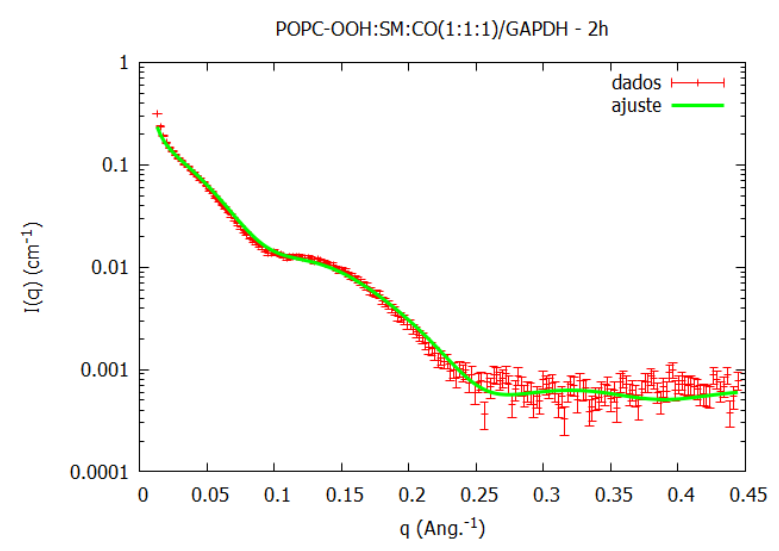

(b) Medida após $2 \mathrm{~h}$

Figura 6.15: Ajuste de vesículas compostas por POPC-OOH:SM:CO(1:1:1) [8.33mM] com a enzima GAPDH $[2 \mathrm{mg} / \mathrm{mL}]$ a partir do PDB do tetrâmero, para medidas realizadas: a) logo após a mistura das soluções da proteína com a membrana modelo - $0 h$ e b) após $2 h$ de espera em banho térmico a $37^{\circ} \mathrm{C}$. 
Com a finalidade de se obter um melhor resultado para as membranas modelo compostas por POPC, POPC:POPC-OOH(67:33), POPC:POPC-OOH(33:67) e POPC-OOH na presença da GAPDH, foram realizados ajustes das curvas de SAXS considerando a possibibilidade de dissociação da proteína da forma tetramérica para dímeros ou monômeros. Para isto, em cada ajuste, foram utilizados para a proteína dois modelos de PDB: tetrâmero/dímero e tetrâmero/monômero. Os ajustes aos dados experimentais obtidos para as curvas de SAXS nos tempos de medida $0 h$ e $2 h$ para a composições lipídicas POPC, POPC:POPC-OOH(67:33), POPC:POPC-OOH(33:67) e POPC-OOH estão apresentados nas figuras 6.16, 6.17, 6.18 e 6.19, respectivamente. Os resultados quantitativos referentes ao peso de cada forma oligomérica considerada para o ajuste estão apresentados na tabela 6.2

Pode-se observar que em todos os casos os ajustes obtidos a partir dos PDBs do tetrâmero/dímero são tão bons quanto os obtidos usando os PDBs do tetrâmero/monômero, ou seja, não se pode distinguir a partir do ajuste em qual estado oligomérico a enzima se dissociou. A similaridade entre os ajustes refletiu nos parâmetros estruturais, exceto para POPC puro medido após $2 h$ que apresentou uma diferença de 17\% entre os resultados para dímero (peso 51\%) e monômero (peso 34\%). Por outro lado, o sistema composto por POPC puro medido em tempo 0h não apresentou dissociação em dímero ou monômero, indicando que nesse cenário a GAPDH manteve a estrutura de tetrâmero, em bom acordo com o resultado observado por Cortez et al. [38] para membranas modelo zwiteriônicas.

Para os sistemas que contém POPC-OOH medidos logo após a mistura (tempo 0h), foi observado que a quantidade de tetrâmeros cresce à medida em que aumentamos a concentração de POPC-OOH na membrana, variando de 34\% para vesículas com 33\% de POPC-OOH para $65 \%$ para membranas modelo com $100 \%$ de POPC-OOH, mostrando que as composi- 
ções lipídicas intermediárias apresentam maior efeito de interação com a GAPDH. Por outro lado, não foi observado um padrão na variação de estrutura oligomérica entre as composições para as medidas realizadas após duas horas. Esse resultado sugere que GAPDH interage de forma diferente com cada composição lipídica ao longo do tempo. Comparando a dissociação entre os tempos $0 h$ e $2 h$ para cada composição, observou-se que o maior efeito ocorreu para vesículas com $67 \%$ de POPC-OOH, que variou a quanntidade de tetrâmero de $47 \%$ no tempo $0 h$ para $12 \%$ em medidas realizadas após duas horas.

Tabela 6.2: Porcentagem de cada PDB obtido para os ajustes dos sistemas de membrana/GAPDH para diferentes composições lipídicas (POPC, POPC:POPC-OOH(67:33), POPC:POPC-OOH(33:67) e POPC-OOH). As medidas foram realizadas no tempo zero (legenda $0 \mathrm{~h}$ ) e após duas horas de descanso das amostras em banho térmico a $37^{\circ} \mathrm{C}$ (legenda $2 \mathrm{~h})$.

\begin{tabular}{|c|c|c|c|c|c|c|c|c|}
\hline & \multicolumn{8}{|c|}{ Peso de cada modelo de PDB } \\
\hline & \multicolumn{2}{|c|}{ POPC } & \multicolumn{2}{|c|}{$\begin{array}{c}\text { POPC:POPC-OOH } \\
(67: 33)\end{array}$} & \multicolumn{2}{|c|}{$\begin{array}{c}\text { POPC:POPC-OOH } \\
(33: 67)\end{array}$} & \multicolumn{2}{|c|}{ POPC-OOH } \\
\hline & $0 \mathrm{~h}$ & $2 \mathrm{~h}$ & $0 \mathrm{~h}$ & $2 \mathrm{~h}$ & $0 \mathrm{~h}$ & $2 \mathrm{~h}$ & $0 \mathrm{~h}$ & $2 \mathrm{~h}$ \\
\hline Tetrâmero (\%) & $100(1)$ & $49(1)$ & $34(1)$ & $20(1)$ & $\overline{47(2)}$ & $12(2)$ & $65(3)$ & $\overline{59(4)}$ \\
\hline Díme & $0(1)$ & $51(1)$ & $66(1)$ & $80(1)$ & $53(2)$ & $88(2)$ & $35(3)$ & $41(4)$ \\
\hline Tetrâmero (\%) & 100(1) & $66(1)$ & $35(3)$ & $20(3)$ & $43(3)$ & $9(3)$ & $59(2)$ & $53(3)$ \\
\hline Monômero (\%) & $0(1)$ & $34(1)$ & $65(3)$ & $80(3)$ & $57(3)$ & $91(3)$ & $41(2)$ & $47(3)$ \\
\hline
\end{tabular}




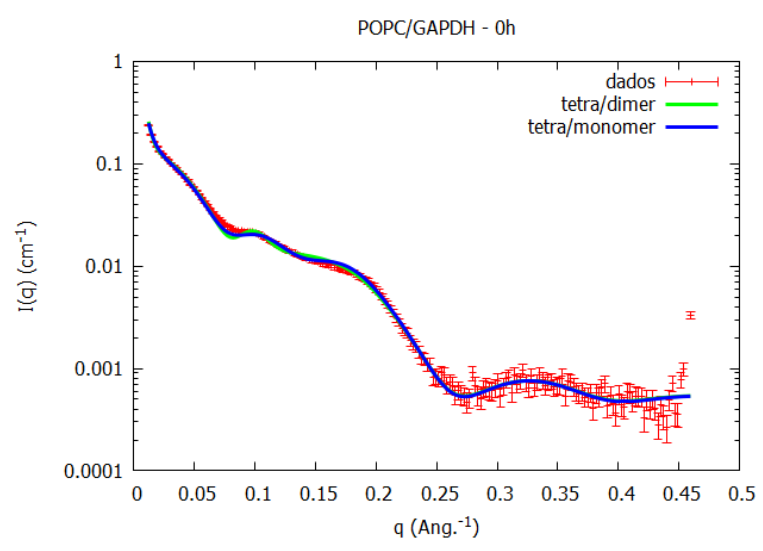

(a) Medida $0 \mathrm{~h}$

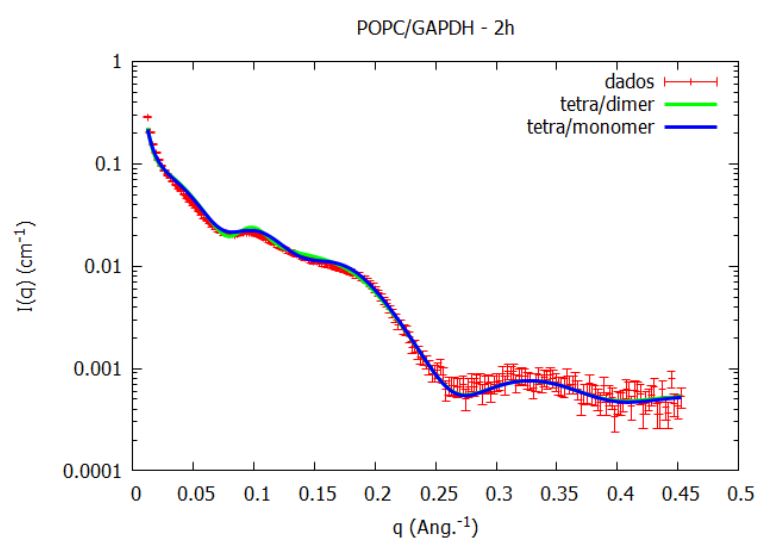

(b) Medida após $2 \mathrm{~h}$

Figura 6.16: Ajuste de vesículas compostas por POPC [8.33mM] com a enzima GAPDH $[2 \mathrm{mg} / \mathrm{mL}]$ a partir de dois PDBs - tatrâmero/dímero (curva verde) e tetrâmero/monômero (curva azul), para medidas realizadas: a) logo após a mistura das soluções da proteína com a membrana modelo - $0 h$ e b) após $2 h$ de espera em banho térmico a $37^{\circ} \mathrm{C}$.

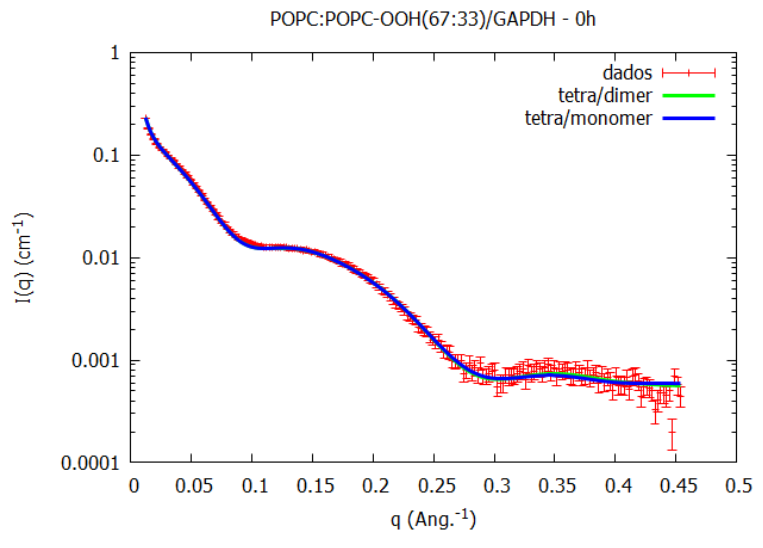

(a) Medida $0 \mathrm{~h}$

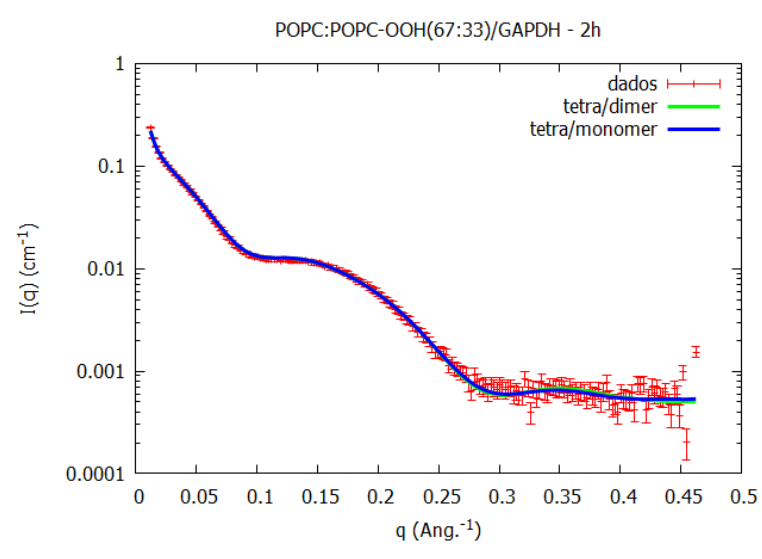

(b) Medida após $2 \mathrm{~h}$

Figura 6.17: Ajuste de vesículas compostas por POPC:POPC-OOH (67:33) [8.33mM] com a enzima GAPDH $[2 \mathrm{mg} / \mathrm{mL}]$ a partir de dois PDBs - tatrâmero/dímero (curva verde) e tetrâmero/monômero (curva azul), para medidas realizadas: a) logo após a mistura das soluções da proteína com a membrana modelo - $0 h$ e b) após $2 h$ de espera em banho térmico a $37^{\circ} \mathrm{C}$. 


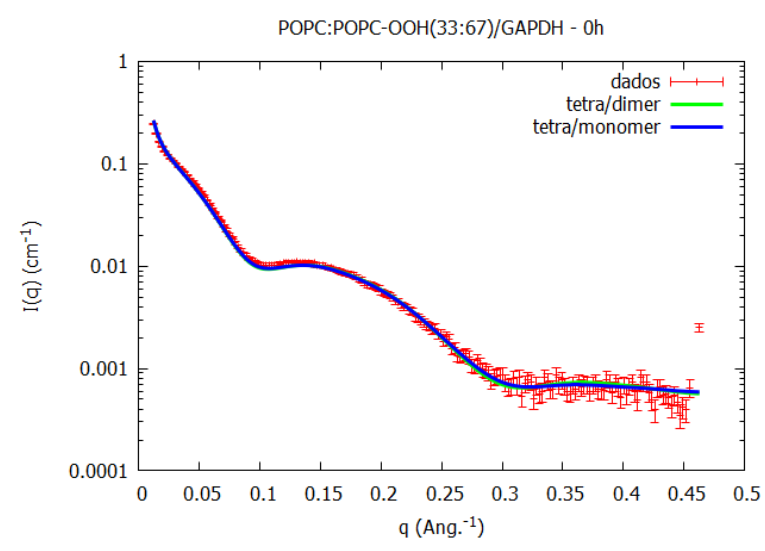

(a) Medida $0 \mathrm{~h}$

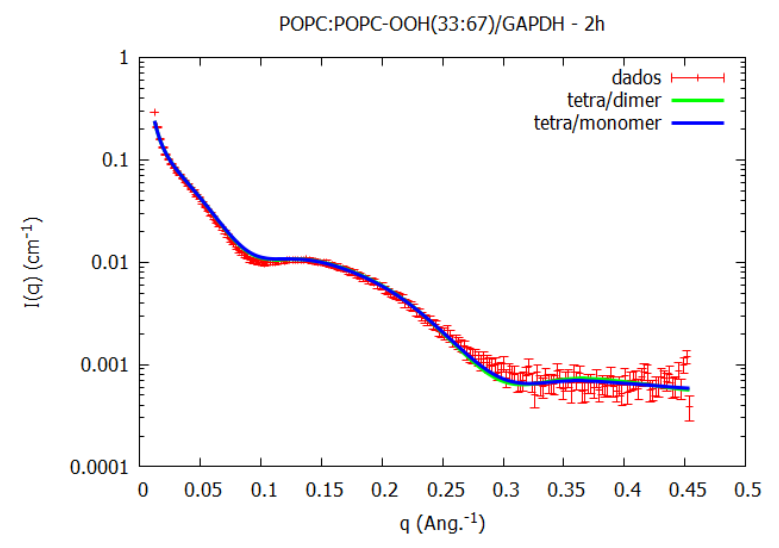

(b) Medida após $2 \mathrm{~h}$

Figura 6.18: Ajuste de vesículas compostas por POPC:POPC-OOH (33:67) [8.33mM] com a enzima GAPDH $[2 \mathrm{mg} / \mathrm{mL}]$ a partir de dois PDBs - tatrâmero/dímero (curva verde) e tetrâmero/monômero (curva azul), para medidas realizadas: a) logo após a mistura das soluções da proteína com a membrana modelo - $0 h$ e b) após $2 h$ de espera em banho térmico a $37^{\circ} \mathrm{C}$.

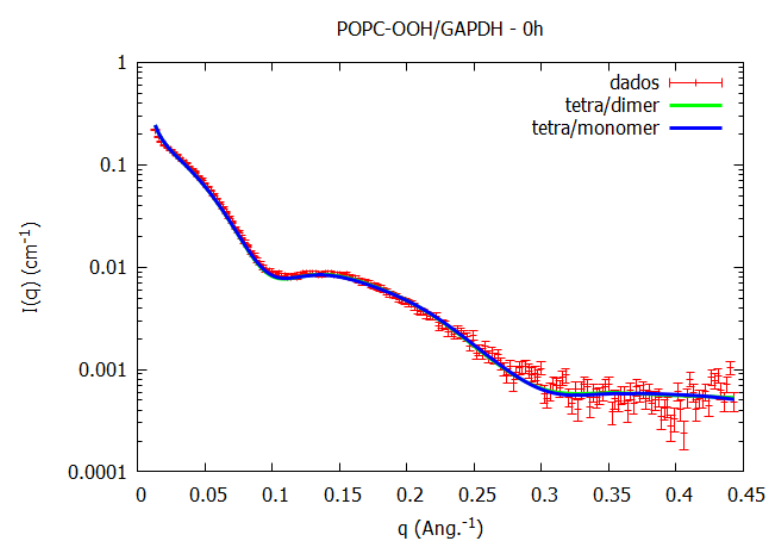

(a) Medida $0 \mathrm{~h}$

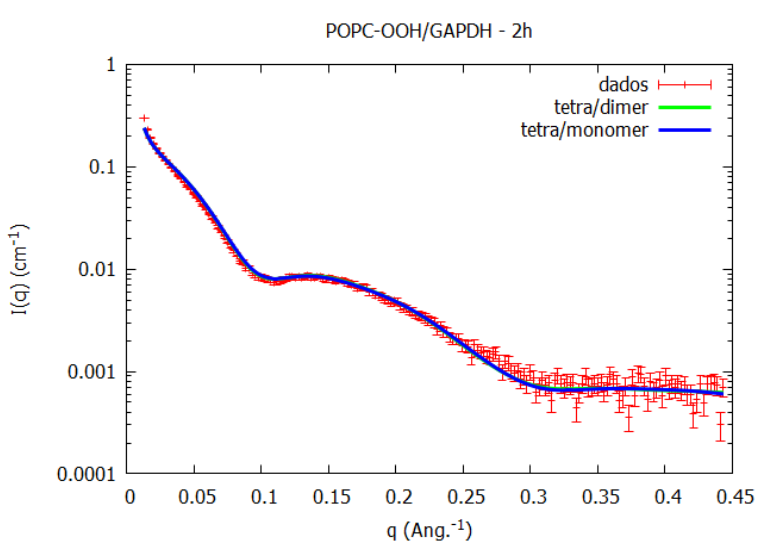

(b) Medida após $2 \mathrm{~h}$

Figura 6.19: Ajuste de vesículas compostas por POPC-OOH $[8.33 \mathrm{mM}]$ com a enzima GAPDH $[2 \mathrm{mg} / \mathrm{mL}]$ a partir de dois PDBs - tatrâmero/dímero (curva verde) e tetrâmero/monômero (curva azul), para medidas realizadas: a) logo após a mistura das soluções da proteína com a membrana modelo - $0 h$ e b) após $2 h$ de espera em banho térmico a $37^{\circ} C$. 


\subsection{Conclusão}

A análise das curvas de SAXS da enzima GAPDH via modelo de PDB mostrou que ao longo de duas horas de exposição à radiação síncrotron a GAPDH não apresentou alteração estrutural, mantendo a forma de tetrâmero. O estudo da interação da enzima com vesículas grandes de diferentes composições lipídicas (POPC:POPC-OOH (1:0), (67:33), (33:67), (0:1), POPC:SM:CO e POPC-OOH:SM:CO), incluindo oxidação e domínios lipídicos, mostrou que a GAPDH sofre agregação independente do nível de oxidação da membrana modelo, uma vez que tal efeito foi observado para vesículas não oxidadas compostas por POPC e POPC:SM:CO. Por outro lado, as curvas de SAXS do sistema membrana/GAPDH em função do tempo de interação apresentaram perfil de SAXS indicativo de alteração na estrutura quaternária da enzima após duas horas de interação para todos as composições. Em uma análise complementar para vesículas de POPC e POPC-OOH foi observado que após 24 horas de interação a enzima GAPDH apresentou perfil de SAXS próximo ao observado para a interação de 2 horas, indicando que a interação entre os dois componentes atingiu seu limite em torno de 2 horas.

A quantificação da estrutura oligomérica da enzima devido à possível interação com membranas modelo mostrou que na presença de vesículas oxidadas de POPC:POPC-OOH (67:33), (33:67) e (0:1) a GAPDH sofre dissociação da forma inicial de tetrâmero para monômeros ou dímeros, não sendo possível a distinção entre os dois. Para medidas realizadas diretamente após a mistura das soluções $(t=0 h)$ foi observado maior dissociação para vesículas com menor grau de oxidação compostas por POPC:POPC-OOH (67:33). No entanto, para o tempo de interação de $2 h$ a enzima apresentou maior dissociação na presença de membranas modelo compostas por POPC:POPC-OOH (33:67), que apresentou variação na quantidade de tetrâmero de $\sim 47 \%$ no tempo $t=0 h$ para $\sim 12 \%$ em medidas realizadas 
após duas horas. Já sistemas compostos por vesículas puras de POPC apresentaram estrutura quaternária de tetrâmero para GAPDH medida em $t=0 h$ e dissociação em dímero ou monômero para interação de $2 h$, com uma diferença de $17 \%$ entre os resultados para dímero (peso 51\%) e monômero (peso 34\%). Na presença de vesículas compostas por POPC:SM:CO e POPC-OOH:SM:CO a GAPDH manteve sua estrutura quaternária de tetrâmero mesmo após $2 h$ de interação. Esse resultado sugere que a formação de domínios lipídicos compostos por SM e CO inibe a dissociação da enzima em monômeros ou dímeros. 


\section{Capítulo 7}

\section{Conclusão}

Como conlcusão final deste trabalho temos:

- O modelo de 3 regiões se mostrou bom para a determinação estrutural de bicamadas lipídicas com diferentes composições.

- Os efeitos de fotossensibilização observados nesse trabalho, nas condições avaliadas, não foram significativos no que se refere à danos físicos (ruptura e formação de poros) em membranas.

- O modelo de grupos químicos se mostrou capaz de determinar a posição de cada grupo químico, com especial elucidação para a posição dos grupos oxidados. Resultado esse novo na literatura.

- A enzima GAPDH sofre agregação lenta na presença de membranas. E após 2 horas de interação sofre dissociação em dímeros ou monômeros, exceto para os sistemas ternários com SM e CO. 



\section{Referências Bibliográficas}

[1] D. L. Nelson and M. M. Cox, Principios de Bioquimica de Lehninger. artmed, 2014.

[2] N. Kucerka, F. A. Heberle, J. Pan, and J. Katsaras, "Structural significance of lipid diversity as studied by small angle neutron and x-ray scattering," Membranes $\mathbf{5}$ (2015), no. 3, 454 .

[3] F. A. Bettelheim, W. H. Brown, M. K. Campbell, and S. O. Farrel, Introdução à Bioquímica. CENGAGE Learning, 2012.

[4] G. L. Nicolson, "The fluid mosaic model of membrane structure: Still relevant to understanding the structure, function and dynamics of biological membranes after more than 40years," Biochimica et Biophysica Acta (BBA) - Biomembranes 1838 (2014), no. 6, 1451 - 1466. Membrane Structure and Function: Relevance in the Cell's Physiology, Pathology and Therapy.

[5] G. L. Nicolson, "The fluid-mosaic model of membrane structure: Still relevant to understanding the structure, function and dynamics of biological membranes after more than 40 years," Biochimica et Biophysica Acta (BBA) - Biomembranes 1838 (2014), no. 6, 1451 - 1466. Membrane Structure and Function: Relevance in the Cell's Physiology, Pathology and Therapy. 
[6] M. E. Greenberg, X.-M. Li, B. G. Gugiu, X. Gu, J. Qin, R. G. Salomon, and S. L. Hazen, "The lipid whisker model of the structure of oxidized cell membranes," The Journal of Biological Chemistry 283 (2008) 2385-2396.

[7] Á. Catalá, "Lipid peroxidation modifies the assembly of biological membranes "the lipid whisker model"," Frontiers in Physiology 5 (2015) 520.

[8] A. Catalá, "Lipid peroxidation modifies the picture of membranes from the fluid mosaic model to the lipid whisker model," Biochimie 94 (2012), no. 1, 101 - 109. Lipids in all their states.

[9] G. van Meer, D. R. VoelKer, and G. W. Feigenson, "Membrane lipids: where they are and how they behave," Nature Reviews Molecular Cell Biology 9 (2008) 112-124.

[10] P. Siani, R. de Souza, L. Dias, R. Itri, and H. Khandelia, "An overview of molecular dynamics simulations of oxidized lipid systems, with a comparison of $\{$ ELBA $\}$ and \{MARTINI\} force fields for coarse grained lipid simulations," Biochimica et Biophysica Acta (BBA) - Biomembranes 1858 (2016), no. 10, 2498 - 2511. Biosimulations of lipid membranes coupled to experiments.

[11] G. W. Feigenson and J. T. Buboltz, "Ternary phase diagram of dipalmitoyl-pc/dilauroyl-pc/cholesterol: Nanoscopic domain formation driven by cholesterol," Biophysical Journal 80 (2001), no. 6, 2775 - 2788.

[12] T. A. Enoki, F. A. Heberle, and G. W. Feigenson, "Fret detects the size of nanodomains for coexisting liquid-disordered and liquid-ordered phases," Biophysical Journal 114 (2018), no. 8, 1921 - 1935.

[13] R. F. M. de Almeida, A. Fedorov, and M. Prieto, 
"Sphingomyelin/phosphatidylcholine/cholesterol phase diagram: Boundaries and composition of lipid rafts," Biophysical Journal 85 (2003), no. 4, 2406-2416.

[14] D. G. Ackerman and G. W. Feigenson, "Multiscale modeling of four-component lipid mixtures: Domain composition, size, alignment, and properties of the phase interface," The Journal of Physical Chemistry B 119 (2015), no. 11, 4240-4250.

[15] D. Scherfeld, N. Kahya, and P. Schwille, "Lipid dynamics and domain formation in model membranes composed of ternary mixtures of unsaturated and saturated phosphatidylcholines and cholesterol," Biophysical Journal 85 (2003), no. 6, 3758 3768.

[16] R. Itri, H. C. Junqueira, and O. Mertins, "Membrane changes under oxidative stress: the impact of oxidized lipids," Biophysical Reviews 6 (2014) 47-61.

[17] J. P. Tardivo, A. D. Giglio, C. S. de Oliveira, D. S. Gabrielli, H. C. Junqueira, D. B. Tada, D. Severino, R. de Fátima Turchiello, and M. S. Baptista, "Methylene blue in photodynamic therapy: From basic mechanisms to clinical applications," Photodiagnosis and Photodynamic Therapy 2 (2005), no. 3, 175 - 191.

[18] A. Catalá, "Lipid peroxidation of membrane phospholipids generates hydroxy-alkenals and oxidized phospholipids active in physiological and/or pathological conditions," Chemistry and Physics of Lipids 157 (2009), no. 1, 1 - 11.

[19] O. Mertins, I. O. Bacellar, F. Thalmann, C. M. Marques, M. S. Baptista, and R. Itri, "Physical damage on giant vesicles membrane as a result of methylene blue photoirradiation," Biophysical Journal 106 (2014), no. 1, 162 - 171.

[20] G. Weber, T. Charitat, M. S. Baptista, A. F. Uchoa, C. Pavani, H. C. Junqueira, 
Y. Guo, V. A. Baulin, R. Itri, C. M. Marques, and A. P. Schroder, "Lipid oxidation induces structural changes in biomimetic membranes," Soft Matter 10 (2014) $4241-4247$.

[21] Suélen Tadéia Gasparetto Buck, Relação entre eficiência fotodinâmica, citotoxicidade e propriedades moleculares de corantes para aplicação em terapia fotodinâmica. Tese de doutorado, Instituto de Química de São Carlos, 2009.

[22] K. A. Riske, T. P. Sudbrack, N. L. Archilha, A. F. Uchoa, A. P. Schroder, C. M. Marques, M. S. Baptista, and R. Itri, "Giant vesicles under oxidative stress induced by a membrane-anchored photosensitizer," Biophysical Journal 97 (2009), no. 5, 1362 $-1370$.

[23] T. M. Tsubone, M. S. Baptista, and R. Itri, "Understanding membrane remodelling initiated by photosensitized lipid oxidation," Biophysical Chemistry 254 (2019) 106263.

[24] M. Vignoni, M. N. Urrutia, H. C. Junqueira, A. Greer, A. Reis, M. S. Baptista, R. Itri, and A. H. Thomas, "Photo-oxidation of unilamellar vesicles by a lipophilic pterin: Deciphering biomembrane photodamage," Langmuir 34 (2018), no. 50, $15578-15586$.

[25] T. T. Tasso, J. C. Schlothauer, H. C. Junqueira, T. A. Matias, K. Araki, É. Liandra-Salvador, F. C. T. Antonio, P. Homem-de Mello, and M. S. Baptista, "Photobleaching efficiency parallels the enhancement of membrane damage for porphyrazine photosensitizers," Journal of the American Chemical Society 141 (2019), no. 39, 15547-15556. 
[26] A. P. Castano, T. N. Demidova, and M. R. Hamblin, "Mechanisms in photodynamic therapy: part one-photosensitizers, photochemistry and cellular localization," Photodiagnosis and Photodynamic Therapy 1 (2004), no. 4, 279 - 293.

[27] G. L. Nicolson and M. E. Ash, "Lipid replacement therapy: A natural medicine approach to replacing damaged lipids in cellular membranes and organelles and restoring function," BBA - Biomembranes 1838 (2014) 1657 - 1679.

[28] G. Spiteller, "The relation of lipid peroxidation processes with atherogenesis: A new theory on atherogenesis," Molecular Nutrition and Food Research 49 (2005), no. 11, 999-1013.

[29] G. O. Fruhwirth, A. Loidl, and A. Hermetter, "Oxidized phospholipids: From molecular properties to disease," BBA - Molecular Basis of Disease 1772 (2007) 718 $-736$.

[30] N. A. Strobel, R. G. Fassett, S. A. Marsh, and J. S. Coombes, "Oxidative stress biomarkers as predictors of cardiovascular disease," International Journal of Cardiology 147 (2011) 191 - 201.

[31] F. H. Greig, S. Kennedy, and C. M. Spickett, "Physiological effects of oxidized phospholipids and their cellular signaling mechanisms in inflammation," Free Radical Biology and Medicine 52 (2012) 266 - 280.

[32] R. Volinsky and P. K. J. Kinnunen, "Oxidized phosphatidylcholines in membrane-level cellular signaling: from biophysics to physiology and molecular pathology," FEBS Journal 280 (2013) 2806 -2816.

[33] S. Pope, J. M. Land, and S. J. R. Heales, "Oxidative stress and mitochondrial 
dysfunction in neurodegeneration; cardiolipin a critical target?," BBA - Bioenergetics 1777 (2008) $794-799$.

[34] H. Mitomo, W.-H. Chen, and S. L. Regen, "Oxysterol-induced rearrangement of the liquid-ordered phase: A possible link to alzheimer's disease?," Journal of the American Chemical Society 131 (34) (2009) 12354 - 12357.

[35] T. Farooqui and A. A. Farooqui, "Lipid-mediated oxidative stress and inflammation in the pathogenesis of parkinson's disease," Parkinson's Disease 2011 (2001) $247467-247476$.

[36] T. T. Reed, "Lipid peroxidation and neurodegenerative disease," Free Radical Biology and Medicine 51 (2011), no. 7, $1302-1319$.

[37] C. M. Torres-Bugeau, C. D. Borsarelli, C. J. Minahk, and R. N. Chehín, "The key role of membranes in amyloid formation from a biophysical perspective," Current Protein and Peptide Science 12 (2011) 166-180.

[38] L. M. Cortez, C. L. Ávila, C. M. T. Bugeau, R. D. M. Ricardo N. Farías, and R. N. Chehín, "Glyceraldehyde-3-phosphate dehydrogenase tetramer dissociation and amyloid fibril formation induced by negatively charged membranes," FEBS Letters 584 (2010) 625-630.

[39] E. Niki, "Lipid peroxidation: Physiological levels and dual biological effects," Free Radical Biology and Medicine 47 (2009) 469 - 484.

[40] P. K. Kinnunen, K. Kaarniranta, and A. K. Mahalka, "Protein-oxidized phospholipid interactions in cellular signaling for cell death: From biophysics to clinical correlations," BBA - Biomembranes 1818 (2012) 2446 - 2455. 
[41] V. Ruipérez, F. Darios, and B. Davletov, "Alpha-synuclein, lipids and parkinson's disease," Progress in Lipid Research 49 (2010), no. 4, 420 - 428.

[42] V. Koppaka and P. H. Axelsen, "Accelerated accumulation of amyloid \& proteins on oxidatively damaged lipid membranes," Biochemistry 39(32) (2000) 10011-10016.

[43] D. A. Butterfield, M. L. B. Lange, and R. Sultana, "Involvements of the lipid peroxidation product, hne, in the pathogenesis and progression of alzheimer's disease," Biochimica et Biophysica Acta (BBA) - Molecular and Cell Biology of Lipids 1801 (2010), no. 8, 924 - 929. Lipids and Alzheimer's Disease.

[44] L. Liu, H. Komatsu, I. V. Murray, and P. H. Axelsen, "Promotion of amyloid beta protein misfolding and fibrillogenesis by a lipid oxidation product," Journal of Molecular Biology 377 (2008), no. 4, 1236 - 1250.

[45] A. W. Girotti and T. Kriska, "Role of lipid hydroperoxides in photo-oxidative stress signaling," Antioxidants $\mathscr{G}$ Redox Signaling 6 (2004) 301 - 310.

[46] P. Jurkiewicz, L. Cwiklik, P. Jungwirth, and M. Hof, "Lipid hydration and mobility: An interplay between fluorescence solvent relaxation experiments and molecular dynamics simulations," Biochimie 94 (2012) 26 - 32.

[47] J. Wong-ekkabut, Z. Xu, W. Triampo, I.-M. Tang, D. P. Tieleman, and L. Monticelli, "Effect of lipid peroxidation on the properties of lipid bilayers: A molecular dynamics study," Biophysical Journal 93 (2007) 4225-4236.

[48] Y. Guo, V. A. Baulin, and F. Thalmann, "Peroxidised phospholipid bilayers: insight from coarse-grained molecular dynamics simulations," Soft Matter 12 (2016) 263-271. 
[49] J. Garrec, A. Monari, X. Assfeld, L. M. Mir, and M. Tarek, "Lipid peroxidation in membranes: The peroxyl radical does not "float"," The Journal of Physical Chemistry Letters 5 (2014) 1653-1658.

[50] S. Sankhagowit, S.-H. Wu, R. Biswas, C. T. Riche, M. L. Povinelli, and N. Malmstadt, "The dynamics of giant unilamellar vesicle oxidation probed by morphological transitions," BBA - Biomembranes 1838 (2014) 2615 - 2624.

[51] C. K. Haluska, M. S. Baptista, A. U. Fernandes, A. P. Schroder, C. M. Marques, and R. Itri, "Photo-activated phase separation in giant vesicles made from different lipid mixtures," BBA - Biomembranes 1818 (2012) 666 - 672.

[52] T. M. Tsubone, H. C. Junqueira, M. S. Baptista, and R. Itri, "Contrasting roles of oxidized lipids in modulating membrane microdomains," Biochimica et Biophysica Acta (BBA) - Biomembranes 1861 (2019), no. 3, 660 - 669.

[53] J. Heuvingh and S. Bonneau, "Asymmetric oxidation of giant vesicles triggers curvature-associated shape transition and permeabilization," Biophysical Journal 97 (2009) $2904-2912$.

[54] K. A. Runas and N. Malmstadt, "Low levels of lipid oxidation radically increase the passive permeability of lipid bilayers," Soft Matter 11 (2015) 499-505.

[55] W. Caetano, P. S. Haddad, R. Itri, D. Severino, V. C. Vieira, M. S. Baptista, A. P. Schröder, and C. M. Marques, "Photo-induced destruction of giant vesicles in methylene blue solutions," Langmuir 23 (2007) 1307-1314.

[56] H. Khandelia and O. G. Mouritsen, "Lipid gymnastics: Evidence of complete acyl 
chain reversal in oxidized phospholipids from molecular simulations," Biophysical Journal 96(7) (2009) 2734-2743.

[57] J.-P. Mattila, K. Sabatini, and P. K. J. Kinnunen, "Oxidized phospholipids as potential molecular targets for antimicrobial peptides," BBA - Biomembranes 1778 (2008) $2041-2050$.

[58] A. Makky and M. Tanaka, "Impact of lipid oxidization on biophysical properties of model cell membranes," The Journal of Physical Chemistry B 119 (2015), no. 18, $5857-5863$.

[59] S. S. Davies, A. V. Pontsler, G. K. Marathe, K. A. Harrison, R. C. Murphy, J. C. Hinshaw, G. D. Prestwich, A. S. Hilaire, S. M. Prescott, G. A. Zimmerman, and T. M. McIntyre, "Oxidized alkyl phospholipids are specific, high affinity peroxisome proliferator-activated receptor gamma ligands and agonists," J. Biol. Chem. 276 (2001) $16015-16023$.

[60] O. Glatter and O. Kratky, Small Angle X-ray Scattering. Academic Press, 1982.

[61] R. Eisberg and R. Resnick, Física Quântica: Átomos, Moléculas, Sólidos, Núcleos e Partículas. Elsevier, 1974.

[62] J. M. Ruso and Ângel Pineiro, Proteins in Solution and at Interfaces. Wiley, 2013.

[63] D. I. Svergun and L. A. Feigin, Structure Analysis by Small-Angle X-Ray and Neutron Scattering. Plenum Press, 1987.

[64] E. M. Sales, Estudos estruturais do processo de agregação entre proteinas amilóides em solução. Tese de doutorado, IFUSP, 2012. 
[65] F. Spinozzi, C. Ferrero, M. G. Ortore, A. D. M. Antolinos, and P. Mariani, "Genfit: software for the analysis of small-angle x-ray and neutron scattering data of macromolecules in solution," Journal of Applied Crystallography 47 (2014) $1132-1139$.

[66] G. Pabst, A. Hodzic, J. Strancar, S. Danner, M. Rappolt, and P. Laggner, "Rigidification of neutral lipid bilayers in the presence of salts," Biophysical Journal 93 (2007), no. 8, $2688-2696$.

[67] N. Chu, N. Kucerka, Y. Liu, S. Tristram-Nagle, and J. F. Nagle, "Anomalous swelling of lipid bilayer stacks is caused by softening of the bending modulus," Phys. Rev. E 71 (Apr, 2005) 041904.

[68] C. Monzel and K. Sengupta, "Measuring shape fluctuations in biological membranes," Journal of Physics D: Applied Physics 49 (may, 2016) 243002.

[69] M. M. Domingues, M. L. Bianconi, L. R. Barbosa, P. S. Santiago, M. Tabak, M. A. Castanho, R. Itri, and N. C. Santos, "rbpi21 interacts with negative membranes endothermically promoting the formation of rigid multilamellar structures," Biochimica et Biophysica Acta (BBA) - Biomembranes 1828 (2013), no. 11, 2419 2427.

[70] F. Spinozzi, L. Paccamiccio, P. Mariani, , and L. Q. Amaral, "Melting regime of the anionic phospholipid dmpg: New lamellar phase and porous bilayer model," Langmuir 26(9) (2010) 6484-6493.

[71] F. Spinozzi, C. Ferrero, M. G. Ortore, A. D. M. Antolinos, and P. Mariani, "Genfit: software for the analysis of small-angle x-ray and neutron scattering data of 
macromolecules in solution," Journal of Applied Crystallography Supplementary Material (2014) 1-21.

[72] R. D. Rosa, F. Spinozzi, and R. Itri, "Hydroperoxide and carboxyl groups preferential location in oxidized biomembranes experimentally determined by small angle x-ray scattering: Implications in membrane structure," Biochimica et Biophysica Acta (BBA) - Biomembranes 1860 (2018), no. 11, 2299 - 2307.

[73] M. G. Ortore, F. Spinozzi, P. Mariani, A. Paciaroni, L. R. S. Barbosa, H. Amenitsch, M. Steinhart, J. Ollivier, and D. Russo, "Combining structure and dynamics: non-denaturing high-pressure effect on lysozyme in solution," Journal of The Royal Society Interface 6 (2009), no. Suppl 5, S619-S634.

[74] M. L. Frazier, J. R. Wright, A. Pokorny, and P. F. Almeida, "Investigation of domain formation in sphingomyelin/cholesterol/popc mixtures by fluorescence resonance energy transfer and monte carlo simulations," Biophysical Journal 92 (2007), no. 7, $2422-2433$.

[75] P. Pathak and E. London, "Measurement of lipid nanodomain (raft) formation and size in sphingomyelin/popc/cholesterol vesicles shows tx-100 and transmembrane helices increase domain size by coalescing preexisting nanodomains but do not induce domain formation," Biophysical Journal 101 (2011) 2417-2425.

[76] M. Ruiz-Arguello, M. Veiga, J. L. Arrondo, F. M. Goni, and A. Alonso, "Sphingomyelinase cleavage of sphingomyelin in pure and mixed lipid membranes. influence of the physical state of the sphingolipid," Chemistry and Physics of Lipids 114 (2002), no. 1, $11-20$. 
[77] A. Pokorny, L. E. Yandek, A. I. Elegbede, A. Hinderliter, and P. F. Almeida, "Temperature and composition dependence of the interaction of $\hat{\mathrm{I}}^{\prime}$-lysin with ternary mixtures of sphingomyelin/cholesterol/popc," Biophysical Journal 91 (2006), no. 6, $2184-2197$.

[78] T. Frühwirth, G. Fritz, N. Freiberger, and O. Glatter, "Structure and order in lamellar phases determined by small-angle scattering," Journal of Applied Crystallography 37 (Oct, 2004) 703-710.

[79] R. Koynova and M. Caffrey, "Phases and phase transitions of the phosphatidylcholines," Biochimica et Biophysica Acta (BBA) - Reviews on Biomembranes 1376 (1998), no. 1, 91 - 145.

[80] S. Leekumjorn and A. K. Sum, "Molecular characterization of gel and liquid-crystalline structures of fully hydrated popc and pope bilayers," The Journal of Physical Chemistry B 111 (2007), no. 21, 6026-6033.

[81] D. A. Brown and E. London, "Structure and function of sphingolipid- and cholesterol-rich membrane rafts," Journal of Biological Chemistry 111 (1998) 1 - 9.

[82] G. S. M. Campos, O papel de lipídios oxidados e surfactantes como promotores de agregados proteicos tipo amilóide. Tese de doutorado, IFUSP, 2019.

[83] C. L. P. Oliveira, B. B. Gerbelli, E. R. T. Silva, F. Nallet, L. Navailles, E. A. Oliveira, and J. S. Pedersen, "Gaussian deconvolution: a useful method for a form-free modeling of scattering data from mono- and multilayered planar systems," Journal of Applied Crystallography 45 (Dec, 2012) 1278-1286.

[84] C. Dietrich, L. Bagatolli, Z. Volovyk, N. Thompson, M. Levi, K. Jacobson, and 
E. Gratton, "Lipid rafts reconstituted in model membranes," Biophysical Journal 80 (2001), no. 3, $1417-1428$.

[85] H. A. Rinia and B. de Kruij, "Imaging domains in model membranes with atomic force microscopy," FEBS Letters 504 (2001) 194-199.

[86] S. Y. Bhide, Z. Zhang, and M. L. Berkowitz, "Molecular dynamics simulations of sops and sphingomyelin bilayers containing cholesterol," Biophysical Journal 92 (2007), no. $4,1284-1295$.

[87] T. E.M and K. J.M., "Photochemical interactions of methylene blue and analogues with dna and other biological substrates," Journal of photochemistry and photobiology 21 (2-3) (1993) 103- 124.

[88] H. C. Junqueira, Sintese e estudos das propriedades fotoinduzidas de derivados fenotiazinicos em sistemas biomiméticos. Tese de doutorado, IQUSP, 2008.

[89] I. O. L. Bacellar, C. Pavani, E. M. Sales, R. Itri, M. Wainwright, and M. S. Baptista, "Membrane damage efficiency of phenothiazinium photosensitizers," Photochemistry and Photobiology 90 (2014), no. 4, 801-813.

[90] C. S. Oliveira, R. Turchiello, A. J. Kowaltowski, G. L. Indig, and M. S. Baptista, "Major determinants of photoinduced cell death: Subcellular localization versus photosensitization efficiency," Free Radical Biology and Medicine 51 (2011), no. 4, $824-833$.

[91] I. de Oliveira Lima Bacellar, Elucidando as interações e reações levando à permeabilização fotoinduzida de membranas. Tese de doutorado, IQUSP, 2017. 
[92] J. A. Bonacin, F. M. Engelmann, D. Severino, H. E. Toma, and M. S. Baptista, "Singlet oxygen quantum yields in water using beetroot extract and an array of leds," Journal of the Brazilian Chemical Society 20(1) (2009) 31-36.

[93] C. Tanielian, L. Golder, and C. Wolff, "Production and quenching of singlet oxygen by the sensitizer in dye-sensitized photo-oxygenations," Journal of Photochemistry 25 (1984), no. 2, $117-125$.

[94] Y. Usui, "Determination of quantum yield of singlet oxygen formation by photosensitization," Chemistry Letters (1973) 743-744.

[95] R. Dimova, "Recent developments in the field of bending rigidity measurements on membranes," Advances in Colloid and Interface Science 208 (2014) 225 - 234. Special issue in honour of Wolfgang Helfrich.

[96] N. Kučerka, J. F. Nagle, J. N. Sachs, S. E. Feller, J. Pencer, A. Jackson, and J. Katsaras, "Lipid Bilayer Structure Determined by the Simultaneous Analysis of Neutron and X-Ray Scattering Data," Biophys. J. 95 (2008) 2356-2367.

[97] D. Marsh, "Molecular volumes of phospholipids and glycolipids in membranes," Chem. Phys. Lipids 163 (2010) $667-677$.

[98] J. Wong-Ekkabut, Z. Xu, W. Triampo, I.-M. Tang, D. P. Tieleman, and L. Monticelli, "Effect of lipid peroxidation on the properties of lipid bilayers: A molecular dynamics study," Biophys J. 93 (2007), no. 12, 4225 - 4236.

[99] K. A. Runas, S. J. Acharya, J. J. Schmidt, and N. Malmstadt, "Addition of cleaved tail fragments during lipid oxidation stabilizes membrane permeability behavior," Langmuir 32 (2016), no. 3, 779-786. 
[100] F. Spinozzi and R. Itri, "Small-angle scattering of stacks of large bilayers with cylindrically shaped defects," In preparation (2017).

[101] N. Kučerka, M.-P. Nieh, and J. Katsaras, "Fluid phase lipid areas and bilayer thicknesses of commonly used phosphatidylcholines as a function of temperature," BBA - Biomembranes 1808 (2011) 2761-2771.

[102] C. L. Ávila, C. M. Torres-Bugeau, L. R. S. Barbosa, E. M. Sales, M. O. Ouidja, S. B. Socias, M. S. Celej, R. Raisman-Vozari, D. Papy-Garcia, R. Itri, and R. N. Chehín, "Structural characterization of heparin-induced glyceraldehyde-3-phosphate dehydrogenase protofibrils preventing a-synuclein oligomeric species toxicity," Journal of Biological Chemistry 289 (2014) 13838-13850.

[103] S. W. C.-J. A. M. Kaufmann, A. N. Anselmo, W. Stark, and M. G. Grutter, "Structure of rabbit-muscle glyceraldehyde-3-phosphate dehydrogenase," Acta Crystallographica Section D - Biological Crystallography D59 (2003) 2218-2227. 



\section{Apêndice A}

\section{Protocolo - síntese do lipídio oxidado}

\section{POPC-OOH}

Para a síntese do lipídio oxidado POPC-OOH 24,7mg de POPC foram dissolvidas em 1,2 $\mathrm{mL}$ de metanol deuterado e adicionado $20 \mu \mathrm{L}$ de azul de metileno (que estava a uma concentração igual a $3 \mathrm{mM}$ ) à solução. O tubo de ensaio foi preenchido com oxigênio e então colocado no sonicador por 10 minutos para homogeneizar a solução e em seguida irradiado por 45 minuntos com LED vermelho $(\lambda=633 \mathrm{~nm})$ a uma distância de $\sim 20 \mathrm{~cm}$. Devido ao aquecimento causado pela irradiação a solução foi resfriada em gelo a cada 10 minutos. O aparato para irradiação foi mantido sobre uma chapa magnética durante o processo e dentro do tubo de ensaio foi colocado em agitador magnético.

Os resíduos do FS foram retirados usando sílica e em seguida foi realizada a dosagem de fosfato para determinar a concentração da solução.

A confirmação da molécula foi realizada por espectroscopia de massa no Instituto de Química da USP. 
A produção do lipídio POPC-OOH utilizado nesta tese foi realizada pela Dr(a). Helena Junqueira do Instituto de Química da USP. 


\section{Apêndice B}

\section{Artigo publicado}

Os resultados da caracterização de membranas modelo oxidadas a partir da utilização do modelo de grupos químicos, apresentado no Capítulo 5 gerou uma contribuição nova na literatura a partir da publicação do artigo intitulado Hydroperoxide and carboxyl groups preferential location in oxidized biomembranes experimentally determined by small angle $X$ ray scattering: Implications in membrane structure.

O artigo pode ser acessado através do endereço: https://doi.org/10.1016/j.bbamem. 2018.05 .011 